LEANDRO DE AMORIM RATAMERO

EFEITOS DO ETANOL HIDRATADO NO COMPORTAMENTO TRIBOLÓGICO DO SISTEMA CAME-TUCHO EM CONDIÇÕES LUBRIFICADAS

São Paulo 
EFEITOS DO ETANOL HIDRATADO NO COMPORTAMENTO TRIBOLÓGICO DO SISTEMA CAME-TUCHO EM CONDIÇÕES LUBRIFICADAS

Tese apresentada à Escola Politécnica da Universidade de São Paulo para obtenção do título de Doutor em Ciências 


\title{
EFEITOS DO ETANOL HIDRATADO NO COMPORTAMENTO TRIBOLÓGICO DO SISTEMA CAME-TUCHO EM CONDIÇÕES LUBRIFICADAS
}

\author{
Tese apresentada à Escola Politécnica da Universidade de São Paulo \\ para obtenção do título de Doutor em Ciências \\ Área de Concentração: Engenharia Mecânica
}

Orientador: Prof. Dr. Roberto Martins de Souza

São Paulo 
Autorizo a reprodução e divulgação total ou parcial deste trabalho, por qualquer meio convencional ou eletrônico, para fins de estudo e pesquisa, desde que citada a fonte.

Este exemplar foi revisado e corrigido em relação à versão original, sob responsabilidade única do

São Paulo de

Assinatura do autor:

Assinatura do orientador:

Catalogação-na-publicação

Ratamero, Leandro

Efeitos do etanol hidratado no comportamento tribológico do sistema came-tucho em condições lubrificadas / L. Ratamero -- versão corr. -- São Paulo, 2019

$162 \mathrm{p}$.

Tese (Doutorado) - Escola Politécnica da Universidade de São Paulo. Departamento de Engenharia Mecânica.

1.Tribologia 2.Came-tucho 3.Atrito 4.Etanol hidratado I.Universidade de São Paulo. Escola Politécnica. Departamento de Engenharia Mecânica II.t. 


\section{AGRADECIMENTOS}

Meus mais sinceros agradecimentos aos companheiros do LFS Poli-USP, da UTFPr, da Mahle Metal Leve, da Ford Motor Company, da Hef Durferrit e da Ultraterm Ind. Com. LTDA. Sem o vosso incentivo e ajuda a realização deste trabalho não seria possível.

Em especial, agradeço ao meu orientador, Prof. Dr. Roberto Martins de Souza, pela constante, precisa e paciente orientação. 
“A simplicidade é o último grau de sofisticação.” Leonardo da Vinci 


\section{RESUMO}

Este trabalho trata das forças de atrito em sistemas came-tucho de ação direta, particularmente, nariz de came e tucho, sistemas estes normalmente empregados em motores de combustão interna ciclo Otto, bi-combustíveis. Neste contexto, o trabalho descreve fenômenos tribológicos, propõe uma nova abordagem experimental para a medição das forças de atrito e propõe uma nova e simples descrição teórica sobre a tribologia do contato cametucho.

Os sistemas came-tucho de ação direta apresentam peculiaridades mecânicas e condições típicas de superfícies, de came e de tucho, que influenciam no comportamento tribológico. Por se tratar de um contato lubrificado, as condições e propriedades do lubrificante também desempenham um papel importante.

Em certas condições específicas de uso veicular, utilizando-se o etanol hidratado como combustível, este pode misturar-se ao lubrificante do motor. Este trabalho esclarece, via experimentação, em condições lubrificadas, os efeitos do etanol hidratado no comportamento tribológico do contato entre o nariz de came e o tucho, que representa uma das piores condições tribológicas presentes em motores de combustão interna ciclo Otto. Mais especificamente, são pesquisados efeitos do etanol hidratado, adicionado e misturado ao lubrificante, em termos de forças e coeficientes de atrito.

Experimentos em máquina pino-disco foram realizados, visando auxiliar na compreensão dos fenômenos de atrito resultantes das adições de etanol hidratado.

Um aparato de bancada monocame foi proposto e construído. $\mathrm{O}$ aparato permitiu medir, diretamente, as forças de atrito entre came e tucho. O sistema é constituído por peças reais de um motor de combustão interna, num esforço de reproduzir, fora de um motor real em operação, o funcionamento mecânico do par came-tucho. Duas células de carga irão medir simultaneamente a força normal de contato e a força de atrito devido ao contato came-tucho.

Foi possível verificar que a adição de etanol hidratado promove uma redução das forças totais de atrito nariz de came-tucho, nas condições específicas dos experimentos monocame realizados, fenômeno este devido ao aumento de espessura de filme lubrificante, que ocorre por efeito de crescimento de viscosidades com as adições de etanol hidratado.

Com base nos dados experimentais coletados, e considerando um modelo elastohidrodinâmico, foi possível propor um novo modelo semi-empírico, para descrever os resultados experimentais. Este novo modelo utiliza, como base, as Lei de Coulomb e a Lei de Newton da viscosidade, adaptadas para o sistema em estudo. 


\section{ABSTRACT}

This work analyzes the friction forces in direct action cam-tappet systems, particularly cam nose and tappet, systems normally used in bi-fuels Otto cycle internal combustion engines. In this context, this text describes tribological phenomena, proposes a new experimental approach to the measurement of frictional forces and proposes a new and simple theoretical description on the tribology of cam-tappet contact.

Direct-action cam-tappet systems present mechanical peculiarities and typical surface, cam and tappet conditions, which influence the tribological behavior. Since it is a lubricated contact, the conditions and properties of the lubricant also play an important role.

In certain vehicle-specific conditions, using hydrated ethanol as fuel, it can be mixed with the engine lubricant. This work analyzes, through experimentation under lubricated conditions, the effects of hydrated ethanol on the tribological behavior of the contact between the cam nose and the tappet, which represents one of the worst tribological conditions in an Otto's internal combustion engine. More specifically, effects of hydrated ethanol, added and blended to the lubricant, are analyzed in terms of frictional forces and coefficients.

Experiments in a pin-on-disk machine were carried out, aiming at helping to understand the phenomena of friction resulting from the addition of hydrated ethanol.

A monocame bench was designed and built. The apparatus allowed to directly measure the frictional forces between cam and tappet. The system consists of actual parts of an internal combustion engine, trying to reproduce the mechanical operation of the cam and tappet, outside a real engine in operation. Two load cells have simultaneously measured the normal contact force and the frictional force due to the cam-to-tappet contact.

Results indicate that the addition of hydrated ethanol promotes a reduction of the total forces of cam-tappet nose friction, under the specific conditions of the monocame experiments, due to the increase in the thickness of the lubricating film, which occurs due to viscosity growth with the addition of hydrated ethanol to oil after vehicle use.

Based on the experimental data collected, and considering an elastohydrodynamic model, it was possible to propose a new semi-empirical model to describe the experimental results. This new model is based on the Coulomb's law and on the Newton's law of viscosity, adapted for the system under study. 


\section{LISTA DE FIGURAS}

- Figura 1: Reprodução das Tabelas de Thurson

- Figura 2: Curvas típicas obtidas por Martens, mostrando coeficiente de atrito em função da "pressão"

- Figura 3: A 'Máquina de Teste de Óleo" (Ölprobirmaschine) de Martens, 1887

- Figura 4: Distribuição de Perdas Energéticas em Veículo Automotor

- Figura 5: Distribuição de Energia de Combustível de um Carro de Tamanho Médio de Passageiros Durante um Ciclo Urbano

- Figura 6: Variação da Viscosidade Cinemática com Temperatura

- Figura 7: Curva de Temperatura Experimental de Johnson

- Figura 8: Coeficientes de Atrito para Lubrificante Envelhecido em Laboratório

- Figura 9: Coeficientes de Atrito para Lubrificante Envelhecido em Veículo

- Figura 10: Coeficientes de Atrito para Lubrificante Envelhecido em Bancada

- Figura 11: Mudança em Aditivos Durante Envelhecimento em Veículo

- Figura 12: Lubrificantes Utilizados e Coeficientes de Atrito

- Figura 13: Sistema Comando de Válvulas (SCV) de um Motor a Combustão Interna

- Figura 14: Sistema Tucho Mecânico de Ação Direta, TMAD, em detalhe

- Figura 15: Região de Contato Came Tucho

- Figura 16: Nariz de Came

- Figura 17: Excentricidade entre Came e Tucho

- Figura 18: Diferentes Regimes Tribológicos ao Longo do Ciclo Came

- Figura 19: Razão de Velocidades de Rotação Came-Tucho

- Figura 20: Velocidade de spin x RPM Came por Kim e Han

- Figura 21: Cabeçote de Motor V6 3.5 L em Teste de Bancada

- Figura 22: Espessura de Filme em Contato EH

- Figura 23: Espessura de Filme Central segundo Kushwahu e Rahnejat

- Figura 24: Contatos Came-Tucho, Configuração Geométrica de Gecin

- Figura 25: Coeficientes da Atrito Came-Tucho para duas Rugosidades

- Figura 26: Torques Resistentes Modelo x Medidos

- Figura 27: CA para start-up Came Tucho Revestidos e não Revestidos

- Figura 28: Valores Experimentais e Numéricos para Coeficientes de Atrito no Ensaio block

- Figura 29: Resultados de Forças de Atrito Considerando-se Efeitos de Flash Temperature

- Figura 30: Perfil de Velocidades Ph1, Segundo a Norma NBR 6601 
- Figura 31: Princípio do Experimento Pino-Disco

- Figura 32: Detalhe de Usinagem na Ponta do Pino

- Figura 33: Curvatura Obtida no Pino

- Figura 34: Ilustração do Contato em Linha

- Figura 35: Braço e Pinça do Equipamento Plint TE67

- Figura 36: Aparato Pino-Disco Utilizado - Plint TE67

- Figura 37: Visão Geral do Tribômetro Came-Tucho, TCT

- Figura 38: Interior do Reservatório de Óleo Estrutural

- Figura 39: Esquema do Interior da Célula

- Figura 40: Célula em Visão Explodida

- Figura 41: Amplificador de Sinal e Osciloscópio

- Figura 42: Sinais Elétricos e Forças da CCV em Ensaio Estático e Dinâmico

- Figura 43: Sinais Elétricos e Forças da CCH em Ensaio Dinâmico

- Figura 44: Diminuição de Segundo Pico por Aumento de Pré-Carga

- Figura 45: Forças de Atrito Came-Tucho - Dados Experimentais a Menos dos Valores

Analíticos

- Figura 46: Coeficientes de Atrito, CA, Came-Tucho com Lubrificante SJ20W50

- Figura 47: Sumário da Atividade Experimental

- Figura 48: Determinação de ddp de Sinal de Força de Atrito pela CCH

- Figura 49: Pontos de Avaliação de Rugosidades em Pino e Disco

- Figura 50: Pontos Analisados na Perfilometria Óptica

- Figura 51: Evolução da Força de Atrito Pino-disco com Adição de Etanol Hidratado (1)

- Figura 52: Coeficientes de Atrito, Disco Usinado, com Adição de Etanol Hidratado (1)

- Figura 53: Evolução da Força de Atrito Pino-disco (H-DLC) com Adição de Etanol

Hidratado (1)

- Figura 54: Coeficientes de Atrito, Disco H-DLC, com Adição de Etanol Hidratado (2)

- Figura 55: Resultados de CAs para Ensaios Esfera-Disco de Costa e Spikes a $40^{\circ} \mathrm{C}$

- Figura 56: Dados de ddp para Tuchos Normais e H-DLC, ao Longo do Tempo de

Experimentação Lubrificante Envelhecido

- Figura 57: Dados de Força de Atrito para Tuchos Normais e H-DLC para Diferentes Teores de Etanol - Lubrificante Envelhecido

- Figura 58: Dados de CA para Tuchos Normais e H-DLC para Diferentes Teores de Etanol Lubrificante Envelhecido 
- Figura 59: Viscosidades Dinâmicas das Misturas Etanol Hidratado x Lubrificante 5W30 Envelhecido para $40^{\circ} \mathrm{C}$

- Figura 60: Viscosidades Dinâmicas das Misturas Etanol Hidratado x Lubrificante para $50{ }^{\circ} \mathrm{C}$

- Figura 61: Wrage e Goering Viscosidade Cinemáticas com Adição de Etanol

- Figura 62: Variação da Piezo-Viscosidade com a Adição de Etanol Hidratado

- Figura 63: Variação das Espessuras de Filme Central para Adições de Etanol Hidratado

- Figura 64: Variação da Piezo-Viscosidade com a Adição de Etanol Hidratado

- Figura 65: Variação da Espessura de Filme Central para Adição de Etanol Hidratado

- Figura 66: Marcas de Desgaste em Tucho Monocame

- Figura 67: Contatos Possíveis Nariz de Came - Tucho, com Tilting

- Figura 68: Limite de Tilting para Came-Tucho-Guia

- Figura 69: Detalhe da Geometria de Contato Limítrofe

- Figura 70: Forças de atrito pino-disco experimental x teórico

- Figura 71: Forças de Atrito Experimental x teórico EH para Ensaios Pino-Disco com Disco Usinado

- Figura 72: Forças de Atrito Experimental x teórico EH para Ensaios Pino-Disco com Disco Revestido H-DLC

- Figura 73: Redução da Extensão de Contato Limítrofe, com Teores de Etanol

- Figura 74: Espessuras de Filme Lubrificante Central e Médio

- Figura 75: Forças LEH Nariz de Came - Tucho Normal

- Figura 76: Forças LEH Nariz de Came - Tucho H-DLC

- Figura 77: CA total para Tucho Normal de Produção

- Figura 78: CA total para Tucho Revestisdo com H-DLC

- Figura 79: Viscosidades Dinâmicas do Óleo SAE 30 HVI

- Figura 80: Valores de CA Dyson \& Naylor x Valores CA Modelo LEH

- Figura 81: Fatores nas Condições Tribológicas Came-Tucho 


\section{LISTA DE TABELAS}

- Tabela 1: Sumário de Regimes de Lubrificação. Adaptado de [3]

- Tabela 2: Comparação de rugosidades Superficiais $\left(\mathrm{R}_{\mathrm{Z}}\right)$ de Partes em Contato. Extraído de [8]

- Tabela 3: Aditivos de Proteção de Superfícies. Extraído de [10]

- Tabela 4: Aditivos de Desemenho. Extraído de [10]

- Tabela 5: CAs Obtidos por Autores Recentes

- Tabela 6: Materiais, Tratamentos Térmicos e Acabamentos dos Pinos-Discos

- Tabela 7: Parâmetros Pino-Disco x Parâmetros Esfera-Disco

- Tabela 8: Dados Entrada, Modelo EHL Pino-Disco

- Tabela 9: Dados Intermediários, Modelo EHL Pino-Disco

- Tabela 10: Dados Saída, Modelo EHL Pino-Disco Usinado

- Tabela 11: Dados Saída: Modelo EHL Pino-Disco H-DLC

- Tabela 12: Dados Entrada, Modelo EHL Monocame

- Tabela 13: Dados Intermediários, Modelo EHL Monocame

- Tabela 14: Dados Saída, Modelo EHL Monocame Tucho Normal

- Tabela 15: Dados Saída: Modelo EHL Monocame Tucho H-DLC

- Tabela 16: Sumário de Dados Modelo EHL x Experimental 


\section{LISTA DE ABREVIAÇÕES E SIGLAS}

a-C:H: carbono amorfo hidrogenado

AISI: american iron and steel institute

ASTM: american society for testing and materials

BSFC: brake specific fuel consumption

BIPM: bureau international des poinds et mesures

CA: coeficiente de atrito

$\mathrm{CA}_{\mathrm{L}}$ : coeficiente de atrito limítrofe

$\mathrm{CCH}$ : célula de carga horizontal

CCV: célula de carga vertical

EH: modelo elastohidrodinâmico

EHL: modelo elastohidrodinâmico de contato em linha

G1: lubrificante base grupo I

H-DLC: hydrogenated diamond like carbon

LEHL: modelo semi-empírico limitroelastohidrodinâmico de contato em linha

MoDTC: molibdênio ditiocarbonat

NBR: norma brasileira

PAOs: Polialfaolefinas

$\mathrm{Ph} 1$ : fase 1 do ciclo cidade

RPM: rotações por minuto

SAE: society of automotive engineers

SCV: sistema commando de válvulas

TEHL: thermal elastohydrodynamic lubricated

TMAD: tucho mecânico de ação direta 


\section{LISTA DE SÍMBOLOS}

$\alpha$ : índice de piezoviscosidade

v. coeficiente de Poisson do material

$\eta$ : coeficiente de viscosidade dinâmica

- $n$ : densidade de asperezas adimensional

$h_{m e d}:$ espessura de filme média entre came e tucho

$A_{c}$ : termo dependente das espessuras de filmes lubrificantes e rugosidades

$A_{p v}:$ área de contato piezoviscoso

$C A_{L}$ : coeficiente de atrito limítrofe

$E^{\prime}$ : módulo de elasticidade combinado dos materiais do came e do tucho

$F_{a t}:$ força de atrito total

$F_{l}$ : força de atrito limítrofe

$F_{r}$ : força de atrito total came-tucho

$F_{v}:$ módulo da força de atrito viscosa

$L_{C}$ largura de came

$L_{L}$ extensão de contato limítrofe

$R_{c t}:$ raio de coroa de tucho

$W_{a}$ : carregamento de asperezas

$\eta_{0}$ : viscosidade nas CNTPs

$\tau_{0}$ e $\alpha_{0}:$ constantes

$\tau_{1}$ e $\tau_{2}$ : fatores de tensões cisalhantes $\mu$ : viscosidade dinâmica

$\mu_{o}$ : viscosidade dinâmica à pressão atmosférica

$b$ : largura média de Hertz

$d$ : espessura de filme do lubrificante

$E$ : módulo de elasticidade do material

E’: módulo efetivo de elasticidade

$G$ : número adimensional de material

$h$ : espessura de filme

$H$ : espessura de filme adimensional

$h_{c}$ : espessura de filme central

$H_{c}$ : espessura de filme central adimensional

$h d$ : dureza Vickers

$h_{\text {min }}$ : espessura de filme mínima 
$h_{T}$ : separação média entre superfícies

$L_{a}$ : razão de carregamento de aspereza

$n$ : densidade de asperezas

$p$ : pressão total

$p:$ carregamento de asperezas

$P^{\prime \prime}$ : pressão total adimensional

$p_{a}$ : pressão sobre uma aspereza individual

$P_{a}$ : pressão total adimensional de asperezas

$p_{h}$ : pressão hidrodinâmica

$P_{h}$ : pressão total adimensional hidrodinâmica

$R$ : raio de contato equivalente

$U$ : velocidade de rolagem adimensional

$u$ : velocidade de rolamento

$u$ : velocidade pino-disco / velocidade de rolamento came-tucho

$V$ : número de dureza adimensional

vc: velocidade de nariz de came referência estática

vr: velocidade de tucho no raio médio de contato

$w$ : carregamento por unidade de comprimento

$W$ : número adimensional de carregamento

$w_{1}$ : interferência crítica inicial

$w_{2}$ : interferência crítica no início do escoamento plástico

$X$ : coordenada adimensional

$x$ : coordenada de direção de movimento

$X_{\text {end: }}$ coordenada adimensional de saída

$x_{\text {end: }}$ posição de saída

$X_{\min }$ : coordenada adimensional de entrada

$x_{\min }$ : posição de entrada

$y_{s}$ : distância entre a linha média da superfície e a linha média dos topos

$Z$ : índice de viscosidade-pressão

$\alpha$ : coeficiente de pressão-viscosidade

$\beta$ : raio de asperezas

$\rho$ : densidade do lubrificante

$\rho_{o}$ : densidade do lubrificante à pressão atmosférica 
$\sigma$ : desvio padrão das alturas de asperezas

$\sigma_{s}$ : desvio padrão dos picos das alturas de asperezas

$\Phi_{x}$ : fator de pressão de escoamento

$\Psi$ : rugosidade composta das superfícies contíguas

$A$ : área de contato de Hertz

$H t$ : altura do tucho

$P$ carregamento normal total

$P$ : força normal máxima de contato

$P^{\prime}$ : pressão de contato de Hertz

$R^{\prime}$ : raio combinado (nariz de came - coroa de tucho)

$R c$ : raio de nariz de came

Rct: raio de coroa de tucho

$R q$ : rugosidade quadrática média

$S$ : separação entre tucho e guia

$d$ : separação das superfícies deslizantes

$m$ : fator de correção

$u$ : velocidade relativa de contato

$\eta$ : piezoviscosidade de Roelands 


\section{Sumário}

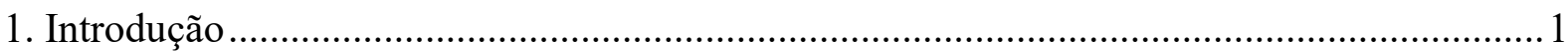

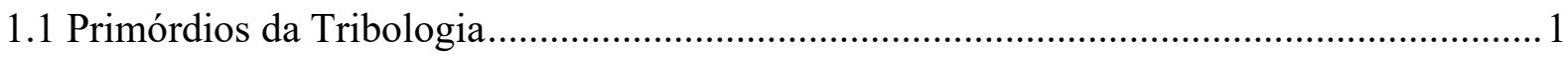

1.2 Panorama Energético de Perdas em Motores de Combustão Interna ................................... 6

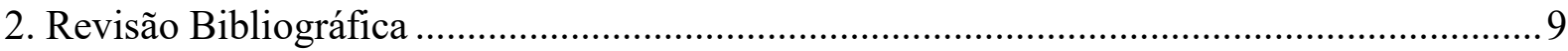

2.1 Lubrificantes de Motores de Combustão Interna ..............................................................

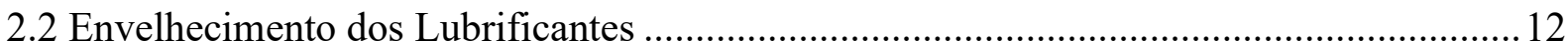

2.3 O Sistema Came e Tucho Mecânico de Ação Direta, TMAD............................................ 17

2.4 Efeitos dos Atritos Came-Tucho em Motores ....................................................................24

2.5 Modelamento Tribológico Aplicado às Interações Came-Tucho .......................................26

2.6 Modelos de Forças de Atrito Came-Tucho Ação Direta ...................................................... 34

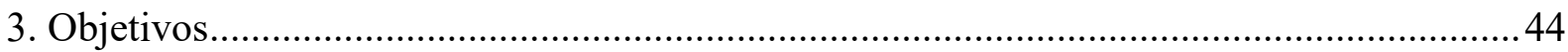

3.1 Regime Padrão de TMAD com Presença de Etanol ...........................................................4

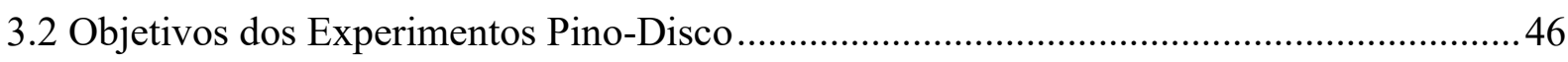

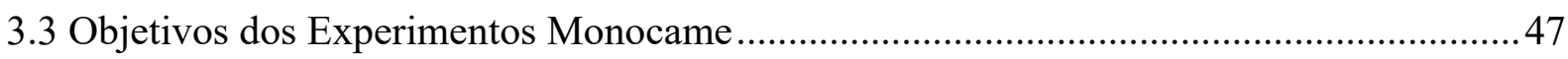

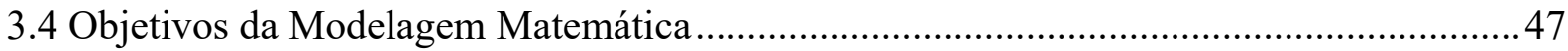

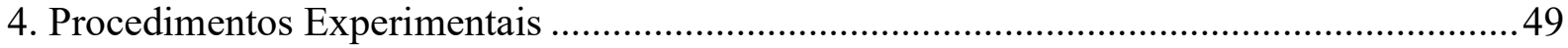

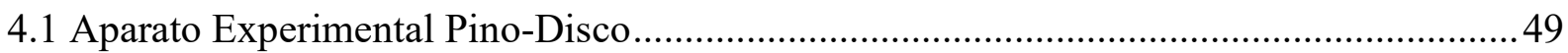

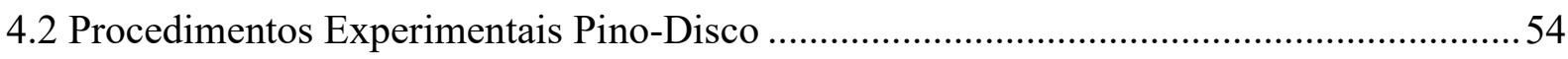

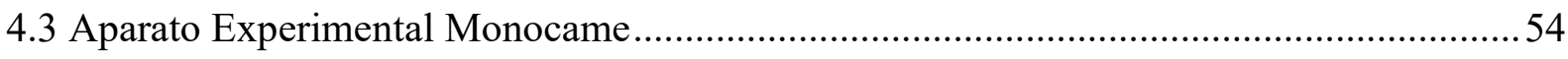

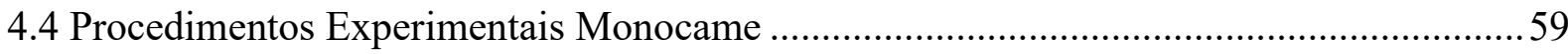

4.4.1 Ensaios Preliminares de Forças Normais, Horizontais e de Atrito ............................60

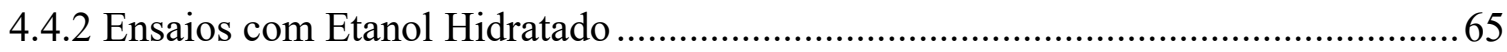

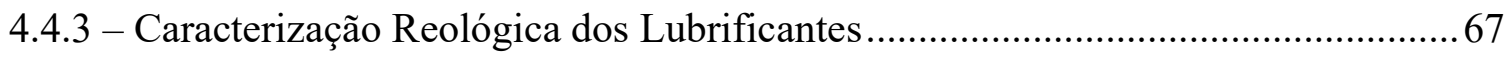

4.4.4 - Caracterização da Topografia das Superfícies .....................................................68

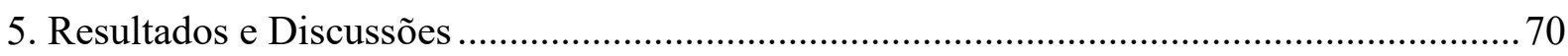

5.1 Resultados dos Ensaios Pino-Disco com Etanol Hidratado .............................................. 70

5.2 Resultados dos Ensaios Monocame com Etanol Hidratado ............................................... 74

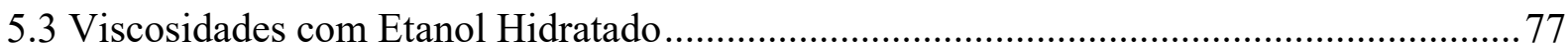

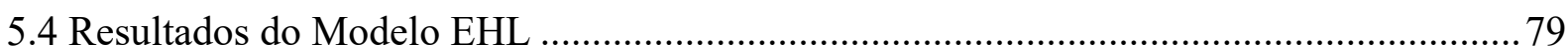

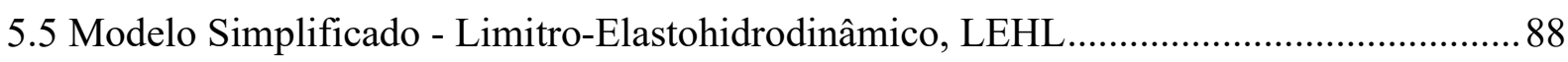

5.6 Modelo LEHL Aplicado aos Dados Experimentais Pino-Disco .......................................95

5.7 Modelo LEHL Aplicado aos Dados Experimentais Monocame .......................................97 
5.8 Modelo LEH Aplicado aos Dados Experimentais de Dyson ........................................... 102

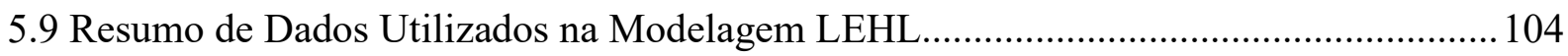

5.10 Discussão Geral Sobre as Condições Tribológicas Came-Tucho .................................. 105

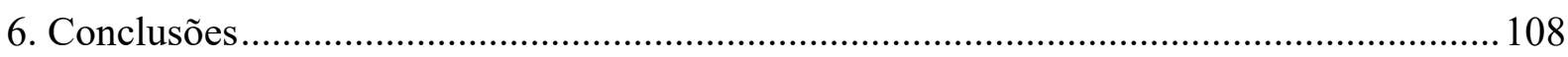

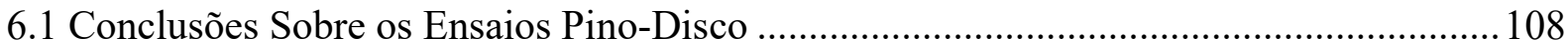

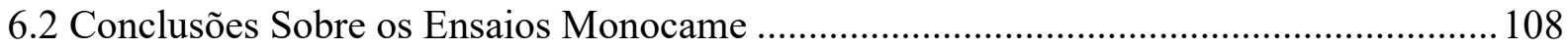

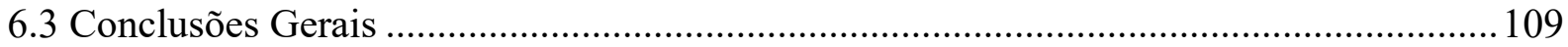

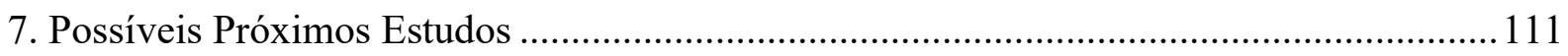

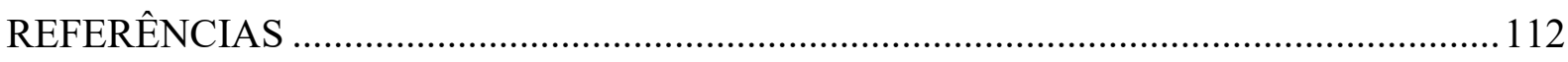

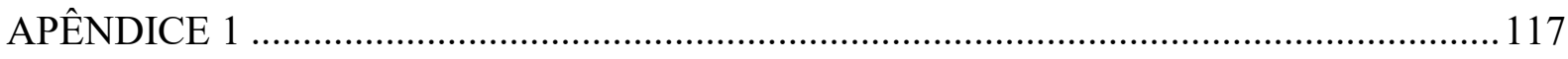

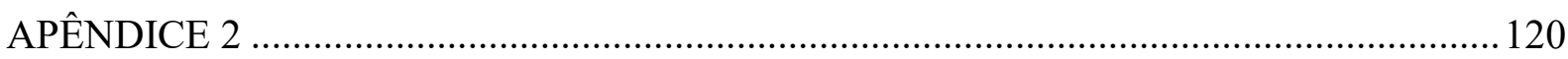

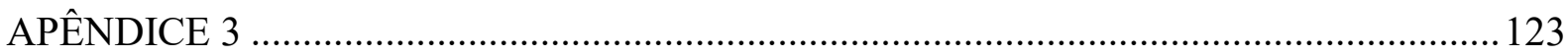

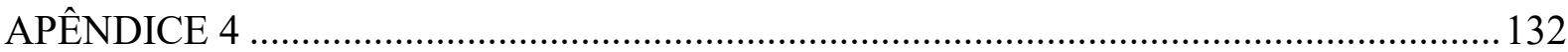




\section{Introdução}

\subsection{Primórdios da Tribologia}

Em contatos mecânicos, a lubrificação é geralmente utilizada visando reduzir atrito e aumentar a integridade das superfícies em contato ao longo do tempo. Existem vários regimes de lubrificação que serão discutidos em maiores detalhes mais adiante.

A história sobre as descobertas relativas aos regimes de lubrificação, para os contatos deslizantes lubrificados, tem origem no século XIX. A relação funcional entre o coeficiente de atrito e o produto da velocidade de deslizamento e viscosidade, dividida pela carga normal, foi experimentalmente explorada por Adolf Martens, em 1888, antes de Richard Stribeck fazer suas medidas, em 1902. No entanto, os trabalhos de base neste domínio de hidrodinâmica experimental foram publicados ainda antes, por volta de 1854, por Gustave A. Hirn, em 1879 por Robert H. Thurston e em 1883, por Beauchamp Tower [1].

Uma das primeiras máquinas de testes com lubrificação, que fornecem diretamente o valor dos coeficientes de atrito, para mancais de deslizamento de aplicação ferroviária, foi concebida em meados dos anos 1870, por Thurston, no Instituto Stevens de Tecnologia nos Estados Unidos [1]. Posteriormente, suas máquinas se tornaram comercialmente disponíveis. Os resultados obtidos com testes naquela máquina foram sumarizados por Thurston, que escreveu:

"... É facilmente visto que a mudança no valor do coeficiente de atrito com a mudança de velocidade não é grande em máquinas nas quais a velocidade permanece dentro dos limites usuais..."

"...As condições que produzem diferenças mais relevantes são da natureza do óleo, da pressão, e da temperatura. A velocidade de deslizamento determina um limite além do qual a intensidade da pressão não pode ser aumentada sem perigo de aquecimento; mas o efeito da sua variação sobre o coeficiente de fricção é normalmente menor do que qualquer das outras condições especificadas...".

"...A resistência devido ao atrito varia com a velocidade, diminuindo com o aumento da velocidade. Esta resistência varia rapidamente em velocidades muito baixas, entre 1 e 10 pés por segundo, e varia lentamente quando velocidades mais elevadas são atingidas, até que mudanças no regime ocorram por aumento de temperaturas, a uma taxa muito baixa, em toda a gama de velocidades normais de fricção em máquinas...", 
"...A temperatura mínima de fricção nas condições destas experiências é de cerca de $\mathrm{T}=15 \sqrt{ } \mathrm{v}$, para uma pressão de cerca de 200 psi...".

Thurston estava, portanto, perto de estabelecer a curva "Stribeck", mas ele não apresentava gráficos do tipo "Stribeck". No entanto, os dados fornecidos mostraram a transição entre regime hidrodinâmico completo de lubrificação e alguma interação entre asperezas (regime misto). Os coeficientes de atrito foram determinados, para diferentes temperaturas do óleo, velocidades e pressões de contato. A Figura 1 mostra gráficos construídos a partir dos dados publicados por Thurston [1].

Figura 1 - Reprodução das Tabelas de Thurson

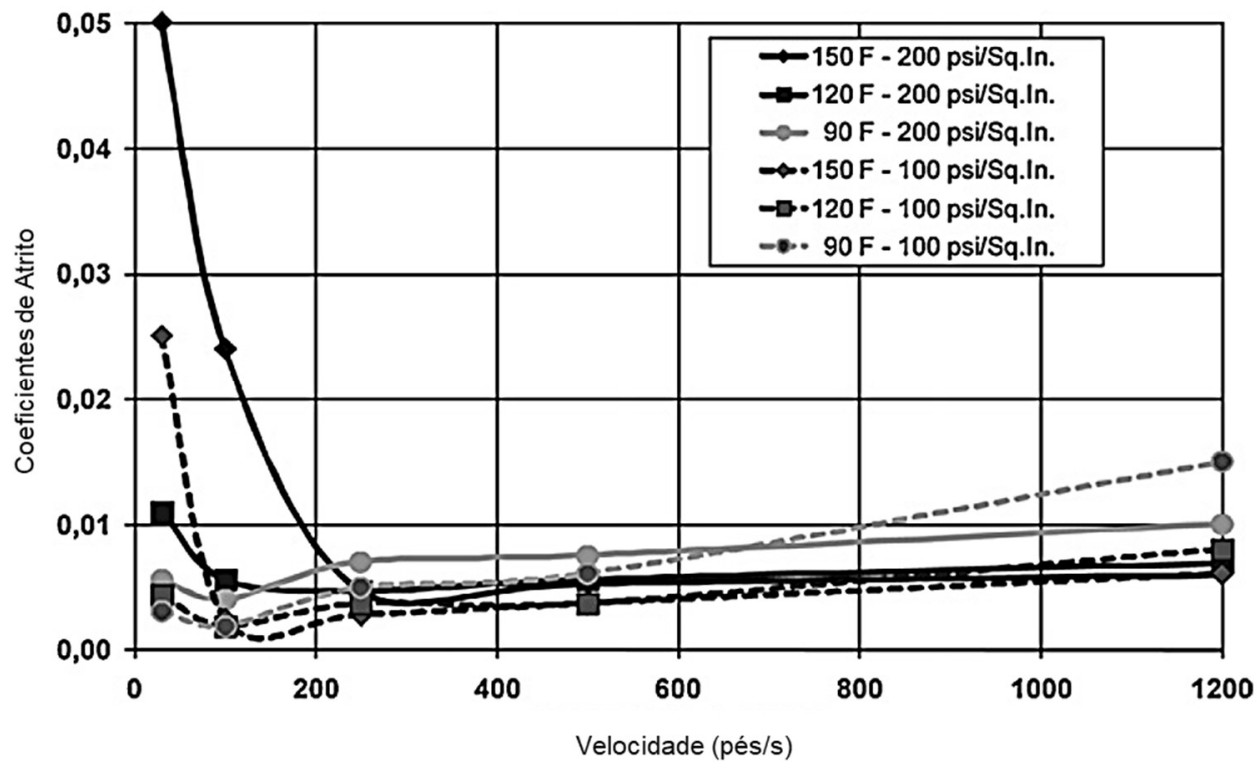

Extraído de [1]

Stribeck estudou sistematicamente a variação de atrito entre duas superfícies (mancais de deslizamento ferroviário) lubrificadas com óleo, como função da velocidade, para diferentes cargas. Seus resultados foram publicados em 1902 [1].

Os gráficos da força de atrito relatados por Stribeck resultam de uma série de experimentos em mancais de deslizamento que mostraram claramente o valor mínimo de atrito, agora conhecido como a transição entre a lubrificação de filme fluido completo e algumas interações de asperezas sólidas (regime misto). Stribeck estudou diferentes materiais de rolamento e proporções diâmetro/comprimento de eixo de 1:1 a 1:2. A máxima velocidade de deslizamento foi de $4 \mathrm{~m} / \mathrm{s}$ e a pressão de contato geométrica foi limitada a $5 \mathrm{MPa}$. Estas condições de operação relacionam-se com mancais de deslizamento de vagão ferroviário. 
Foi então que Gumbel utilizou as descobertas experimentais de Stribeck, cerca de 10 anos após sua publicação, e traçou o coeficiente de atrito contra o parâmetro de lubrificação adimensional $\eta \mathrm{N} / \mathrm{P}$, no qual $\eta$ é a viscosidade, $\mathrm{N}$ a velocidade angular (por exemplo RPM de um mancal) e P é a carga projetada na geometria da superfície (em carga por unidade de área) $[1]$.

Adolf Martens descobriu uma "curva de regime de atrito", similar à de Stribeck, 14 anos antes deste, como mostrado na Figura 2 [2].

Figura 2 - Curvas típicas obtidas por Martens, mostrando coeficiente de atrito em função da "pressão" (água morna, 99.6mm diâmetro eixo de aço temperado, sendo executado em rolamentos casquilhos feitos a partir de "Rotguß" (latão vermelho, uma liga Cu-Sn-Zn fundido; linhas pontilhadas para $v=1,0 \mathrm{~m} / \mathrm{s}$ ).

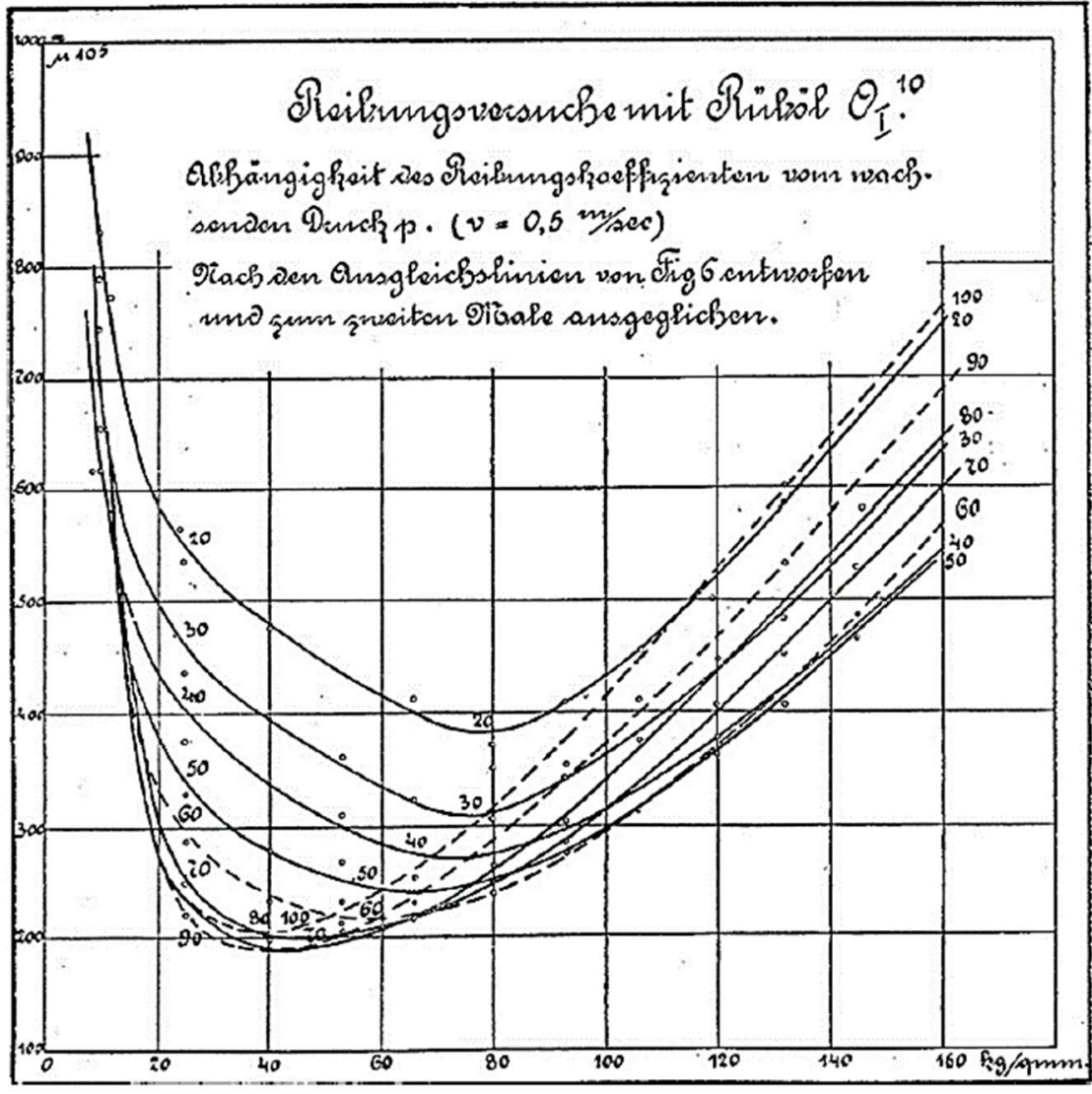

Extraído de [2]

Em sua pesquisa de atrito, Martens utilizou a máquina de teste mostrada na Figura 3 para estudar a mudança de atrito entre superfícies lubrificadas (aqui, óleo de colza refinado) em 
função do contato geométrico, pressão e velocidade, em uma geometria eixo-casquilho para a lubrificação de mancais em eixos ferroviários [2].

Figura 3 - A 'Máquina de Teste de Óleo" (Ölprobirmaschine) de Martens, 1887

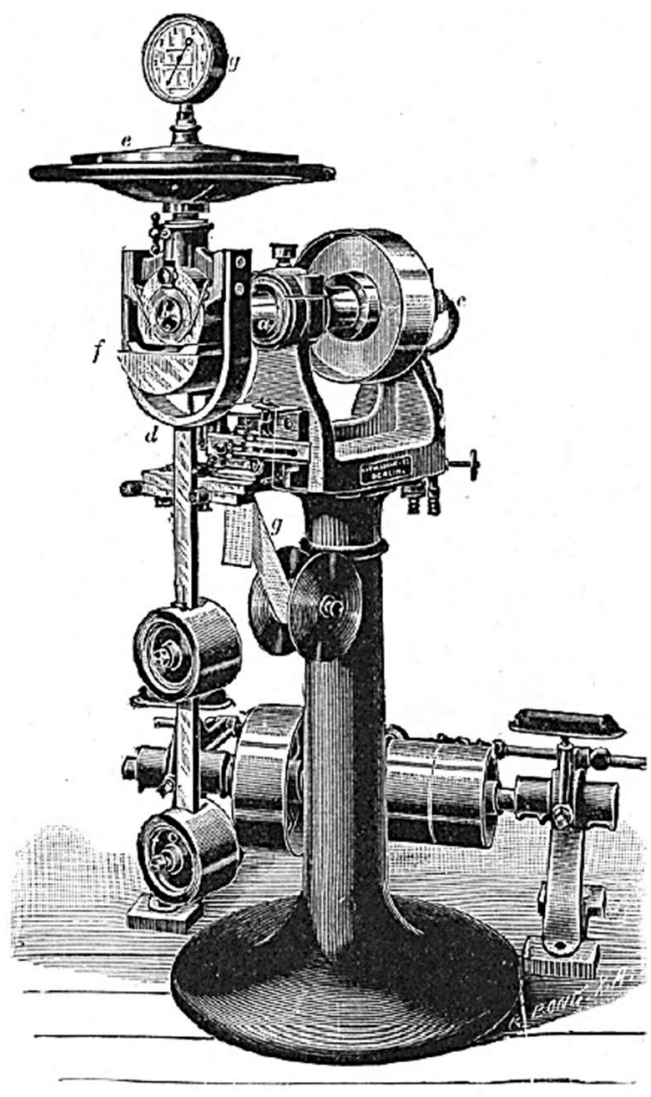

Extraído de [2]

Ao comparar os resultados de Thurston, Martens e Stribeck, o mínimo no coeficiente de atrito foi encontrado para duas superfícies lubrificadas:

(A) por Stribeck, como uma função da velocidade a diferentes pressões de contato;

(B) por Martens, em função da pressão de contato para diferentes velocidades e para diferentes viscosidades de óleo de colza, modificadas através de mudança de temperatura;

(C) por Thurston como função da velocidade a diferentes pressões.

Como já dito, as curvas de Stribeck e Martens originam-se em estudos sobre mancais de deslizamento de vagões ferroviários, cujos contatos limitam-se a velocidades máximas de 4 $\mathrm{m} / \mathrm{s}$ e cargas de $5 \mathrm{MPa}$. Entretanto, em componentes mecânicos, são comuns contatos lubrificados com velocidades superiores e/ou cargas maiores, chegando à 1 ou $2 \mathrm{GPa}$. Estes contatos de altas cargas promovem, em geral, regimes de lubrificação elasto-hidrodinâmicos, 
nos quais observam-se deformações elásticas (e até plásticas) nas regiões de contato, onde o filme fino de lubrificante é aprisionado e apresenta, em geral, propriedades não Newtonianas.

De uma forma geral, além das previsões da curva de Stribeck, pode-se resumir os regimes tribológicos conforme apresentado na Tabela 1.

Tabela 1 - Sumário de Regimes de Lubrificação. Adaptado de [3]

\begin{tabular}{|l|l|}
\hline $\begin{array}{l}\text { Regime de } \\
\text { Lubrificação }\end{array}$ & Características \\
\hline Hidrodinâmico & $\begin{array}{l}\text { As superfícies em contato estão idealmente isentas de filme } \\
\text { lubrificante separando as superfícies e deslizam com } \\
\text { predominância de contatos de asperezas. }\end{array}$ \\
\hline Misto & $\begin{array}{l}\text { Lubrificação completa filme fluido na qual as superfícies estão } \\
\text { completamente separadas. A viscosidade dinâmica do lubrificante é } \\
\text { a sua propriedade mais importante. }\end{array}$ \\
\hline $\begin{array}{l}\text { Elasto- } \\
\text { hidrodinâmico }\end{array}$ & $\begin{array}{l}\text { Há interação de asperezas das superfícies em algum grau e as } \\
\text { características de regimes de lubrificação hidrodinâmico, limítrofe, } \\
\text { ou mixed-EHD, são influentes. }\end{array}$ \\
\hline $\begin{array}{l}\text { onde a deformação elástica das superfícies e o efeito da pressão } \\
\text { sobre a viscosidade são importantes. }\end{array}$ \\
\hline
\end{tabular}

Os citados regimes de lubrificação regem os fenômenos tribológicos que ocorrem com os mancais (bearings), anéis de pistão (piston rings), came-tucho (cam-tappet) e com dentes de engrenagens em contato, num motor de combustão interna ou transmissão mecânica, por exemplo. Estes componentes dependem de diferentes modos de lubrificação para um desempenho satisfatório e, na verdade, cada um pode desfrutar de mais de uma forma de lubrificação durante um ciclo.

Os regimes de lubrificação que ocorrem num dado contato mecânico precisam ser muito bem compreendidos pelo projetista do equipamento (ou peças em contato) de tal forma que o seu projeto promova características de baixo atrito (se desejável) e longa durabilidade.

As melhorias de eficiência energética almejadas hoje em dia no desenvolvimento de motores envolvem, muitas vezes, componentes menores com velocidades de superfície e 
temperaturas mais elevadas e cargas de contato também maiores. Surgem, também, solicitações importantes para aqueles que desenvolvem lubrificantes, como a tendência de baixa viscosidade, por exemplo, que leva a espessuras reduzidas de filme e a potenciais problemas de durabilidade, como descrito no próximo ítem.

\subsection{Panorama Energético de Perdas em Motores de Combustão Interna}

Os automóveis que hoje em dia operam primordialmente em cidades estão sujeitos a regimes de velocidades ao longo do tempo que implicam em baixas frequências de rotação dos motores. No Brasil, estes motores, ciclo Otto, são movidos a gasolina (com teor de etanol hidratado em sua composição) ou etanol hidratado somente, ou mistura de ambos. São os chamados motores bi-combustíveis ou flex-fuel.

Os motores Otto bi-combustíveis fazem parte do objeto deste trabalho.

Em termos de eficiência energética do veículo, os motores, por si só, são responsáveis por uma parcela significativa de perdas energéticas por atrito entre suas partes móveis [3]. Cerca de $10 \%$ da energia fornecida pelo combustível é perdida em um motor a combustão interna devido aos atritos internos. Essa quantidade de energia perdida corresponde a cerca de $25 \%$ da potência específica a plena carga, e é maior em cargas parciais. Em vazio, ou "marcha lenta", $100 \%$ da potência indicada é consumida pelo atrito.

A Figura 4 mostra a distribuição de energia em um motor 2.0 L Otto em plena carga, a 5000 RPM [3].

Figura 4 - Distribuição de Perdas Energéticas em Veículo Automotor Dotado de Motor 2.0 L

Otto

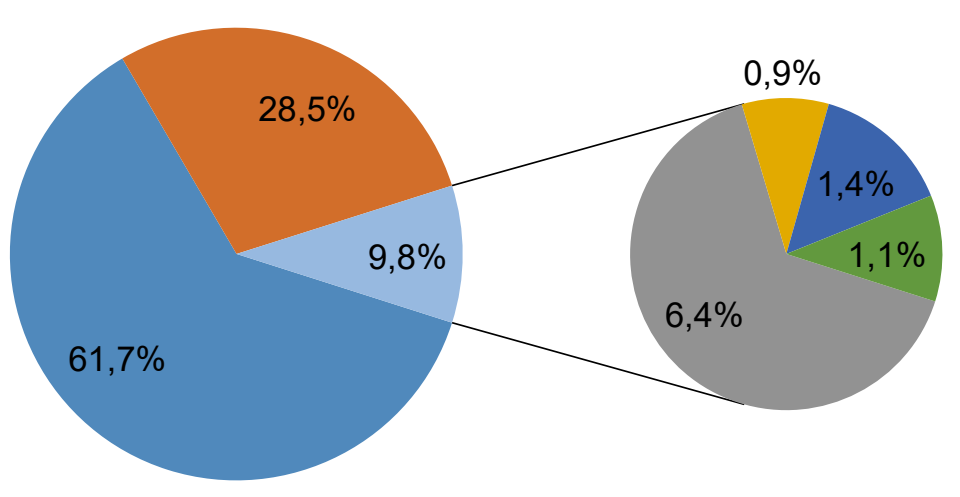

- Perdas Térmicas

- Trabalho Mecânico

- Gases de Exaustão e Acessórios

Anéis de Segmento

- Pistão-Cilindro

- Comando de Válvulas

Extraído de [3] 
A plena carga, o sistema comando de válvulas é responsável por cerca de $1 \%$ das perdas energéticas.

Numa situação de ciclo urbano, as perdas são diferentes daquelas apresentadas em plena carga. Na Figura 5, dados apresentados por Andersson [4] são representados e exibe-se a distribuição de energia de combustível queimado, para um veículo de tamanho médio, de passageiros, durante um ciclo urbano.

Figura 5 - Distribuição de Energia de Combustível de um Carro de Tamanho Médio de Passageiros Durante um Ciclo Urbano

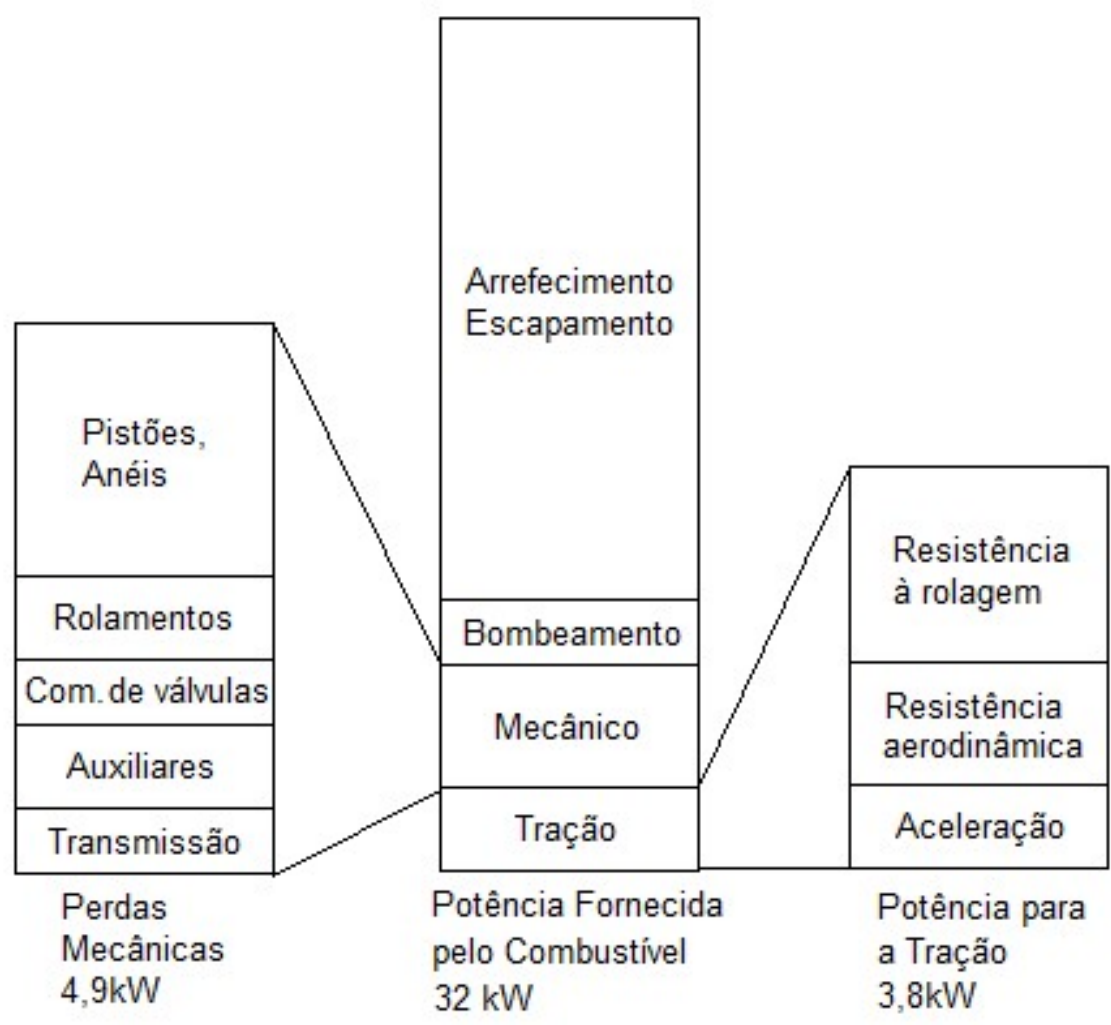

Extraído e adaptado de [4]

As perdas mecânicas, neste caso, representam cerca de $15 \%$ da potência fornecida pela queima de combustível. Mesmo 1\% de melhoria na economia de combustível de um modelo de veículo é de grande relevância econômica e ambiental, conforme afirmado por Wong e Tung [5]. Ratamero e Ventura [6] calcularam que o benefício em economia de combustível, para um veículo pequeno de passageiros, dotado de motor Otto I3, é da ordem de $0.5 \%$ com o emprego de tuchos revestidos com H-DLC, em comparação com tuchos normais de produção, num ciclo combinado cidade-estrada. 
As propriedades dos lubrificantes empregados desempenham um papel central, na tribologia de motores flex-fuel, em associação com o projeto mecânico do motor/transmissão. Não somente a economia de combustível, mas também o desempenho de veículos, depende destas propriedades do lubrificante. Tomanik, Lastres e Carvalho realizaram ensaios em motor monocilindro e em veículo real, comparando resultados de atritos internos e de desempenho em aceleração veicular, para dois lubrificantes comerciais diferentes, um de "alta viscosidade" e outro de "baixa viscosidade". Os autores observaram uma redução em torno de 52\% nos atritos internos do mono-cilindro, em quatro regimes representativos de condições de uso urbano, e uma redução de $6,3 \%$ de tempo de retomada de 60 a $100 \mathrm{~km} / \mathrm{h}$, com veículo $1.4 \mathrm{~L}$ gasolina [7].

Pouco se sabe sobre os efeitos do etanol hidratado no comportamento tribológico cametucho mecânico de ação direta, tanto em termos de variações das forças de atrito, quanto por desgastes decorrentes das interações com o lubrificante, com seus aditivos e com as interações com as superfícies metálicas.

Este trabalho visa contribuir com este tema, especialmente no que se refere às ações da presença do etanol hidratado no lubrificante e nas forças de atrito came-tucho de ação direta. 


\section{Revisão Bibliográfica}

\subsection{Lubrificantes de Motores de Combustão Interna}

$\mathrm{Na}$ engenharia de motores de combustão interna, a lubrificação é um tópico fundamental. O intuito da lubrificação é preservar as superfícies em contato e reduzir os níveis de atrito.

O acabamento das superfícies que entram em contato é de grande importância. Motores contemporâneos diferem de motores mais antigos, especialmente pelo fino acabamento de suas superfícies em contato [8]. A Tabela 2 exibe valores de rugosidade superficial, $R_{Z}$, de algumas partes de um motor mais antigo e de um motor dos anos 90.

Tabela 2 - Comparação de Rugosidades Superficiais $\left(\mathrm{R}_{\mathrm{Z}}\right)$ de Partes em Contato Extraído de [8]

\begin{tabular}{|l|c|c|}
\hline & Motor 1995 & Motor anterior a 1995 \\
\hline Nariz de Came $(\mu \mathrm{m})$ & 1,0 & 1,8 \\
\hline Tucho $(\mu \mathrm{m})$ & 1,0 & 2,3 \\
\hline Mancal de Eixo Virabrequim $(\mu \mathrm{m})$ & 0,3 & 0,6 \\
\hline Mancal de Eixo Manivela $(\mu \mathrm{m})$ & 0,3 & 0,5 \\
\hline
\end{tabular}

As partes finamente polidas, em contato, favorecem a formação de filme de lubrificante. Além disso, aditivos, como o MoDTC, (ditiocarbonato de molibdênio) e o ZDDP (ditiofosfato de zinco), modificadores de atrito, auxiliam na diminuição de atritos limítrofes, especialmente a altas temperaturas.

A composição dos lubrificantes modernos é complexa e deve atender a uma série de demandas características, como, por exemplo, temperaturas em cárter que podem chegar a 130 ${ }^{\circ} \mathrm{C}$, com veículo rebocando em aclive, e temperaturas na região dos pistões que podem chegar a $250{ }^{\circ} \mathrm{C}$ ou mais. Necessita-se atender também às solicitações do motor a baixas temperaturas, no momento da ignição [9].

Os lubrificantes de motor são compostos por óleo base, de origem mineral ou sintética, ou uma mistura de ambos, e aditivos. O óleo base apresenta-se numa proporção de 80 a $95 \%$ em volume. O restante do volume é composto por aditivos, com ação de modificação de atritos, remoção de resíduos, e outras funções. 
Neste trabalho, o lubrificante plenamente formulado será denominado lubrificante, e o óleo base será denominado óleo, uma vez que o óleo compõe o lubrificante, junto aos aditivos.

Os óleos base de origem mineral são obtidos pela destilação fracionada do petróleo e por reações químicas. Por esta razão, a seleção do petróleo utilizado é importante. Para a formulação de lubrificantes de motor, os preferidos são os petróleos parafínicos e os naftênicos.

Os óleos base de origem sintética são sintetizados a partir de substâncias mais simples, para compor as cadeias carbônicas. Para uso automotivo, são quatro os tipos de óleos básicos sintéticos: Polialfaolefinas (PAOs), Ésteres de Ácido Dibásico, Ésteres de Poliol e Aromáticos Alquilatos. Com a exceção dos fluídos poliglicóis, todos estes possuem viscosidades semelhantes aos óleos minerais leves. Contudo, apresentam maior resistência às condições severas de baixas e altas temperaturas, tornando-se, assim, atrativos para compor misturas [10].

Os aditivos possuem funções diversas, mas, basicamente, são de proteção superficial ou de desempenho.

A Tabela 3 apresenta os tipos de aditivos mais empregados em proteção de superfícies e suas funções específicas.

Tabela 3 - Aditivos de Proteção de Superfícies

Extraído e adaptado de [10]

\begin{tabular}{|l|l|}
\hline \multicolumn{1}{|c|}{ Tipo de Aditivo } & \multicolumn{1}{c|}{ Funções } \\
\hline $\begin{array}{l}\text { Anti-desgaste e Pressão } \\
\text { extrema }\end{array}$ & $\begin{array}{l}\text { Reduz desgastes, previne formação de marcas e variações } \\
\text { dimensionais. Proporciona formação de filme fluido, } \\
\text { prevenindo interações metal-metal }\end{array}$ \\
\hline $\begin{array}{l}\text { Inibidor de Corrosão e } \\
\text { Ferrugem }\end{array}$ & $\begin{array}{l}\text { Previne corrosão das partes metálicas em contato com o } \\
\text { lubrificante. Promove um filme protetivo. Neutraliza ácidos } \\
\text { corrosivos }\end{array}$ \\
\hline Detergente & $\begin{array}{l}\text { Mantém as superfícies livres de depósitos. Promove redução } \\
\text { de lama e verniz }\end{array}$ \\
\hline Dispersante & $\begin{array}{l}\text { Mantém insolúveis os contaminantes dispersos no lubrificante, } \\
\text { ligando-se a eles }\end{array}$ \\
\hline Modificador de Atrito & $\begin{array}{l}\text { Reduz os coeficientes de atrito. Promove adsorção preferencial } \\
\text { em materiais de superfície ativa }\end{array}$ \\
\hline
\end{tabular}


A Tabela 4 apresenta os tipos de aditivos mais empregados em desempenho e suas funções específicas.

Tabela 4 - Aditivos de Desempenho

Extraído e adaptado de [10]

\begin{tabular}{|l|l|}
\hline \multicolumn{1}{|c|}{ Tipo de Aditivo } & \multicolumn{1}{c|}{ Funções } \\
\hline Redutor de Ponto de & $\begin{array}{l}\text { Auxilia o lubrificante a fluir em baixa temperatura. Modifica a } \\
\text { formação de cristais de cera para reduzir travamentos }\end{array}$ \\
\hline Agente de Vedação & $\begin{array}{l}\text { Dilata seladores elastoméricos. Promove reações químicas } \\
\text { com elastômeros para propiciar melhores vedações }\end{array}$ \\
\hline $\begin{array}{l}\text { Modificador de } \\
\text { Viscosidades }\end{array}$ & $\begin{array}{l}\text { Reduz a variação da viscosidade com a temperatura. São } \\
\text { polímeros que expandem com o aumento de temperatura para } \\
\text { compensar o "afinamento" do óleo }\end{array}$ \\
\hline Antiespuma & $\begin{array}{l}\text { Evita que o lubrificante forme espuma. Reduz as tensões } \\
\text { superficiais para colapsar a formação de espuma }\end{array}$ \\
\hline Antioxidante & $\begin{array}{l}\text { Retarda decomposição oxidativa. Decompõe peróxidos e } \\
\text { cancela reações de radical livre }\end{array}$ \\
\hline Desativador de Metal & $\begin{array}{l}\text { Reduz o efeito catalítico dos metais na taxa de oxidação. } \\
\text { Forma filme inativo na superfície metálica }\end{array}$ \\
\hline
\end{tabular}

O efeito das temperaturas na viscosidade dos lubrificantes é dramático. A Figura 6 mostra como a viscosidade decai, em função do aumento de temperatura, para alguns lubrificantes convencionais, classificação SAE [11]. 
Figura 6 - Variação da Viscosidade Cinemática com Temperatura

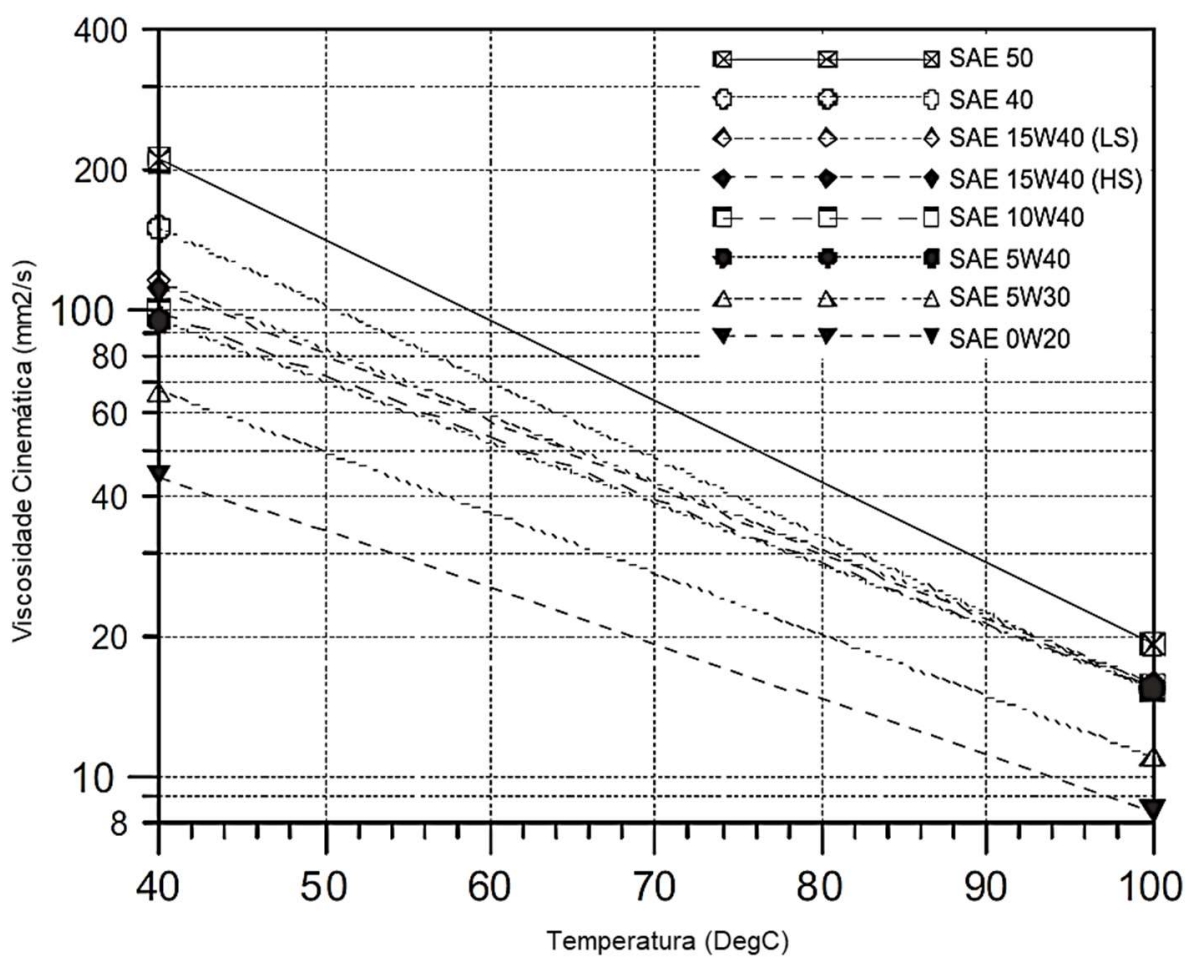

Extraído de [11]

O uso dos modificadores de viscosidade auxilia na estabilização da viscosidade do lubrificante, para várias temperaturas operacionais do motor de combustão interna.

\subsection{Envelhecimento dos Lubrificantes}

Os lubrificantes envelhecem ao longo do tempo e com o uso veicular, mudando constantemente as suas propriedades. Este processo se dá, basicamente, por oxidação do óleo base e pela perda das capacidades aditivas.

Quanto à capacidade de misturar-se com etanol hidratado, o envelhecimento é preponderante, como apresentado no APÊNDICE 2. Observou-se, experimentalmente, que quanto maior o grau de envelhecimento do lubrificante plenamente formulado (SN5W30), maior será a sua capacidade de misturar-se ao etanol hidratado e maior será a estabilidade da mistura.

A oxidação pode alterar a viscosidade durante a operação do motor.

Johnson e colaboradores avaliaram amostras de lubrificante 5W20, resultantes de processos de envelhecimento, assim como ensaiaram lubrificante novo [12]. Os lubrificantes envelhecidos não continham MoDTC e o lubrificante novo continha MoDTC. Basicamente, os 
autores utilizaram três métodos de envelhecimento de lubrificante: em laboratório, em veículo e em motor de bancada.

O processo de envelhecimento de lubrificante em laboratório consistiu em manter 60 $\mathrm{cm}^{3}$ de lubrificante a $160{ }^{\circ} \mathrm{C}$, exposto a uma mistura gasosa de $\mathrm{O}_{2}, \mathrm{~N}_{2}$ e $\mathrm{NO}_{2}$, num fluxo de 200 $\mathrm{cm}^{3}$ por minuto.

O processo de envelhecimento de lubrificante em veículo deu-se com o uso de um modelo Lincoln Town 4.61 SOHC V8. O veículo rodou num simulador de rodovia por distância equivalente a $6437 \mathrm{~km}$.

O processo de envelhecimento de lubrificante em bancada consistiu em aplicar ao motor 4.61 SOHC V8 um ciclo específico, que incluiu um processo inicial de envelhecimento de lubrificante numa temperatura de $125^{\circ} \mathrm{C}$, por $16 \mathrm{~h}$, no intuito de estabilizá-lo.

Os autores do trabalho recolheram amostras destes lubrificantes depois dos processos de envelhecimento e realizaram testes duradouros em um tribômetro de movimento alternado (Plint TE77) com configuração pino-disco, imerso em lubrificante, para verificar a estabilidade ao longo do tempo e com variações de temperatura. Também realizaram alguns ensaios químicos.

A curva de temperatura imposta às amostras, em ensaios Plint, é representada na Figura 7.

Figura 7 - Curva de Temperatura Experimental de Johnson

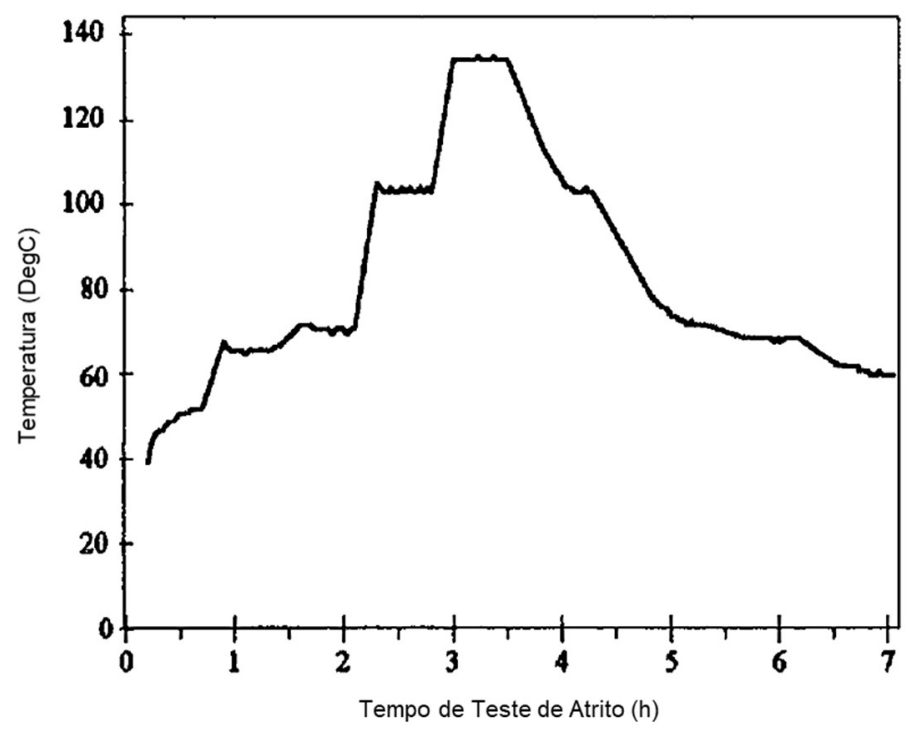

Extraído de [12]

Os testes em Plint tiveram a duração de 7 h, conforme exibe a Figura 7. 
Para amostras de lubrificante envelhecido em laboratório, a Figura 8 apresenta os resultados obtidos por Johnson, para vários tempos de envelhecimento.

Figura 8 - Coeficientes de Atrito para Lubrificante Envelhecido em Laboratório

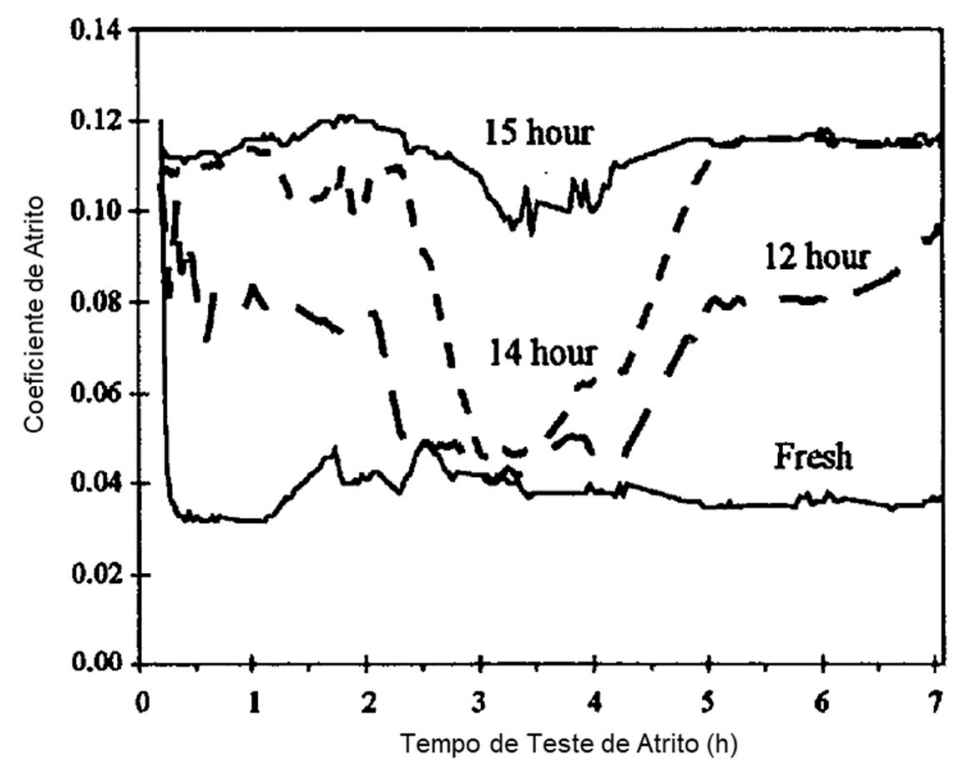

Extraído de [12]

Os resultados obtidos por Johnson para o lubrificante envelhecido em veículo, para vários quilômetros equivalentes de envelhecimento, estão apresentados na Figura 9.

Figura 9 - Coeficientes de Atrito para Lubrificante Envelhecido em Veículo

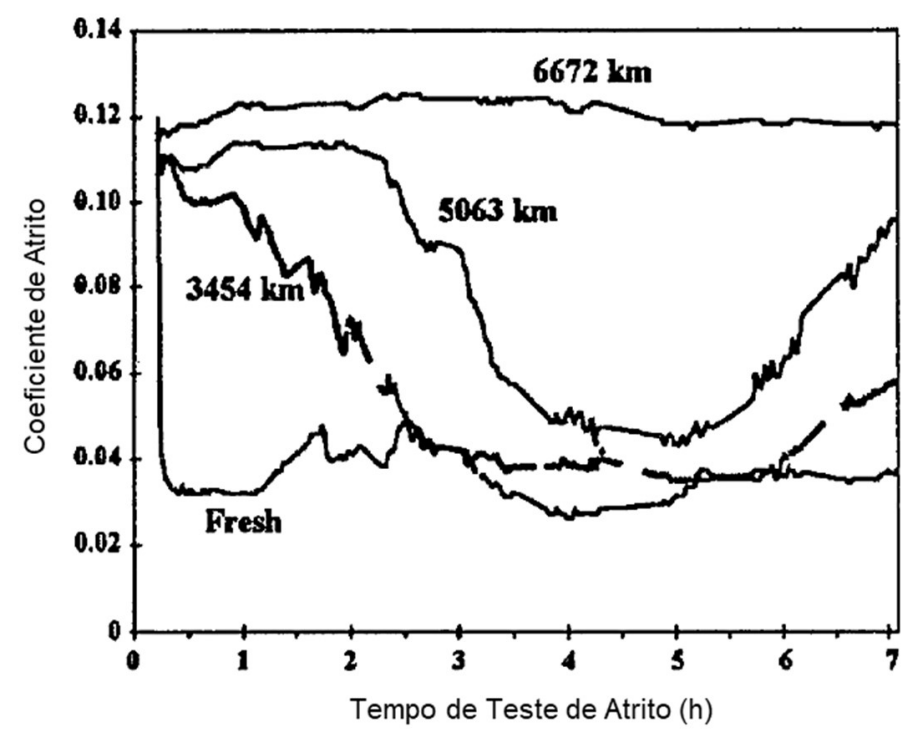

Extraído de [12] 
A Figura 10 apresenta os resultados para uma amostra de lubrificante envelhecido em bancada, coletada ao final do ensaio.

Figura 10 - Coeficientes de Atrito para Lubrificante Envelhecido em Bancada

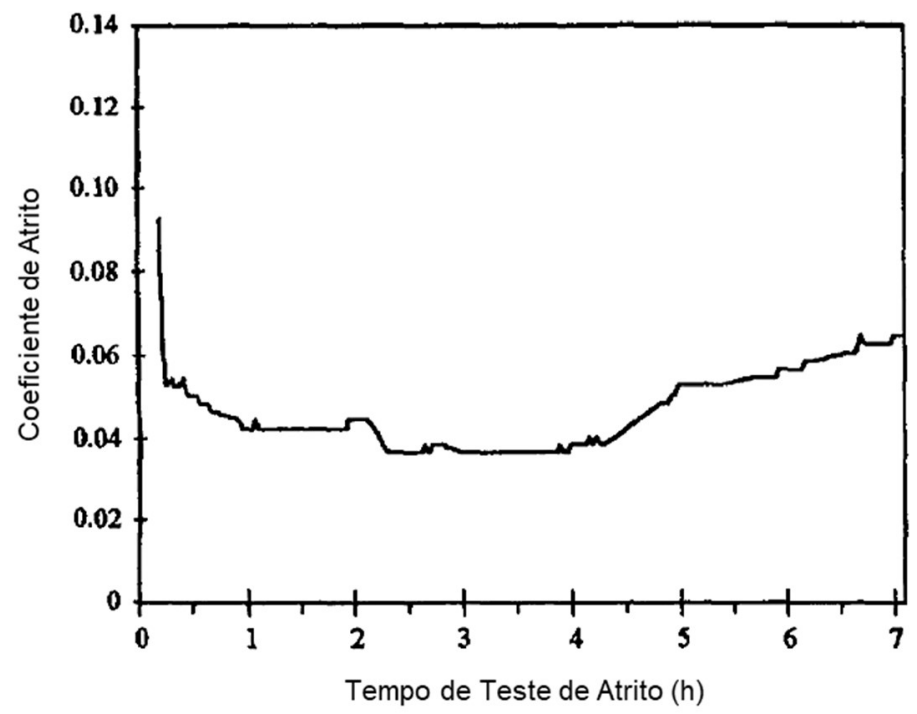

Extraído de [12]

As amostras coletadas em veículo foram analisadas em laboratório, revelando a sua concentração de MoDTC e a sua capacidade antioxidante. Os resultados são exibidos na Figura 11.

Figura 11 - Mudança em Aditivos Durante Envelhecimento em Veículo

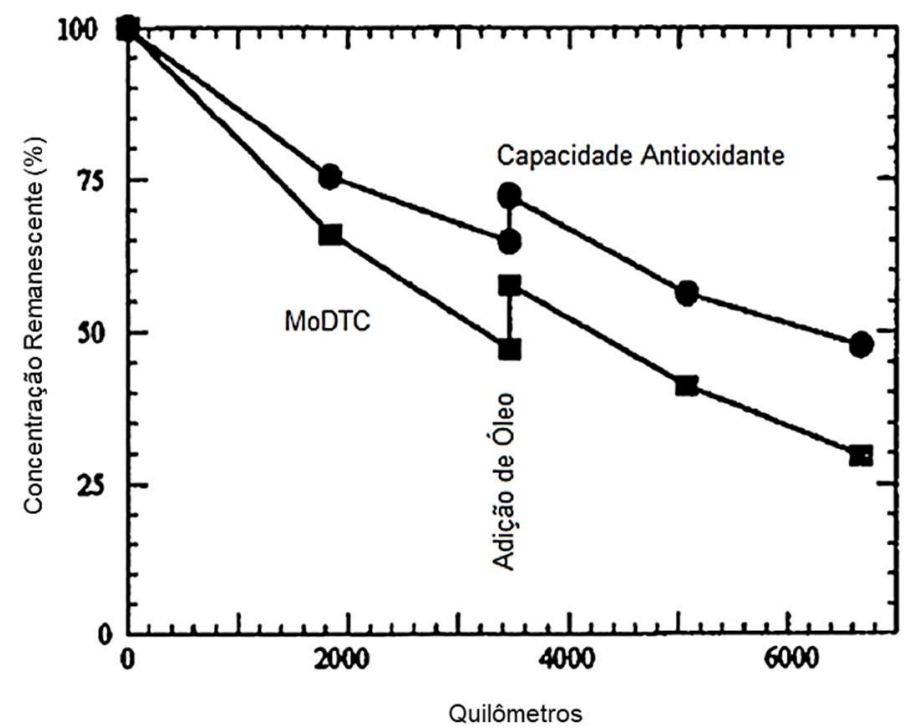

Extraído de [12] 
É notável a diminuição da concentração de MoDTC ao longo do uso veicular, assim como a diminuição da capacidade antioxidante. Johnson cita que o MoDTC possui, além da capacidade de reduzir os atritos em regime limítrofe, a capacidade de retardar o processo de oxidação do lubrificante.

As experiências de Johnson mostram que o comportamento viscoso de lubrificantes formulados varia significativamente em função do tempo de envelhecimento e varia ao longo do tempo de ensaio de atrito. Nos instantes de 2 e 5,5 horas, nos ensaios em Plint, realizados por Johnson, temos a mesma temperatura de $70{ }^{\circ} \mathrm{C}$. Nestes instantes, os lubrificantes apresentam, para os três modos de envelhecimento, diferentes respostas em viscosidades. A exceção cabe ao lubrificante mais envelhecido, o mais estável, e em segundo plano ao lubrificante novo, que, por sua vez, apresenta grande variação no início dos testes em Plint.

Tominaga e Tsuyoshi [8] realizaram testes com cinco lubrificantes diferentes num motor de bancada, V8, came-tucho de ação direta, injeção eletrônica de combustível, avaliando o consumo de combustível em função do tipo de lubrificante empregado. Os autores avaliaram comportamentos tribológicos via ensaios ball on disk. A Figura 12 exibe um comparativo de coeficientes de atrito entre lubrificante novo e lubrificante envelhecido, para os cinco diferentes lubrificantes testados.

Figura 12 - Lubrificantes Utilizados e Coeficientes de Atrito

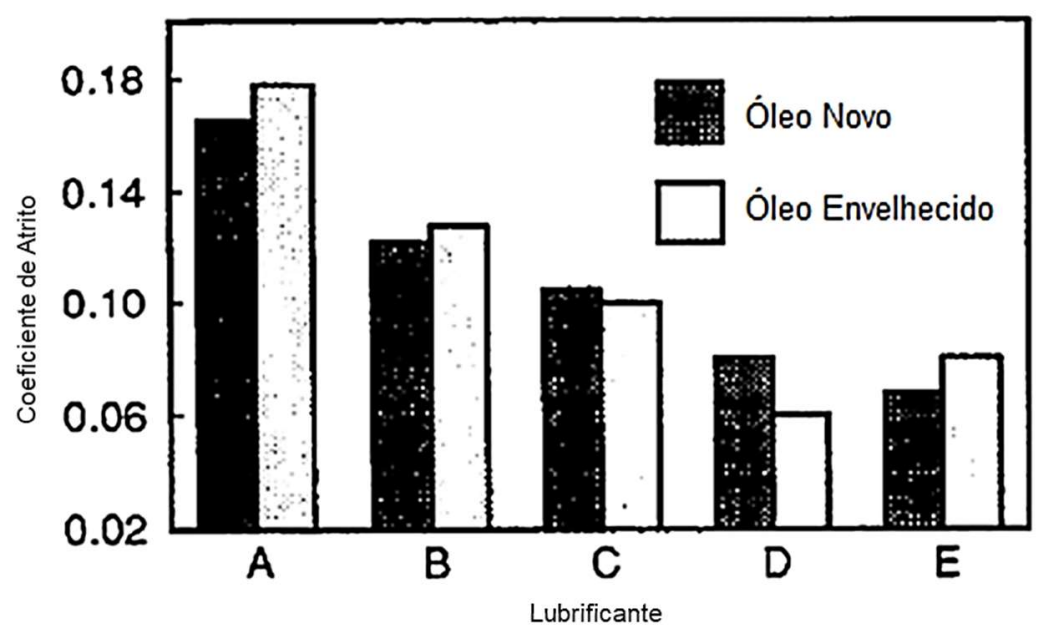

Extraído de [8]

O consumo de combustível do motor em bancada, para cinco tipos de lubrificantes classificação SAE, somente foi medido após uma operação de envelhecimento de 32 h no motor de teste, a fim de simular a degradação dos lubrificantes durante o serviço no campo [8]. 
Ademais, o tipo de contato mecânico, em termos de carregamentos, velocidades de deslizamento entre superfícies, temperaturas, etc, promovem diferentes comportamentos tribológicos. Desta forma, para uma melhor compreensão global da tribologia came-tucho, é necessário um olhar mais detalhado a respeito da mecânica das interações came-tucho de ação direta, objetivo do próximo tópico.

\subsection{O Sistema Came e Tucho Mecânico de Ação Direta, TMAD}

Um dos sistemas do motor sujeito a atritos consideráveis, e que contribui para o consumo de combustível do veículo, é o sistema de controle e acionamento de válvulas de admissão e descarga de gases, o sistema comando de válvulas (SCV). Este sistema é o responsável pela aspiração de ar e pela exaustão de gases queimados nos cilindros do motor.

O SCV mais comum empregado em motores quatro tempos é o mecânico por eixo comando de válvulas, que utiliza cames e tuchos mecânicos de ação direta (TMAD). Ele é constituído, essencialmente, por cames, tuchos, eixos comando de válvulas, molas e válvulas, conforme exibe a Figura 13. Nesta figura apresenta-se o sistema considerado neste trabalho.

Figura 13 - Sistema Comando de Válvulas (SCV) de um Motor a Combustão Interna 1: came 2: tucho 3: eixo comando 4: mola 5: válvula

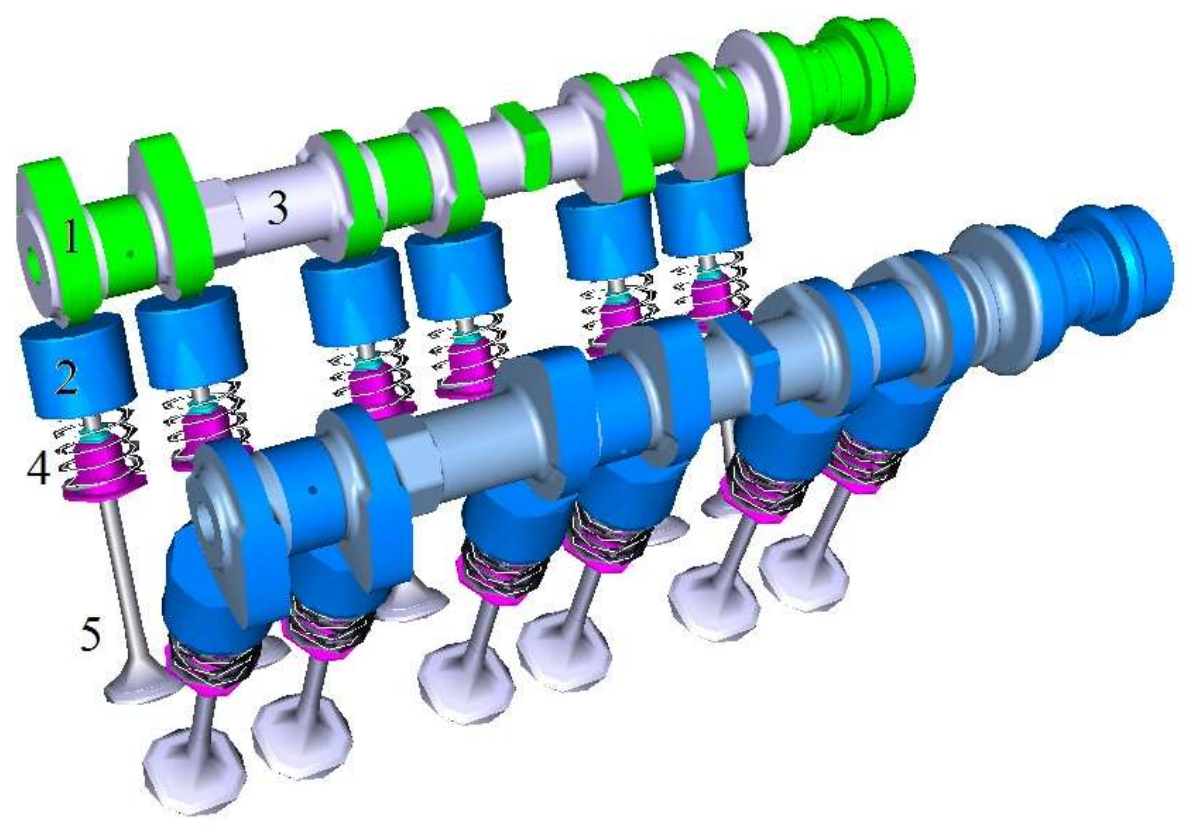

Cortesia Ford Motor Company 
O eixo comando de válvulas gira solidário ao eixo virabrequim, fazendo com que os cames nele afixados sofram um movimento rotativo. Os cames, ao girarem, promovem o deslocamento dos tuchos e das válvulas, devido ao seu perfil não circular, alongado. As molas instaladas promovem o movimento de retorno das válvulas e tuchos e desta forma o movimento de "abre e fecha" das válvulas se realiza sincronicamente, ou seja, de acordo com a posição angular do eixo virabrequim.

Para motores quatro tempos, a frequência de rotação do eixo comando de válvulas é a metade da frequência de rotação do eixo virabrequim.

Todo o conjunto é lubrificado com lubrificante plenamente formulado, especialmente o contato came-tucho, num esforço de minimizar os atritos e desgastes, visando melhorar o desempenho tribológico do sistema.

A Figura 14 ilustra um dispositivo TMAD em detalhe.

Figura 14 - Sistema Tucho Mecânico de Ação Direta, TMAD, em detalhe

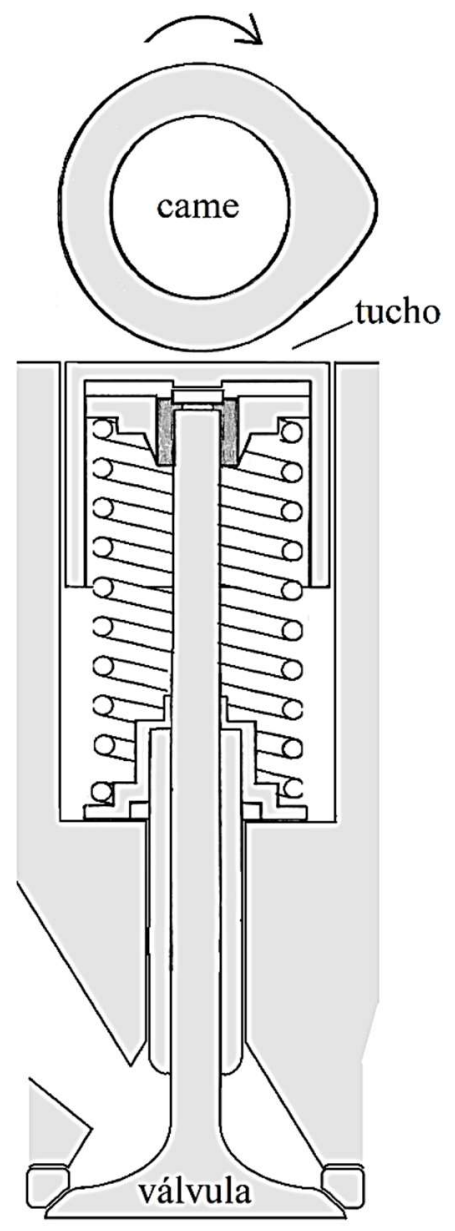

$\mathrm{O}$ autor 
O sistema came-tucho é responsável por cerca de $7 \%$ das perdas de torque por atrito no motor [6]. Os esforços por atrito e os desgastes entre o came e o tucho dependem das velocidades relativas das partes, do estado das superfícies em contato, das condições de lubrificação e temperatura e dos materiais e geometrias do came e do tucho. As velocidades, temperaturas e condições de lubrificação dependem das condições e das demandas do veículo.

Existem vários perfis de came, que promovem vários comportamentos diferentes no processo de abertura das válvulas. Motores de uso comum e motores de competição podem diferir significativamente neste quesito.

A região de contato entre o came e o tucho muda de posição em relação a um ponto fixo, dependendo da posição angular do came (sliding). A Figura 15 ilustra tal fato.

Figura 15 - Região de Contato Came Tucho

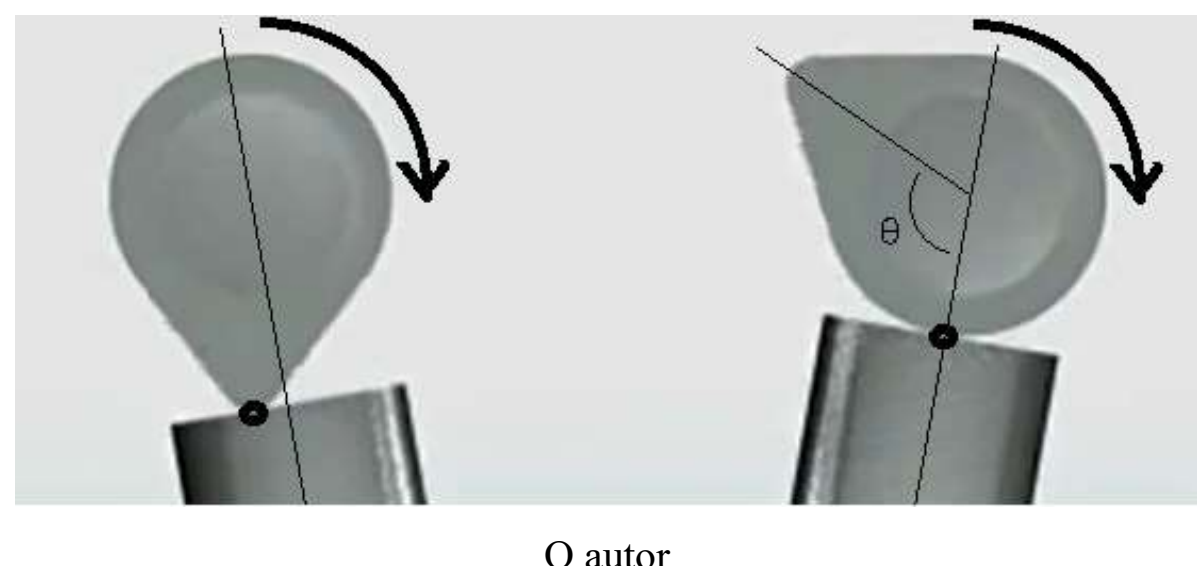

$\mathrm{O}$ autor

Nota-se, portanto, que a velocidade da região de contato entre came e tucho é dependente não somente da velocidade de rotação do came, mas também da posição angular instantânea do came. É nesta região que ocorrem os efeitos tribológicos mais importantes do sistema TMAD.

A posição angular instantânea de came, $\theta$, varia conforme o eixo comando de válvulas gira, conforme exibe a Figura 15. Vários autores adotam a referência de zero grau de came $(\theta$ $=0^{\circ}$ ) para a posição angular de came correspondente ao máximo lift de válvula, ou correspondentemente, para o contato nariz de came e tucho. $\mathrm{O}$ autor deste trabalho assim o considera. Outros autores não o adotam assim. Portanto, ao longo do texto, será possível encontar referências que consideram ângulos de came diferente de zero para o máximo lift de válvula. 
Usualmente, existe uma folga entre o came e o tucho, quando o nariz do came se afasta do tucho. Esta folga está representada na Figura 14. Nariz do came é a parte mais excêntrica do came, como exibido na Figura 16.

Figura 16 - Nariz de Came

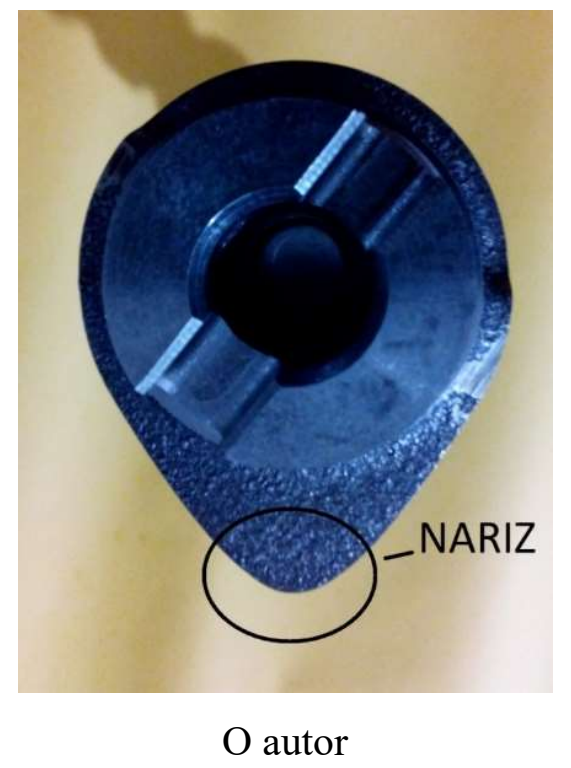

Ao girar, o nariz do came tende a se aproximar da superfície do tucho, até um momento no qual estas superfícies se tocam. Como efeitos, há a geração de ruído e eventualmente há ruptura do filme lubrificante.

O contato entre o came e o tucho é excêntrico em relação ao centro do tucho. Desta forma, é induzido um movimento de rotação do tucho (spin), limitado unicamente pelos atritos entre o tucho e o guia no qual ele se insere. A Figura 17 ilustra a referida excentricidade de contato came-tucho.

A lubrificação do par came-tucho depende fortemente das cargas e das velocidades de deslizamento e rolagem. Devido a estas características mecânicas, o regime tribológico varia muito, a depender do ângulo de came $\theta$, podendo este variar desde limítrofe (boundary) até elasto-hidrodinâmico. A Figura 18 exibe tal comportamento, como obtido analiticamente por Teodorescu et al [18]. 
Figura 17 - Excentricidade entre Came e Tucho

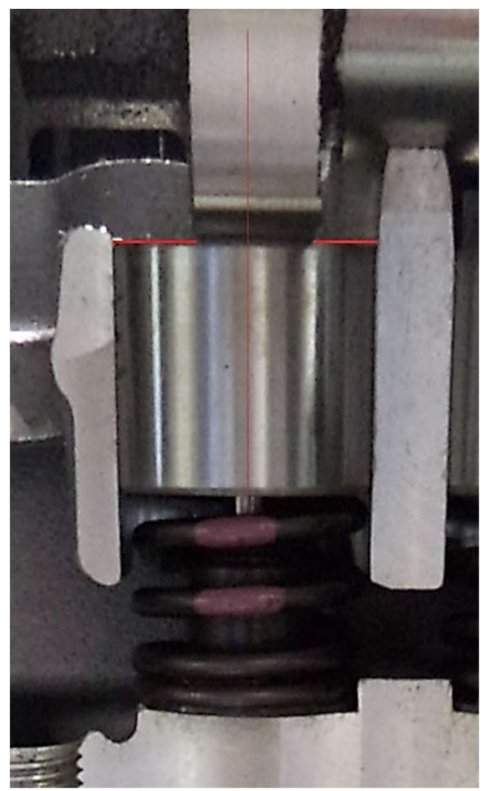

$\mathrm{O}$ autor

Figura 18 - Diferentes Regimes Tribológicos ao Longo do Ciclo Came

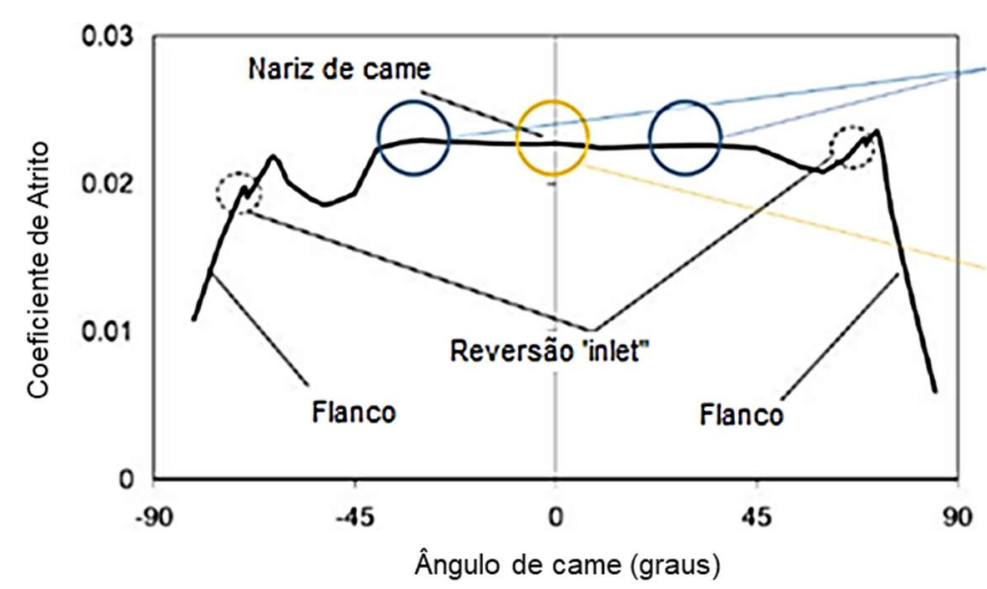

Regime Misto: predominância de regime boundary;

Regime

Elastohidrodinâmico;

Extraído e adaptado de [18]

A folga existente entre o tucho e seu guia permite o movimento de acionamento da válvula e permite o movimento de rotação do próprio tucho. Esta folga contém lubrificante proveniente do sistema de lubrificação do comando de válvulas. 
Dyson e Naylor [13] descreveram um modelo teórico para a determinação da velocidade de spin do tucho, como uma função da velocidade angular do came e em função da posição angular do tucho. A Figura 19 exibe os resultados de Dyson.

Figura 19 - Razão de Velocidades de Rotação Came-Tucho

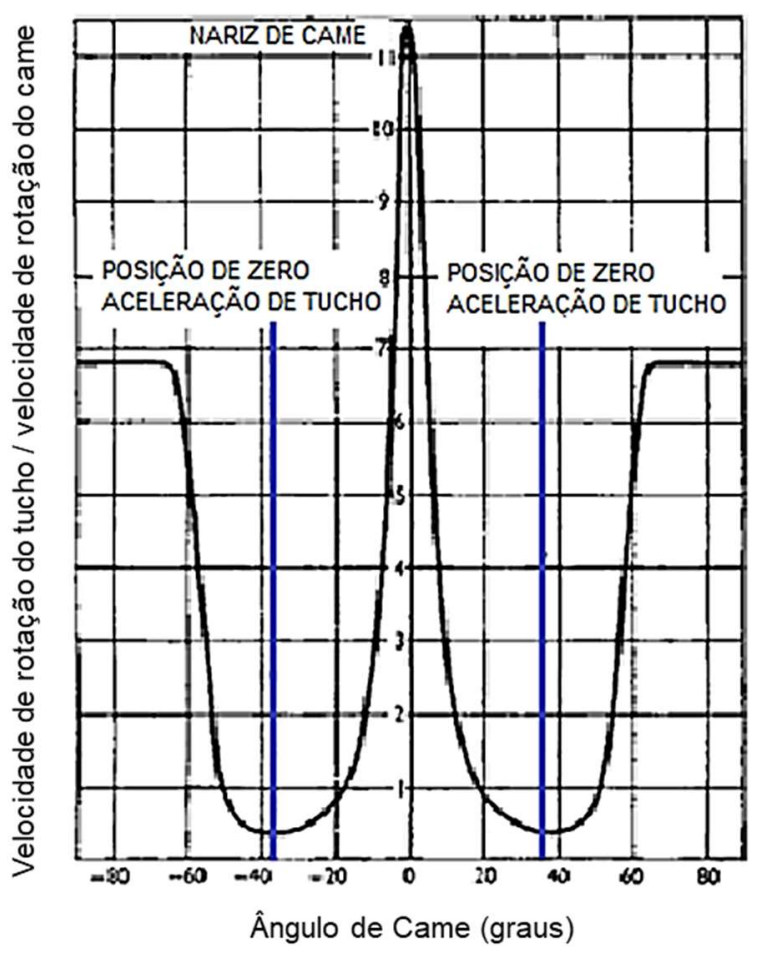

Extraído e adaptado de [13]

Dyson verificou experimentalmente esta relação para uma grande variedade de tuchos e analisou uma faixa considerável de velocidades de rotação de tucho, entre 25 e 200 RPM. Para velocidades de rotação de motor entre 1000 e 2500 RPM, as velocidades de rotação de tucho não desviaram consideravelmente, entre os valores medidos e os valores calculados teoricamante.

Além do movimento de rotação do próprio tucho, spin, outro movimento importante do tucho o movimento de balanço (tilting). Devido: (i) à separação entre o tucho e sua guia (Figura 15), (ii) ao contato excêntrico de came com tucho e (iii) ao movimento relativo do ponto de contato devido à rotação do came, os esforços de contato se dão ciclicamente e fora de eixo. Como resultado, o tucho, cujo apoio é central, realiza o movimento de tilting. Este efeito foi bem descrito teoricamante por Teodorescu e colaboradores [14]. Presumidamente, o titlting de tucho é uma fonte de ruídos e vibrações no sistema. 
Kim e Han realizaram estudos teóricos e experimentais sobre spin de tuchos em TMAD. Os autores utilizaram um aparato mono came dotado de um dispositivo óptico para a aquisição de dados de velocidade de rotação [15]. Assim como Dyson, os autores encontraram que a velocidade de spin cresce com a velocidade de rotação do came, porém, é afetada pelo titlting do tucho e seus "impactos" com a parede guia. A Figura 20 mostra os resultados encontrados por estes autores para 2000 RPM de rotação do motor, temperatura de lubrificante $90^{\circ} \mathrm{C}$, excentricidade came-tucho de $0,5 \mathrm{~mm}$ e folga tucho-guia de $0,02 \mathrm{~mm}$.

Figura 20 - Velocidade de spin x RPM Came por Kim e Han

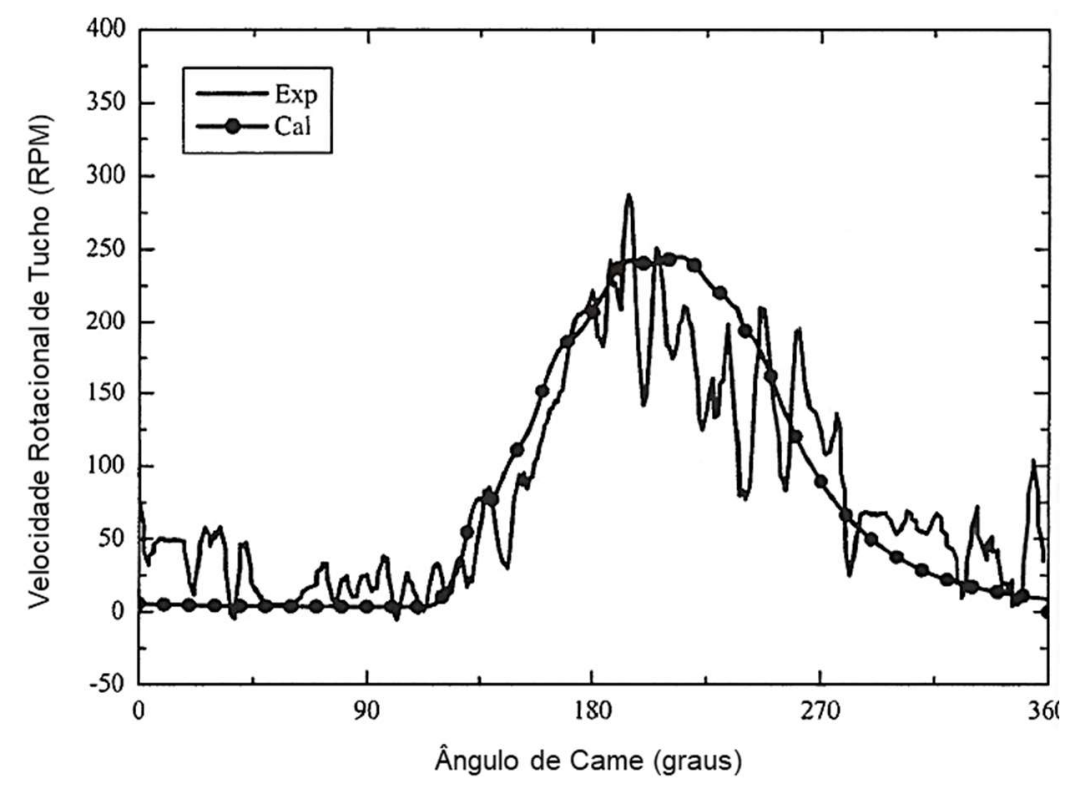

Extraído de [15]

Os resultados experimentais (Exp) apresentam bastante ruído em comparação com os resultados teóricos $(\mathrm{Cal})$. Estes ruídos devem ter origem nos efeitos de titlting e seus "choques" com a parede guia.

O spin do tucho é benéfico ao par tribológico came-tucho, por fazer variar a localização de contato do tucho com o came, evitando um "cavamento" localizado no tucho.

Para promover condição tribológica mais favorável nos sistemas came-tucho, pode-se empregar filmes finos na coroa do tucho. O filme mais popular é o H-DLC, uma camada micrométrica de carbono amorfo hidrogenado, cujos efeitos são desejáveis para a redução dos atritos e diminuição dos desgastes [16].

Dependendo da mecânica do sistema, do lubrificante utilizado, das temperaturas envolvidas e das condições de superfície, o regime tribológico específico para came-tucho pode 
variar desde hidrodinâmico até elastohidrodinâmico e misto [17] [18], como afirmado anteriormente.

O contato mais severo, em termos de forças de atrito, é aquele do nariz do came com o tucho, posição esta que corresponde ao maior deslocamento e abertura da válvula, e consequentemente, às maiores forças normais de contato e com as maiores velocidades de contato.

As forças de atrito entre came e tucho repercutem nos gastos energéticos do veículo. $\mathrm{O}$ próximo tópico relata estudos experimentais já realizados neste sentido.

\subsection{Efeitos dos Atritos Came-Tucho em Motores}

Testes de laboratório, com o auxílio de aparatos de bancada, procuraram estabelecer a parcela de perdas devido aos atritos came-tucho no contexto de SCV e no contexto de perdas de torque motor, assim como delinear parâmetros que influenciam na tribologia do sistema.

Schamel, Grischke e Bethke apontaram que o SCV é responsável por grande parte das perdas por atrito, especialmente a baixas velocidades, uma condição na qual a economia de combustível é muito importante. O SCV pode ser responsável por até $25 \%$ de perdas por atrito de um motor de combustão em frequências de rotação motor inferiores a 2000 RPM [19].

Teodorescu, Taraza, Henein e Bryzik analisaram os atritos num SCV de um motor de combustão interna e tentaram separar a contribuição de cada um dos diferentes componentes nas perdas totais por atrito, neste sistema. Estes autores realizaram medições em motor [20], e verificaram que o coeficiente de atrito entre a came e tucho reduz-se com um aumento da velocidade angular do motor. Também mostraram que o atrito entre o nariz do came e tucho são os maiores possíveis.

Gangopadhyay, Soltis e Johnson descreveram ações para reduzir as perdas por atrito em SCV dotados de TMAD, através de acabamento e textura de superfície ou com revestimentos dos tuchos com filmes finos DLC. Embora o SCV contribua apenas com 6-10 \% das perdas totais de atrito de um motor, todas as oportunidades são exploradas para reduzir as perdas por atrito, desde que sejam rentáveis [21].

Calabretta, Cacciatore e Carden realizaram testes de bancada com um trem de válvulas de um motor V12, dotado de TMAD, e mostraram que a perda de torque varia ligeiramente com a temperatura do óleo lubrificante quando os tuchos não são revestidos [22]. Substituindo os tuchos normais por tuchos revestidos com H-DLC, os autores apresentaram maior variação de perdas de torque por atrito devido a diferentes temperaturas do óleo lubrificante utilizado. 
Concluiu-se que é importante levar em conta as temperaturas de óleo de lubrificação quando se opera com tuchos revestidos com H-DLC. Temperaturas mais elevadas geraram maior atrito a baixas velocidades [22].

Gangopadhyay e colaboradores afirmam que o atrito no contacto came-tucho, TMAD, é responsável por cerca de $85 \%$ das perdas por atrito no sistema comando de válvulas [16]. Testes de bancada foram executados com um cabeçote de motor $3.5 \mathrm{~L}$ V6 e medições de torque devido ao atrito foram realizadas em um dos eixos comando de válvulas, para várias frequências de rotação do motor. A Figura 21 exibe o equipamento utilizado.

Figura 21 - Cabeçote de Motor V6 3.5L em Teste de Bancada

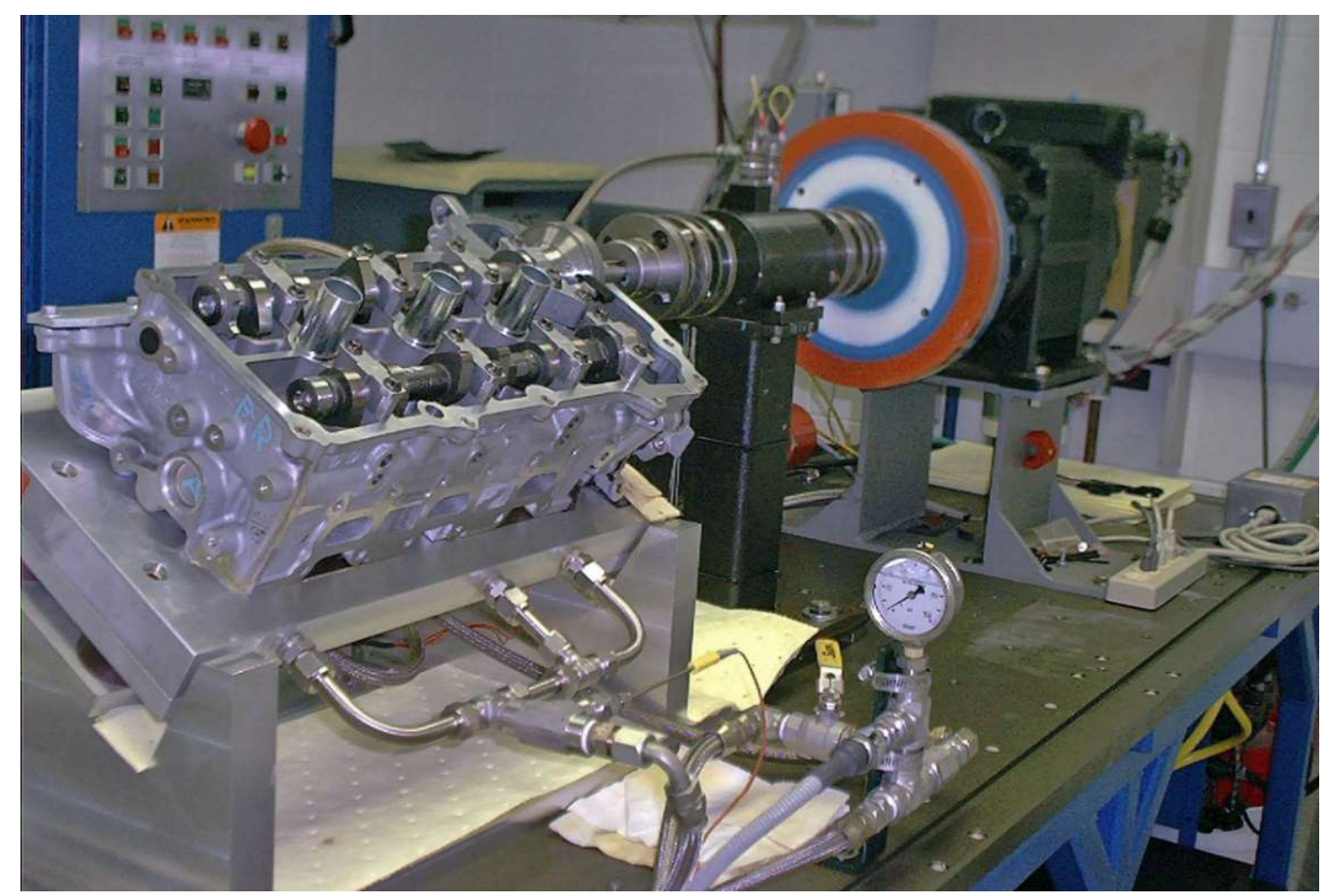

Extraído de [16] - Cortesia Arup Gangopadhyay - Ford Motor Company

Os efeitos das perdas de torque por atrito foram comparados com o uso de tuchos padrão (16CrMn5, $62 \mathrm{RC}$ de dureza, 0,10 $\mu \mathrm{m}$ de rugosidade $\mathrm{Ra})$, tuchos polidos $(0,04 \mu \mathrm{m}$ de rugosidade $\mathrm{Ra}$ ), tuchos revestidos Mn-Fosfato (1,7 $\mu \mathrm{m}$ de rugosidade $\mathrm{Ra})$ e tuchos revestidos

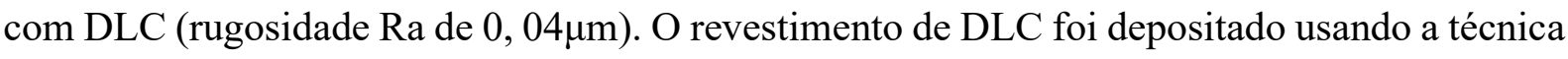
de deposição física de vapor e continha tungstênio e silício. O lubrificante utilizado foi o SAE 5W-20 GF-4, aquecido externamente. Substituindo apenas os tuchos, foram obtidas diminuições dos torques resistentes com o emprego de tuchos revestidos com DLC. Os tuchos 
revestidos com DLC permitiram uma redução de até $32 \%$ nas perdas de torque por atrito em relação aos tuchos normais de produção.

Bouchet e Martin [23] descreveram ensaios tribológicos em bancada, utilizando cames e tuchos revestidos com DLC montados num aparato monocame acionado por um motor elétrico. Estes autores mediram o torque resistente no eixo comando de válvulas e as cargas normais aplicadas, simultaneamente. A 2000 RPM, foi obtida uma redução de $45 \%$ de atritos came-tucho, com o emprego de revestimentos ta-C no came e no tucho, comparando-se com resultados obtidos com revestimentos fosfato convencionais.

Adicionalmente, modelamentos físico-matemáticos dos atritos came-tucho permitem descrever e até antever efeitos de forças de atrito e perdas energéticas, tais como relatados no tópico 2.4, em função de variações de parâmetros tribológicos relevantes.

Os próximos tópicos, 2.5 e 2.6, apresentam bases, encontradas na literatura, para tais modelamentos.

\subsection{Modelamento Tribológico Aplicado às Interações Came-Tucho}

É bem conhecido que o contato entre o nariz do came e o tucho é o mais crítico, tribologicamente, e que corresponde às maiores forças entre estas partes [24] [25].

O contato entre o came e o tucho TMAD se dá de forma transiente, enquanto o came passa de uma fase de não contato, para uma fase de contato e crescente esforço normal, promovendo a abertura da válvula.

O atrito no contato nariz de came - tucho surge devido a contribuições elastohidrodinâmicas e de contato de asperezas. Quando é assegurada uma espessura de filme lubrificante, a contribuição para o atrito é devida à ação viscosa, apenas sob condições de deslizamento. Contudo, são encontradas menores espessuras de filme lubrificante nas posições de entrada e saída de came, onde não ocorre movimento de arraste, antes e depois do contato de nariz de came. Portanto, podem ocorrer interrupções num filme lubrificante contínuo, dependendo da rugosidade composta das superfícies de contato em movimento relativo, dentre outros fatores. Daí o comportamento exibido na Figura 18, para ângulos de came entre -90 e 45 graus, ou entre 45 e 90 graus.

O contato entre asperezas entre came e tucho foram estudadas por Teodorescu [26], que se utilizou das relações de Greenwood-Tripp. A parcela EHL também foi estudada por Teodorescu e colaboradores [18]. 
Para avaliar a contribuição EHL e de contato entre asperezas, os autores apresentaram um parâmetro $y$, descrito pela Equação 1:

$$
y=d / \Psi
$$

onde

$d$ : espessura de filme central do lubrificante;

$\Psi$ : rugosidade composta das superfícies contíguas;

A rugosidade combinada é obtida pela Equação 2.

$$
\Psi=\sqrt{\Psi_{1}^{2}+\Psi_{2}^{2}}
$$

onde $\Psi_{1}$ e $\Psi_{2}$ são as rugosidades das superfícies em contato.

Segundo Teodorescu, o contato de asperezas ocorre mais intensamente quando $\mathrm{y}<3$. [18].

Durante o funcionamento, o perfil de came sofre uma deformação elástica na zona de contato. Devido à alta pressão desenvolvida entre o perfil do came e do tucho, a lubrificação deste contato, quando houver, é elasto-hidrodinâmica. A viscosidade do lubrificante aumenta exponencialmente com a pressão e uma película de lubrificante pode ser mantida entre o came e o tucho. A suposição básica do regime EHD é que a distribuição de pressão ao longo da área de contato deve satisfazer tanto a equação de Reynolds, para a película de óleo, quanto as equações de elasticidade, para a deformação das partes de contato.

As altas piezo-viscosidades atingidas pelo lubrificante, no contato, acarretam forças de atrito de origem viscosa relevantes, ao passo que as forças de atrito limite são atribuídas aos contatos elásticos e plásticos entre as pontas das asperezas, das duas superfícies de contato [14] [27].

A área de contato, $A$, no sistema nariz de came-tucho pode ser avaliada por meio de um contato entre dois cilindros. O primeiro cilindro possuiria raio de curvatura corresponde ao raio de curvatura do nariz do came, para $\theta=0$, e o segundo cilindro possuiria raio de curvatura semelhante ao raio de coroa do tucho. Desta forma, as considerações de elasticidade de Hertz levam à seguinte relação para a área de contato [26]): 


$$
A=\sqrt{\frac{2 R L P}{\pi E^{\prime}}}
$$

Equação 3

onde

$R$ é o raio combinado (nariz de came - coroa de tucho);

$E^{\prime}$ é o módulo de elasticidade combinado dos materiais do came e do tucho;

Embora o modelo de Hertz tenha sido desenvolvido para corpos sem deslizamento relativo, admite-se, neste contexto, que os efeitos do deslizamento são desprezíveis, pois os coeficientes de atrito são tipicamante menores que 0,3 [28].

O raio combinado é calculado por [26]:

$$
\frac{1}{R^{\prime}}=\frac{1}{R_{c}}+\frac{1}{R_{c t}}
$$

onde

$R_{c t}$ é o raio de coroa de tucho;

O módulo de elasticidade combinado é dado por [26]:

$$
\frac{1}{E^{\prime}}=\frac{1}{2}\left[\frac{1-v_{1}^{2}}{E_{1}}+\frac{1-v_{2}^{2}}{E_{2}}\right]
$$

onde

$E$ é o módulo de elasticidade do material;

$v$ é o coeficinete de Poisson do material;

Desta forma, é possível calcular a pressão de contato hertziana por:

$$
P^{\prime}=\frac{P}{A}
$$

Equação 6

A espessura de filme de lubrificante que se aprisiona no espaço entre o came e o tucho, na região de contato hertziana, depende muito pouco da carga aplicada. Segundo Dowson, o efeito de quase independência da espessura de filme com a carga aplicada é um dos resultados 
teóricos-experimentais mais importantes da elastohidrodinâmica, EH. Por outro lado, a espessura de filme é afetada pelas condições do lubrificante no inlet (viscosidade, velocidade de rolamento, temperatura).

A espessura de filme não é completamente uniforme, mas atinge um valor mais ou menos constante na região central de contato, conforme ilustra a Figura 22 (linha preta no gráfico).

Figura 22 - Espessura de Filme em Contato EHL

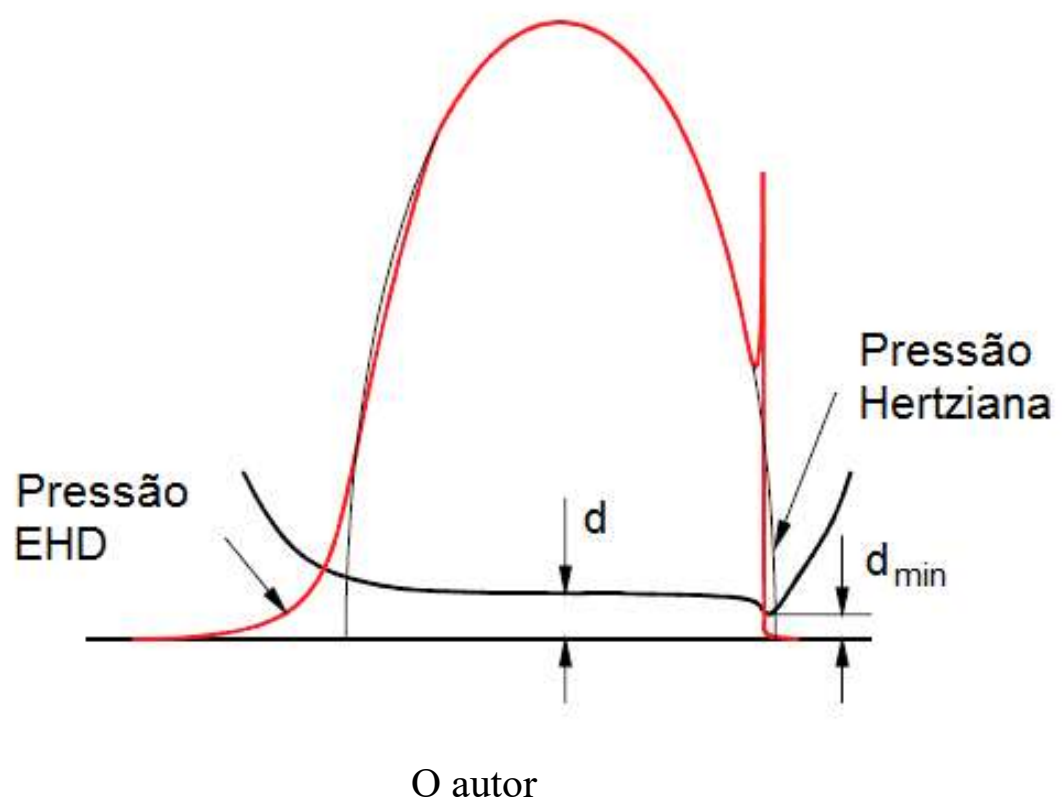

Diversas formulações foram propostas para relacionar, por exemplo, a viscosidade dinâmica com a pressão. Para pressões moderadas, até $500 \mathrm{MPa}$, pode-se utilizar a Equação de Barus [29]. Para pressões maiores, até algo em torno de 1 GPa, são necessárias outras relações, que são pressões típicas que surgem nas interações came-tucho. Correlações bem conhecidas para pressões maiores são dadas por Roelands [18]. Roelands afirmou que, na prática da lubrificação, a grande maioria dos lubrificantes, normalmente em uso, podem ter seu comportamento descrito pela Lei de Newton das viscosidades, sob condições normais de operação encontradas em certos elementos de máquinas. Para todos os lubrificantes minerais testados, afirma ele, não se encontrou considerável desvio em relação à lei de Newton para taxas de cisalhamento entre $10^{3}$ e $10^{6} \mathrm{~s}^{-1}$. Por outro lado, pôde-se observar consideráveis desvios quando se atinge cerca de $10^{7} \mathrm{~s}^{-1}$. Roelands ressalta que exceções podem assumir significado prático para óleos minerais misturados com polímeros e para certos tipos de óleos sintéticos poliméricos [30]. 
Para interações came-tucho, a Equação de Roelands para viscosidade-pressãotemperatura pode ser descrita, conforme feito por Theodorescu et al. [18] (Equação 7).

$$
\eta=\eta_{0} \exp \left[\ln \eta_{0}+9,67\right]\left[\left(1+5,1 \cdot 10^{-9} \cdot P^{\prime}\right)^{Z}-1\right]
$$

onde

$$
Z=\alpha /\left[5,1 \cdot 10^{-9}\left(\ln \eta_{0}+9,67\right)\right]
$$

Equação 8

$P^{\prime}$ : pressão de contato de Hertz;

$\alpha$ : índice de piezoviscosidade;

Hoglund [31] explica que dois tipos de regimes de lubrificação EH podem ser definidos: duro e macio. O regime EH duro está relacionado com materiais de alto módulo elástico, como metais. Nestes casos, a influência da pressão sobre a viscosidade do lubrificante desempenha um papel importante em conjunto com a deformação elástica dos corpos. A pressão máxima num contato deste tipo pode atingir 3-4 GPa e a espessura de película mínima que separa as superfícies de contato está na faixa de 0,1 a $1 \mu \mathrm{m}$. As deformações elásticas nesse contato são várias ordens de magnitude maiores do que a espessura mínima do filme. A viscosidade do lubrificante pode ser 10 ordens de magnitude maior dentro da conjunção lubrificada, em comparação com o valor à pressão atmosférica. Coeficientes viscosidade-pressão para diferentes óleos foram fornecidos por Hoglung e apresentados na Figura 23 [31].

Figura 23 - Valores de Coeficiente Pressão - Viscosidade para Algumas Substâncias Pressure-viscosity coefficients for different oils

\begin{tabular}{lllll}
\hline Lubricant & \multicolumn{3}{l}{ Pressure-viscosity coefficient, $\alpha\left(\mathrm{GPa}^{-1}\right)$} \\
\cline { 2 - 5 } & $20^{\circ} \mathrm{C}$ & $40^{\circ} \mathrm{C}$ & $60^{\circ} \mathrm{C}$ & $80^{\circ} \mathrm{C}$ \\
\hline Naphthenic mineral oil & 26.5 & 23.4 & 20.0 & 16.4 \\
Mix of paraffinic/ & 23.0 & 20.8 & 18.5 & 16.1 \\
naphthenic oil, 50-50 & & & & \\
Paraffinic mineral oil & 19.8 & 18.2 & 16.6 & 15.0 \\
Rapeseed oil & 18.9 & 17.5 & 16.3 & 14.6 \\
Polyglycol & 18.7 & 16.0 & 13.2 & 10.5 \\
Pine tree oil & 17.2 & 15.6 & 13.7 & 12.5 \\
TMP-ester & 15.5 & 14.4 & 13.1 & 12.2 \\
Diester & 14.6 & 13.6 & 12.8 & 11.6 \\
Polyalphaolefin & 15.5 & 13.8 & 12.2 & 10.5 \\
\hline
\end{tabular}

Extraído de [31] 
Masjedi e Khonsari criaram um modelo teórico de grande utilidade para o estudo de regimes de lubrificação em muitas aplicações industriais, tais como dentes de engrenagem, rolamentos de elementos rolantes, seguidores de cames e semelhantes, governado pela denominada lubrificação elastohidrodinâmica de contato em linha (EHL). O modelo surge com a equação de Reynolds modificada por Patir e Cheng, sendo resolvida em conjunto com a deformação superficial e o modelo estatístico de micro-contato elasto-plástico de aspereza de Zhao. As condições de operação são consideradas estacionárias e isotérmicas [32].

Os resultados de um extenso conjunto de simulações numéricas foram utilizados para desenvolver equações adequadas para determinar a espessura central e mínima do filme, bem como a proporção de carga de aspereza, para contatos lineares.

A Equação 9 é para a espessura de filme central:

$$
\begin{aligned}
H_{c}= & \frac{h_{c}}{R}=2.691 W^{-0.135} U^{0.705} G^{0.556} \\
& \times\left(1+0.2 \bar{\sigma}^{1.222} V^{0.223} W^{-0.229} U^{-0.748} G^{-0.842}\right)
\end{aligned}
$$

Equação 9

A Equação 10 é para a espessura de filme mínima ( $\mathrm{d}_{\min }$ da Figura 22$)$ :

$$
\begin{aligned}
H_{\min }= & \frac{h_{\min }}{R}=1.652 W^{-0.077} U^{0.716} G^{0.695} \\
& \times\left(1+0.026 \bar{\sigma}^{1.120} V^{0.185} W^{-0.312} U^{-0.809} G^{-0.977}\right)
\end{aligned}
$$

Equação 10

A Equação 11 descreve a taxa percentual de forças devido aos contatos de asperezas:

$$
\begin{aligned}
L_{a}= & 0.005 W^{-0.408} U^{-0.088} G^{0.103} \\
& \times\left[\ln \left(1+4470 \bar{\sigma}^{6.015} V^{1.168} W^{0.485} U^{-3.741} G^{-2.898}\right)\right]
\end{aligned}
$$

Os termos adimensionais empregados são: 


$$
\begin{gathered}
H=\frac{h}{R}, \quad \bar{\mu}=\frac{\mu}{\mu_{0}}, \quad \bar{\rho}=\frac{\rho}{\rho_{0}}, \\
U=\frac{\mu_{0} u}{E^{\prime} R}, \quad W=\frac{w}{E^{\prime} R}, \quad G=\alpha E^{\prime}, \bar{\sigma}=\frac{\sigma}{R}
\end{gathered}
$$

Algumas conclusões foram tiradas por Masjedi e Khonsari e podem ser verificadas em simulações matemáticas computacionais por variações impostas de parâmetros:

1 - A espessura do filme aumenta à medida que a rugosidade aumenta. Isso pode ser atribuído à contribuição da carga carregada pelas asperezas, bem como à influência de asperezas no fluxo, conforme ditado pelos fatores de fluxo na equação de Reynolds modificada;

2 - Observa-se que, ao aumentar a rugosidade da superfície, o nível da pressão aumenta. Para grandes valores de rugosidade superficial, o pico de pressão quase desaparece. Também notase que a localização do pico de pressão tende a se aproximar do centro à medida que a rugosidade aumenta. As simulações também mostram que a amplitude do pico de pressão é reduzida consideravelmente quando a compressibilidade do lubrificante é levada em consideração. Picos muito afiados são previstos quando o lubrificante é suposto incompressível;

3 - A espessura do filme diminui pouco, aumentando-se a carga. A espessura do filme não é muito sensível à variação da carga, especialmente a valores de carga mais altos. Também se observa que a dependência da espessura do filme sob carga é mais notável em valores de rugosidade maiores;

4 - A espessura do filme é muito sensível à velocidade relativa entre as superfícies em contato, e aumenta ao aumentar esta velocidade. De fato, o aumento da velocidade de deslizamento altera o regime de lubrificação;

5 - A espessura do filme não é fortemente influenciada pela dureza. O efeito da dureza torna-se mais perceptível em valores de rugosidade superficial mais elevados. A dependência da espessura do filme com a dureza é maior em valores de dureza mais baixos, pois a estes valores a deformação da aspereza tende a ser totalmente plástica. Então, a espessura do filme torna-se quase constante quando as asperezas sofrem deformação elasto-plástica e plástica. Com valores 
de dureza mais elevados, a deformação é totalmente elástica e a espessura do filme aumenta de novo;

6 - Nas abordagens estatísticas de contato de asperezas, a espessura do filme é igual à distância entre as linhas médias das superfícies. Assim, as fórmulas de espessura de filme acima não representam as distâncias locais entre os topos das asperezas. Portanto, enquanto a espessura mínima real de filme, de um ponto de vista deterministico, pode ser igual a zero, isto é, quando as pontas de asperezas entram em contato, a espessura mínima de película representa a distância mínima entre as linhas médias das asperezas superficiais. É importante notar que, para os casos em que o parâmetro de filme (Equação $1 \operatorname{com} \psi=$ Rq) é menor que 0,5 , a equação de Reynolds modificada por Patir e Cheng não é válida. Nesses casos, espera-se que o regime de lubrificação caia em regime limítrofe em vez de EH. Portanto, depois de calcular a espessura do filme, o parâmetro do filme deve ser verificado para garantir resultados precisos. Também é aconselhável que, quando a proporção de carga de aspereza obtida for muito grande (como mais de 70\%), os resultados devem ser usados com precaução, mesmo que o parâmetro do filme seja maior que 0,5 . Isso ocorre porque, nesses casos, o comportamento tribológico torna-se próximo do contato seco, o que geralmente acontece em superfícies com valores de rugosidade muito grandes, sob baixas cargas.

Entretanto, o modelo EHL não apresenta diretamente as forças de atrito entre came e tucho, mas sim previsões de espessura de filme lubrificante. O próximo tópico se encarrega de rever a atualidade dos modelos matemáticos de forças de atrito came-tucho.

Como já mencionado anteriormente, as condições tribológicas came-tucho variam com o ângulo de came, desde regimes hidrodinâmicos até regimes elasto-hidrodinâmicos. Kushwahu e Rahnejat [24], utilizando uma solução combinada de multi-corpos com soluções de Reynolds elasto-hidrodinâmicas transientes, demonstraram que a espessura de filme central varia com o ângulo de came conforme exibe a Figura 23. 
Figura 23 - Espessura de Filme Central segundo Kushwahu e Rahnejat

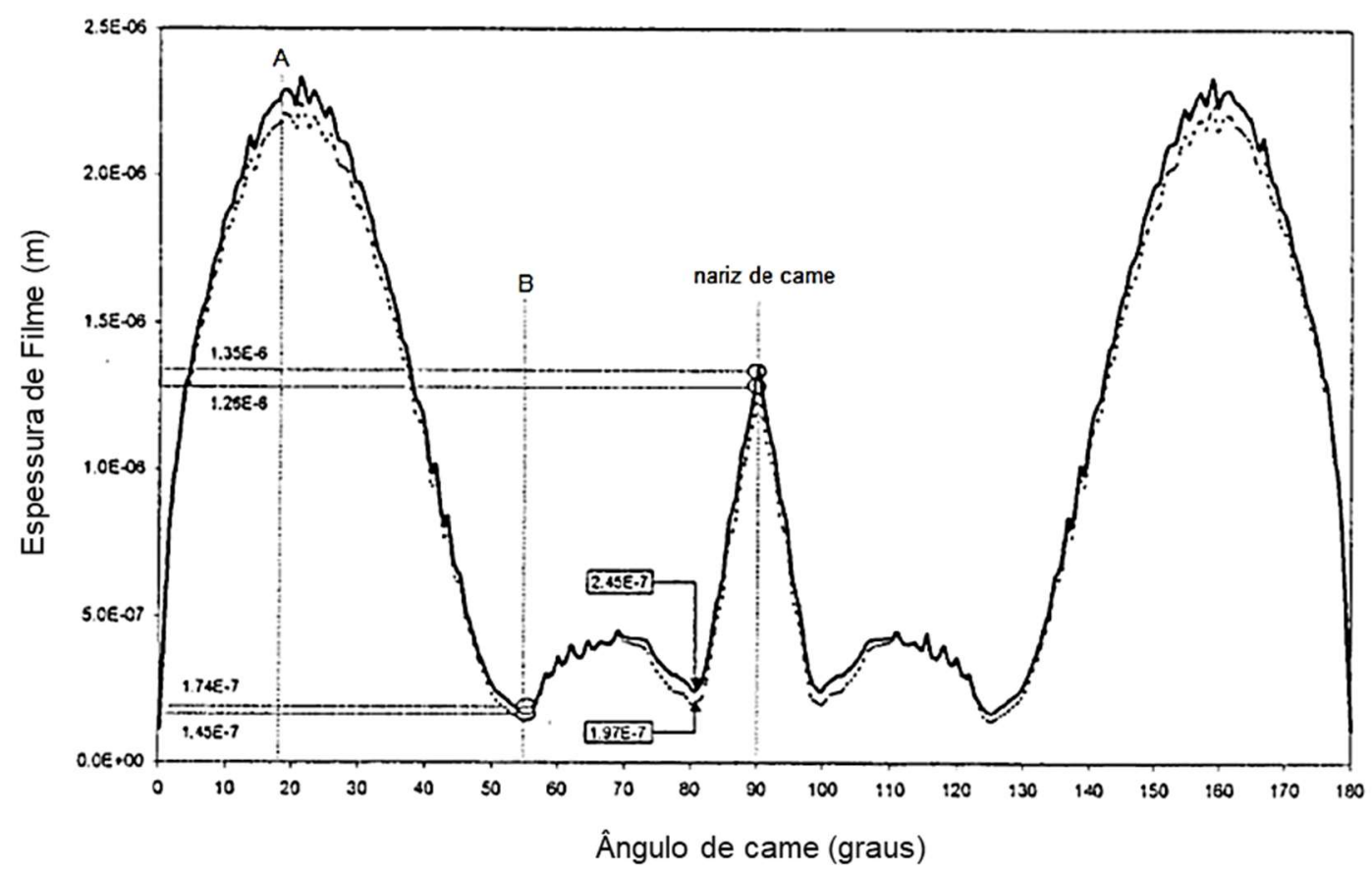

Extraído de [24]

Nas regiões de máxima espessura de filme lubrificante, ponto "A" da Figura 23, predomina o comportamento hidrodinâmico, ao passo que nas regiões de mínima espessura de filme, ponto "B" da Figura 23, predomina o comportamento mixed-EHL, conforme apontado pelos autores. No ponto "B", muito provavelmente haverá contato limítrofe, apesar das baixas cargas envolvidas.

\subsection{Modelos de Forças de Atrito Came-Tucho Ação Direta}

O modelo elasto-hidrodinâmico, até agora apresentado, é capaz de descrever satisfatoriamente a espessura de filme central do lubrificante, assim como a espessura de filme mínima, no contato em linha, uniforme, para contatos came-tucho. Também é possível determinar as piezo-viscosidades envolvidas nos contatos. Entretanto, as forças oriundas do cisalhamento do filme piezo-viscoso, para serem determinadas, precisam ser descritas por modelos próprios.

As forças de atrito came-tucho de ação direta são, primariamente, de natureza elastohidrodinâmica [32], o que significa que dependem das interações viscosas do filme lubrificante e dos contatos de asperezas, além de dependerem de parâmetros geométricos de came, de tucho e de guia, das temperaturas médias e flash, das propriedades reológicas do 
lubrificante e aditivos, do perfil do carregamento ao longo do tempo de ciclo de came, das massas inerciais envolvidas e de fenômenos mecânicos próprios do sistema, tais como spin e tilting de tucho.

As abordagens teóricas, para este sistema, diferem quanto aos métodos matemáticos utilizados, tais como resoluções de equações de Reynolds unidimensional modificadas, uso de métodos numéricos Newton-Raphson, abordagens Lagrangeanas e outros. Diferentes associações de fenômenos relativos às interações came-tucho promovem diferentes resultados obtidos.

Por exemplo, Gecin (1992) montou um modelo misto capaz de descrever as forças de atrito com a variação típica de carregamentos do sistema, que inclui efeitos de squeeze de filme (resolvendo uma equação de Reynolds unidimensional), flash temperature (por um fator de correção térmica), de spin de tucho (considerando atritos tucho-guia) e contatos de asperezas, por Greenwood and Tripp. A separação dos planos em contato é adotada como a espessura de filme lubrificante nominal. [33].

Gecim obteve que os atritos de natureza hidrodinâmica são função da viscosidade do lubrificante e da temperatura do filme no contato, que por sua vez é dependente dos atritos totais e que é fracamente dependente das cargas aplicadas. Em termos de coeficientes de atrito, Gecin obteve os resultados exibidos na Figura 24.

Figura 24 - Contatos Came-Tucho, Configuração Geométrica de Gecin

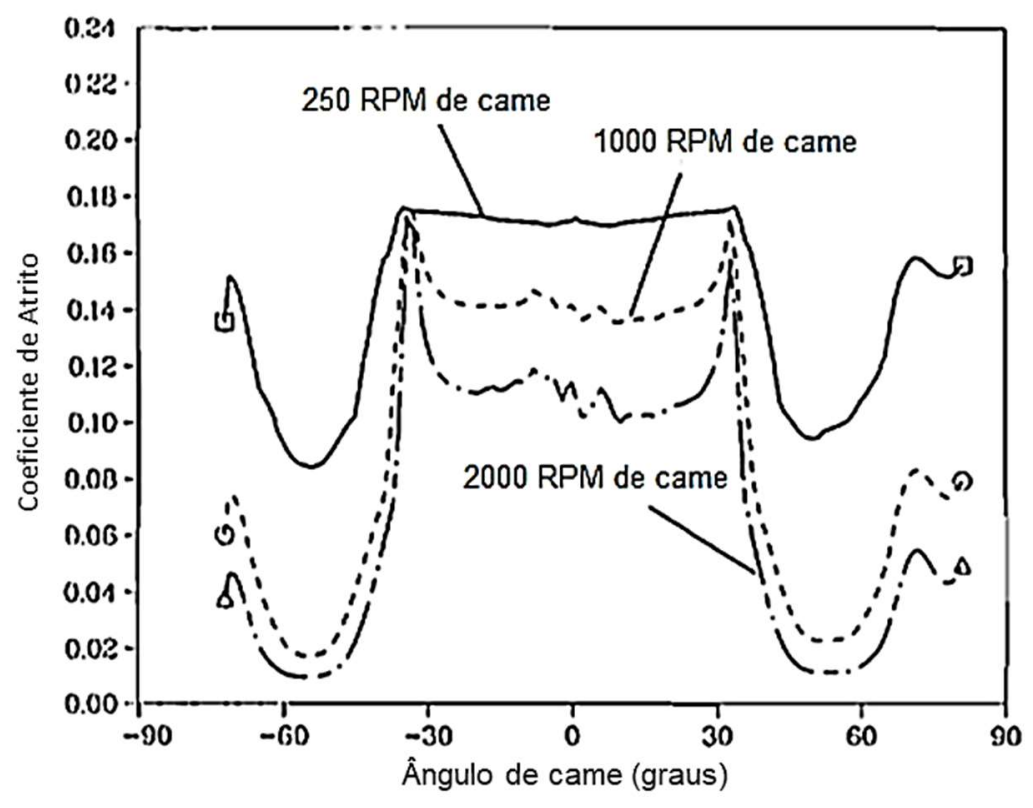

Extraído de [33] 
Observa-se uma redução dos coeficientes de atrito entre came e tucho, para grau zero de came, com o seu aumento da velocidade de rotação e nota-se que, apesar das maiores forças de contato atuarem na região de zero grau came, os maiores coeficientes de atrito surgem em torno dos \pm 45 graus.

Teodorescu e Taraza investigaram as condições tribológicas entre came e tucho, levando em conta as características dinâmicas multicorpos, o comportamento elasto-hidrodinâmico do contato, e o spin de tucho, com modelagem triobológica dos atritos tucho-guia [14]. Os autores apresentaram um modelo simplificado de forças de atrito came-tucho e validaram os seus resultados via medições em um motor mono-cilindro diesel.

Teodorescu e Tanaza descrevem três modelos, que são incorporados a uma análise multi-corpos:

a) Um modelo came-tucho de atritos;

b) Um modelo tucho-guia de atritos;

c) Um modelo de spin de tucho;

O modelo tucho-guia de atritos compreende três regimes tribológicos, a saber, atritos hidrodinâmicos, atritos mistos e atritos limítrofes. Estes regimes surgem da consideração de titlting de tucho.

Realizando considerações de equilíbrios de forças e momentos, Teodoreco e Taraza montaram um sistema de equações de equilíbro que descrevem de forma acurada a dinâmica do tucho, com as considerações de tilting.

O modelo came-tucho de atrito, regido principalmente pelo deslizamento do nariz do came, em relação ao tucho (aproximadamente 60 \% da operação de válvulas), é descrito como a soma de uma força de atrito de origem piezo-viscosa e uma força de atrito de origem limítrofe, um regime misto de lubrificação. As forças de atrito limítrofes, $F_{b}$, são descritas pelo clássico modelo de Greenwood e Tripp [27], e as forças piezo-viscosas, $F_{V}$, são descritas pela relação descrita na Equação 12.

$$
F_{V}=0,99\left[\tau_{0} A+\chi\left(P-p^{\prime}\right)\right] \quad \text { Equação } 12
$$

onde

$F_{V}$ é a força piezo-viscosa;

$\tau_{0}$ é a tensão de Eyring;

$A$ é a área de contato de Hertz; 
$X$ é a taxa de variação na tensão cisalhante com a pressão;

$P$ é a força normal de contato came-tucho;

$p^{\prime}$ é o carregamento de asperezas;

A força total de atrito, $F_{f c}$, entre came e tucho é descrita por Teodorescu e Tanaza pela Equação 13.

$$
F_{f c}=F_{b}+F_{v}
$$

O modelo de spin de tucho é baseado em equilíbrio de torques atuantes no tucho e oferece respostas em velocidades angulares obtidas por integração numérica das acelerações angulares deste.

Como resultado, Teodorescu e Taraza conseguiram descrever, de forma satisfatória, as velocidades de spin de tucho e as forças de atrito tucho-guia, para algumas velocidades rotacionais de came diferentes. Entretanto, não apresentam resultados totais de atritos cametucho. Eles afirmam que "investigações adicionais devem ser realizadas para determinar a influência da rotação do came na força de atrito came-tucho, considerando um contato em linha bi-dimensional."

Zhou e Richardson [34] desenvolveram um modelo EHL para análises gerais de interações came-tucho [34]. O modelo prevê espessura de filme lubrificante, forças de atrito, perdas energéticas, e os efeitos das texturas de superfícies. Estes autores utilizaram uma equação de Reynolds unidimensional, modificada por Patir e Cheng, para contatos rugosos, obtendo espessuras de filme lubrificante e apresentaram uma equação de força total de atritos came-tucho, Equação 14.

$$
F_{r}=\tau_{0} A_{c}+\alpha_{0} W_{a}+D_{c} \int\left(\tau_{1}+\tau_{2}\right) d x
$$

onde

$F_{r}$ é a força de atrito total came-tucho;

$\tau_{0}$ e $\alpha_{0}$ são constantes;

$A_{c}$ é dependente das espessuras de filmes lubrificantes e rugosidades;

$W_{a}$ é o carregamento de asperezas;

$D_{c}$ é a largura do came; 
$\tau_{1}$ e $\tau_{2}$ são obtidos a partir de equações diferenciais dependentes de vários parâmetros como espessura de filme lubrificante, fatores de tensões cisalhantes, etc.

Zhou e Richardson desenvolveram um códico (Multipol) para a determinação de parâmetros cinemáticos de came e de tucho, cujas saídas foram lidas por outro código, desenvolvido por Dowson e Toyoda (CTM99) na determinação iterativa de espessuras de filme lubrificante, forças de atrito, perdas energéticas. Zhou e Richardson realizaram um estudo de caso, com parâmetros similares aos encontrados no sistema came-tucho de um motor V8. O lubrificante de referência foi Texaco SN5W30. Entre outros resultados, Zhou e Richardson obtiveram coeficientes de atrito, para duas diferentes rugosidades, a $130{ }^{\circ} \mathrm{C}$ e para velocidade de rotação de came de 50 Hz (3000 RPM) (Figura 25).

Figura 25 - Coeficientes da Atrito Came-Tucho para duas Rugosidades

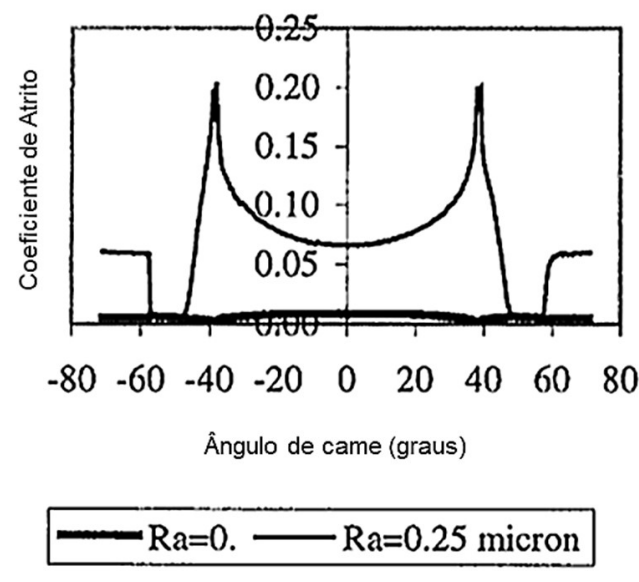

Extraído de [34]

Para perdas energéticas, Zhou e Richardson cruzaram informações a respeito de torque resistente de eixo de cames, para um motor V8, obtidos via modelo e obtidos via medição direta (Figura 26).

Zhou e Richardson observaram que os valores previstos são sempre menores, e atribuíram a superioridade dos dados medidos às perdas em hastes de válvula - guia e mancais de came, interações não previstas no modelo. Os comportamentos dinâmicos da válvula e da mola também podem contribuir para a diferença entre os valores medidos e previstos, uma vez que a energia potencial na mola, quando as válvulas estão totalmente abertas, não será totalmente recuperada quando as válvulas fecham. 
Figura 26 - Torques Resistentes Modelo x Medidos

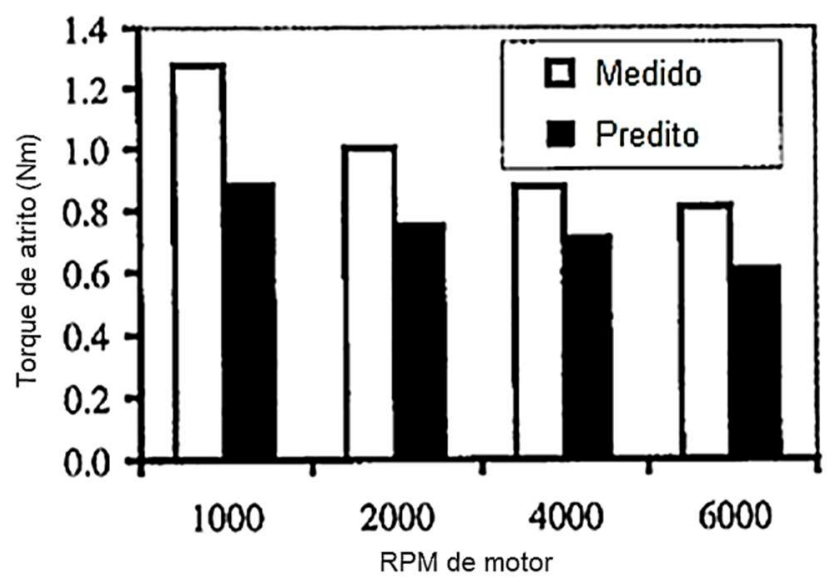

Extraído de [34]

Meng, Yuand e Xie (2018) investigaram o desempenho de lubrificação do contato cametucho durante o start-up do motor, para came e tucho revestidos. Os autores estudaram os efeitos do isolamento térmico do revestimento no desempenho tribológico, durante o processo de partida. Um modelo numérico para a análise da lubrificação elasto-hidrodinâmica térmica de contato de came-tucho revestido foi apresentado, sendo este baseado na equação de Reynolds e em equações de balanço de energia, resolvidas numericamente e simultaneamente [35].

As forças de atrito came e tucho, em vários ângulos de came, são obtidas pela Equação 15.

$$
F_{f}=\int_{x_{s}}^{x_{e}}\left(\frac{h \partial P}{\partial x}+\eta \frac{u_{a}-u_{b}}{h}\right) d x
$$

onde

$F_{f}$ é a força de atrito came tucho;

$x_{s}$ e $x_{e}$ são posições inicial e final de filme, respectivente;

$h$ é a espessura de filme lubrificante;

$\eta$ é a viscosidade do lubrificante;

$u_{a}$ e $u_{b}$ são as velocidades das superfícies de came e tucho, respectivamente;

$P$ é a pressão de filme no contato; 
O método de Newton amortecido foi usado para resolver a equação de Reynolds, para um dado domínio de temperatura. Então, métodos numéricos adicionais foram utilizados para resolver as equações de energia e para obter o campo de temperaturas.

Como resultado para o coeficiente de atrito (CA) em start-up, os autores obtiveram o gráfico da figura 27.

Figura 27 - CA para start-up, Came Tucho Revestidos e não Revestidos

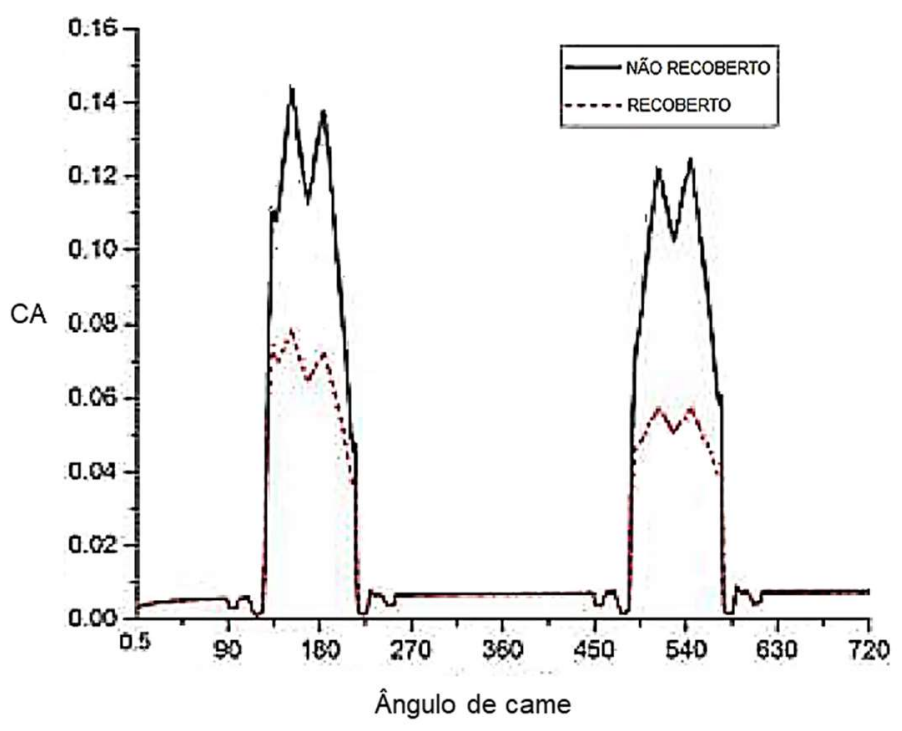

Extraído de [35]

Roshan, Priest, Neville, Morina e Xia alertam que estudos recentes mostraram que os modelos existentes de atrito do trem de válvulas não são capazes de prever com segurança o atrito em condições de lubrificação limítrofe e mista e não são sensíveis à química do lubrificante. Uma técnica de regressão linear múltipla foi utilizada para obter um modelo de atrito em filme lubrificante, com contatos de asperezas, a partir de dados de atrito retirados de testes de tribômetro tipo block on ring. O modelo foi desenvolvido empiricamente em função da concentração de ZDDP (Zinc dialkyldithiophosphates), MoDTC, detergente e dispersante no óleo e na temperatura e velocidade de deslizamento. O modelo de atrito resultante é sensível à química do lubrificante na lubrificação de limítrofe [46]. Os lubrificantes testados foram formulados por $10 \%$ Ester adicionado a um óleo base PAO e variadas aditivações, totalizando 21 formulações.

Os coeficientes de atrito obtidos, para diferentes temperaturas e diferentes velocidades de delizamento, foram os exibidos na Figura 28. 
Figura 28 - Valores Experimentais e Numéricos para Coeficientes de Atrito no Ensaio block on ring

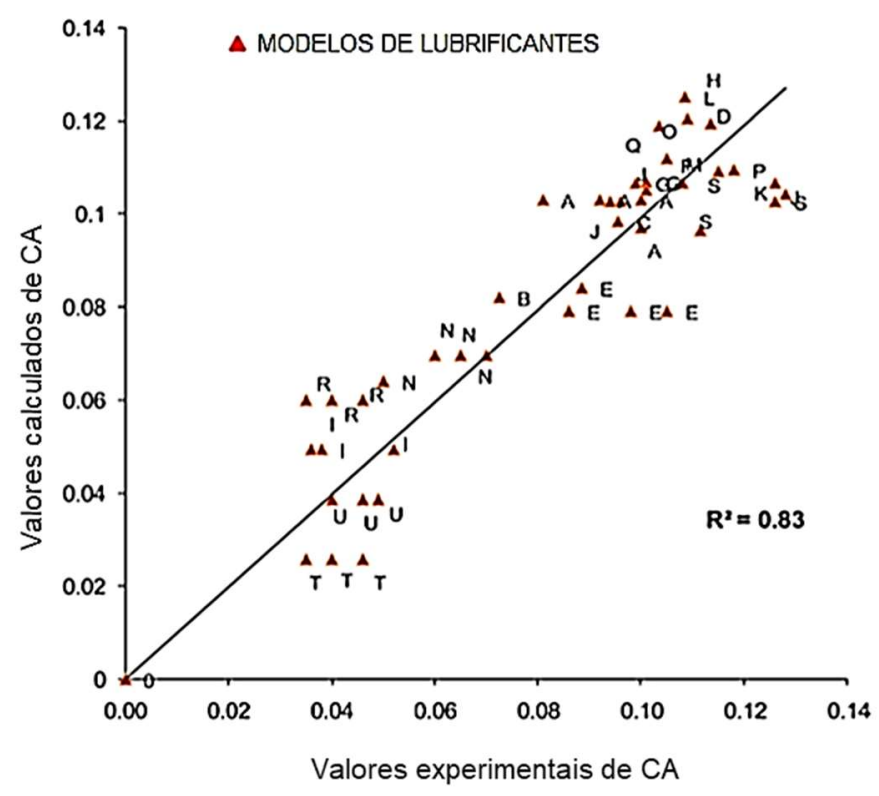

Extraído de [46]

Umar, Mufti e Khurram (2018) descreveram o desenvolvimento de uma abordagem numérica baseada em análises de atrito lubrificado came-tucho de ação direta (e também de rolamento), predizendo efeitos de flash temperature, em regime EHL. Os autores utilizaram um modelo H Block's para flash temperature, e Equação de Walther para a viscosidade do lubrificante em altas temperaturas [36].

Umar, Mufti e Khurram alertam que, devido à pequena espessura de filme lubrificante e devido às altas tensões cisalhantes, o fluído não apresentará um comportamento Newtoniano. Desta forma, eles sumarizam soluções numéricas para as forças de atrito came-tucho conforme exibe a Equação 16.

$$
F=F_{B}+\left(1-\frac{A_{r}}{A_{a}}\right) F_{H}
$$

Equação 16

onde

$F$ é a força total de atrito came-tucho;

$F_{B}$ é a força de atrito limítrofe came-tucho por contatos de asperezas;

$F_{H}$ é a força hidrodinâmica;

$A_{r}$ é a área de contato real de asperezas;

$A_{a}$ é a área aparente de contato; 
Os resultados obtidos por Umar, Mufti e Khurram, em termos de forças de atrito cametucho, para diferentes temperaturas e diferentes RPMs, e considerando-se efeitos de flash temperature, podem ser vistos na Figura 29.

Figura 29 - Resultados de Forças de Atrito Considerando-se Efeitos de Flash Temperature

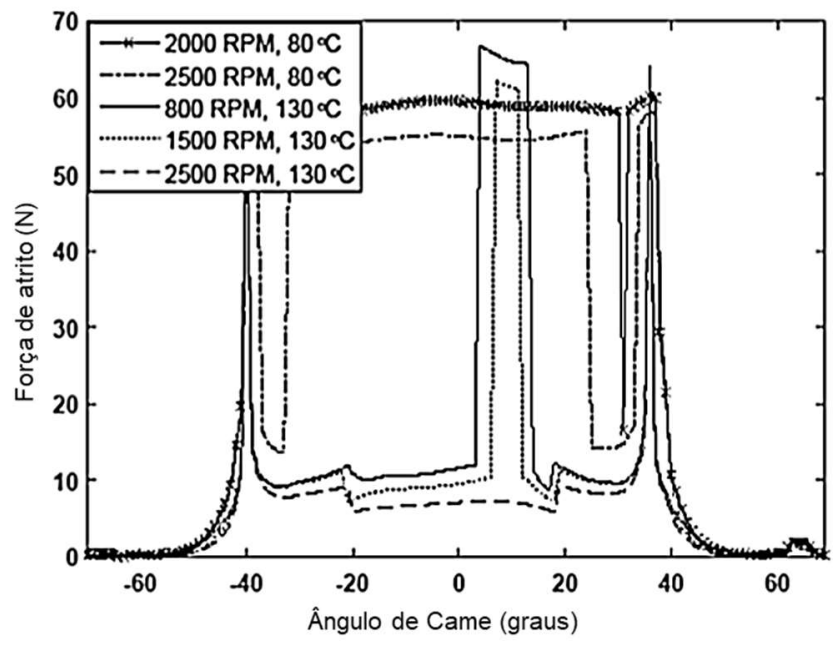

Extraído de [36]

Em todos estes casos apresentados, para a determinação das forças de atrito came-tucho, os modelos eram de natureza EHL, de contato em linha, com excessão do modelo limítrofe block on ring.

Pode-se acrescentar os resultados experimentais obtidos por Dyson \& Naylor, com uma variedade de cames e tuchos, em motor real [13], a 600 RPM e lubrificante óleo base SAE30 HNV. Estes autores obtiveram coeficientes de atrito entre 0,08 e 0,12, predominantemente entre nariz de came e tucho.

Pode-se resumir os atritos avaliados pelos autores descritos neste tópico, em termos de abordagem aplicada e coeficientes de atrito, conforme mostra a Tabela 5.

Tabela 5 - CAs obtidos por Autores Recentes

\begin{tabular}{|c|c|c|}
\hline Autor & Abordagem & CA \\
\hline Dyson \& Naylor & Método experimental & 0,08 a 0,12 a 600 RPM em lab \\
\hline Gecin [33] & Método numérico & 0,15 a 1000 RPM (Figura 25) \\
\hline Zhou [34] & Método numérico & 0,07 a 3000 RPM (Figura 26) \\
\hline Meng [35] & Método numérico & 0,12 para start-up (Figura 28) \\
\hline Roshan [46] & Método experimental & 0,02 a 0,12 block on ring (Figura 29) \\
\hline
\end{tabular}


Desta forma, pode-se apreciar uma grande variabilidade de coeficientes de atrito obtidos, de uma forma geral, variando entre 0,02 e 0,15, determinados por diferentes modelos e métodos, para os contatos came e tucho em geral.

Os coeficientes de atrito came-tucho dependem de muitos parâmetros reológicos, geométricos, mecânicos e químicos do lubrificante, porém, estes variam consideravelmente com o ângulo de came, como obtido por Gecin [33], Figura 25, assim como obtido por outros pesquisadores, por meios numéricos ou experimentais. Em geral, nos sistemas TMAD, não há contato entre came e tucho, exceto entre os ângulos de aproximadamente $-40^{\circ}$ a $+40^{\circ}$, como já descrito anteriormente. Dentro desta faixa de ângulos, os regimes tribológicos mudam, e associando-se a este fato a variação de carga e de velocidade de deslizamento no contato, podese observar a grande variabilidade de coeficientes de atrito apresentados. 


\section{Objetivos}

O objetivo principal deste trabalho é gerar conhecimentos novos sobre os efeitos da diluição do etanol hidratado nas condições tribológicas came-tucho e propor uma nova abordagem sobre avaliação de atritos no contato came-tucho mecânico de ação direta em contatos lubrificados.

Devido à grande quantidade de parâmetros envolvidos nas interações came-tucho, tais como: regime de RPMs do eixo comando de válvulas, temperaturas, presença de contaminates (como o etanol hidratado) no lubrificante, diferentes perfis de came, diferentes geometrias de tucho, etc, é necessário definir, a princípio, um regime padrão de atuação do TMAD. O próximo ítem se encarrega de definir este padrão.

\subsection{Regime Padrão de TMAD com Presença de Etanol}

Em certas situações específicas de uso veicular, o etanol hidratado, utilizado como combustível, pode misturar-se ao lubrificante do motor, alterando suas propriedades lubrificantes [37]. Este fenômeno afeta os atritos entre o came e o tucho. A durabilidade e a eficiência energética do motor também podem ser afetadas nestas condições.

O regime de trabalho do sistema TMAD depende exclusivamente do regime de operação do veículo em termos de velocidades e trocas de marchas e pode se configurar de infinitas formas nas mãos do usuário comum.

Normas reguladoras foram criadas visando estabelecer um padrão de dirigibilidade que represente, da forma mais próxima possível, o uso do veículo pela maioria das pessoas no mundo real. A NBR 6601 [38], por exemplo, define um comportamento típico de velocidades de veículo em meio urbano, ao longo do tempo. Este perfil de velocidades é subdividido em quatro fases, $\mathrm{Ph} 1, \mathrm{Ph} 2, \mathrm{Ph} 3$ e $\mathrm{Ph} 4$. A Ph1 é igual à $\mathrm{Ph} 3$ e a $\mathrm{Ph} 2$ é igual à $\mathrm{Ph} 4$. Estas são fases de medições de emissões gasosas e de consumo de combustível adotadas oficialmente nos E.U.A. e no Brasil.

O perfil completo da $\mathrm{Ph} 1$ de velocidades pode ser visto na Figura 30. 
Figura 30 - Perfil de Velocidades Ph1, Segundo a Norma NBR 6601

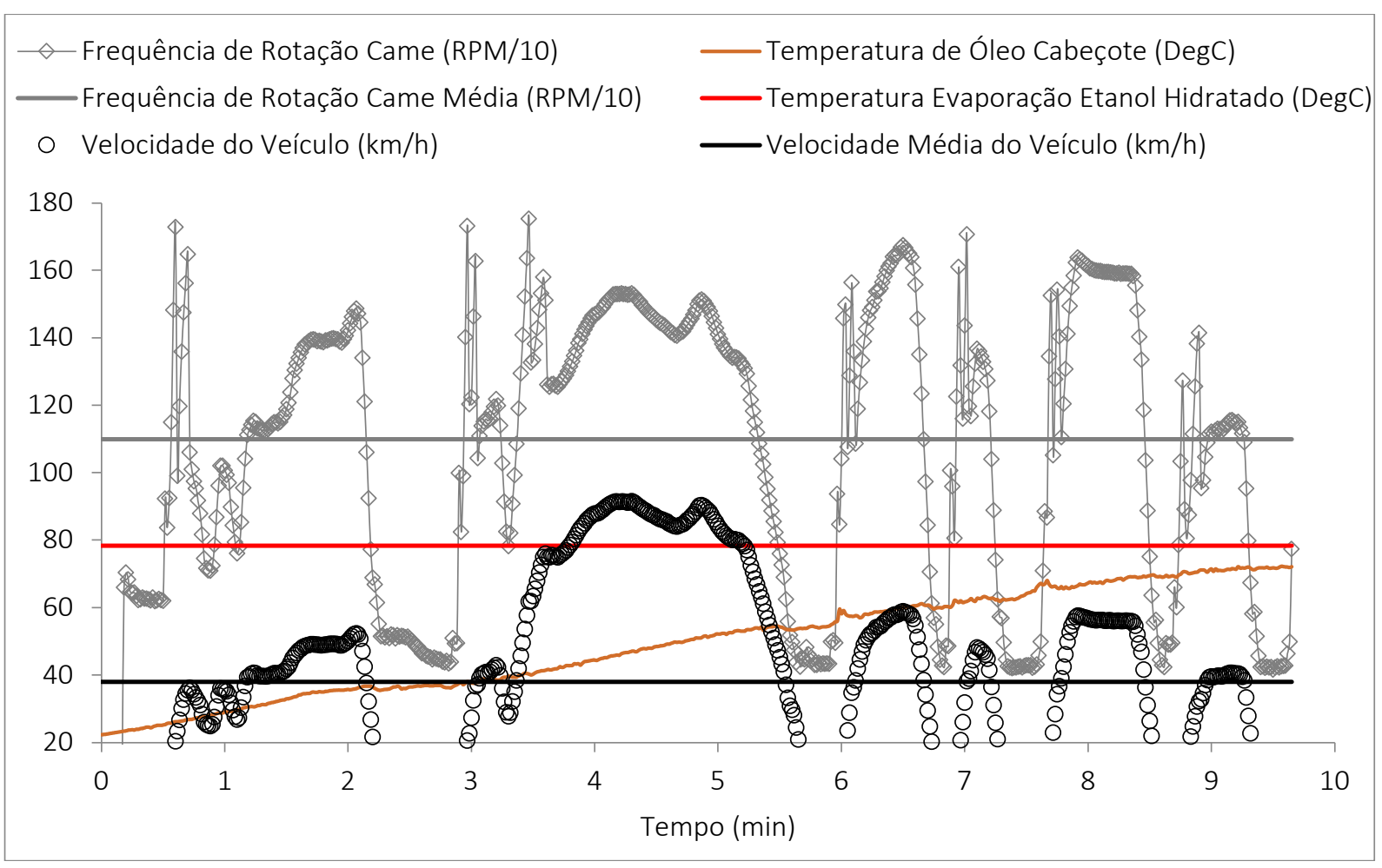

$\mathrm{O}$ autor

A demanda de um motor três cilindros, 1.01 de cilindrada, injeção eletrônica, em termos de RPMs, pode ser representada pela curva "RPM/10" na Figura 30. Nota-se que as frequências de rotação do eixo virabrequim variam entre 800 RPM e 3600 RPM, aproximadamente. Como o eixo comando de válvulas gira com frequência de rotação à metade da frequência de rotação do eixo virabrequim, a sua frequência de rotação mínima será de cerca de 400 RPM (7 Hz) e a sua frequência de rotação máxima será de cerca de 1800 RPM $(30 \mathrm{~Hz})$. Temos, então, uma frequência de rotação média de 1100 RPM $(18 \mathrm{~Hz})$.

Na fase Ph1, de acordo com Schamel, Grischke e Bethke [19] pode-se ter até $25 \%$ de perdas de torque no motor, por atrito entre came e tucho. Mas, de acordo com Gangopadhyay, Uy, McWatt, Zdrodowski e Simko [16] podem ser empregadas técnicas de minimização de perdas por atrito com o uso de tuchos revestidos com H-DLC, por exemplo.

As temperaturas do lubrificante do motor podem ser representadas pelo gráfico "Temp. Óleo DegC" na Figura 30, ao longo de toda a Ph1. As temperaturas do lubrificante, na região do contato came-tucho, nunca ultrapassam a temperatura de ebulição do Etanol $\left(78,4{ }^{\circ} \mathrm{C}\right)$ na Ph1. 
Vale ressaltar que estas condições não correspondem às condições exigidas para que haja o efeito de deposição de etanol no óleo lubrificante, como descrevem Pinto, Nadai e Martins [37]. Porém, descrevem, teoricamente, um "uso comum" veicular em meios urbanos.

O ponto de ebulição do etanol hidratado combustível é de $78,4{ }^{\circ} \mathrm{C}$. Desta forma, presume-se-se que, na $\mathrm{Ph} 1$, não haverá evaporação considerável de Etanol presente no lubrificante, caso este tenha sido depositado previamente à execução do ciclo.

Como experimentalmente demonstrado (ANEXO 2), o lubrificante envelhecido adquire capacidade de misturar-se ao etanol hidratado, tanto mais quanto mais envelhecido for. Desta forma, o lubrificante utilizado nos experimentos será o SN5W30, envelhecido em motor de combustão interna. Portanto, o objetivo de trabalho, em termos de lubrificação, é avaliar o comportamento tribológico came-tucho, com lubrificante envelhecido ao máximo, com adições de etanol hidratado.

São pouco conhecidos os efeitos, nas forças de atrito came-tucho, quando da presença de etanol hidratado no lubrificante do motor, inclusive no regime de $\mathrm{Ph} 1$ descrito. Visando esclarecer sobre os efeitos do etanol hidratado nas interações came-tucho, este trabalho utilizase da realização de dois procedimentos experimentais, um procedimento pino-disco e um procedimento monocame, que visam reproduzir tais fenômenos de contato, e da implementação de um modelamento físico-matemático, que visa descrever tais fenômenos de contato.

Todos estes procedimentos e modelamento baseiam-se nas condições de Ph1 apresentadas.

\subsection{Objetivos dos Experimentos Pino-Disco}

O objetivo dos ensaios pino-disco será reproduzir, da forma mais fiel possível, as condições tribológicas nariz de came e tucho, para as condições de uso veicular expressas no ítem 3.1, com adições de etanol hidratado ao lubrificante.

São frequentes as tentativas de reproduzir os fenômenos tribológicos com ensaios pinodisco. Por exemplo, Rehan Zahid et al [39] descrevem experimentos para a determinação dos efeitos da aplicação de DLC, de uma forma geral, para além das condições específicas cametucho. Dentre os experimentos citados, os autores apontam para o uso de experimentos pinodisco. Shanta, Molina e Soloiu [40] descreveram experimentos pino-disco para a investigação da contaminação de biodiesel no lubrificante do motor. 


\subsection{Objetivos dos Experimentos Monocame}

Experimentações com cabeçotes inteiros de motor em bancada, medindo-se os torques resistentes no eixo comando de válvulas, como realizadas por Gangopadhyay, Uy, McWatt, Zdrodowski e Simko [41] exigem uma série de cálculos e considerações matemáticas para que se extraia informações sobre os atritos entre came e tucho.

Experimentações com dispositivos, como os contruídos por Bas, Biyiklioglu and Cuvalci [42], não utilizam tuchos, válvulas, guias de válvulas e guias de tuchos reais de um motor a explosão.

Medições diretas por "strain gauges", adaptados a blocos de cabeçote em motor real em funcionamento, como feitas por A. Dyson, M.A., and H. Naylor [13], estão sujeitas a muitos ruídos, que por vezes impossibilitam a leitura de sinais úteis.

Visando contornar estes problemas, foi idealizado e construído um aparato experimental cujos objetivos são:

1 - Utilizar peças reais de um motor de combustão interna: cames, tuchos, molas, válvulas, guias de válvulas e guias de tuchos, numa montagem possivelmente idêntica à de um determinado motor, para a aquisição de forças de atrito came-tucho;

2 - Medir diretamente as forças normais e tangenciais de contato came-tucho, simultaneamente e instantaneamente;

3 - Permitir mudanças no tipo de lubrificante utilizado, se necessário;

4 - Permitir mudanças de temperatura do lubrificante, se necessário;

5 - Permitir a fácil inserção de etanol hidratado no meio lubrificante;

Desta forma, procurou-se reunir as melhores características dos aparatos já desenvolvidos e descritos na literatura, procurando-se eliminar as características consideradas desfavoráveis, no sentido de ser o mais fiel possível na construção mecânica do sistema cametucho, objetivando a captação direta de informações de forças de contato came-tucho.

\subsection{Objetivos da Modelagem Matemática}

O modelo EHL descrito na seção 2.5 poderá ser aplicado às condições pino-disco e monocame, de forma a ajudar na compreensão dos fenômenos tribológicos.

Algumas adaptações do modelo EHL foram implementadas, no intuito de descrever as espessuras de filme lubrificante no contato. 
Foram introduzidas várias viscosidades diferentes de misturas lubrificante-etanol hidratado, em condições normais de pressão, com considerações de temperaturas e adições de teores de etanol hidratado, como dados de entrada para os cálculos de piezo-viscosidades.

Adaptou-se o modelo EHL, utilizado como base, por meio de adaptações das Leis de Newton e de Coulomb, gerando um proposto modelo simplificado semi-empírico limitroelastohidrodinâmico, LEHL, cujo objetivo principal é o de descrever as forças e coeficientes de atrito entre nariz de came e tucho obtidos pelos experimentos pino-disco e monocame realizados.

Portanto, os objetivos da aplicação do modelo EHL e do modelo semi-empírico simplificado LEHL são:

1 - Descrever as espessuras de filme central e mínima, nas condições de ambos os experimentos;

2 - Determinar o comportamento das espessuras de filme lubrificante em função de adições de etanol hidratado no lubrificante;

3 - Descrever as forças de atrito e os coeficientes de atrito nariz de came - tucho; 


\section{Procedimentos Experimentais}

\subsection{Aparato Experimental Pino-Disco}

Deseja-se efetuar ensaios lubrificados que reproduzam os contatos nariz de came e tucho. Portanto, necessita-se promover um deslizamento entre uma superfície tipo "nariz de came" e uma peça tipo "tucho", aplicando-se uma carga normal entre as peças em contato e medindo-se as forças de contato normal e as forças de atrito.

Estes ensaios, por se tratar de ensaios controlados em laboratório, podem fornecer informações importantes dos atritos de contato em linha, sem efeitos mecânicos próprios dos contatos came-tucho, tais como: spin, tilting, vibrações, etc.

O princípio do experimento pode ser representado conforme a Figura 31.

Um disco é posto para girar numa desejada frequência de rotação. O pino, sob a ação de uma carga controlada, entra em contato com o disco. Um sensor piezoelétrico captura as forças de atrito entre pino e disco e todas estas informações são enviadas a um computador para seu devido registro.

Figura 31 - Princípio do Experimento Pino-Disco

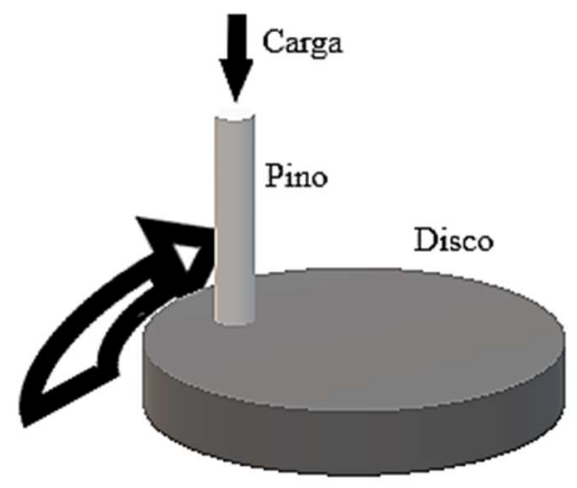

$\mathrm{O}$ autor

Os discos devem ser fabricados com o mesmo material do tucho, com os mesmos tratamentos térmicos das peças de motor e com o mesmo acabamento superficial, assim como os pinos devem ser feitos à semelhança dos cames.

Visando proporcionar um contato em linha, semelhante ao observado nas interações came-tucho TMAD, necessita-se usinar a ponta do pino com um raio de curvatura definido. A Figura 32 apresenta um pino já usinado. 
Figura 32 - Detalhe de Usinagem na Ponta do Pino

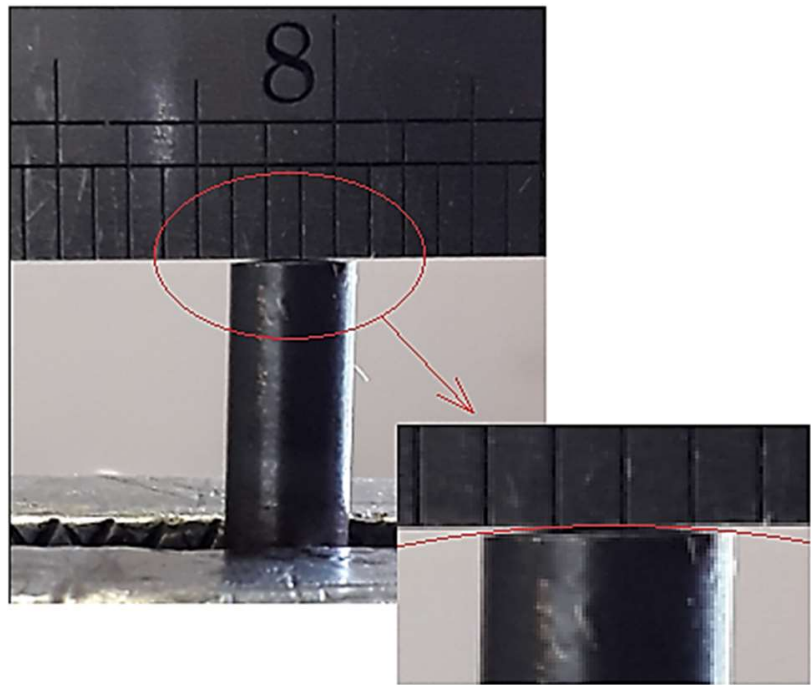

O autor

A Figura 33 exibe a curvatura obtida no pino.

Figura 33 - Curvatura Obtida no Pino

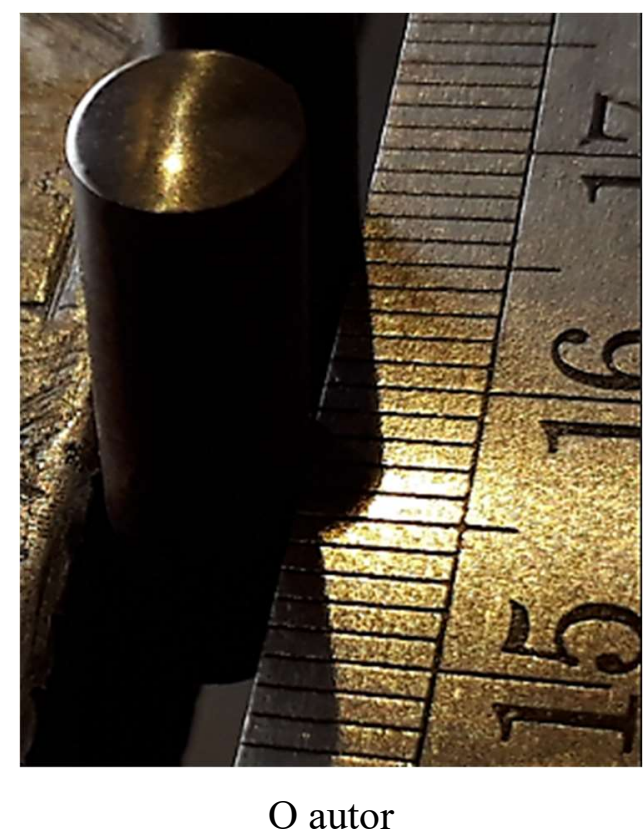

No momento de realizar os ensaios em Pino-disco, é necessário garantir que o contato em linha ocorra perpendicular a uma circunferência do disco, no ponto de contato. A Figura 34 ilustra o contato em linha. 
Figura 34 - Ilustração do Contato em Linha

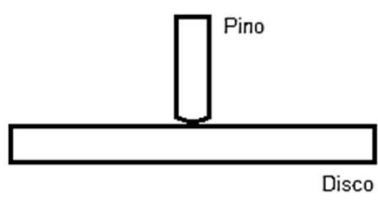

(A)

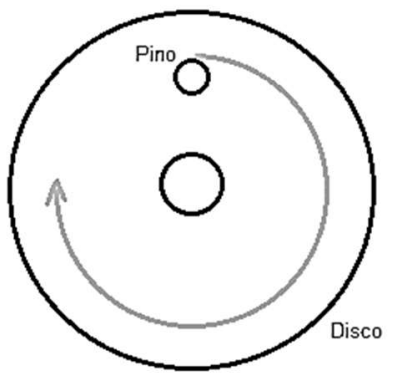

(B)

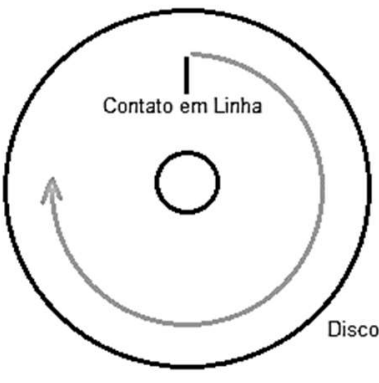

(C)

$\mathrm{O}$ autor

Em (A), visão lateral de pino em disco. Em (B), visão superior de pino em disco. Em (C), visão do contato em linha.

No momento no qual monta-se o sistema, a profundidade que o pino adentra a pinça (Figura 35-B), deve ser regulada de tal forma que o contato em linha seja uniforme, o que pode ser verificado via inspeção visual contra a luz, quando se abaixa o braço (Figura 35-A) sobre a cuba. A Tabela 6 exibe os materiais, tratamentos térmicos e acabamentos superficiais dos pinos e discos para ensaio.

Tabela 6 - Materiais, Tratamentos Térmicos e Acabamentos dos Pinos e Discos

\begin{tabular}{|c|c|c|c|c|}
\hline & Material & Dimensões & $\begin{array}{l}\text { Tratamento Térmico } \\
\text { (Cortesia Ultraterm) }\end{array}$ & $\begin{array}{l}\text { Acabamento } \\
\text { de Superfície }\end{array}$ \\
\hline Pinos & $\begin{array}{c}\text { Ferro } \\
\text { Fundido } \\
\text { Nodular }\end{array}$ & $\begin{array}{l}\varnothing 6 \mathrm{~mm} \times 20 \\
\text { mm, Raio de } \\
\text { curvatura } 32 \\
\text { mm }\end{array}$ & $\begin{array}{l}\text { Têmpera Superficial } \\
\text { (aquecimento ao } \\
\text { rubro por } 20 \text { s e } \\
\text { resfriamento abrupto } \\
\text { por jato d'água) }\end{array}$ & $\begin{array}{l}\text { Lixamento } \\
\text { Grit } 2000\end{array}$ \\
\hline Discos usinados & $\begin{array}{c}\text { Aço } \\
\text { 16MnCr5 }\end{array}$ & $\begin{array}{c}\varnothing 70 \mathrm{~mm} \times 8 \\
\mathrm{~mm}\end{array}$ & $\begin{array}{l}\text { Cementação de } \\
\text { camada de } 1 \mathrm{~mm}, \\
\text { seguido de têmpera e } \\
\text { revenimento. }\end{array}$ & $\begin{array}{l}\text { Usinado } \\
\text { (torneado) }\end{array}$ \\
\hline
\end{tabular}

Os "discos usinados" são discos sem polimento, visando reproduzir superfícies de tuchos já usados.

Segue descrição do aparato utilizado no Laboratório de Fenômenos de Superfície (LFS) da Escola Politécnica da Univerrsadade de São Paulo (Poli-USP), Plint TE67. 
A Figura 35 exibe o braço do equipamento erguido (A), no qual introduz-se uma pinça com o pino (B).

Figura 35 - Braço e Pinça do Equipamento Plint TE67

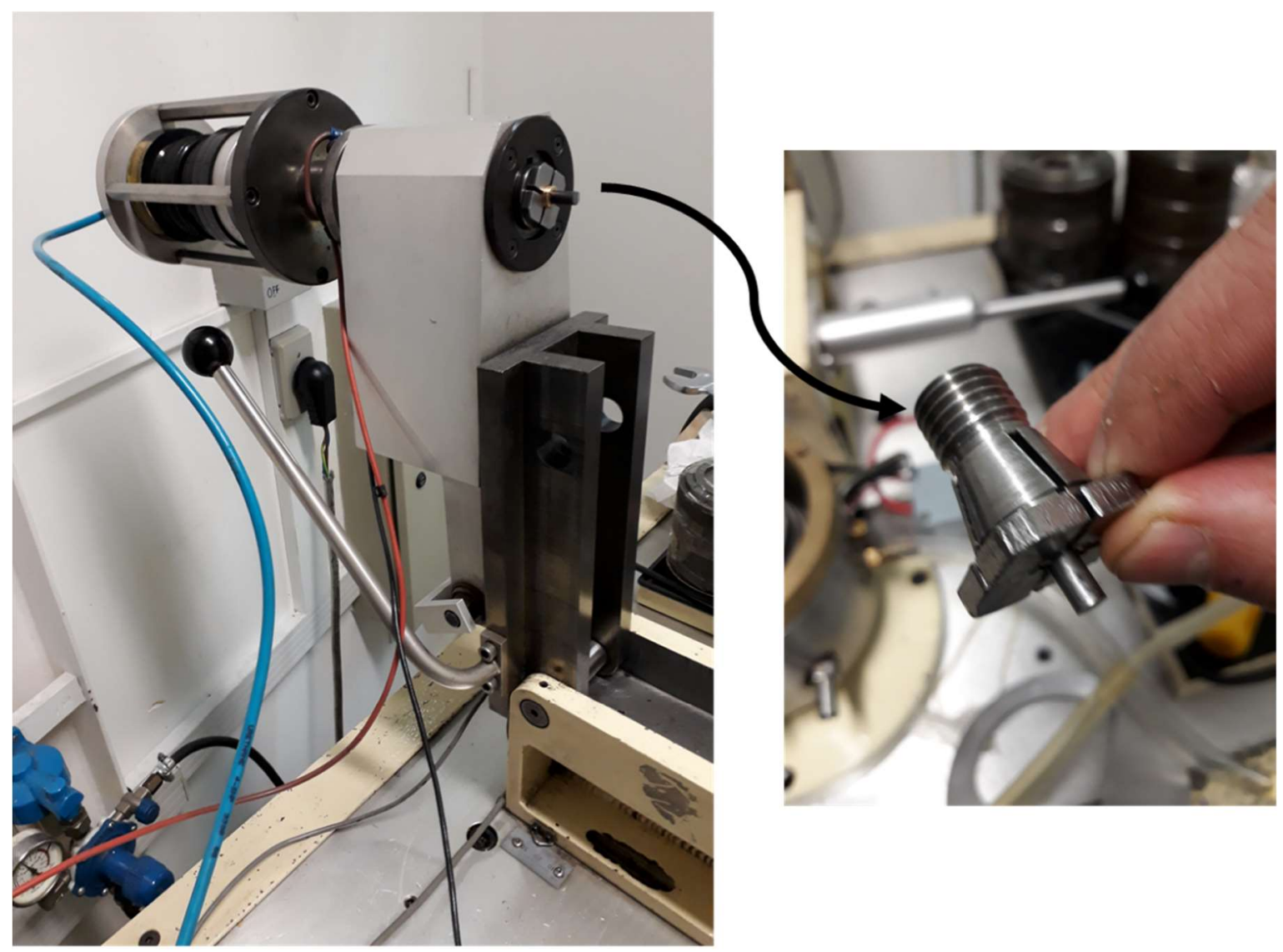

(A)

(B)

Laboratório de Fenômenos de Superfície, LFS, Poli USP

A Figura 36 é uma fotografia do aparato, no qual pode ser visualizado um sistema de bomba injetora de lubrificante, cuja função é gerar um fluxo contínuo de lubrificante, com temperatura controlada a partir de informação de temperatura na saída do bico injetor, via termopar. $\mathrm{O}$ aquecimento do lubrificantre em fluxo é realizado através de um trocador térmico controlado, anexo ao sistema bomba injetora.

Na Figura 36, pode-se observar a cuba, cuja função é abrigar o disco em rotação, banhado em lubrificante, cuba esta munida de uma saída de lubrificante para o retorno deste para o sistema de bomba injetora. 
Figura 36 - Aparato Pino-Disco Utilizado - Plint TE67

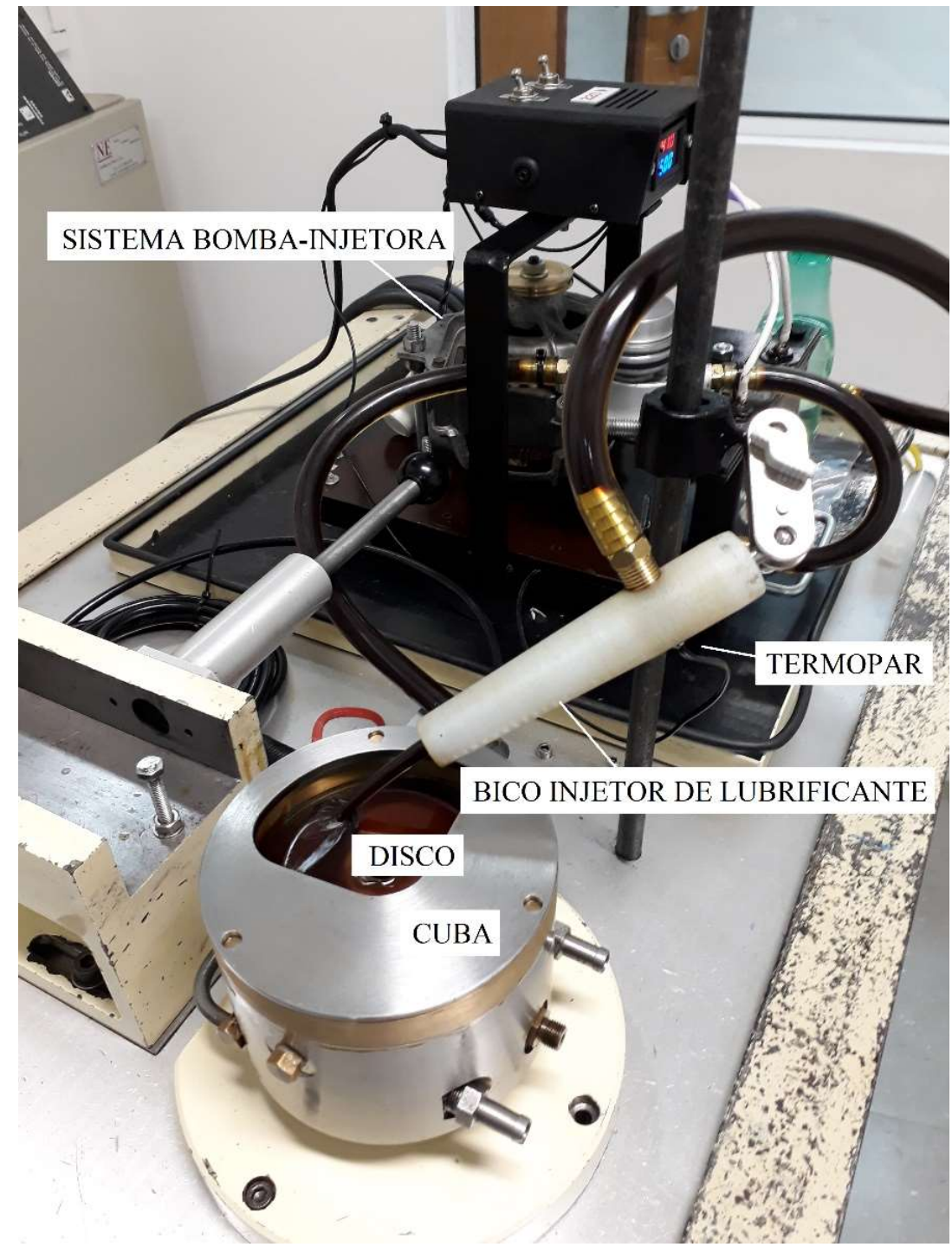

Laboratório de Fenômenos de Superfície, LFS, Poli USP

O lubrificante utilizado foi o SAE5W30, semissintético, envelhecido em motor.

O envelhecimento do lubrificante, plenamente formulado, comercial, ocorreu pelo uso em veículo flex-fuel, circulando majoritariamente em ciclo urbano, com combustível etanol hidratado e em demanda suave.

O lubrificante foi utilizado até que se completassem 10,000 km rodados em veículo, sem adições de lubrificante novo. Quando completada a quilometragem, o lubrificante foi retirado e devidamente acondicionado para uso nos ensaios. 


\subsection{Procedimentos Experimentais Pino-Disco}

Os experimentos foram realizados seguindo os seguintes passos, em ordem cronológica: 1 - Montagem de disco e pino e verificação direta de contato em linha; 2 - Setup do equipamento e aquisição: Carga normal sobre pino de 95,6 N, 955 RPM, Raio de contato: $30 \mathrm{~mm}$ (velocidade de contato de $1 \mathrm{~m} / \mathrm{s}$ ao centro do pino), $50{ }^{\circ} \mathrm{C}, 10 \mathrm{~min}$; 3 - Adição de $350 \mathrm{ml}$ de lubrificante SAE5W30, semissintético, envelhecido em motor (10000 $\mathrm{km})$ no circuito de circulação;

4 - Acionamento de sistema de bomba injetora, verificação de estabilização de fluxo de lubrificante e estabilização de temperatura, no caso, $50 \pm 1{ }^{\circ} \mathrm{C}$;

5 - Início da rotação de disco e início da aquisição de dados;

6 - Verificação de estabilização dos valores de força de atrito lidos, após observação de flutuações de break-in;

7 - Após a estabilização das forças de atrito, adição de $20 \mathrm{ml}$ de etanol hidratado. O etanol hidratado, comercial, foi diretamente injetado na cuba, vagarosamente, enquanto o sistema bomba injetora encarregou-se de promover a mistura em alguns ciclos;

8 - Observação de efeitos subsequentes na força de atrito e registro dos dados;

9 - Desmontagem parcial e lavagem do circuito, com lubrificante do mesmo tipo, para a realização de próximo experimento;

10 - Limpeza do equipamento;

Foram realizados dois experimentos em sequência, visando verificar repetibilidade.

\subsection{Aparato Experimental Monocame}

O aparato experimental desenvolvido, no escopo deste trabalho, é um aparato de bancada que procura reproduzir uma situação estacionária de eixo comando de válvula, para as condições típicas urbanas de 1100 RPM (eixo comando) e de temperatura controlada de lubrificante, buscando reproduzir as condições médias descritas no ítem 3.1.

Trata-se de um tribômetro came-tucho, TCT (Figura 37).

Este aparato consiste num motor elétrico de indução 2 cv e 1750 RPM (1), dotado de um volante de inércia no seu eixo (2). Neste eixo fixa-se uma polia (3), que transmite movimento a uma segunda polia (4), solidária a um "eixo comando de válvula" (5). 
Figura 37 - Visão Geral do Tribômetro Came-Tucho, TCT

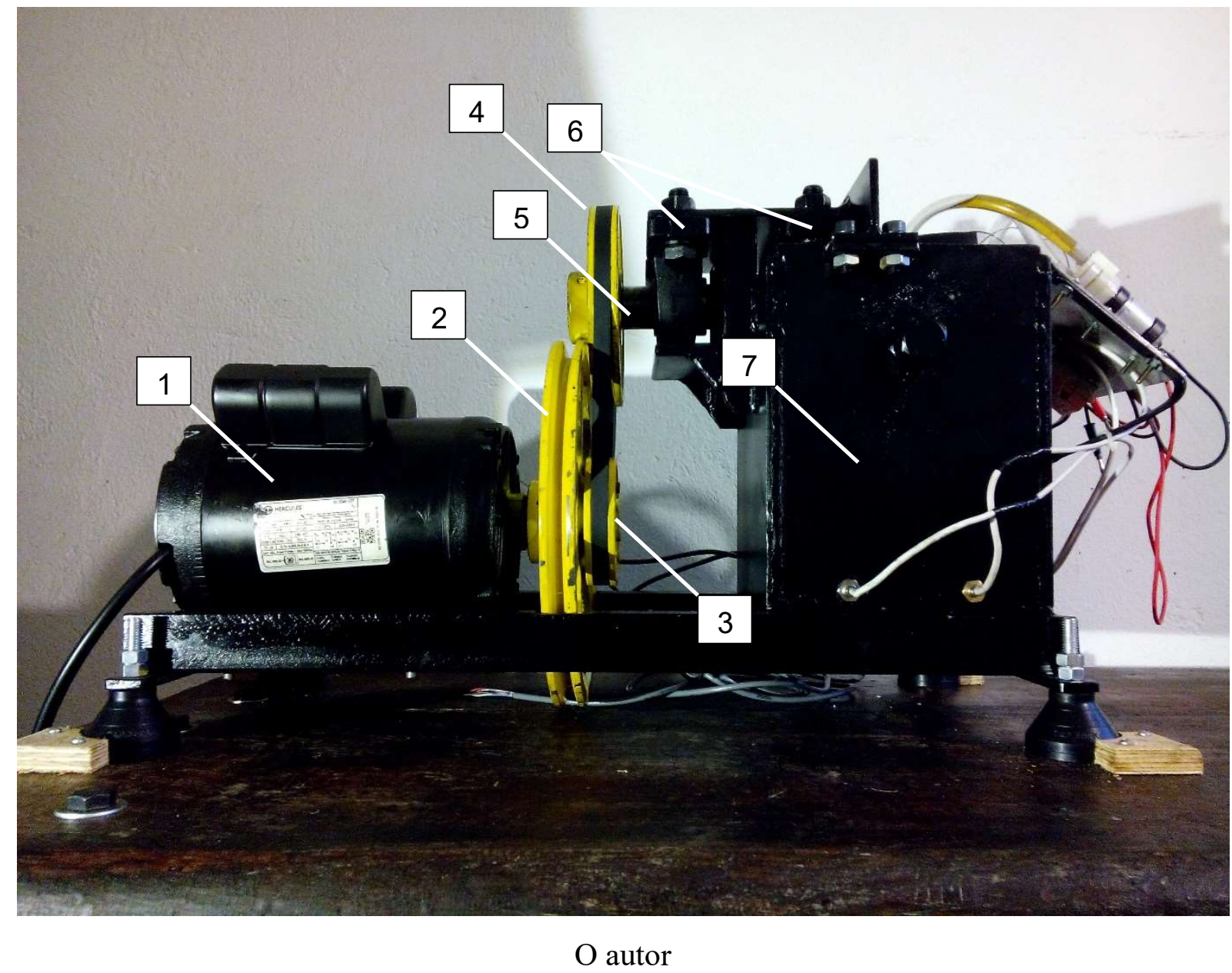

Este "eixo comando de válvula" é apoiado por dois mancais de rolamentos (6). Os mancais de rolamentos são afixados à estrutura da máquina.

O interior do reservatório de lubrificante (7), pode ser visualizado na Figura 38. 
Figura 38 - Interior do Reservatório de Óleo Estrutural

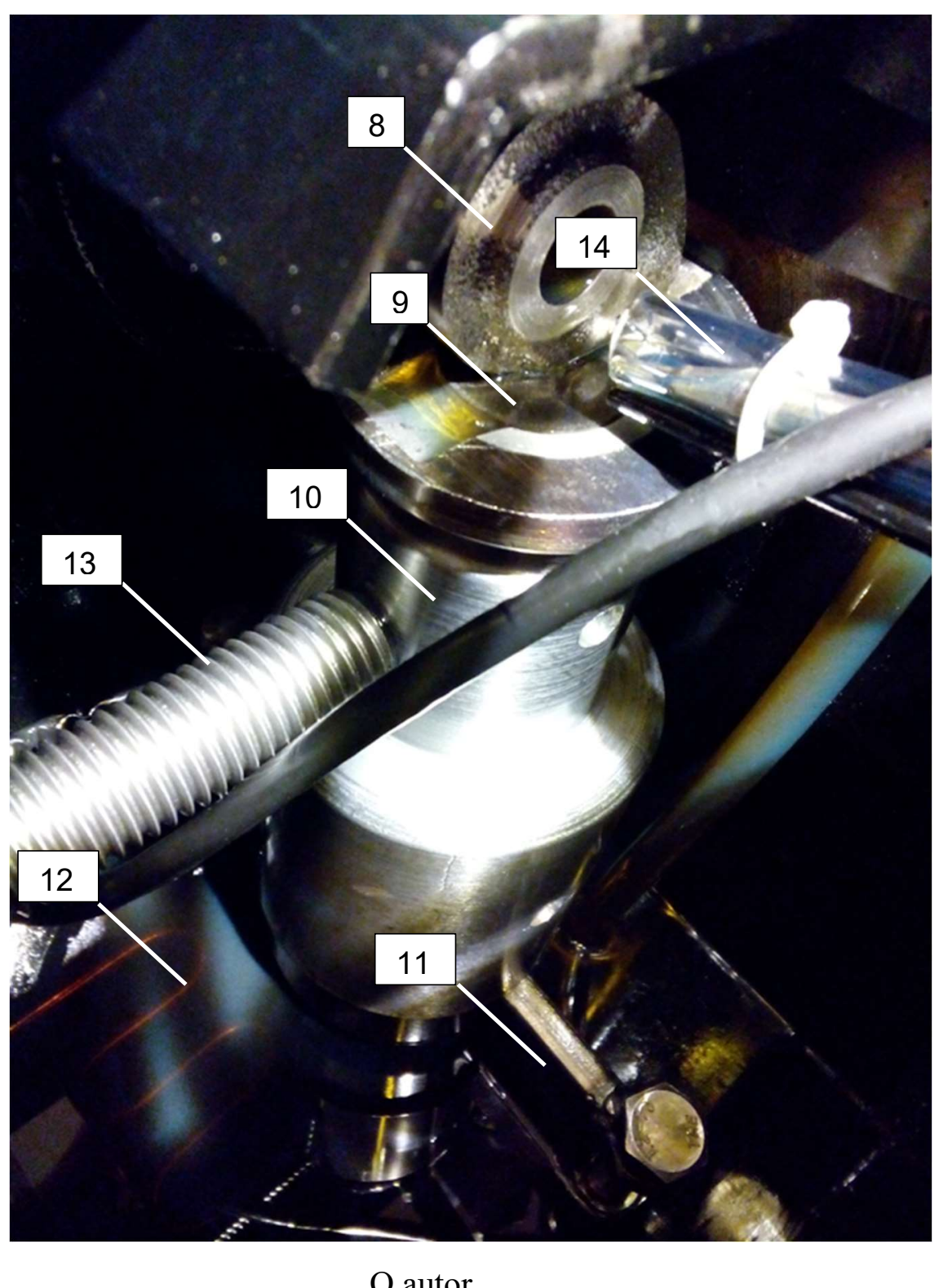

Na Figura 38 pode-se visualizar, na extremidade do eixo comando de válvula, o came afixado (8), o tucho (9) montado numa célula (10) apoiada numa base em balanço (11).

Na Figura 38 também pode-se visualizar uma resistência elétrica (12), cuja ação é controlada eletronicamente, assim como um parafuso de fixação e pré-carga da célula (13) e um tubo de alimentação de lubrificante proveniente de bombeamento elétrico (14).

O lubrificante bombeado é, desta forma, diretamente lançado sobre a região de contato came-tucho, escorre pela estrutura da célula e deposita-se no fundo do reservatório, por 
gravidade. Este será novamente bombeado, realizando assim um ciclo, de forma análoga ao que ocorre num motor de combustão interna.

No interior do tubo de alimentação, na região de saída do lubrificante, existem dois sensores: um é o sensor térmico do controle de temperatura e outro é um sensor térmico de um termômetro eletrônico de monitoramento.

A célula possui em seu interior um conjunto inteiro real de um sistema de válvula, como esquematizado na Figura 39, dotado de mola, retentores, presilhas, válvula, sede de válvula, guia de válvula, etc.

Figura 39 - Esquema do Interior da Célula

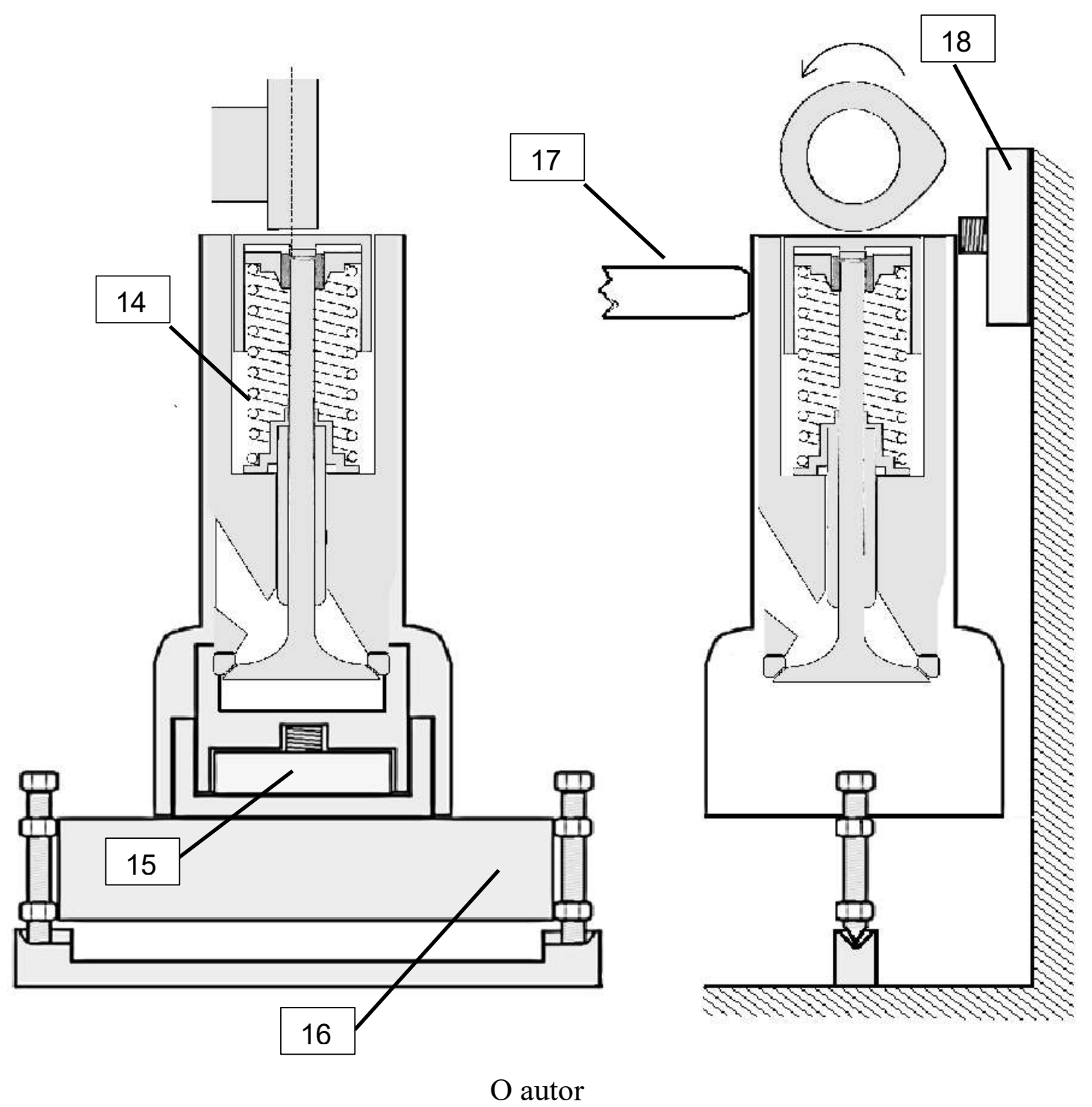

A célula apoia-se verticalmente numa célula de carga (15) para a transmissão de forças de contato verticais (ou normais ao contato), que por sua vez apoia-se numa base (16), em 
balanço, que permite grau de liberdade rotacional. Porém, esta rotação é restrita por um lado pela barra rosqueada de fixação (17) e por outro lado pela célula de carga de captação de forças de contato horizontais (18).

A Figura 40 exibe o núcleo da célula em visão explodida.

Os sinais elétricos gerados pela célula de carga vertical, $\mathrm{CCV}$, e pela célula de carga horizontal, $\mathrm{CCH}$, são captados por um amplificador de sinal de fator 100, constante, e enviados para um osciloscópio ou para um multímetro. (Figura 41).

Figura 40 - Núcleo da Célula em Visão Explodida

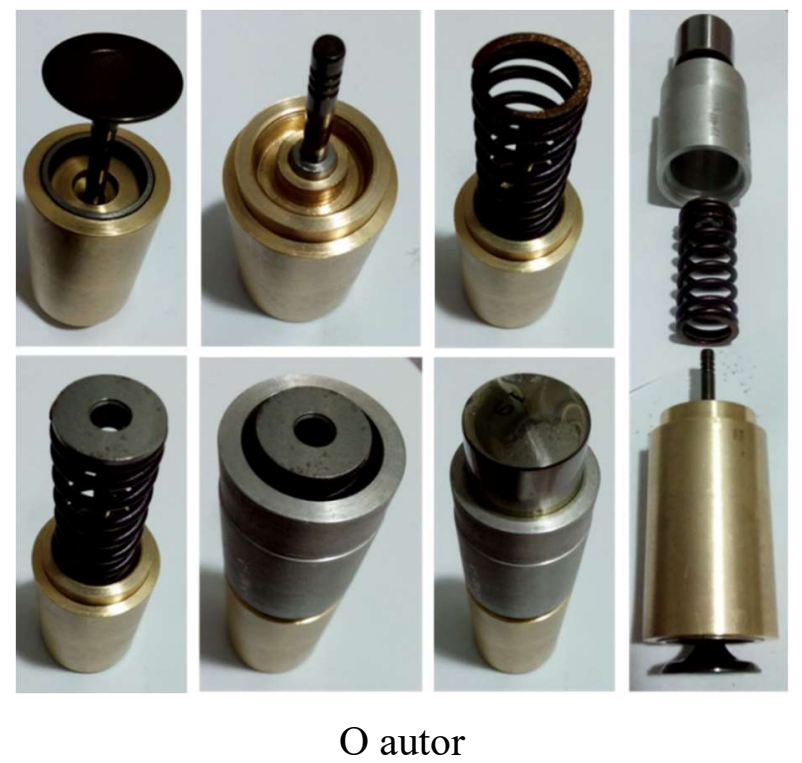

Figura 41 - Amplificador de Sinal e Osciloscópio

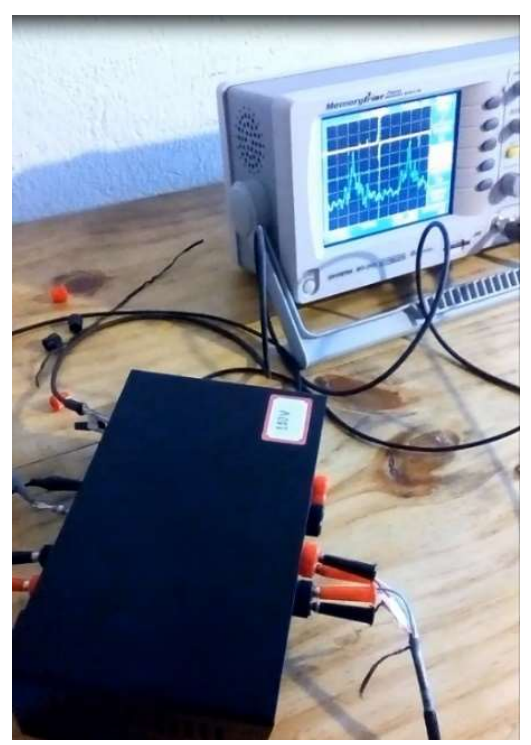

O autor 
O aparato experimental proposto pode ser utilizado para uma grande variedade de ensaios tribológicos na interação came-tucho. Vários estudos experimentais podem ser conduzidos, como por exemplo:

- Excentricidades ou perfis de came;

- Mudanças de rigidez de mola de válvula;

- Variações de folgas tucho-guia de tucho;

- Variações de massas do sistema móvel de válvula;

- Variações de folga came-tucho;

- Mudanças de RPM motor;

- Diferentes materiais de came e de tucho;

- Morfologias de superfícies em contato;

- Efeitos de desgaste e durabilidade;

- Diferentes óleos base e aditivos;

- Efeitos de temperaturas de óleo;

- Efeitos de contaminação de óleo (etanol, gasolina, fuligem, etc...);

- Efeitos de envelhecimento do óleo;

- Vibrações e ruídos do sistema;

\subsection{Procedimentos Experimentais Monocame}

Uma série de experimentos prévios (cerca de 12) foram conduzidos com o intuito geral de aperfeiçoar o equipamento. Pode-se citar algumas tarefas realizadas:

- Verificar a integridade mecânica da máquina;

- Verificar os sinais elétricos obtidos;

- Ajustar folgas e alinhamentos came-tucho,

- Verificar e ajustar fluxo de lubrificante e controle de temperatura deste;

- Validar a máquina em ensaios preliminares, por confronto com resultados de literatura;

- Inferir sobre a sensibilidade do sistema sob efeitos de Etanol no óleo lubrificante;

Previamente a cada experimento, os valores das tensões provenientes das $\mathrm{CCV}$ e $\mathrm{CCH}$ foram conferidos via Multimetro Fluke 206, para a certificação da estabilidade da calibração das células.

Por definição da montadora do motor, a Ford Motor Company, há uma faixa aceitável de folga entre came e tucho, quando o came encontra-se posicionado com o nariz para cima. A 
saber, entre 0,1 e 0,3 mm. Aferiu-se, periodicamente, antes e após cada ensaio, esta folga entre o came e o tucho, garantindo-se que esta folga permaneceu dentro dos limites.

\subsubsection{Ensaios Preliminares de Forças Normais, Horizontais e de Atrito}

Como já descrito neste trabalho, os ângulos de came $\theta$ possuem como referência (zero grau) a posição de máximo deslocamento (lift) do came.

Em geral, o came não toca o tucho, na maior parte do giro. Há uma "folga" entre came e tucho, primordialmente quando o nariz do came aponta para os lados e para cima, baseandose na Figura 14. Esta folga garante o fechamento completo da válvula de admissão ou descarga. Dependendo das especificações do fabricante de dado motor, o valor desta folga varia.

Foram realizados ensaios que visavam aferir a acurácia e a precisão das medidas tomadas com o aparato. Estes ensaios preliminares foram realizados após a observação de estabilização de sinais durante um break-in que durou cerca de quatro horas.

Ensaios estáticos, ou quase-estáticos, de determinação das forças verticais, foram realizados com o uso de um multímetro Fluke 206, para a leitura das tensões amplificadas da célula $\mathrm{CCV}$. Os dados de sinais estáticos foram anotados por observação direta.

Ensaios dinâmicos, utilizando-se lubrificante SJ 20W50, em fluxo contínuo, e numa temperatura de $28{ }^{\circ} \mathrm{C}$, forneceram dados elétricos amplificados, provenientes da $\mathrm{CCV}$, com o uso de um osciloscópio. Os dados de sinais dinâmicos foram coletados eletronicamente e registrados, por oito tomadas subsequentes, o que permitiu avaliar a estabilidade dos sinais, assim como as incertezas das medidas, nas posições angulares de came.

Os resultados obtidos podem ser visualizados na Figura 42, cada ponto como a média dos dados coletados para determinado ângulo de came. 
Figura 42 - Sinais Elétricos e Forças da CCV em Ensaio Estático e Dinâmico a 1100 RPM

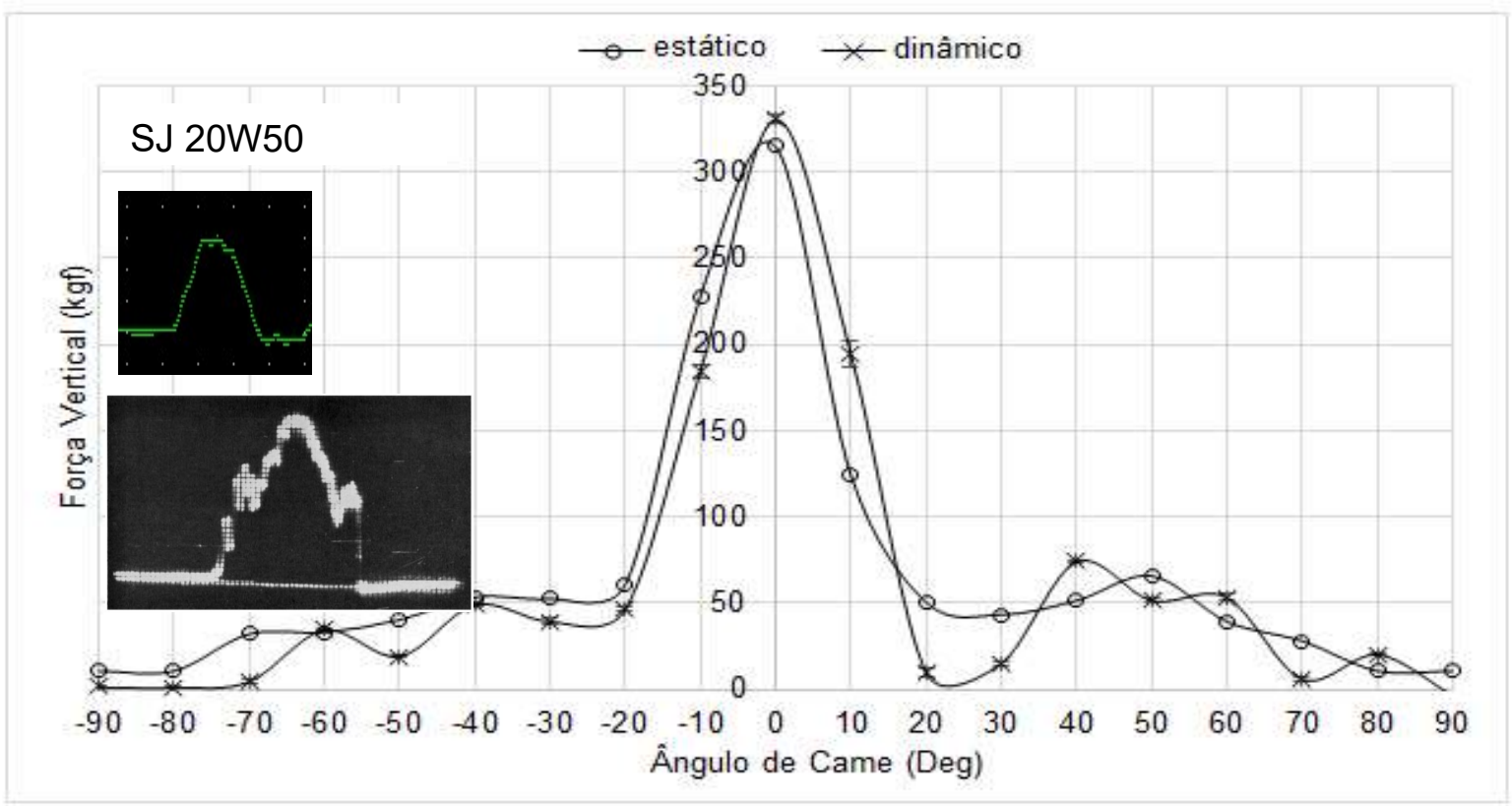

$\mathrm{O}$ autor

O detalhe à esquerda acima, na Figura 42, exibe a forma de sinal elétrico coletado no ensaio dinâmico. Observa-se certa semelhança com o sinal elétrico obtido por Dyson em 1960 [13], a 600 RPM, sub-figura esquerda abaixo.

Observando-se as curvas de forças verticais estáticas e dinâmicas, nota-se que estas pouco diferem, o que corrobora a afirmação de Dyson, de que as forças verticais de contato pouco diferem para baixas frequências de rotação de came.

Os dados obtidos com a CCV também permitiram aferir a frequência de rotação do sistema, através da medição temporal de pico a pico de dois eventos subsequentes, resultando em 1090 RPM. Da mesma forma, dados elétricos foram coletados da $\mathrm{CCH}$, obtendo-se os resultados exibidos na Figura 43.

Os sinais elétricos obtidos, detalhe na Figura 43, esquerda alto, se assemelham aos sinais elétricos obtidos por Dyson [13], detalhe na Figura 43, esquerda baixo, para 600 RPM. Entretanto, nas regiões logo após o pico, por Dyson, há considerável ruído, e pelos dados coletados há a presença de um segundo pico, menor.

Experimentos foram realizados para determinar a natureza do segundo pico. Descobriuse que, aumentando-se a pré-carga aplicada pelo parafuso da Figura 39-13, diminui-se o efeito do segundo pico, como exibe a Figura 44. 
Figura 43 - Sinais Elétricos e Forças da CCH em Ensaio Dinâmico a 1100 RPM

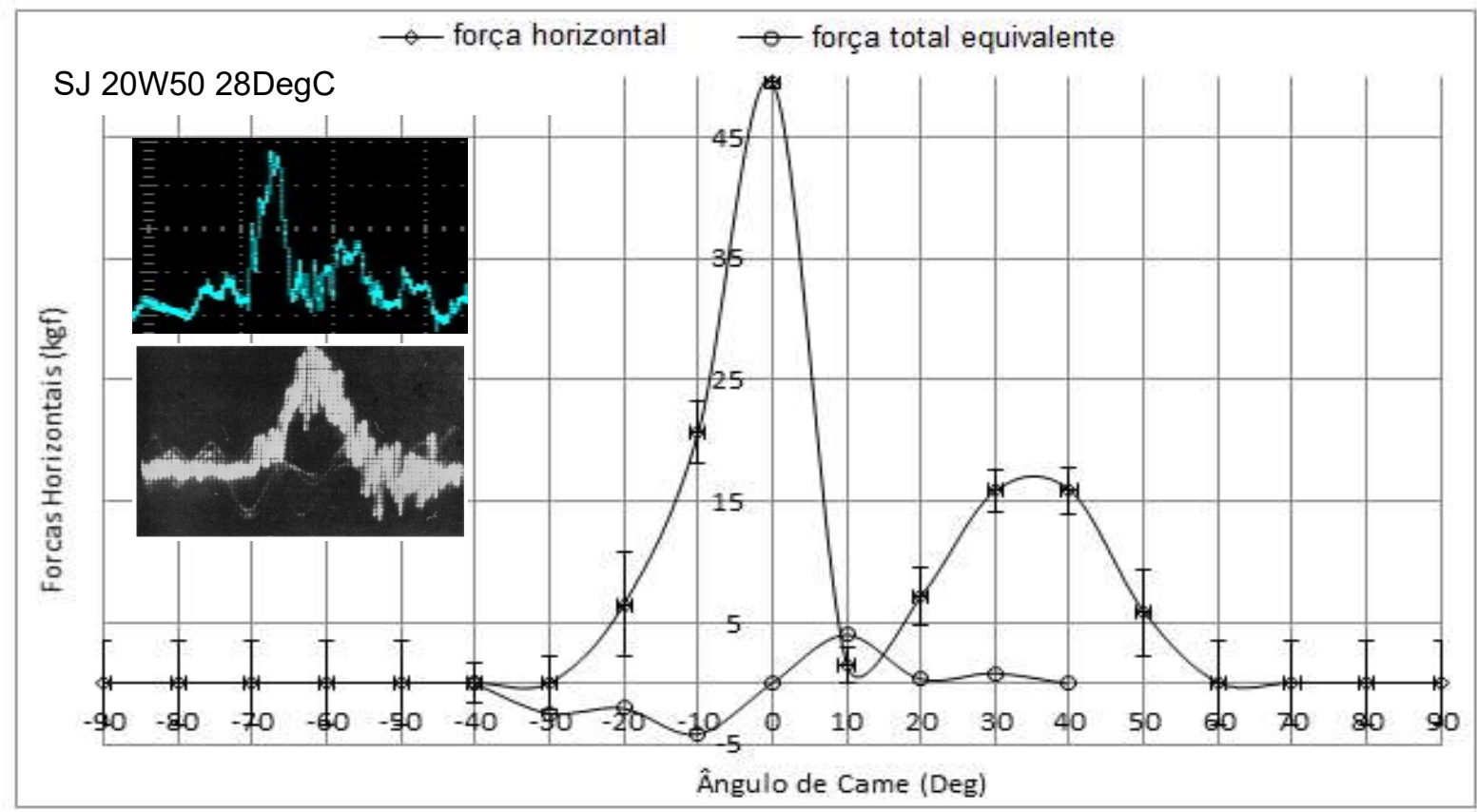

$\mathrm{O}$ autor

Figura 44 - Diminuição de Segundo Pico por Aumento de Pré-Carga
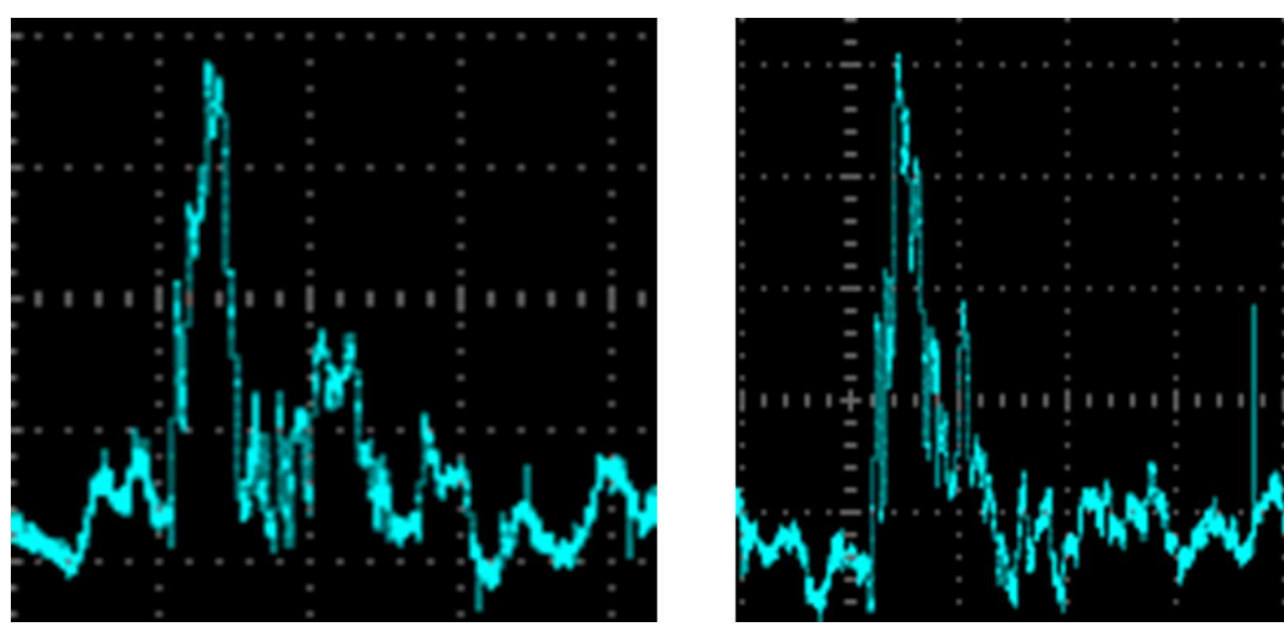

O autor

Desta forma, concluiu-se que o segundo pico se deve a algum efeito dinâmico da própria máquina, ou do conjunto came-tucho, e que, para fins de estudos tribológicos, especialmente no contato nariz de came e tucho, estes efeitos podem ser ignorados.

Outro efeito importante, que pode concorrer com a obtenção de forças de atrito, pela $\mathrm{CCH}$, é o efeito de forças com origem nos momentos gerados pelos contatos came-tucho não centralizados em $\theta=0^{\circ}$. 
Na Figura 43 foi traçada uma curva analítica de "força equivalente de torque". Esta força é calculada como uma força que age no contato came-tucho e que produz o mesmo efeito de torque da força normal vertical excêntrica neste contato. Neste contato surge a referida força normal excêntrica, devido à deformação elástica da mola de válvula por ação da excentricidade do came. Por se tratar de uma força excêntrica, esta gera um torque no sistema de célula, visto que o apoio deste sistema é articulado e central, como exibe a Figura 39. Estas forças, calculadas com base nas geometrias envolvidas e nas forças normais típicas medidas, podem ser subtraídas das forças horizontais obtidas pela $\mathrm{CCH}$, obtendo-se assim, também, com a supressão dos efeitos dinâmicos, uma curva de força de atrito came-tucho. As forças excêntricas podem ser visualizadas na Figura 43.

Portanto, o procedimento para obter-se as forças de atrito entre came e tucho, por este experimento e para todo o campo de ângulos entre $-90^{\circ} \mathrm{e}+90^{\circ}$, consiste em tomar os resultados experimentais de forças horizontais e subtrair delas dados analíticos de torques, suprimindo, assim, os efeitos dinâmicos refletidos pelo segundo pico (Figura 45).

Obviamente este procedimento não é necessário para avaliações de atritos came-tucho para contatos do tipo nariz de came e tucho, objeto deste estudo, pois para zero grau came, a força normal é aplicada no centro do tucho e, assim, não é gerado nenhum momento.

Figura 45 - Forças de Atrito Came-Tucho - Dados Experimentais a Menos de Forças de

\section{Contato Excêntrico}

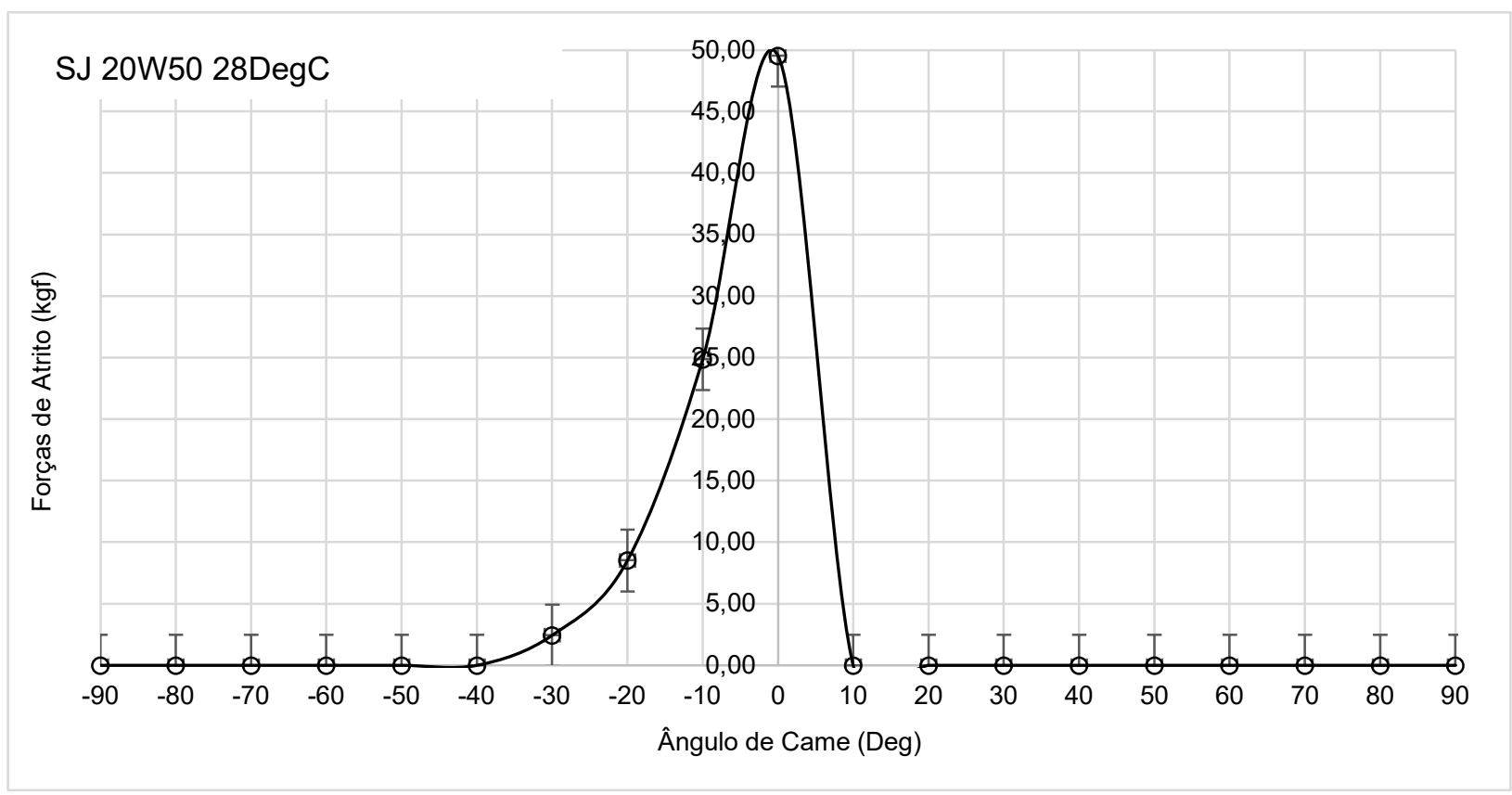

$\mathrm{O}$ autor 
Utilizando-se a Lei de Coulomb, pode-se determinar os coeficientes de atrito (CA) entre came e tucho, com lubrificante SJ20W50, a $28^{\circ} \mathrm{C}$, dividindo-se os dados plotados na Figura 45 pelos dados plotados na Figura 42. A Figura 46 exibe o gráfico de CA obtido.

Figura 46 - Coeficientes de Atrito, CA, Came-Tucho com Lubrificante SJ20W50

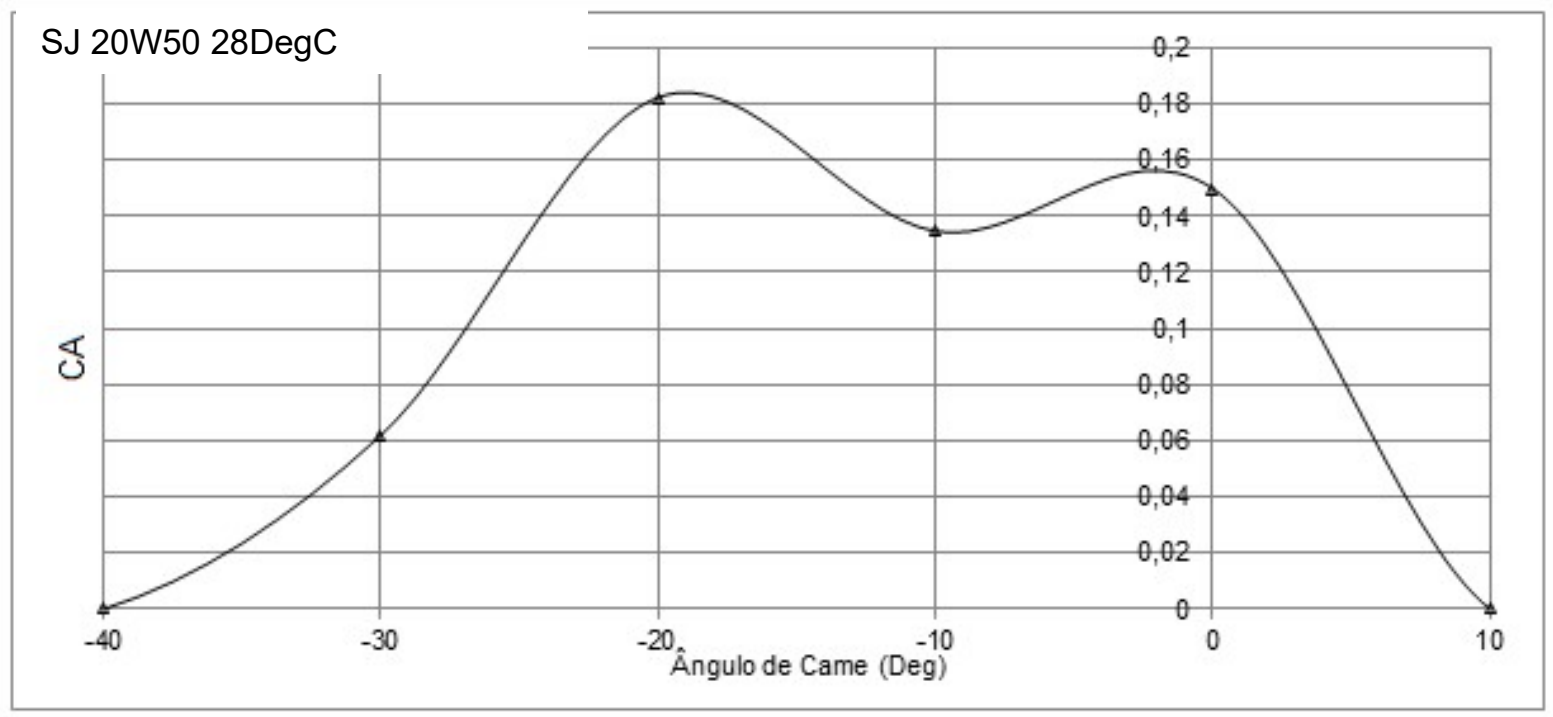

O autor

Dyson [13] obteve valores de CA entre 0,08 e 0,12 nesta região, com lubrificante SAE30HVI, a 600 RPM. O autor afirmou: "O coeficiente de atrito parece ser constante para uma grande faixa de cargas aplicadas... Materiais: came de aço endurecido, tucho de ferro fundido".

As forças verticais dinâmicas de contato foram medidas em várias oportunidades experimentais e mostraram-se muito estáveis, sempre apresentando semelhança com as forças estáticas. Com este fato, aliado à afirmação de Dyson, tomou-se como prática comum a não medição de forças verticais nos experimentos e a adoção dos valores de forças normais estáticas como padrão, nesta faixa de RPMs. Esta ação precisa ser revista em face de eventual modificação das geometrias envolvidas, ou mudança de materiais de mola, etc.

Os procedimentos e dados coletados expostos neste ítem visaram testar e aferir o equipamento. Os efeitos do etanol hidratado no comportamento tribológico came-tucho, verificados experimentalmente, são assunto do próximo ítem. 


\subsubsection{Ensaios com Etanol Hidratado}

Para os ensaios com etanol hidratado foi utilizado lubrificante motor comercial SN5W30 novo e também lubrificante motor comercial SN5W30, envelhecido por $10000 \mathrm{~km}$ de rodagem em veículo.

No experimento em bancada, com o tribômetro came-tucho, porções de etanol hidratado foram adicionadas ao lubrificante em circulação, diretamente e lentamente, até um percentual de mistura, em volume, de cerca de $25 \%$, considerado o máximo possível em motores de combustão interna flex-fuel, por Chui et al [43].

Os experimentos foram realizados seguindo os seguintes passos, em ordem cronológica: 1 - Montagem de came, no eixo, e tucho, na célula, e verificação da folga came-tucho; 2 - Adição de 1 L de lubrificante no reservatório e acionamento da bomba de circulação-injeção de lubrificante;

3 - Início de break-in;

4 - Observação de estabilização de sinais elétricos da $\mathrm{CCH}$, fim do break-in, que ocorreu entre 3,5 a 4 horas;

5 - Acionamento do circuito térmico (aquecimento controlado do lubrificante), verificação de estabilização de temperatura, em torno de $35^{\circ} \mathrm{C}$;

6 - Início de coleta de dados, com tucho normal;

Foram tomadas 10 medidas de dois picos de tensão a cada 5min, ou seja, 20 medidas para cada condição de \% de etanol hidratado, o que gerou um ponto num gráfico Tensão x ml Etanol, ou Força de Atrito x ml Etanol, ou CA por \% de Etanol.

Cada ciclo de medição corresponde a uma adição de etanol hidratado, a saber: inicial ( 0 $\mathrm{ml}$ de etanol) 100, 200, 300 e $400 \mathrm{ml}$ de etanol, o que corresponde a 9,1 \%, 16,7 \%, 23,1 $\%$ e $28,6 \%$ de etanol ao lubrificante. Este processo, no total, consumiu cerca de $30 \mathrm{~min}$. Cada seção de 20 medições levou cerca de $1 \min 40$ s.

7 - Desligamento da máquina, expurgo do lubrificante com etanol hidratado e lavagem dos sistemas com solvente;

8 - Utilizando-se o mesmo came, a mesma configuração da máquina e uma nova porção de 1 L do mesmo de lubrificante envelhecido, procedeu-se à troca do tucho por um tucho revestido com H-DLC;

9 - Repetem-se os passos de 1 a 7 ; 
Nos testes foram utilizados tuchos novos em $16 \mathrm{MnCr} 5$, carbonitretados e temperados, cames novos em ferro fundido nodular com Mn, e demais peças de motor 1.01 Fox Ford. O tucho revestido com filme fino comercial de H-DLC possuia uma camada base de nitreto de cromo $(\mathrm{CrN})$ e uma camada funcional de DLC do tipo a-C:H (cortesia Hef-Durferrit).

O procedimento experimental é sumarizado na Figura 47.

Figura 47 - Sumário da Atividade Experimental

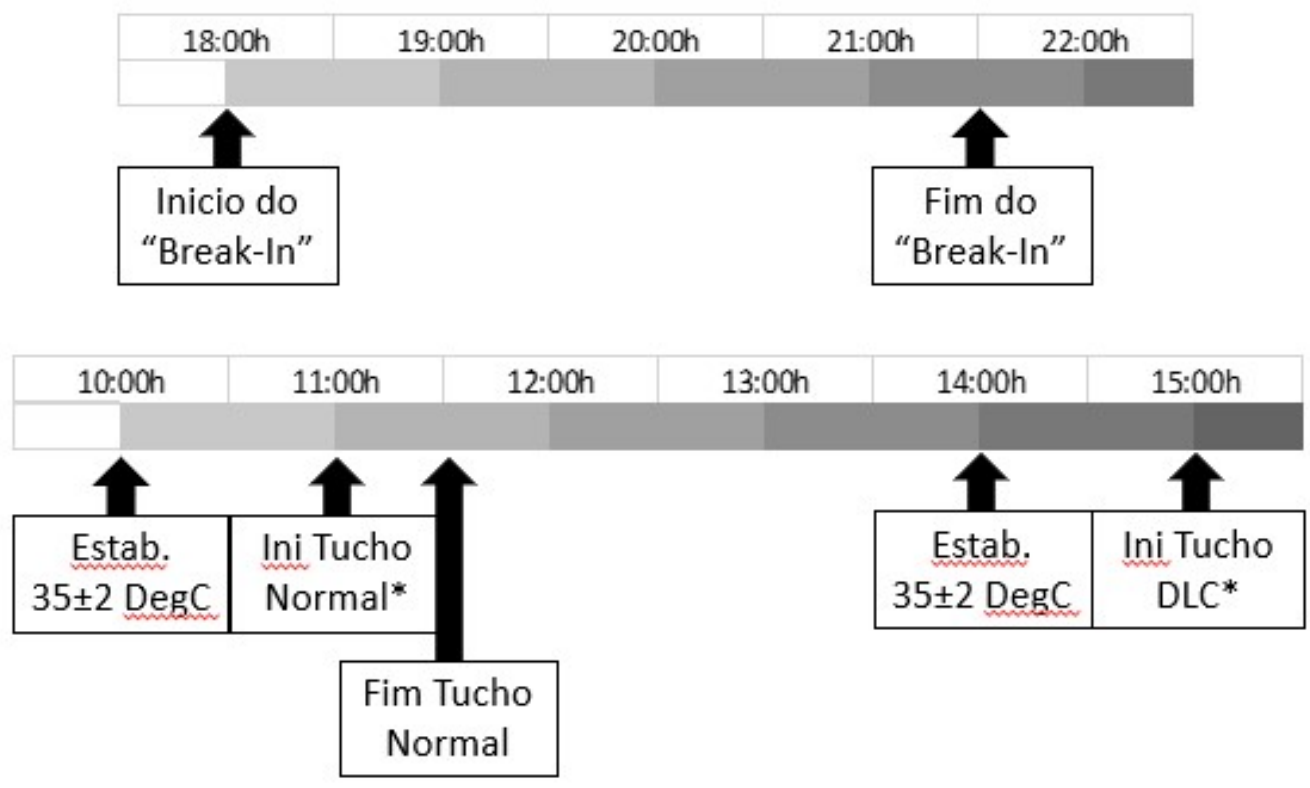

$\mathrm{O}$ autor

Cabe ressaltar que, com o tucho revestido com H-DLC, não se realizou break-in, uma vez que experimentos anteriores mostraram não haver alteração significativa na superfície de H-DLC após longos períodos de utilização em monocame.

Os sinais elétricos obtidos pela $\mathrm{CCH}$ possuem ruídos associados, sejam eles de natureza mecânica, sejam eles de natureza elétrica. Optou-se por não utilizar qualquer filtro eletrônico neste experimento. Mesmo assim, obtiveram-se resultados mensuráveis, o que demonstra vantagem sobre vários aparatos e procedimentos descritos na literatura, nos quais o uso de filtros foi necessário.

Para o tratamento dos sinais e obtenção dos valores de pico para a determinação de forças de atrito, foi necessário considerar, para cada par de picos, um critério de determinação de ddp. Este ddp corresponde, via uso de calibração de célula de carga, a uma força específica mensurada.

A Figura 48 exibe graficamente a estratégia adotada. 
Figura 48 - Determinação de ddp de Sinal de Força de Atrito pela CCH

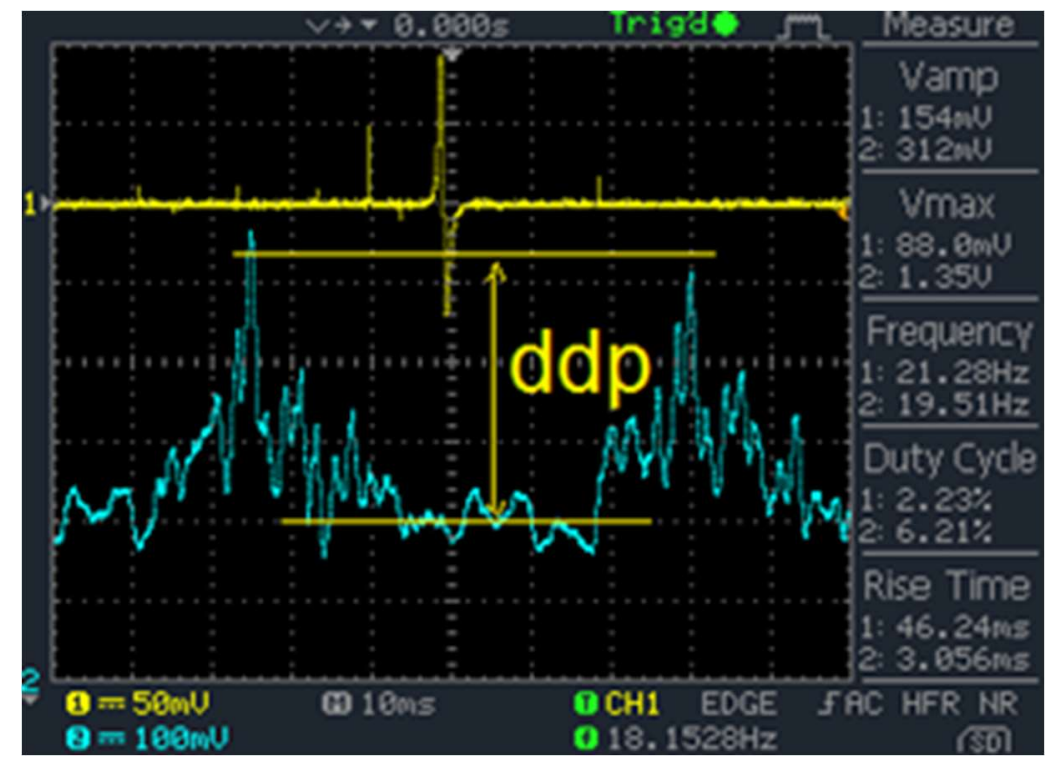

$\mathrm{O}$ autor

A região central entre os dois picos corresponde a uma região de esperada "força de atrito nula", pois ali o came, teoricamente, não faz contato com o tucho. Portanto, tomou-se a média dos valores de tensão na região entre $-10 \mathrm{~ms}$ e $+10 \mathrm{~ms}$ como um valor de tensão de referência.

Tomando o valor exato de cada pico, em cada par, e subtraindo-se este valor do obtido valor de referência, obtém-se dois valores de ddp que podem ser convertidos em valores de força de atrito pela relação linear de calibração de $\mathrm{CCH}$.

O valor da força de atrito é adotado como a média dos 20 valores de ddp e a sua incerteza absoluta é adotada como o desvio padrão desta amostra.

\subsection{3 - Caracterização Reológica dos Lubrificantes}

O lubrificante utilizado nos ensaios tribológicos foi o semi-sintético comercial SAE 5W30, envelhecido em uso veicular (veículo flex-fuel), com o uso de etanol hidratado como combustível, até a finalização de 10.000 km, o limite de "vida" alegado pelo fabricante.

Para determinar as viscosidades do lubrificante, puro ou com etanol hidratado, foram realizadas caracterizações reológicas, cortesia da UTFPr, pelo Laboratório de Reologia do Cernn (Centro de Pesquisa em Reologia e Fluidos Não Newtonianos). Foi utilizado um reômetro rotacional Haake Mars III (Thermo Scientific). O controle se deu através de controle de tensão elétrica. 
As amostras foram previamente homogeneizadas, com o auxílio de um agitador magnético, por $10 \mathrm{~min}$, na temperatura ambiente. Os resultados dos ensaios no reômetro foram obtidos através de ensaios de patamar de taxa de deformação de $\dot{\gamma} 10,00$ 1/s, por um tempo de 10 min, nas temperaturas de $40{ }^{\circ} \mathrm{C}$ e $100{ }^{\circ} \mathrm{C}$.

\subsection{4 - Caracterização da Topografia das Superfícies}

Para que seja caracterizado um regime EHL ou misto, o parâmetro y da Equação 1 deve ser maior que 0,5 [18]. Este parâmetro deve ser menor que 0,5, para que seja observado um regime limítrofe. Para que as espessuras de filme lubrificante sejam calculadas, via modelo EHL, torna-se essencial obter, para tal, informações sobre as rugosidades das superfícies em contato, que são normais de fabricação (novas, retificadas), desgastadas, ou recobertas com HDLC.

Desta forma, análises de rugosidades foram realizadas nas superfícies de contato entre pino e disco, nas regiões de contato, após os ensaios.

Os pontos analisados no pino e no disco estão representados na Figura 49.

(a) Região do Disco Usinado Analisada (trilha mais fraca);

(b) Região do Pino Analisada (ponto central);

Figura 49 - Pontos de Avaliação de Rugosidades em Pino e Disco

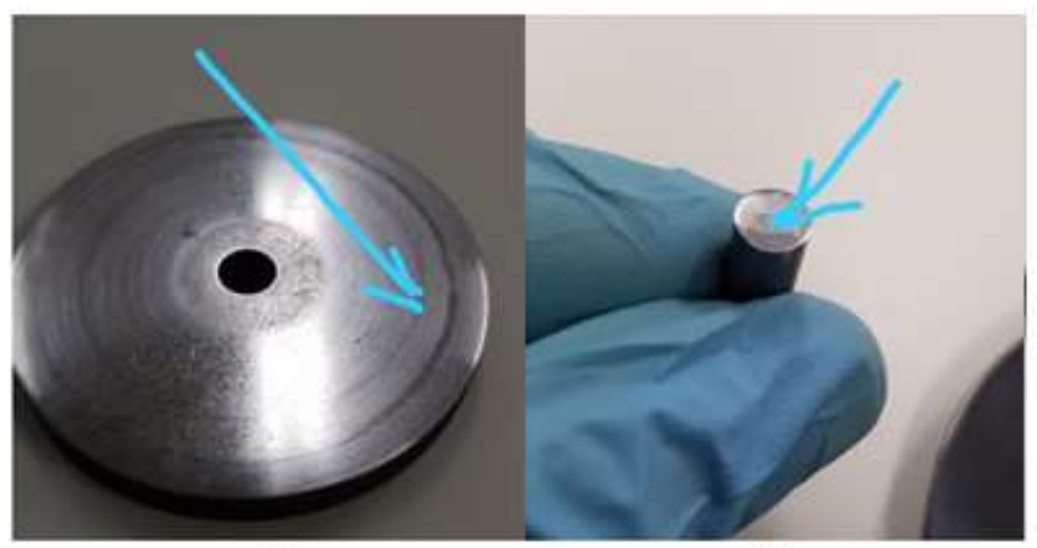

(a)

O autor

Também foram analisados pontos de contato em nariz de came e tuchos, após os experimentos. Os pontos analisados estão representados na Figura 50. 
Figura 50 - Pontos Analisados na Perfilometria Óptica

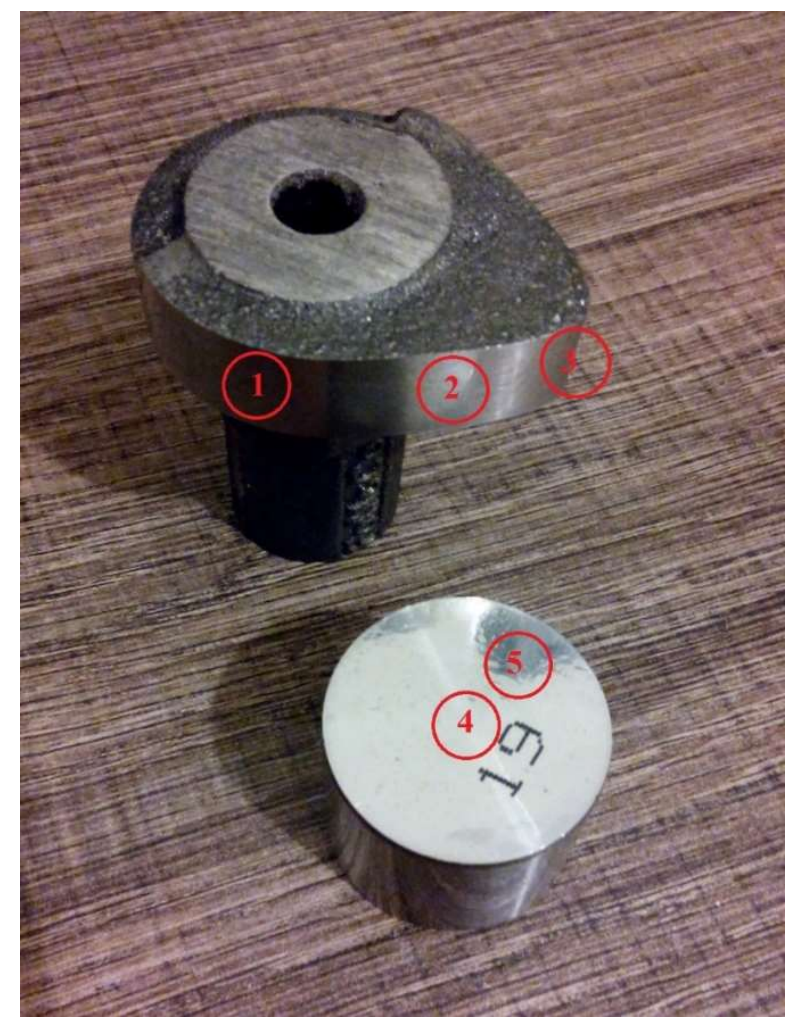

$\mathrm{O}$ autor

Foram tomados os valores dos pontos 3 e 5 como referência de contato, por se tratar de regiões centrais de contato nariz de came e tucho.

O APÊNDICE 1, o APÊNDICE 3 e o APÊNDICE 4 apresentam os relatórios de ensaios da perfilometria óptica realizados em pino, disco, came e tuchos. 


\section{Resultados e Discussões}

\subsection{Resultados dos Ensaios Pino-Disco com Etanol Hidratado}

Foi realizado ensaio, com adição de etanol hidratado, com o uso do disco normal, pino em ferro fundido nodular temperado e lubrificante SN 5W30 envelhecido em motor.

Iniciou-se a coleta de dados no equipamento pino-disco, observando-se a estabilização dos sinais de força de atrito, antes que se iniciasse a adição etanol hidratado. A variação de força de atrito, em decorrência desta adição de etanol, pode ser verificada na Figura 51.

Figura 51 - Evolução da Força de Atrito Pino-disco com Adição de Etanol Hidratado (1)

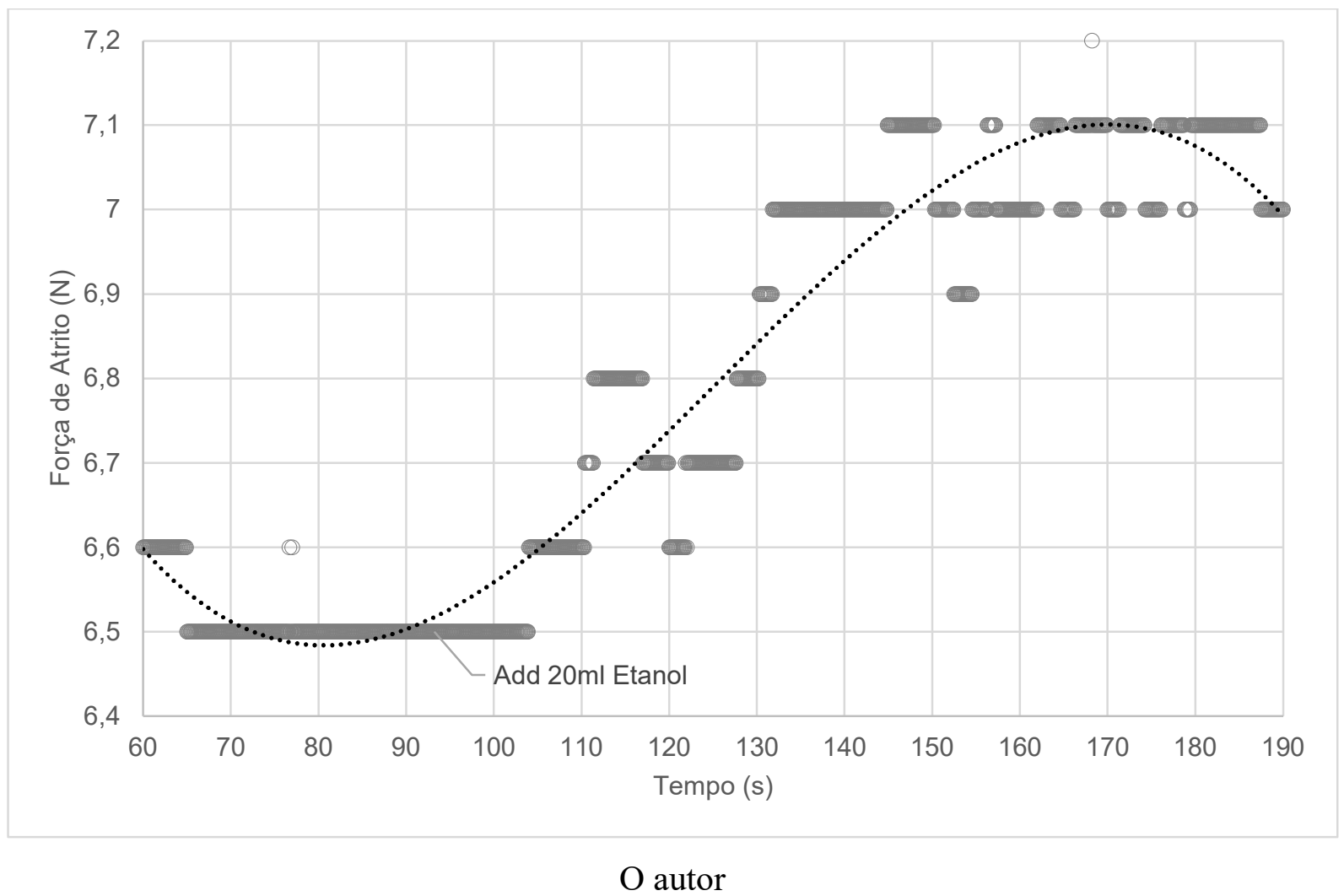

Sabendo-se que a força normal aplicada nos experimentos é de 95,6 N, a Figura 52 apresenta o gráfico dos coeficientes de atrito para o referido experimento. 
Figura 52 - Coeficientes de Atrito, Disco Usinado, com Adição de Etanol Hidratado (1)

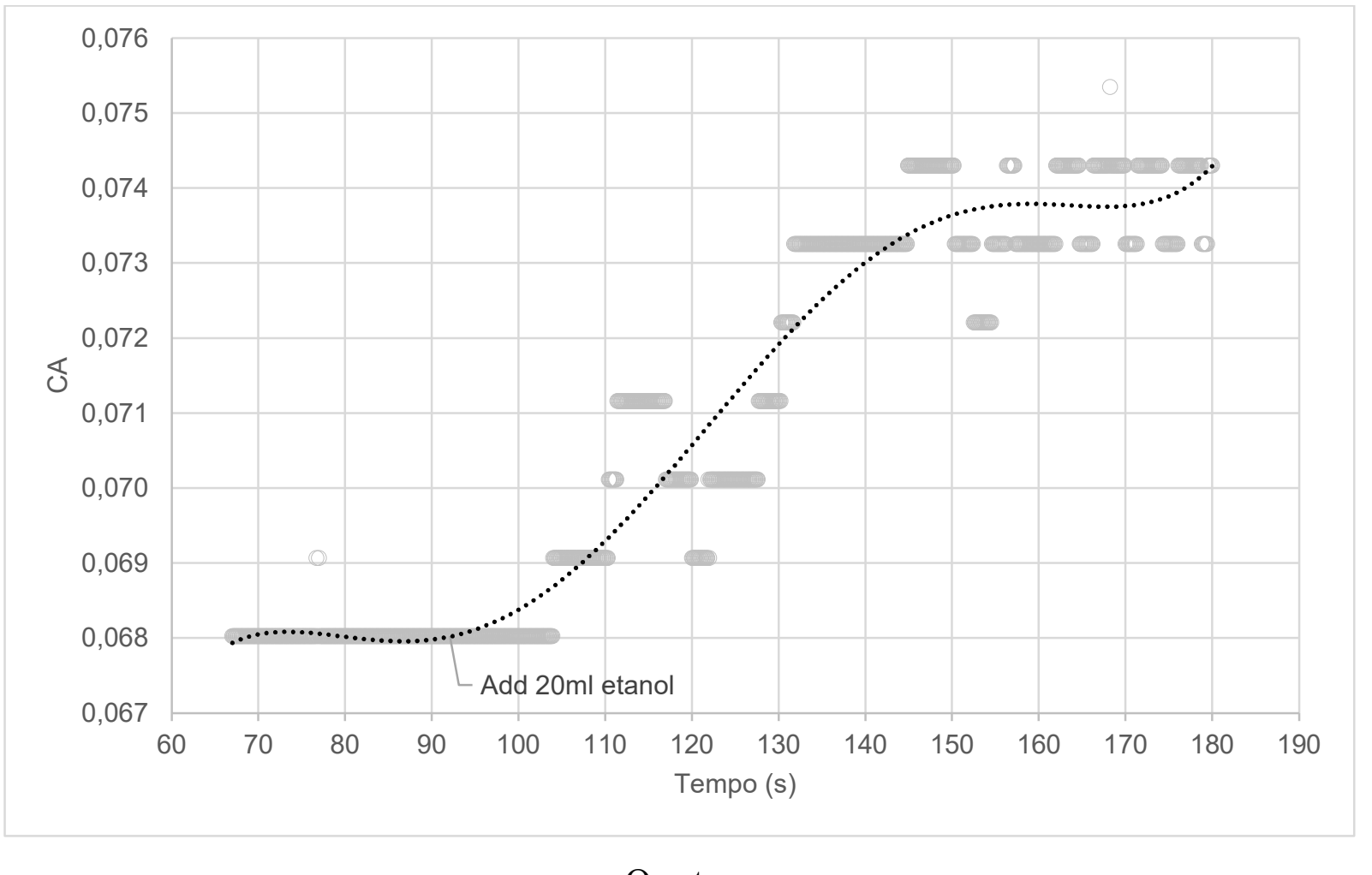

O autor

Observa-se que os valores absolutos dos coeficientes de atrito, para disco normal, mudam numa variação de $+0,005$.

Um segundo experimento, com disco normal, foi realizado, obtendo-se a mesma variação de coeficientes de atrito pino-disco.

Posteriormente, após lavagem de todo o circuito e troca de lubrificante, procedeu-se ao experimento com o uso de um disco revestido com H-DLC (Hef Durferrit). Obteve-se a curva de força de atrito exibida na Figura 53.

Sabendo-se que a força normal aplicada nos experimentos é de 95,6 N, a Figura 54 apresenta o gráfico dos coeficientes de atrito para o referido experimento. 
Figura 53 - Evolução da Força de Atrito Pino-disco (H-DLC) com Adição de Etanol Hidratado (1)

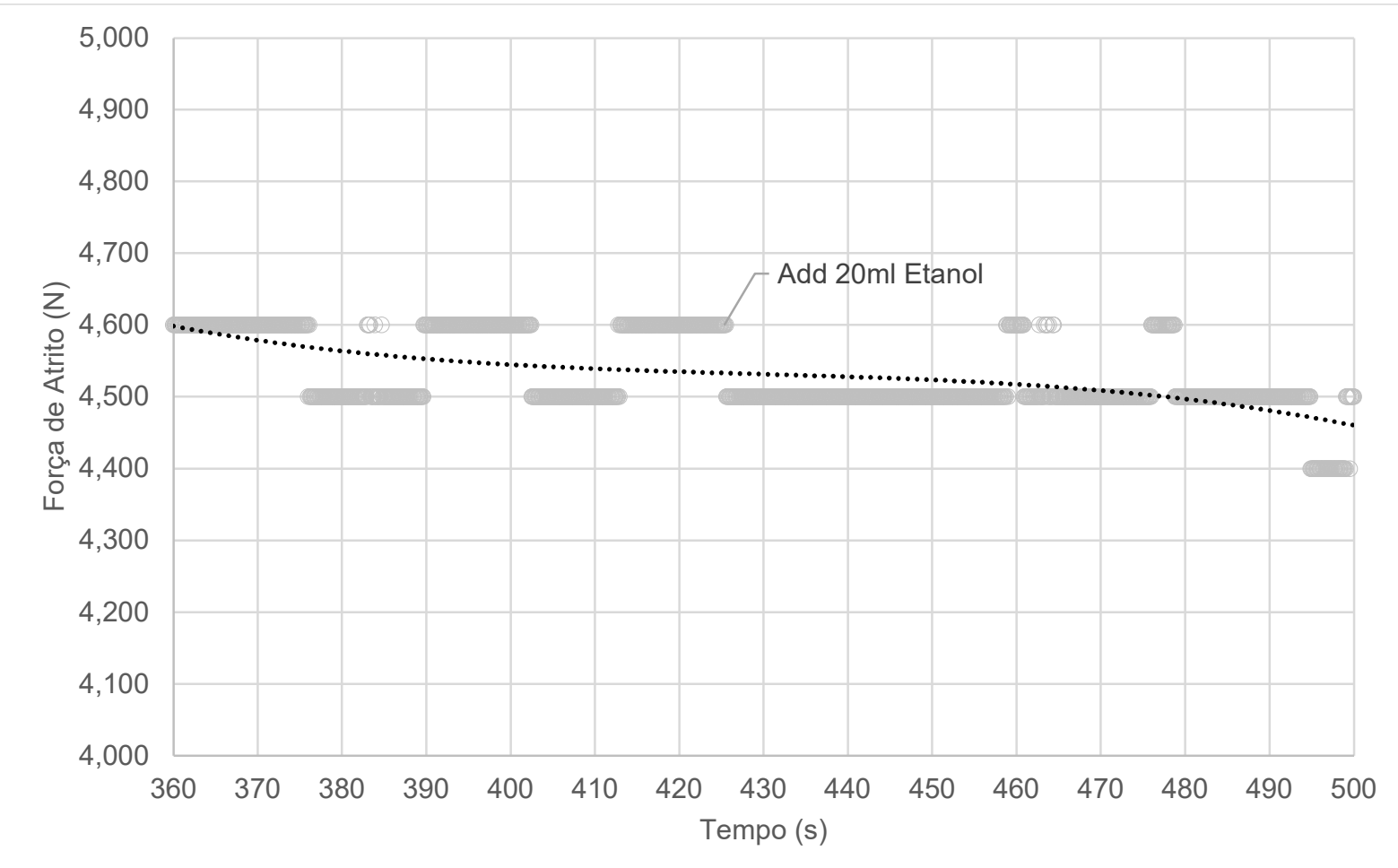

O autor

Figura 54 - Coeficientes de Atrito, Disco H-DLC, com Adição de Etanol Hidratado (2)

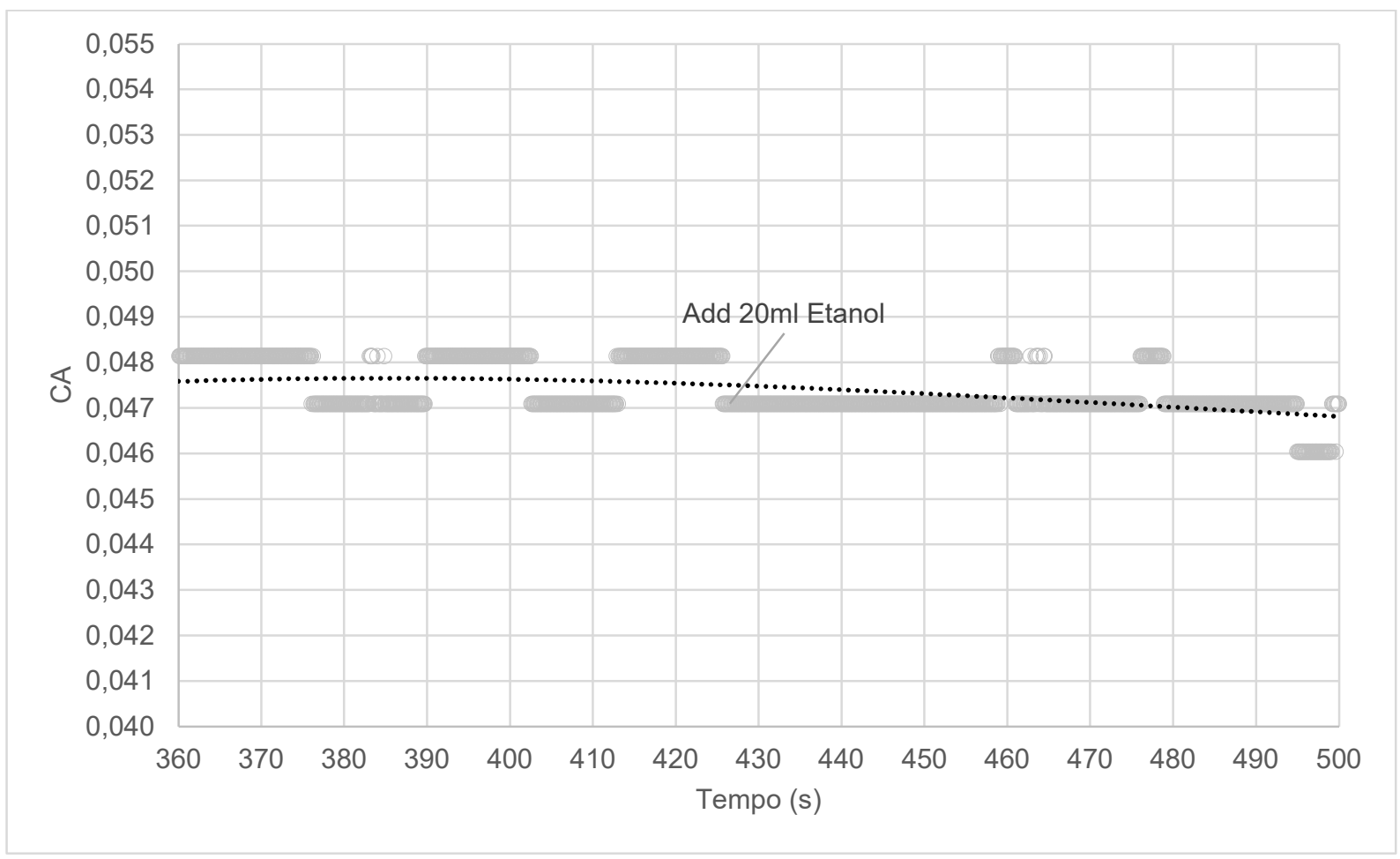

$\mathrm{O}$ autor 
O procedimento foi repetido, obtendo-se o mesmo comportamento.

Nota-se que os valores de coeficiente de atrito para disco H-DLC são, em média, 30 \% menores do que os valores obtidos com disco normal, para antes das adições de etanol. Entretanto, é curioso notar que não houve variação considerável de coeficiente de atrito, com a adição de etanol hidratado, no caso H-DLC.

Costa e Spikes realizaram experimentos esfera-disco entre uma esfera de aço e um disco de aço, ambos feitos de aço AISI 52100, em condições lubrificadas e em velocidades abaixo dos $1 \mathrm{~mm} / \mathrm{s}$, combinando rolling e sliding [44]. O gráfico da Figura 55 exibe os resultados obtidos em ensaios a $40{ }^{\circ} \mathrm{C}$, com lubrificantes GI (óleo base grupo I, comumente utilizado no Brasil) e GI com $2 \%$ de etanol hidratado.

Figura 55 - Resultados de CAs para Ensaios Esfera-Disco de Costa e Spikes a $40{ }^{\circ} \mathrm{C}$

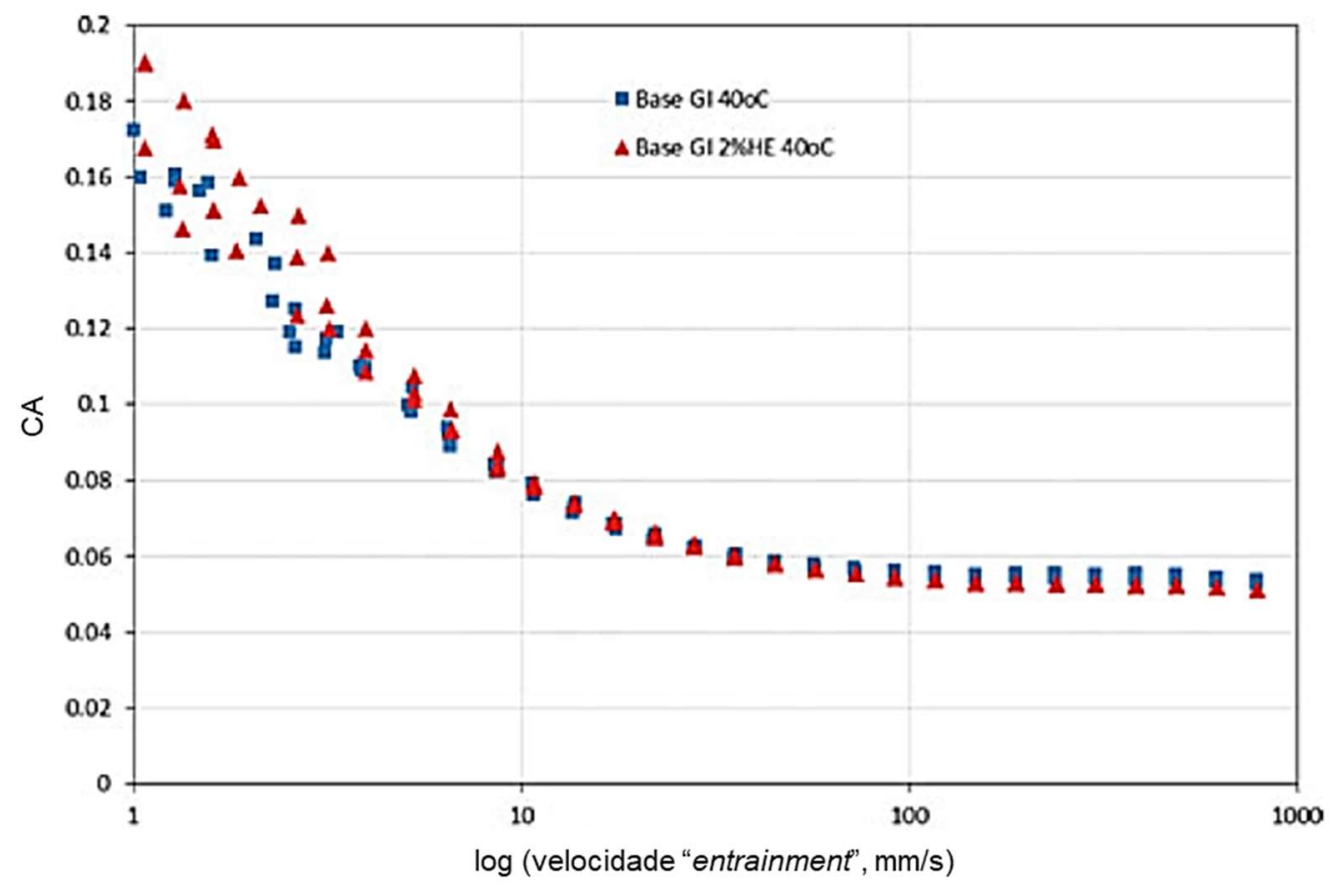

Extraído e adaptado de [44]

Pode-se notar que os coeficientes de atrito pouco variam em velocidades mais altas, sendo ligeiramente maiores para lubrificante não contendo etanol hidratado.

Segue uma tabela comparativa entre parâmetros dos ensaios pino-disco deste trabalho e parâmetros dos ensaios de Costa e Spikes. Tabela 7. 
Tabela 7 - Parâmetros Pino-Disco x Parâmetros Esfera-Disco

\begin{tabular}{|c|c|c|}
\hline Parâmetro & Ensaio Pino-Disco & Ensaio Esfera-Disco \\
\hline Tipo de Contato & Linha & Circular \\
\hline Pressão de Contato (Hertz) & $0,10 \mathrm{GPa}$ & $0,82 \mathrm{GPa}$ \\
\hline Velocidade de Sliding & $1 \mathrm{~m} / \mathrm{s}$ & Até $1 \mathrm{~mm} / \mathrm{s}$ \\
\hline Temperatura & $50 \pm 1^{\circ} \mathrm{C}$ & $20,0 \mathrm{~N}$ \\
\hline Carregamento & $95,6 \mathrm{~N}$ & Aço AISI 52100 \\
\hline Materiais em Contato & Ferro fundido modular & \\
& temperado e aço liga & $16 \mathrm{CnCr} 5$ \\
& SAE5W30 comercial, & Óleo Base Grupo I, novo \\
& envelhecido & \\
\hline Lubrificante & &
\end{tabular}

A despeito das grandes diferenças, em termos de tipo de contato, velocidade de sliding, carregamento e tipo de lubrificante, entre os ensaios de Costa e Spikes e os ensaios pino-disco deste trabalho, observa-se grande semelhança entre os coeficientes de atrito obtidos. Os menores coeficientes de atrito obtidos por Costa e Spikes comparam-se com os resultados experimentais exibidos na Figura 55 e encontram-se próximos de 0,06.

\subsection{Resultados dos Ensaios Monocame com Etanol Hidratado}

Os ensaios descritos na seção 4.4.2, utilizando lubrificante envelhecido SAE 5W30, para tuchos normais de produção e para tuchos revestidos e com H-DLC, com diferentes adições de etanol, revelaram valores de ddp, conforme mostra a Figura 56. 
Figura 56 - Dados de ddp para Tuchos Normais e H-DLC, ao Longo do Tempo de Experimentação Lubrificante Envelhecido

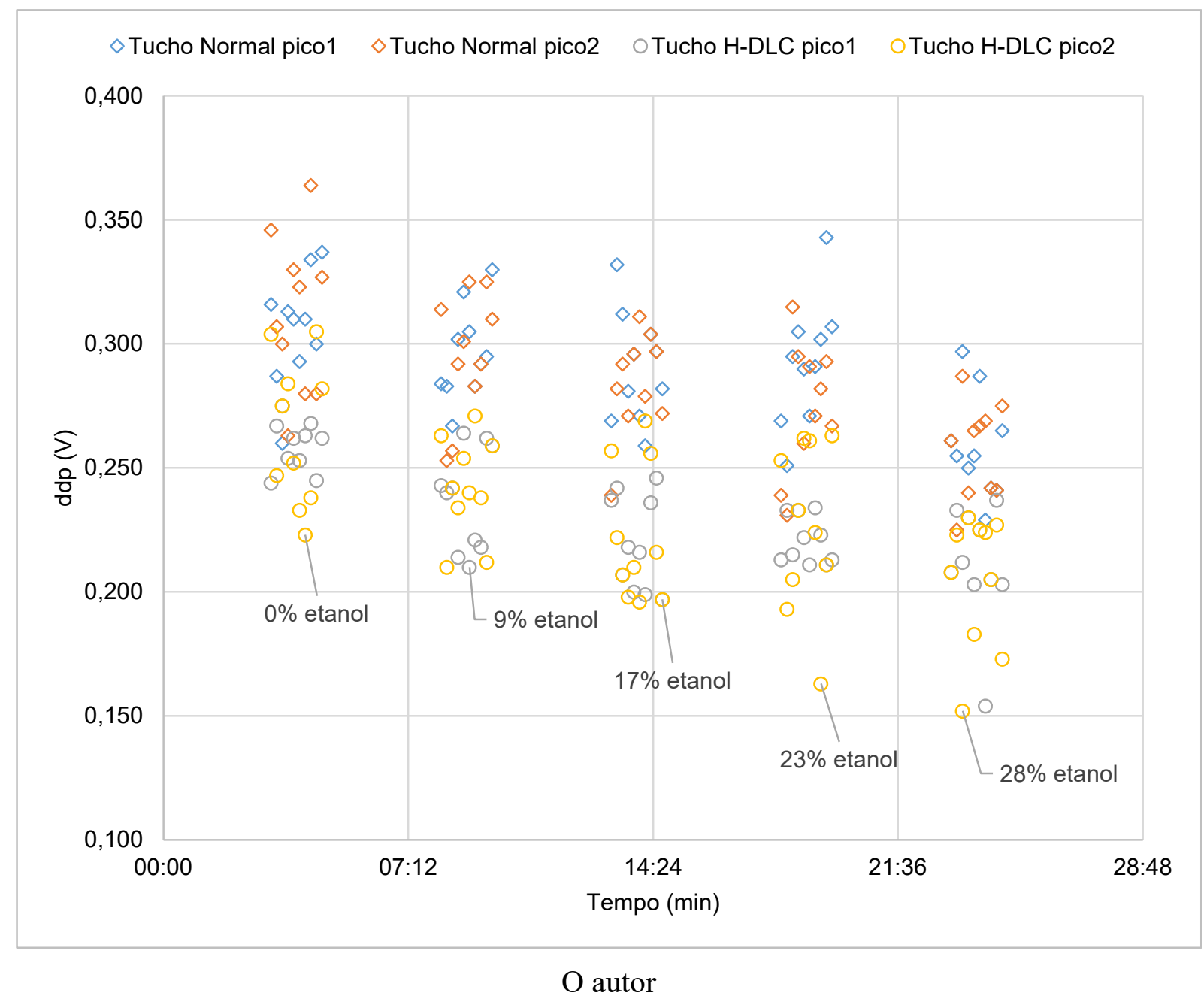

Correspondentemente, as forças de atrito médias entre came e tucho, para diferentes teores de etanol hidratado, e com considerações de barras de erros, são exibidas na Figura 57.

Por fim, considerando-se a força normal de $320 \mathrm{kgf}$, presente no contato nariz de came e tucho, a zero grau de came (Figura 45), calcula-se o coeficiente de atrito entre came e tucho. Figura 58. 
Figura 57 - Dados de Força de Atrito para Tuchos Normais e H-DLC para Diferentes Teores de Etanol - Lubrificante Envelhecido

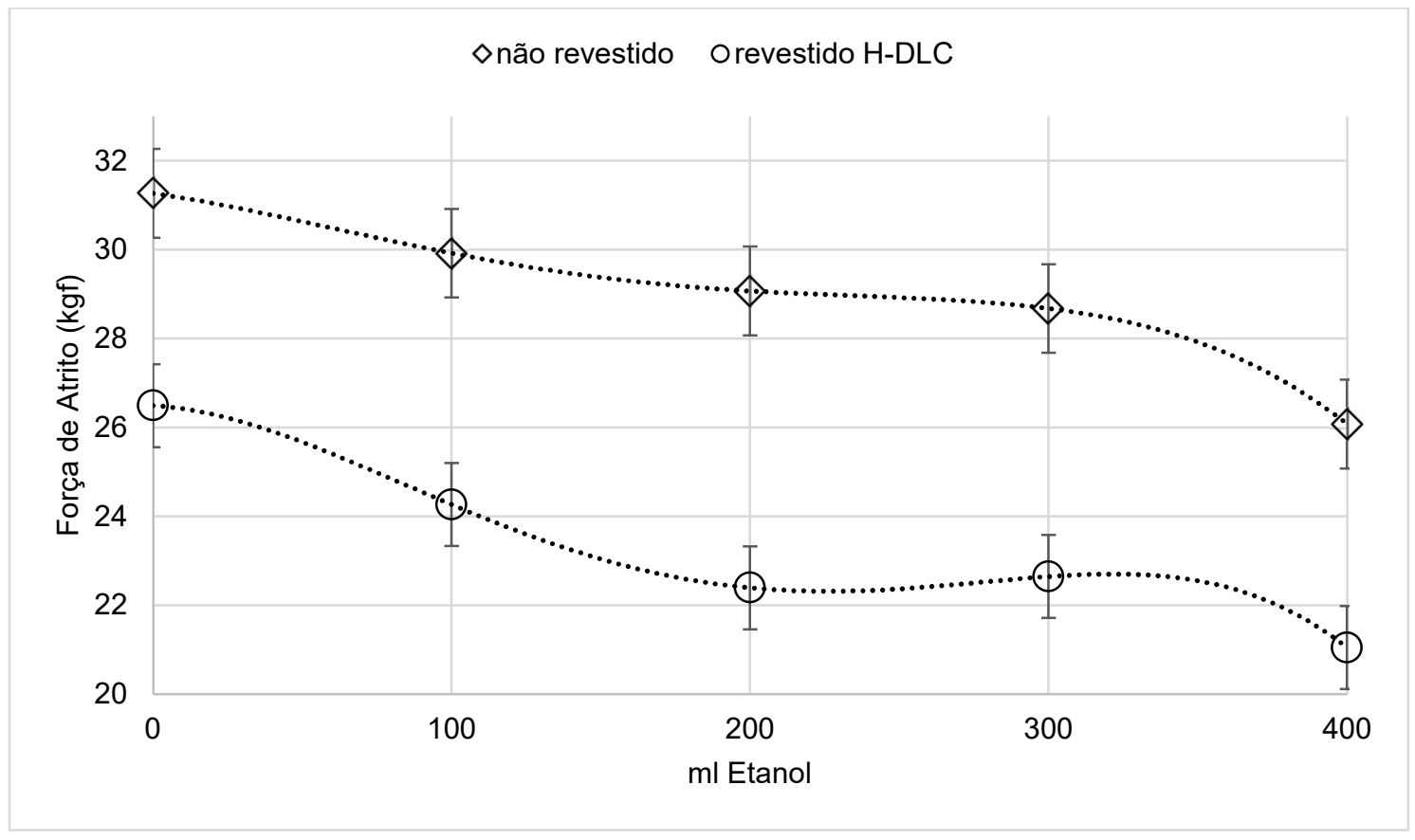

O autor

Figura 58 - Dados de CA para Tuchos Normais e H-DLC para Diferentes Teores de Etanol Lubrificante Envelhecido

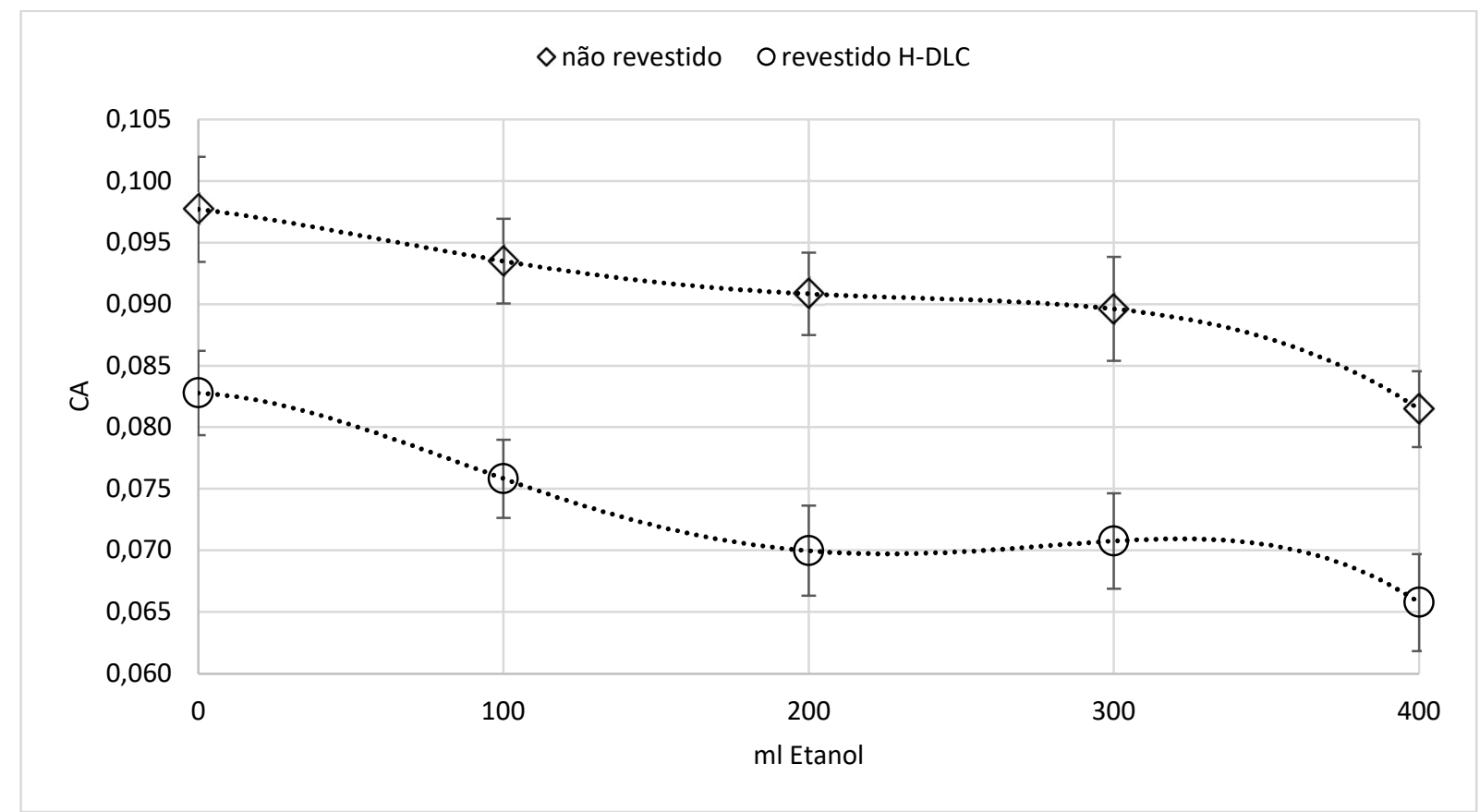

O autor

Os teores de etanol correspondem aos teores apresentados na Figura 56. 
É interessante notar que, ao passo que as adições de etanol hidratado aumentam as forças de atrito nos ensaios pino-disco, para disco normal de produção, tais forças diminuem no ensaio monocame. Algumas interpretações podem ser feitas, em relação a estes fenômenos. O trabalho que segue trata destas interpretações e lança um modelo semi-empírico que é capaz de descrever, simultaneamente, tais resultados.

\subsection{Viscosidades com Etanol Hidratado}

O modelo EH implementado possui, dentre os parâmetros de entrada, a viscosidade do lubrificante (condições normais de temperatura de pressão), para que se possa avaliar as piezoviscosidades de Roelands, dadas pela Equação 7. No caso das adições de etanol hidratado, observou-se, experimentalmente (item 4.4.3), que tais adições afetam a viscosidade da mistura, em função do teor de etanol hidratado inserido.

A Figura 59 exibe estas viscosidades para uma temperatura de $40{ }^{\circ} \mathrm{C}$.

Figura 59 - Viscosidades Dinâmicas das Misturas Etanol Hidratado x Lubrificante 5W30 Envelhecido para $40{ }^{\circ} \mathrm{C}$

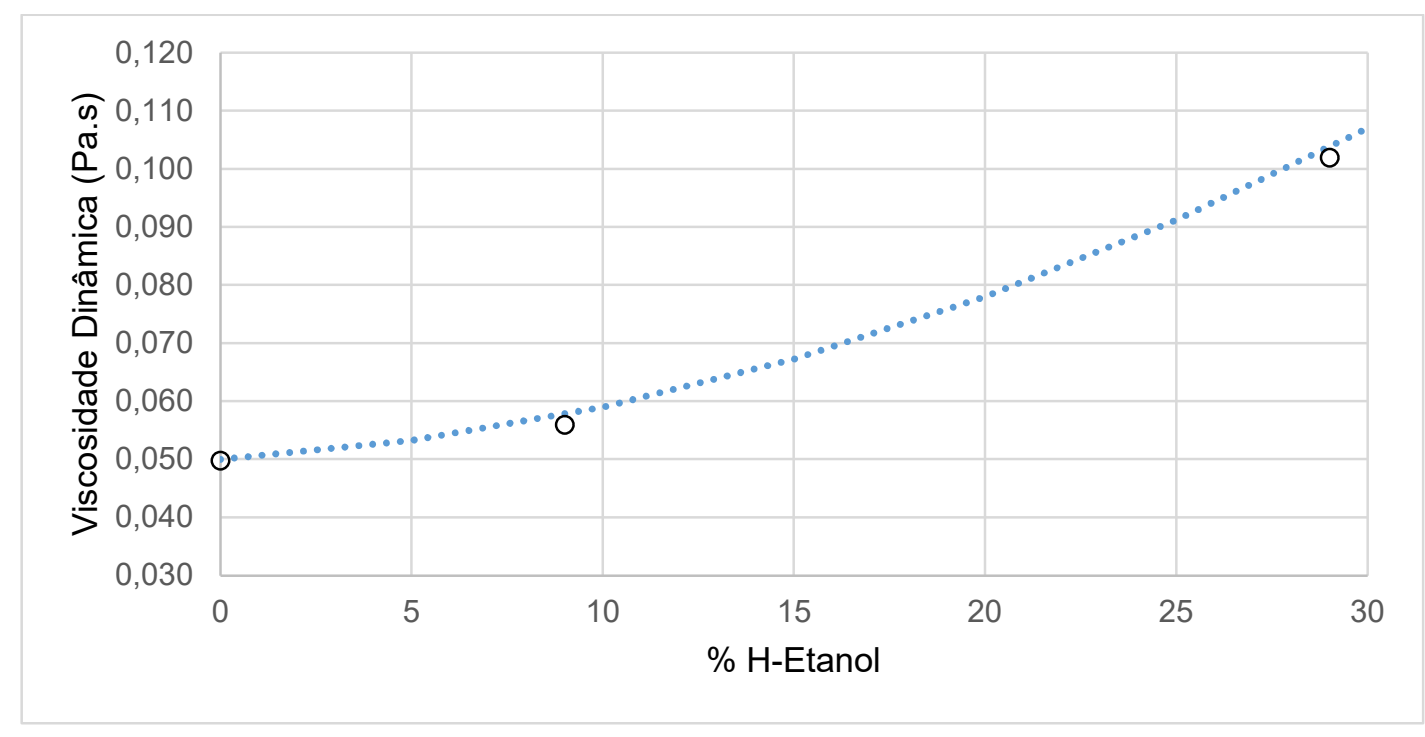

$\mathrm{O}$ autor

A Figura 60 exibe estas viscosidades para uma temperatura de $50^{\circ} \mathrm{C}$. 
Figura 60 - Viscosidades Dinâmicas das Misturas Etanol Hidratado x Lubrificante para $50{ }^{\circ} \mathrm{C}$

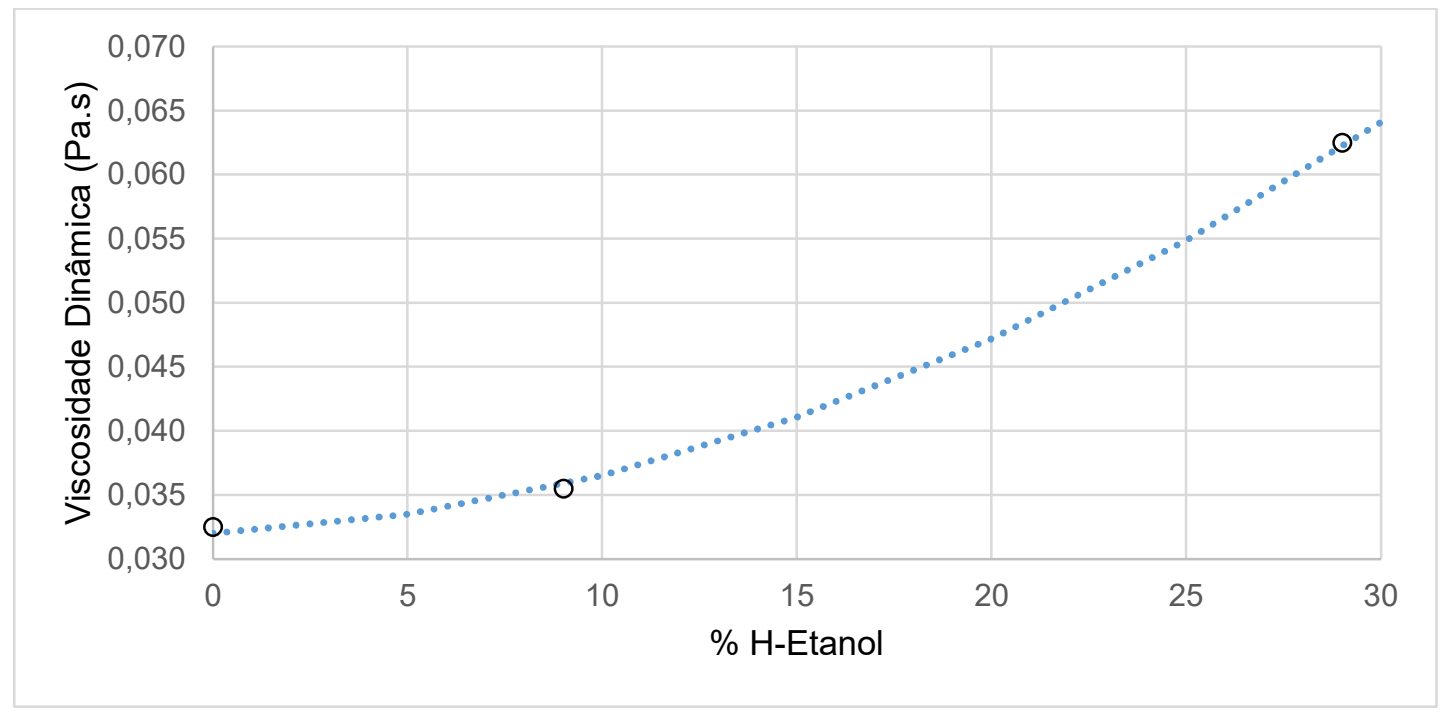

O autor

Pode-se observar que:

1 - As viscosidades diminuem com o aumento da temperatura, como observado, de forma semelhante, por Carvalho e colaboradores [11];

2 - As viscosidades aumentam com as adições de etanol hidratado, o que não era esperado, pelo fato de que experimentos com misturas de etanol hidratado realizados por Wrage e Goering [45], indicaram que a adição de etanol hidratado ao diesel reduz a viscosidade da mistura, como exibido na Figura 61.

Figura 61 - Wrage e Goering Viscosidades Cinemáticas com Adição de Etanol

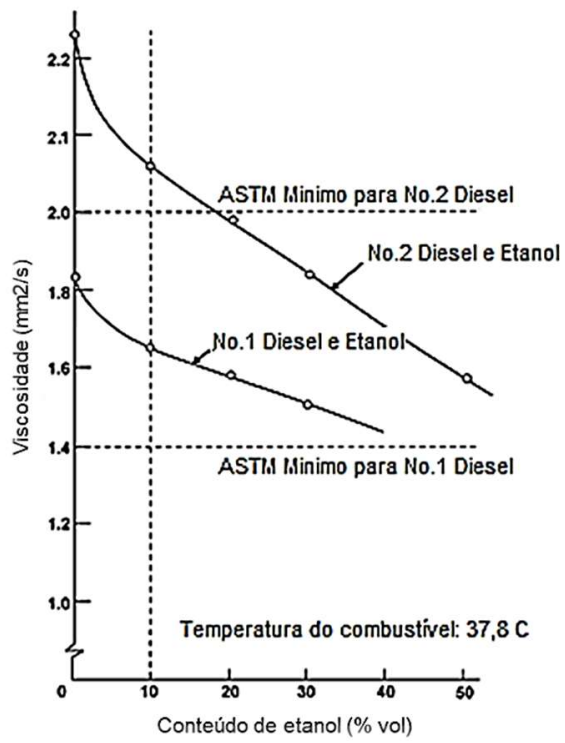

Extraído e adaptado de [45] 
Há muito pouco material literário sobre as viscosidades de misturas etanol-lubrificante.

Ensaios realizados por Costa e Spikes [44] revelaram diminuição das viscosidades de misturas de óleo base e etanol hidratado, embora tenha sido utilizado óleo base puro, novo, ao passo que os ensaios realizados neste trabalho indicaram crescimento das viscosidade, com as adições de etanol hidratado (resultados exibidos nas Figuras 59 e 60), utilizando-se lubrificante comercial, plenamente formulado e envelhecido em motor de combustão interna.

\subsection{Resultados do Modelo EHL}

O modelo EHL, apresentado no item 2.5, entrega como soluções as espessuras de filme lubrificante mínima e média, assim como demais parâmetros de verificação de validade de aplicação do modelo.

A seguir, apresentam-se dados de entrada, dados intermediários e dados de saída para as condições de ensaio em pino-disco e para as condições de ensaio em monocame.

Os dados de entrada consistem em valores de dimensões geométricas, forças aplicadas, rugosidades, propriedades de materiais etc. como pode ser verificado pela Tabela 8 .

Tanto para o caso pino-disco, quanto para o caso monocame, as viscosidades dinâmicas advêm dos ensaios reológicos realizados na UFTPr (item 4.4.3), o índice de piezoviscosidade foi referenciado pelo valor para “óleo mineral”, Hoglund, Figura 23 [31], e as durezas Vickers são informação de fabricante.

Os dados intermediários consistem em velocidades calculadas, parâmetros combinados, etc...

Os dados de saída consistem em resultados numéricos de espessuras de filmes lubrificantes (Equação 9) e parâmetros de avaliação de aplicação do modelo (Equação 1), ou seja, refletem os resultados das equações EHL, advindas das soluções da Equação de Reynolds modificada por Patir \& Cheng.

As tabelas 8, 9, 10 e 11 apresentam dados para os Ensaios Pino-disco com Adição de Etanol: 
Tabela 8 - Dados Entrada, Modelo EHL Pino-Disco

\begin{tabular}{|c|c|}
\hline \multicolumn{2}{|c|}{ DADOS ENTRADA } \\
\hline Raio de nariz de PIN came instantâneo Rc(m) & $3,20 \mathrm{E}-02$ \\
\hline Largura de PIN Came L(m) & $6,00 \mathrm{E}-03$ \\
\hline Raio de coroa de tucho Rct(m) >> DISK & $2,00 \mathrm{E}+03$ \\
\hline Força normal máxima de contato P(N) & $9,56 \mathrm{E}+01$ \\
\hline Rugosidade PIN Rq(m) & $9,75 \mathrm{E}-08$ \\
\hline Rugosidade DISK normal usado Rq(m) & $9,65 \mathrm{E}-08$ \\
\hline Rugosidade DISK DLC novo (like tappet) Rq(m) & $1,47 \mathrm{E}-08$ \\
\hline Módulo de elasticidade PIN came (Pa) & $1,55 \mathrm{E}+11$ \\
\hline Módulo de elasticidade DISK (Pa) & $2,05 \mathrm{E}+11$ \\
\hline Coeficiente de Poisson PIN came (FE50007) & $2,80 \mathrm{E}-01$ \\
\hline Coeficiente de Poisson DISK & $3,00 \mathrm{E}-01$ \\
\hline Dureza Vickers PIN Came FF Cr Mn1,1\%max (FE50007) (Pa) & $2,35 \mathrm{E}+09$ \\
\hline Dureza Vickers DISK 16MnCr5 Carbonitretado Temperaro (Pa) & $1,67 \mathrm{E}+09$ \\
\hline Coeficiente de viscosidade dinâmica óleo 50DegC (Pa.s) & $3,25 \mathrm{E}-02$ \\
\hline Coeficiente de viscosidade dinâmica óleo+Et 5,4\% 50DegC (Pa.s) & $3,37 \mathrm{E}-02$ \\
\hline Coeficiente de viscosidade dinâmica óleo+Et 29\% 50DegC (Pa.s) & $6,25 \mathrm{E}-02$ \\
\hline Indice de piezoviscosidade óleo $\alpha(\mathrm{Pa}-1)$ & $2,20 \mathrm{E}-08$ \\
\hline Indice de piezoviscosidade óleo $\alpha(\mathrm{GPa}-1)$ & 22,0 \\
\hline
\end{tabular}


Tabela 9 - Dados Intermediários, Modelo EHL Pino-Disco

\begin{tabular}{|c|c|}
\hline \multicolumn{2}{|l|}{ DADOS INTERMEDIÁRIOS } \\
\hline Velocidade efetiva PIN DISK normal $\mathrm{u}(\mathrm{m} / \mathrm{s})$ & $1,00 \mathrm{E}+00$ \\
\hline Velocidade efetiva PIN DISK DLC $\mathrm{u}(\mathrm{m} / \mathrm{s})$ & $1,00 \mathrm{E}+00$ \\
\hline Raio combinado R'(m) & $3,20 \mathrm{E}-02$ \\
\hline PIN DISK normal rugosidade combinada $\mathrm{Rq}(\mathrm{m})$ & $1,37 \mathrm{E}-07$ \\
\hline PIN DISK DLC rugosidade combinada $\mathrm{Rq}(\mathrm{m})$ & $9,86 \mathrm{E}-08$ \\
\hline Módulo de Elasticidade Combinado E'(Pa) & $1,93 \mathrm{E}+11$ \\
\hline Menor dureza Vickers hd(Pa) & $1,67 \mathrm{E}+09$ \\
\hline Carregamento Adimensional W & $2,59 \mathrm{E}-06$ \\
\hline Velocidade Adimensional U 0ml etanol & $5,27 \mathrm{E}-12$ \\
\hline Velocidade Adimensional U 5,4ml etanol & $5,46 \mathrm{E}-12$ \\
\hline Material Adimensional G & $4,24 \mathrm{E}+03$ \\
\hline Dureza Adimensional V & $8,65 \mathrm{E}-03$ \\
\hline Rugosidade combinada adimensional normal $\sigma^{\prime}$ & 4,29E-06 \\
\hline Rugosidade combinada adimensional tucho DLC $\sigma^{\prime}$ & $3,08 \mathrm{E}-06$ \\
\hline Área de contato de Hertz (m2) & $9,85 \mathrm{E}-07$ \\
\hline Pressão de contato Hertz (Gpa) & $9,70 \mathrm{E}-02$ \\
\hline Visc. Dinamica Roelands 0\% Etanol $\mu($ Pa.s $)$ & $1,67 \mathrm{E}+01$ \\
\hline Visc. Dinamica Roelands 5,4\% Etanol $\mu$ (Pa.s) & $1,79 \mathrm{E}+01$ \\
\hline
\end{tabular}

Tabela 10 - Dados Saída, Modelo EHL Pino-Disco Usinado

\begin{tabular}{|c|c|c|c|c|}
\hline \multicolumn{3}{|c|}{ DADOS SAÍDA - DISCO USINADO } \\
\hline $\begin{array}{c}\mathrm{ml} \\
\text { Etanol }\end{array}$ & $\begin{array}{c}\% \\
\text { Etanol }\end{array}$ & $\begin{array}{c}\text { Esp. de filme } \\
\text { central hc(m) }\end{array}$ & $\begin{array}{c}\text { Esp. de filme } \\
\text { mínimo } \\
\text { hmin(m) }\end{array}$ & $\begin{array}{c}\text { Parâmetro de filme } \\
(\mathrm{hmin} / \mathrm{Ra}>0,5)\end{array}$ \\
\hline 0 & $0,0 \%$ & $6,19 \mathrm{E}-07$ & $4,85 \mathrm{E}-07$ & 3,5 \\
\hline 20 & $5,4 \%$ & $6,33 \mathrm{E}-07$ & $4,95 \mathrm{E}-07$ & 3,6 \\
\hline 143 & $29 \%$ & $9,51 \mathrm{E}-07$ & $7,17 \mathrm{E}-07$ & 5,2 \\
\hline
\end{tabular}


Tabela 11 - Dados Saída, Modelo EH Pino-Disco DLC

\begin{tabular}{|c|c|c|c|c|}
\hline \multicolumn{3}{|c|}{ DADOS SAÍDA - DISCO DLC } \\
\hline $\begin{array}{c}\mathrm{ml} \\
\text { Etanol }\end{array}$ & $\begin{array}{c}\% \\
\text { Etanol }\end{array}$ & $\begin{array}{c}\text { Esp. de filme } \\
\text { central hc(m) }\end{array}$ & $\begin{array}{c}\text { Esp. de filme } \\
\text { mínimo } \\
\text { hmin(m) }\end{array}$ & $\begin{array}{c}\text { Parâmetro de filme } \\
(\mathrm{hmin} / \mathrm{Ra}>0,5)\end{array}$ \\
\hline 0 & $0,0 \%$ & $6,02 \mathrm{E}-07$ & $4,58 \mathrm{E}-07$ & 4,6 \\
\hline 20 & $5,4 \%$ & $6,16 \mathrm{E}-07$ & $4,68 \mathrm{E}-07$ & 4,7 \\
\hline 143 & $29 \%$ & $9,51 \mathrm{E}-07$ & $7,17 \mathrm{E}-07$ & 7,0 \\
\hline
\end{tabular}

O gráfico da Figura 62 exibe a variação calculada da piezo-viscosidade do lubrificante com a adição de etanol hidratado, nas condições experimentais pino-disco.

Figura 62 - Variação da Piezo-Viscosidade com a Adição de Etanol Hidratado

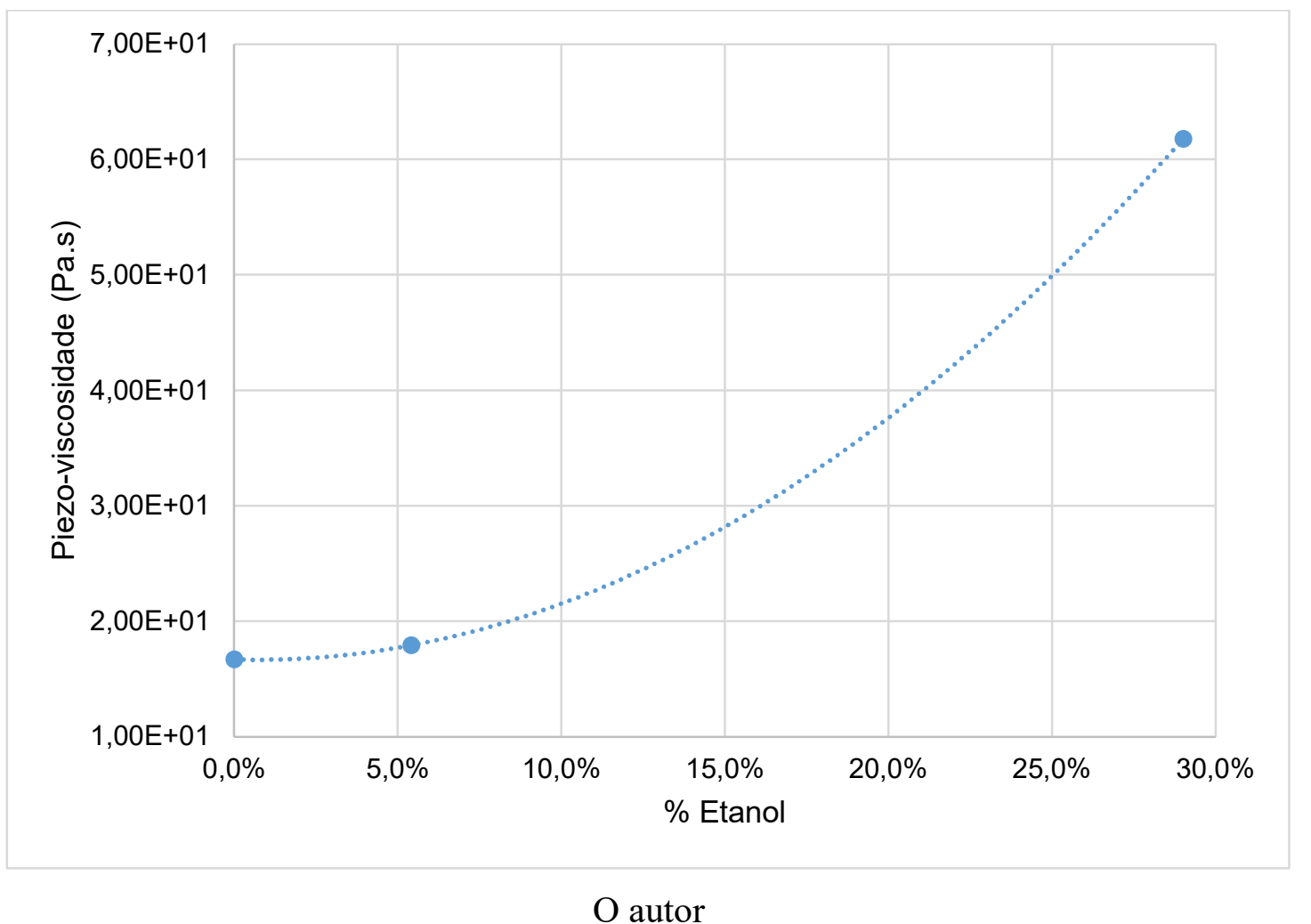

O gráfico da Figura 63 exibe as variações calculadas das espessuras de filme central para adições de etanol hidratado, em ambos os casos, disco normal e disco H-DLC, nas condições experimentais pino-disco. 
Figura 63 - Variação das Espessuras de Filme Central para Adições de Etanol Hidratado

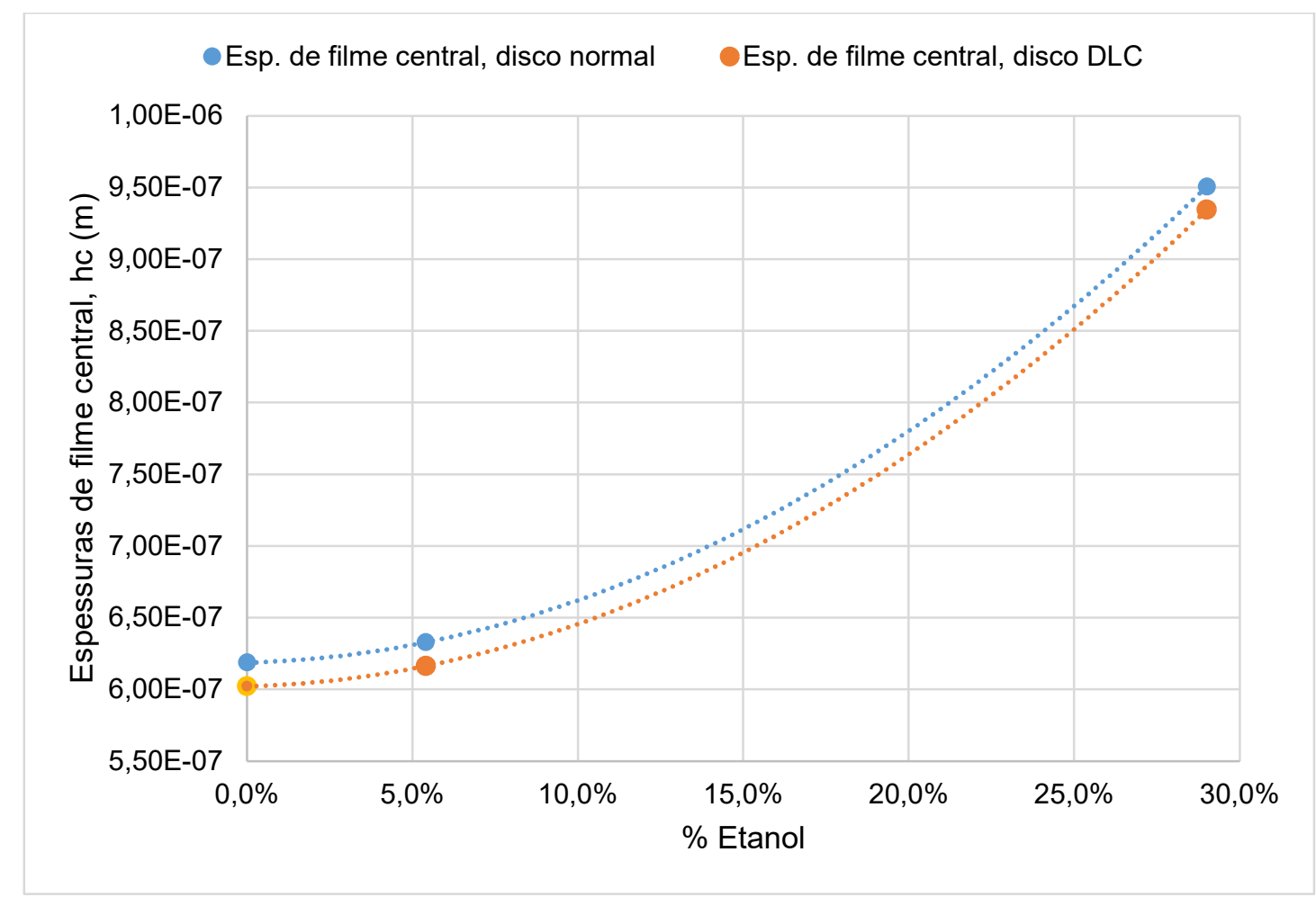

O autor

Observa-se que as espessuras de filme central são ligeiramente diferentes, para o caso “disco normal” e para o caso "disco H-DLC”, porém, ambas são crescentes com as adições de etano hidratado.

Também se observa que os parâmetros de filme são atendidos, em ambos os casos, para qualquer teor de etanol hidratado.

As tabelas 12,13, 14 e 15 apresentam dados para os ensaios monocame, com adição de etanol: 
Tabela 12 - Dados Entrada, Modelo EHL Monocame

\begin{tabular}{|c|c|}
\hline \multicolumn{2}{|l|}{ DADOS ENTRADA } \\
\hline Raio de nariz de came instantâneo $\mathrm{Rc}(\mathrm{m})$ & $2,00 \mathrm{E}-02$ \\
\hline Raio maior do came $\mathrm{Rm}(\mathrm{m})$ & $2,68 \mathrm{E}-02$ \\
\hline Largura de Came L(m) & $1,00 \mathrm{E}-02$ \\
\hline Raio de tucho Rt(m) & $1,35 \mathrm{E}-02$ \\
\hline Excentricidade came contato e $(\mathrm{m})$ & $3,00 \mathrm{E}-03$ \\
\hline Raio de coroa de tucho $\operatorname{Rct}(\mathrm{m})$ & $1,60 \mathrm{E}+00$ \\
\hline Força normal máxima de contato $\mathrm{P}(\mathrm{N})$ & $3,14 \mathrm{E}+03$ \\
\hline RPM do came (RPM) & $1,10 \mathrm{E}+03$ \\
\hline Fator de Dyson & $1,10 \mathrm{E}+01$ \\
\hline Rugosidade came usado $\mathrm{Rq}(\mathrm{m})$ & $2,58 \mathrm{E}-08$ \\
\hline Rugosidade tucho normal usado $\mathrm{Rq}(\mathrm{m})$ & 1,52E-07 \\
\hline Rugosidade tucho DLC usado Rq(m) & $1,47 \mathrm{E}-08$ \\
\hline Módulo de elasticidade came (Pa) & $1,55 \mathrm{E}+11$ \\
\hline Módulo de elasticidade tucho $(\mathrm{Pa})$ & $2,05 \mathrm{E}+11$ \\
\hline Coeficiente de Poisson came (FE50007) & $2,80 \mathrm{E}-01$ \\
\hline Coeficiente de Poisson tucho & $3,00 \mathrm{E}-01$ \\
\hline Dureza Vickers Came FF Cr Mn1,1\%max (FE50007) (Pa) & $2,35 \mathrm{E}+09$ \\
\hline Dureza Vickers Tucho 16MnCr5 Carbonitretado Temperaro $(\mathrm{Pa})$ & $1,67 \mathrm{E}+09$ \\
\hline Indice de piezoviscosidade $\alpha(\mathrm{Pa}-1)$ & $2,20 \mathrm{E}-08$ \\
\hline Viscosidade dinâmica lub. 40DegC (Pa.s) & $5,00 \mathrm{E}-02$ \\
\hline Viscosidade dinâmica lub.+Et 9\% 40DegC (Pa.s) & $5,77 \mathrm{E}-02$ \\
\hline Viscosidade dinâmica lub.+Et 17\% 40DegC (Pa.s) & 7,13E-02 \\
\hline Viscosidade dinâmica lub.+Et 23\% 40DegC (Pa.s) & $8,57 \mathrm{E}-02$ \\
\hline Viscosidade dinâmica lub.+Et 29\% 40DegC (Pa.s) & 1,04E-01 \\
\hline
\end{tabular}


Tabela 13 - Dados Intermediários, Modelo EHL Monocame

\begin{tabular}{|c|c|}
\hline \multicolumn{2}{|l|}{ DADOS INTERMEDIÁRIOS } \\
\hline Velocidade do nariz do came referência estática vc(m/s) & $3,09 \mathrm{E}-00$ \\
\hline Velocidade tucho no raio de contato came-tucho $\mathrm{vr}(\mathrm{m} / \mathrm{s})$ & $2,81 \mathrm{E}-01$ \\
\hline Velocidade de rolamento came-tucho normal $\mathrm{u}(\mathrm{m} / \mathrm{s})$ & $1,69 \mathrm{E}+00$ \\
\hline Velocidade de rolamento came-tucho DLC $\mathrm{u}(\mathrm{m} / \mathrm{s})$ & $1,91 \mathrm{E}+00$ \\
\hline Velocidade relativa came-tucho normal $\mathrm{u}(\mathrm{m} / \mathrm{s})$ & $2,81 \mathrm{E}+00$ \\
\hline Velocidade relativa came-tucho DLC $\mathrm{u}(\mathrm{m} / \mathrm{s})$ & $2,36 \mathrm{E}+00$ \\
\hline Raio combinado $\mathrm{R}^{\prime}(\mathrm{m})$ & $1,98 \mathrm{E}-02$ \\
\hline Tucho/came normal rugosidade combinada $\mathrm{Rq}(\mathrm{m})$ & $1,54 \mathrm{E}-07$ \\
\hline Tucho/came DLC rugosidade combinada $\mathrm{Rq}(\mathrm{m})$ & $2,96 \mathrm{E}-08$ \\
\hline Módulo de Elasticidade Combinado E'(Pa) & $1,93 \mathrm{E}+11$ \\
\hline Menor dureza Vickers hd(Pa) & $1,67 \mathrm{E}+09$ \\
\hline Carregamento Adimensional W & $8,24 \mathrm{E}-05$ \\
\hline Velocidade Adimensional U 0\% Etanol & $2,22 \mathrm{E}-11$ \\
\hline Velocidade Adimensional U 9\% Etanol & $2,55 \mathrm{E}-11$ \\
\hline Velocidade Adimensional U 17\% Etanol & $3,16 \mathrm{E}-11$ \\
\hline Velocidade Adimensional U 23\% Etanol & $3,80 \mathrm{E}-11$ \\
\hline Velocidade Adimensional U 29\% Etanol & $4,59 \mathrm{E}-11$ \\
\hline Material Adimensional G & $4,24 \mathrm{E}+03$ \\
\hline Dureza Adimensional V & $8,65 \mathrm{E}-03$ \\
\hline Rugosidade combinada adimensional tucho normal $\sigma^{\prime}$ & 7,78E-06 \\
\hline Rugosidade combinada adimensional tucho DLC $\sigma^{\prime}$ & $1,50 \mathrm{E}-06$ \\
\hline Área de contato de Hertz (m2) & $5,72 \mathrm{E}-06$ \\
\hline Pressão de contato Hertz (Gpa) & $5,48 \mathrm{E}-01$ \\
\hline Visc. Dinamica combinada Roelands $0 \%$ Etanol $\mu(\mathrm{Pa} . \mathrm{s})$ & $3,95 \mathrm{E}+01$ \\
\hline Visc. Dinamica combinada Roelands 9\% Etanol $\mu(\mathrm{Pa} . \mathrm{s})$ & $5,26 \mathrm{E}+01$ \\
\hline Visc. Dinamica combinada Roelands $17 \%$ Etanol $\mu(\mathrm{Pa} . \mathrm{s})$ & $8,03 \mathrm{E}+01$ \\
\hline Visc. Dinamica combinada Roelands $23 \%$ Etanol $\mu(\mathrm{Pa} . \mathrm{s})$ & $1,16 \mathrm{E}+02$ \\
\hline Visc. Dinamica combinada Roelands $29 \%$ Etanol $\mu$ (Pa.s) & $1,70 \mathrm{E}+02$ \\
\hline
\end{tabular}


Tabela 14 - Dados Saída, Modelo EHL Monocame Tucho Normal

\begin{tabular}{|c|c|c|c|c|}
\hline \multicolumn{5}{|c|}{ DADOS SAÍDA - TUCHO NORMAL } \\
\hline $\begin{array}{c}\mathrm{ml} \\
\text { Etanol }\end{array}$ & $\begin{array}{c}\% \\
\text { Etanol }\end{array}$ & $\begin{array}{c}\text { Esp. de filme } \\
\text { central hc(m) }\end{array}$ & $\begin{array}{c}\text { Esp. de filme } \\
\text { mínimo hmin(m) }\end{array}$ & $\begin{array}{c}\text { Parâmetro de filme } \\
(\mathrm{hmin} / \mathrm{Rq}>0,5)\end{array}$ \\
\hline 0 & $0,0 \%$ & $6,22 \mathrm{E}-07$ & $5,49 \mathrm{E}-07$ & 3,6 \\
\hline 100 & $9,1 \%$ & $6,86 \mathrm{E}-07$ & $6,05 \mathrm{E}-07$ & 3,9 \\
\hline 200 & $16,7 \%$ & $7,94 \mathrm{E}-07$ & $7,00 \mathrm{E}-07$ & 4,6 \\
\hline 300 & $23,1 \%$ & $9,02 \mathrm{E}-07$ & $7,95 \mathrm{E}-07$ & 5,2 \\
\hline 400 & $28,6 \%$ & $1,03 \mathrm{E}-06$ & $9,08 \mathrm{E}-07$ & 5,9 \\
\hline
\end{tabular}

Tabela 15 - Dados Saída, Modelo EHL Monocame Tucho H-DLC

\begin{tabular}{|c|c|c|c|c|}
\hline \multicolumn{5}{|c|}{ DADOS SAÍDA - TUCHO DLC } \\
\hline $\begin{array}{c}\mathrm{ml} \\
\text { Etanol }\end{array}$ & $\begin{array}{c}\% \\
\text { Etanol }\end{array}$ & $\begin{array}{c}\text { Esp. de filme } \\
\text { central hc(m) }\end{array}$ & $\begin{array}{c}\text { Esp. de filme } \\
\text { mínimo Hmin(m) }\end{array}$ & $\begin{array}{c}\text { Parâmetro de filme } \\
(\mathrm{Hmin} / \mathrm{Ra}>0,5)\end{array}$ \\
\hline 0 & $0,0 \%$ & $6,08 \mathrm{E}-07$ & $5,29 \mathrm{E}-07$ & 17,8 \\
\hline 100 & $9,1 \%$ & $6,72 \mathrm{E}-07$ & $5,85 \mathrm{E}-07$ & 19,7 \\
\hline 200 & $16,7 \%$ & $7,79 \mathrm{E}-07$ & $6,80 \mathrm{E}-07$ & 23,0 \\
\hline 300 & $23,1 \%$ & $8,87 \mathrm{E}-07$ & $7,76 \mathrm{E}-07$ & 26,2 \\
\hline 400 & $28,6 \%$ & $1,01 \mathrm{E}-06$ & $8,89 \mathrm{E}-07$ & 30,0 \\
\hline
\end{tabular}

O gráfico da Figura 64 exibe a variação calculada da piezo-viscosidade do lubrificante com a adição de etanol hidratado, nas condições experimentais monocame. 
Figura 64 - Variação da Piezo-Viscosidade com a Adição de Etanol Hidratado

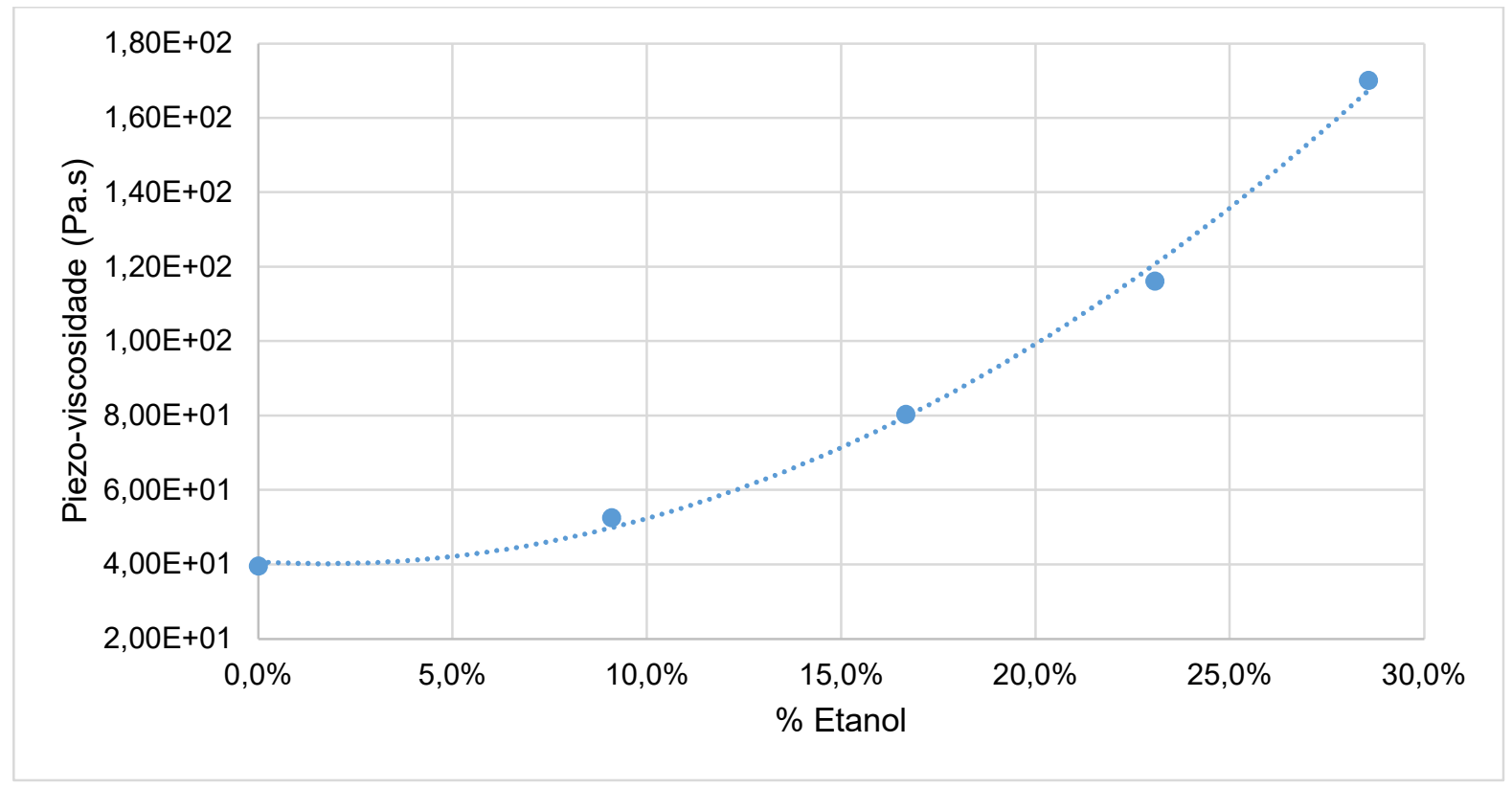

O autor

O gráfico da Figura 65 exibe as variações calculadas das espessuras de filme central, para adições de etanol hidratado, nas condições experimentais monocame.

Figura 65 - Variação da Espessura de Filme Central para Adição de Etanol Hidratado

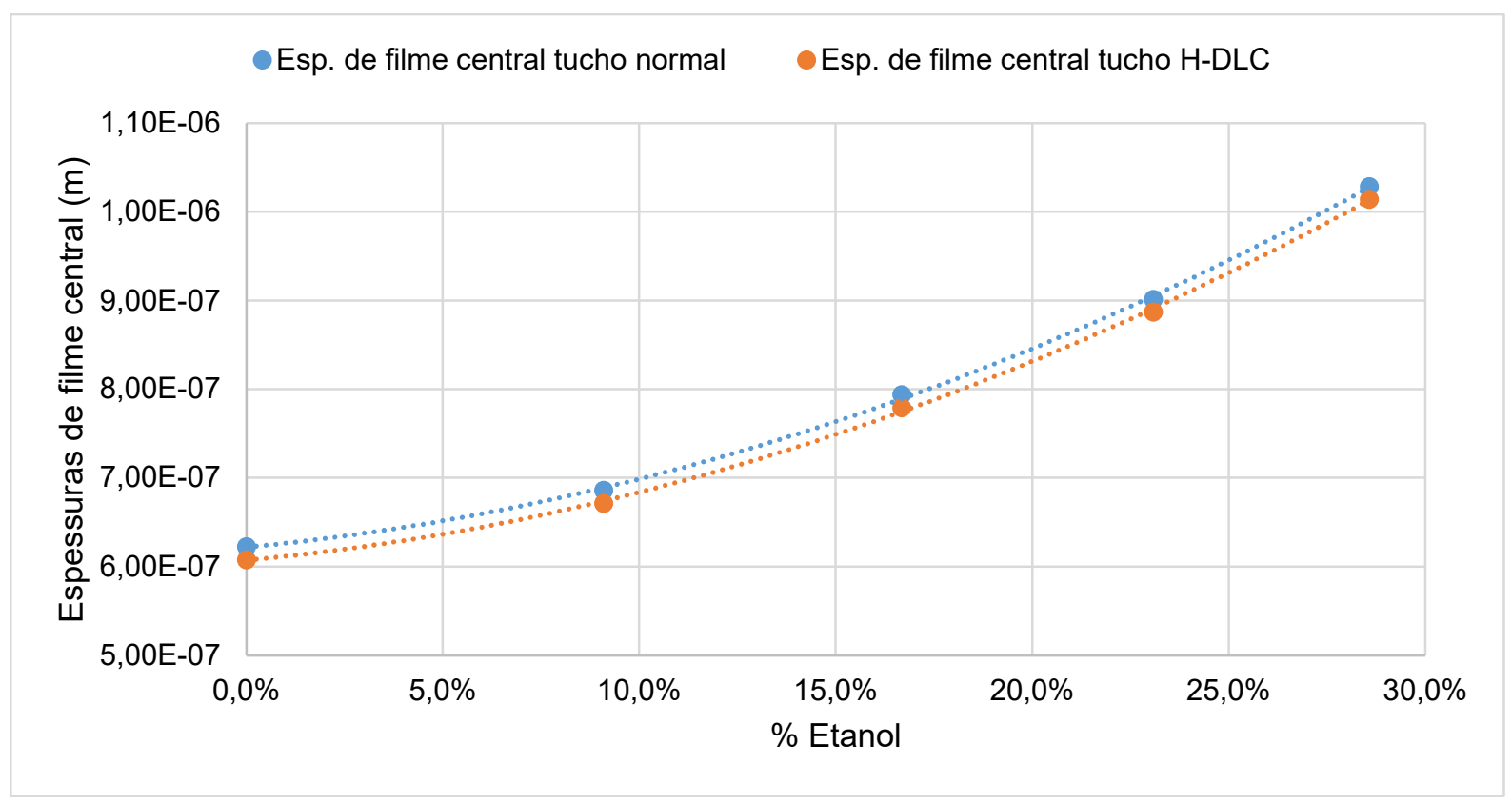

O autor 
É interessante notar que:

1 - As piezo-viscosidades são bem maiores no caso monocame, comparando-se com o caso pino-disco;

2 - Em ambos os casos, monocame e pino-disco, há forte crescimento das espessuras de filme central, com as adições de etanol hidratado;

5.5 Modelo Simplificado - Limitro-Elastohidrodinâmico, LEHL

Em geral, os modelos desenvolvidos para descrever as forças de atrito came-tucho são complexos, pois resolvem o problema mixed-TEHL completo (equação de Reynolds com Patir \& Cheng, flow factors + mecânica do contato, a partir da teoria de semi-espaço elástico + equação da energia para efeitos térmicos + Greenwood-Williamson, para contato rugoso). Adicionalmente, os efeitos não-Newtonianos do lubrificante devem ser considerados, devido às condições de altas pressões e cisalhamentos típicos de contatos concentrados, o que aumenta ainda mais o grau de complexidade dos modelos para as forças e coeficientes de atrito [46]. Em alguns casos, os efeitos dinâmicos dos sistemas são também incorporados aos modelos. Há de se atentar para o fato de que as deformações elásticas são amplamente consideradas nas regiões de contato came-tucho, mas, as deformações elásticas de corpos (tucho, came, guia, etc) são raramente exploradas.

Diante destas dificuldades encontradas nas abordagens teóricas presentes na literatura, propõe-se uma modelagem simples, de cunho semi-empírico, baseada na observação de dados experimentais de forças de atrito came-tucho e na análise crítica de regiões de desgastes em cames e tuchos utilizados em motores e/ou ensaios de bancada, com o mínimo uso de parâmetros para correlação, conforme descrito abaixo.

Os modelos de contato apresentados na literatura sempre baseiam-se em descrições de contatos uniformes, em linha ou elípticos, e os modelos, em geral, procuram descrever a fenomenologia de forma única, dado um ângulo de came e dado um conjunto de dados de esforços, geometrias, materiais e lubrificação envolvidos.

Pode-se observar, em tuchos de sistemas TMAD, oriundos de uso em motores, marcas típicas de desgaste, em formato de coroa. Gangopadhyay afirma que, para tuchos de sistema TMAD, em geral: "os tuchos normais de produção apresentam marcas circulares de desgaste, o que é típico" [16]. Estas marcas aparecem nos tuchos utilizados nos ensaios monocame deste trabalho. 
A Figura 66 exibe marcas de desgaste no tucho utilizado nos ensaios monomcame, cujos resultados foram apresentados neste trabalho.

Figura 66 - Marcas de Desgaste em Tuchos usados em Monocame. Em A: novo, normal usado e com H-DLC usado, da esquerda para a direita. Em B, normal usado em ampliação.

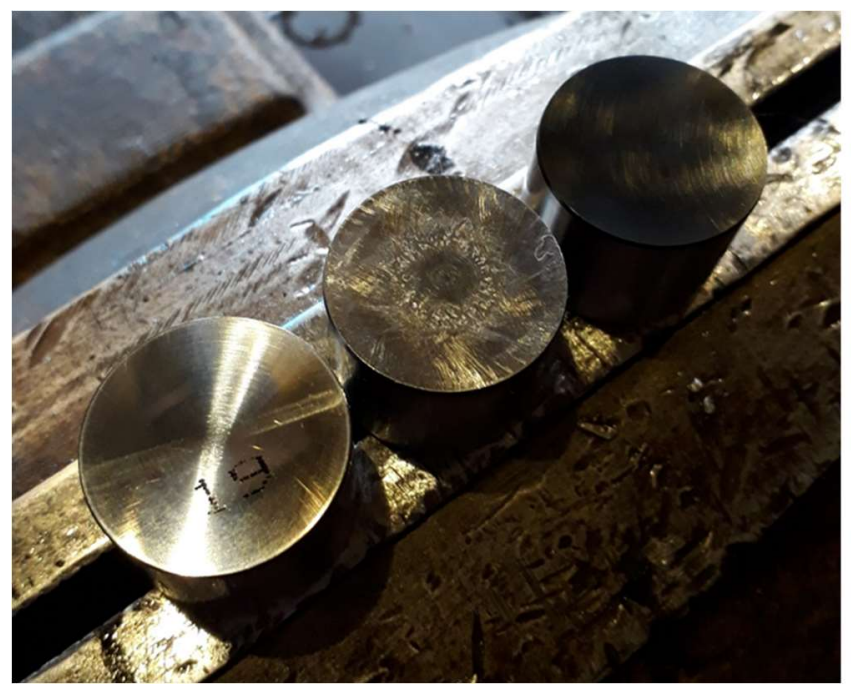

(A)

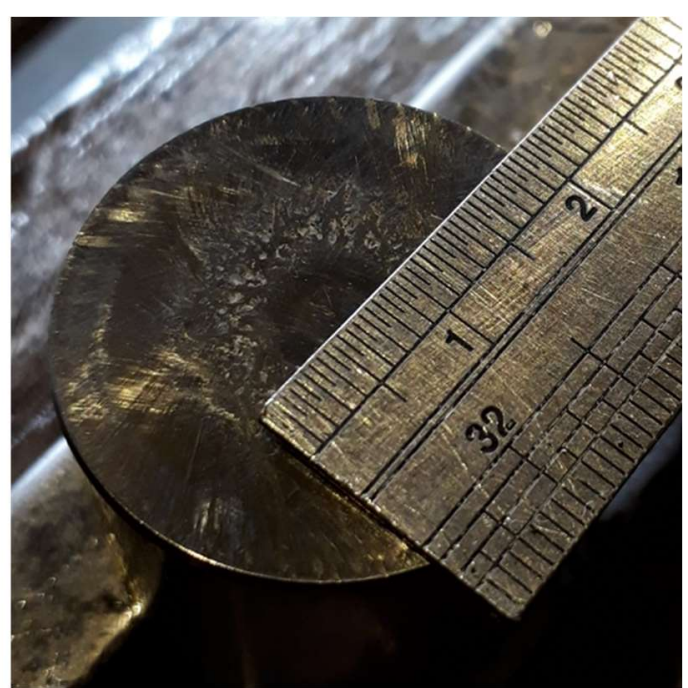

(B)

$\mathrm{O}$ autor

A Figura 66-A exibe três tuchos de mesmas especificações. O primeiro, novo, sem uso, o segundo, utilizado nos ensaios monocame com etanol hidratado, o terceiro, também utilizado nestes ensaios, revestido com camada H-DLC.

Na Figura 66-B, pode-se observar o tucho utilizado nos ensaios monocame, em detalhe. Observa-se uma marca de desgaste em forma de coroa, de largura de até cerca de $5 \mathrm{~mm}$ de largura.

Estas marcas circulares indicam que há contatos de caráter limítrofe ocorrendo entre came e tucho. O spin de tucho seria o responsável pela geometria circular. Embora existam referências na literatura, para a origem destas marcas, devido à velocidade de rolamento nula imediatamente após o início do contato e imediatamente antes do fim do contato came-tucho, presume-se, neste trabalho, que tais marcas tenham, adicionalmente, outra origem.

Lança-se a hipótese de que o tilting do tucho pode promover um contato do tipo EHL + limítrofe, especialmente no contato nariz de came - tucho. A Figura 67 ilustra os possíveis efeitos de tilting nestes contatos. Os desenhos exageram nas dimensões de espessura de filme (separação) came-tucho e ângulo de tilting, para clareza didática. 
Figura 67 - Contatos Possíveis Nariz de Came - Tucho, com Tilting

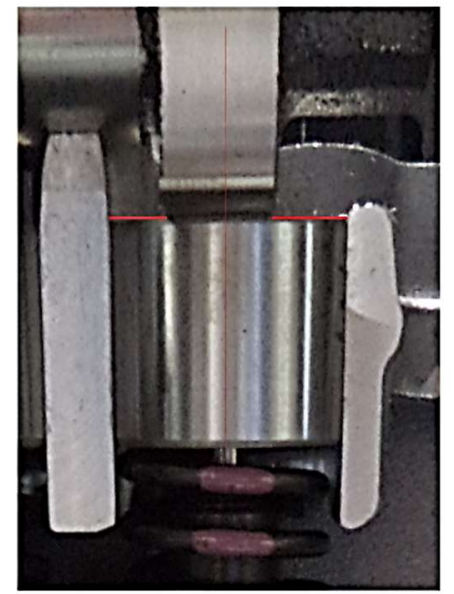

(a)

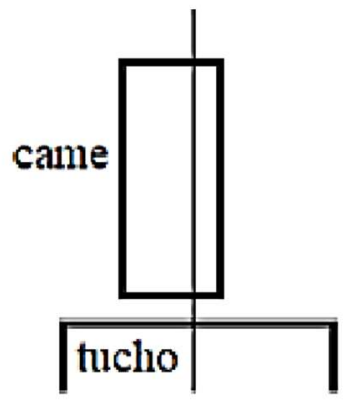

(b)

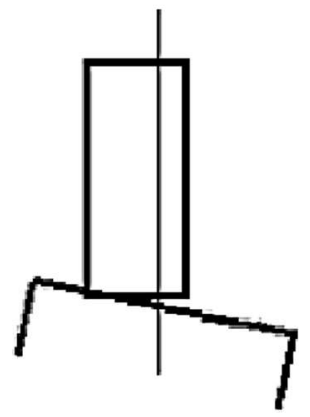

(c)

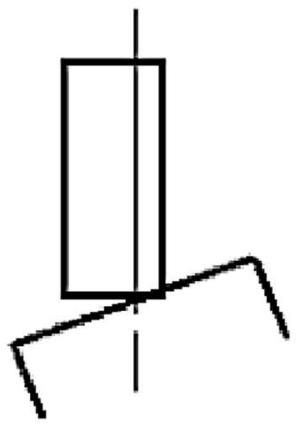

(d)

Na Figura 67-a, observa-se uma fotografia real do par came-tucho, em corte de motor;

Na Figura 67-b observa-se um diagrama do contato EHL sem tilting;

Na Figura 67-c observa-se um diagrama do contato com tilting, havendo interações, a princípio limítrofes, no lado esquerdo;

Na Figura 67-c observa-se um diagrama do contato com tilting, havendo interações, a princípio limítrofes, no lado direito;

Nesta linha, torna-se evidente que há uma extensão de contato limítrife que corresponde à uma fração da extensão total de contato em linha came-tucho.

Propõe-se, neste trabalho, que a Lei de Coulomb do atrito possa ser escrita de forma adequada a este contato parcial limítrofe, conforme exibe a Equação 17, fornecendo uma expressão para o valor do módulo da força de atrito limítrofe, $F_{l}$.

$$
F_{l}=C A_{L} P \frac{L_{L}}{L_{C}}
$$

Onde

$F_{l}$ é a força de atrito limítrofe;

$C A_{L}$ é o coeficiente de atrito limítrofe;

$P$ é o carregamento normal total;

$L_{L}$ é a extensão de contato limítrofe (Figuras 68 e 69);

$L_{C}$ é a largura de came; 
Uma primeira abordagem para a determinação das forças de atrito, devido ao cisalhamento do filme lubrificante, poderia ser obtida pela Lei de Newton de forças viscosas.

A força de fricção viscosa no contato came-tucho poder ser, para fluidos Newtonianos, dada pela Equação 14 .

$$
\frac{F_{v}}{A}=\eta \frac{u}{d}
$$

onde

$F_{v}:$ módulo da força de atrito viscosa;

$\eta$ : coeficiente de viscosidade dinâmica;

$u$ : é a velocidade relativa de contato;

$d$ : é a separação das superfícies deslizantes;

$A$ : área de contato de Hertz;

A viscosidade dinâmica de um lubrificante, em geral, depende de sua composição, da pressão e da temperatura a que está submetido. Fluidos newtonianos são exceções. A aplicação da Equação 18, no problema de contato nariz de came-tucho, leva a erros grosseiros.

Uma adaptação da Equação 18, numa aplicação a fluidos piezoviscosos, sob altas tensões de cisalhamento, pode ser feita considerando-se um fator multiplicador, n, no termo à direita da equação. De fato, há fenômenos físicos associados aos contatos nariz de came - tucho, tais como flash temperature [13] e variações da tensão cisalhante em filme lubrificante sob pressões hertzianas [14], com adições de etanol hidratado, que não são previstos pelo modelo EHL implementado e não são descritos via Lei de Newton das viscosidades.

Outra adaptação é a consideração da separação entre os planos deslizantes da Lei de Newton como a distância média entre as superfícies em contato EHL came-tucho, ou seja, substitui-se o termo de separação de superfícies deslizantes, $d$, por um termo de espessura de filme médio, $h_{\text {med }}$.

No modelo EHL, há a espessura de filme central, que frequentemente é utilizada por autores como parâmetro de separação entre superfícies em contato deslizante, em geral, considerada uma separação constante entre superfícies. Porém, quando as superfícies não estão paralelas, o contato em linha passa a ser não constante. Ou seja, é possível determinar uma espessura de filme média. 
A espessura de filme média passa a ser calculada por considerações geométricas dos contatos came-tucho-guia, sem considerações de deformações elásticas de corpos, exceto na linha de contato came-tucho, preservando os dados referência de área e pressão de contato de Hertz, assim como as propriedades piezoviscosas do lubrificante, calculadas via modelo EHL.

Desta forma, propõe-se, também, neste trabalho, que este contato em linha de separação não constante se deva ao efeito de tilting de tucho.

Quando ocorre tilting, supõe-se que o tucho se desloca de forma angular até que sua borda inferior e sua borda superior toque a guia, conforme exibe a Figura 68. Esse fenômeno ocorre em dois planos.

Figura 68 - Limite de Tilting para Came-Tucho-Guia

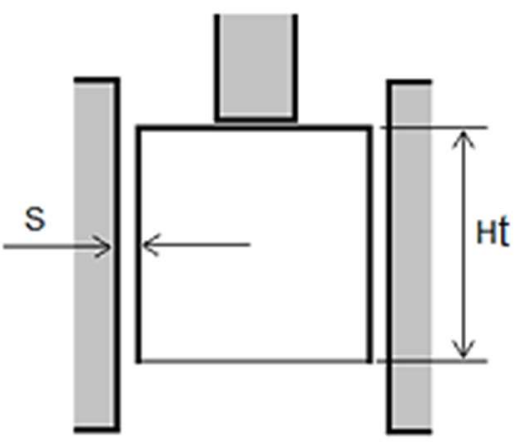

(a)

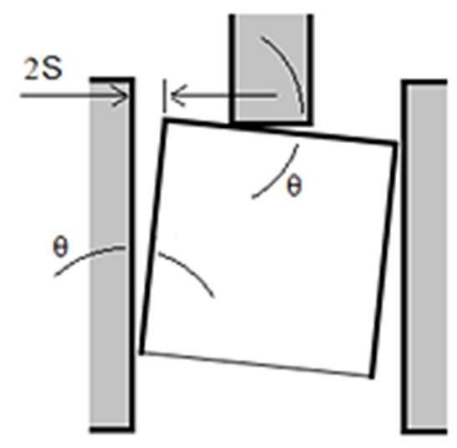

(b)

O autor

$\mathrm{Na}$ Figura 68a, vê-se o tucho sem deslocamento angular e na Figura 68b, vê-se o tucho com deslocamento angular limitado pelo toque com a guia.

Novamente, os desenhos exageram nas dimensões de separação tucho-guia e ângulo de tilting, para clareza didática.

Pode-se inferir que o ângulo de tilting $\theta$ será dado pela Equação 19, visto ser este um ângulo pequeno.

$$
\operatorname{tg}(\theta)=\frac{2 S}{H t}
$$

Onde

$S$ é a separação entre tucho e guia;

$H t$ é a altura do tucho; 
Observando-se o contato came-tucho mais em detalhe, conforme aponta a Figura 69, pode-se propor que há um contato de caráter limítrofe, de largura $L_{L}$, ao longo do qual a deformação do came é elástica.

Figura 69 - Detalhe da Geometria de Contato Limítrofe

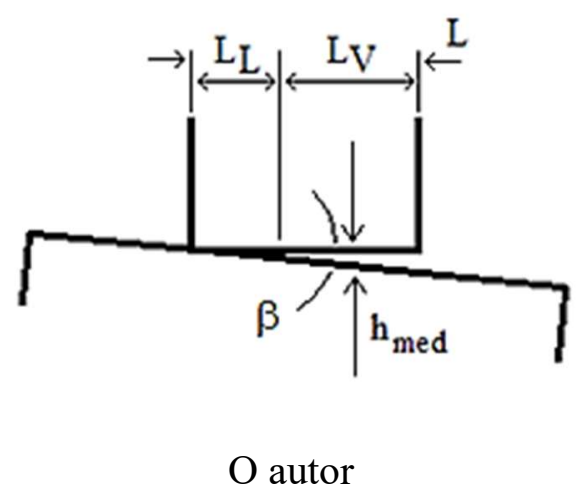

Novamente, há de se chamar atenção que a Figura 69 exibe um exagero no ângulo $\beta$, com a finalidade de tornar a figura didática. De fato, este ângulo é muito próximo de zero. Desta forma, ainda espera-se uma pressão de contato na região $L_{V}$.

A largura de contato $L_{V}$ corresponde à extensão de contato predominantemente viscoso. $L_{C}$ é a largura do came no contato e $h_{m e d}$ é a espessura de filme médio, localizada à metade de $L_{V}$. Portanto, $h_{\text {med }}$ pode ser calculada pela Equação 20.

$$
\operatorname{tg}(\beta)=\frac{h_{m e d}}{L_{V} / 2}
$$

Equação 20

Igualando a Equação 19 com a Equação 20, e rearranjando os termos, pode-se escrever a Equação 21, para a espessura de filme médio.

$$
h_{m e d}=\frac{S\left(L_{C}-L_{L}\right)}{H t}
$$

A Equação 21 aponta para a dependência geométrica da espessura de filme médio com a separação tucho-guia, a largura de came, a largura de contato limítrofe e a altura do tucho. Portanto, variações dimensionais destas grandezas levam a variações dimensionais da espessura de filme central. Além disso, a espessura de filme média é adotada como proporcional à espessura de filme central (quando não há titlting). Assume-se que a espessura de filme média 
cresça linearmente com o crescimento da espessura de filme central, provocado pelos sucessivos aumentos das viscosidades das misturas etanol + lubrificante. Por efeito, $\mathrm{L}_{\mathrm{L}}$ deve diminuir com o aumento de $h_{\text {med }}$.

A Equação 18 pode ser reescrita como:

$$
\frac{F_{v}}{A}=\frac{1}{m} \mu \frac{u}{h_{m e d}}
$$

onde $m$ é o fator de correção.

Utiliza-se, para $\mu$, o coeficiente de piezo-viscosidade.

Substitui-se $d$ por $h_{m e d}$, a espessura de filme médio.

Desta forma, a força de atrito total, que corresponde à soma da força de atrito limítrofe, dada pela Equação 17, com a força de atrito piezoviscosa, dada pela Equação 22, pode ser escrita conforme exibe a Equação 23.

$$
F_{a t}=\frac{1}{m} \mu \frac{u A_{p v}}{h_{m e d}}+C A_{L} P \frac{L_{L}}{L_{C}}
$$

onde

$F_{a t}$ é a força de atrito total;

$A_{p v}=A\left(L_{c}-L_{L}\right) / L_{c}$, é a área de contato piezoviscoso;

$h_{m e d}$ é a espessura de filme média entre came e tucho;

$C A_{L}$ é o coeficiente de atrito limítrofe;

$P$ é o carregamento normal total;

$L_{L}$ é a extensão de contato limítrofe;

$L_{C}$ é a largura de came;

Pelo Bureal international des poinds et mesures (BIPM), uma grandeza física métrica, dependente de grandezas físicas métricas independentes, possuirá variação dependente das variações das medidas independentes. Dada uma grandeza dependente $y=f(x 1, x 2, x 3 \ldots, x n)$, sua variação será dada pela Equação 24 [47].

$$
\delta y^{2}=\left(\frac{\partial f}{\partial x_{1}} \delta x_{1}\right)^{2}+\left(\frac{\partial f}{\partial x_{2}} \delta x_{2}\right)^{2}+\cdots\left(\frac{\partial f}{\partial x_{n}} \delta x_{n}\right)^{2}
$$

onde 
$\delta y$ é a variação da grandeza dependente;

$\delta x_{1}, \delta x_{2}, \delta x_{n}$, são as variações das grandezas independentes;

Pode-se interpretar variações de grandezas independentes como incertezas absolutas das medidas destas e variação da grandeza dependente como erro propagado para esta.

Aplicando-se a Equação 24 à Equação 21, obtém-se a Equação 25.

$$
\delta h_{\text {med }}^{2}=\left(\frac{1}{H t} \delta S\left(L-L_{L}\right)\right)^{2}+\left(-\frac{S}{H t^{2}} \delta H t\left(L-L_{L}\right)\right)^{2}+\left(\frac{S}{H t} \delta L\right)^{2}+\left(-\frac{S}{H t} \delta L_{L}\right)^{2} \text { Equação } 25
$$

Desta forma, a Equação 25 fornecerá a variabilidade da espessura de filme médio, a ser aplicada na Equação 23, gerando um valor da variabilidade das forças de atrito calculadas.

\subsection{Modelo LEHL Aplicado aos Dados Experimentais Pino-Disco}

Confrontando-se os resultados experimentais obtidos nos ensaios pino-disco normal, com os resultados calculados pela Equação $22(\mathrm{~m}=1)$, obtêm-se a relação dada pela Figura 70, entre forças de atrito.

Figura 70 - Forças de atrito pino-disco experimental x teórico

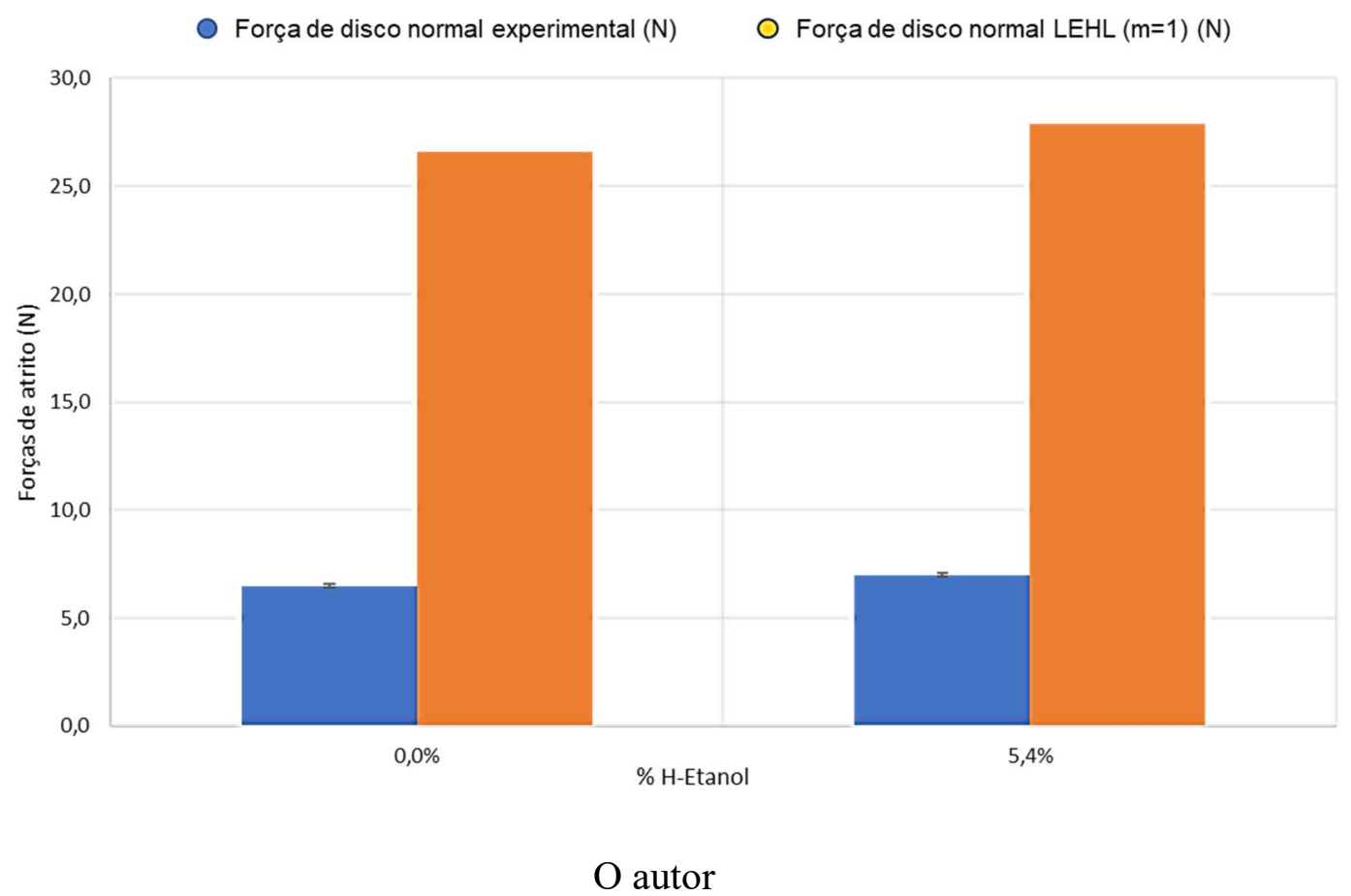


Para ambos os teores de etanol hidratado adicionados no experimento pino-disco, observa-se uma diferença de cerca de $4 \mathrm{x}$ entre as forças de atrito experimentias e calculadas.

Desta forma, com $\mathrm{m}=4$, os resultados teóricos gerados com a Equação 22 foram confrontados com os resultados experimentais obtidos nos ensaios Pino-disco. O gráfico da Figura 71 exibe os resultados plotados, em termos de forças de atrito, para disco usinado (normal).

Figura 71 - Forças de Atrito Experimental x teórico EHL para Ensaios Pino-Disco com Disco Usinado

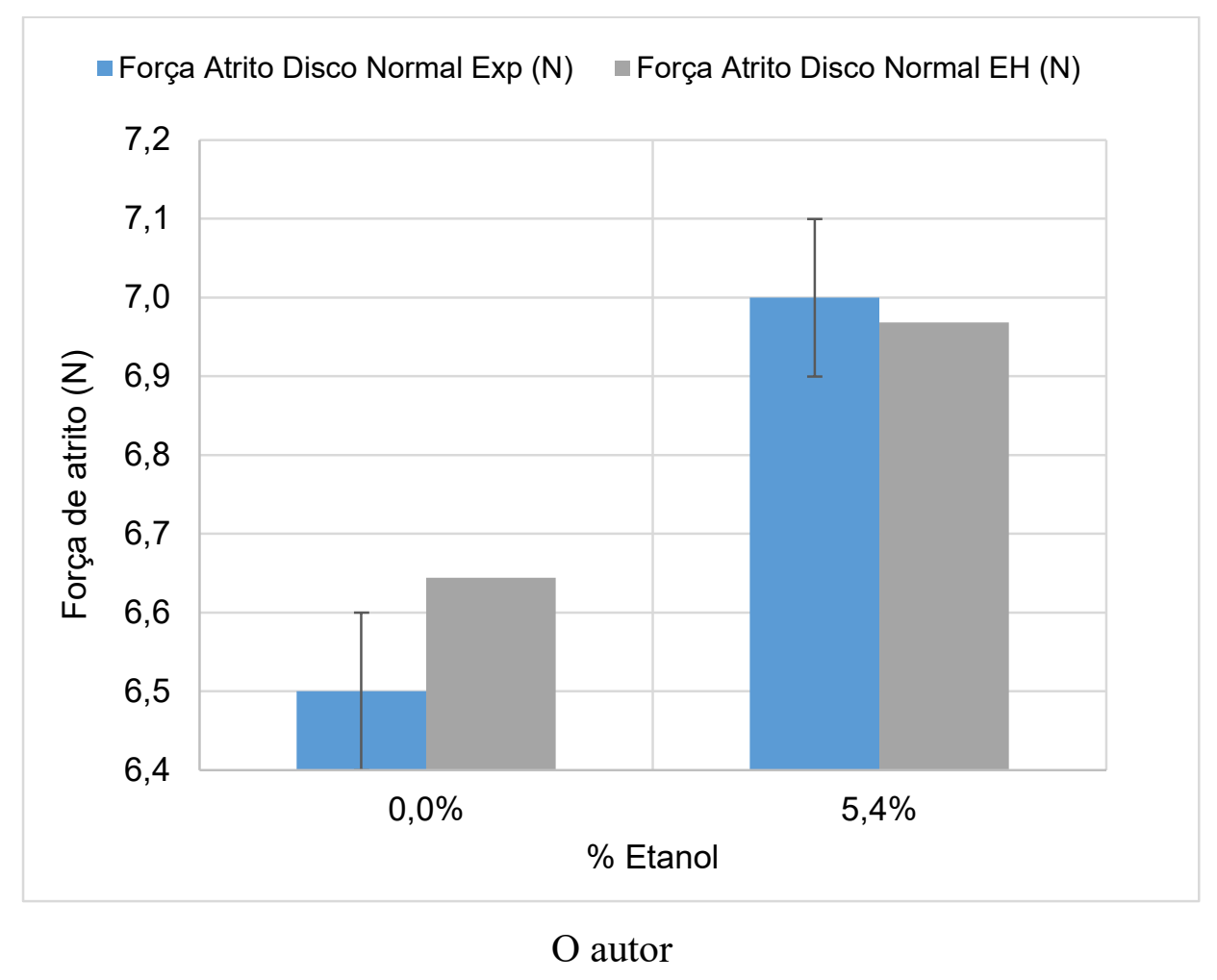

Pode-se observar que os resultados experimentais se relacionam razoavelmente bem com os resultados oriundos do modelo LEHL, para disco usindo.

Entretanto, os resultados experimentais não se relacionam bem com os resultados da Equação 22, para disco H-DLC, mesmo com m=4. (Figura 72). 
Figura 72 - Forças de Atrito Experimental x teórico EHL para Ensaios Pino-Disco com Disco Revestido H-DLC

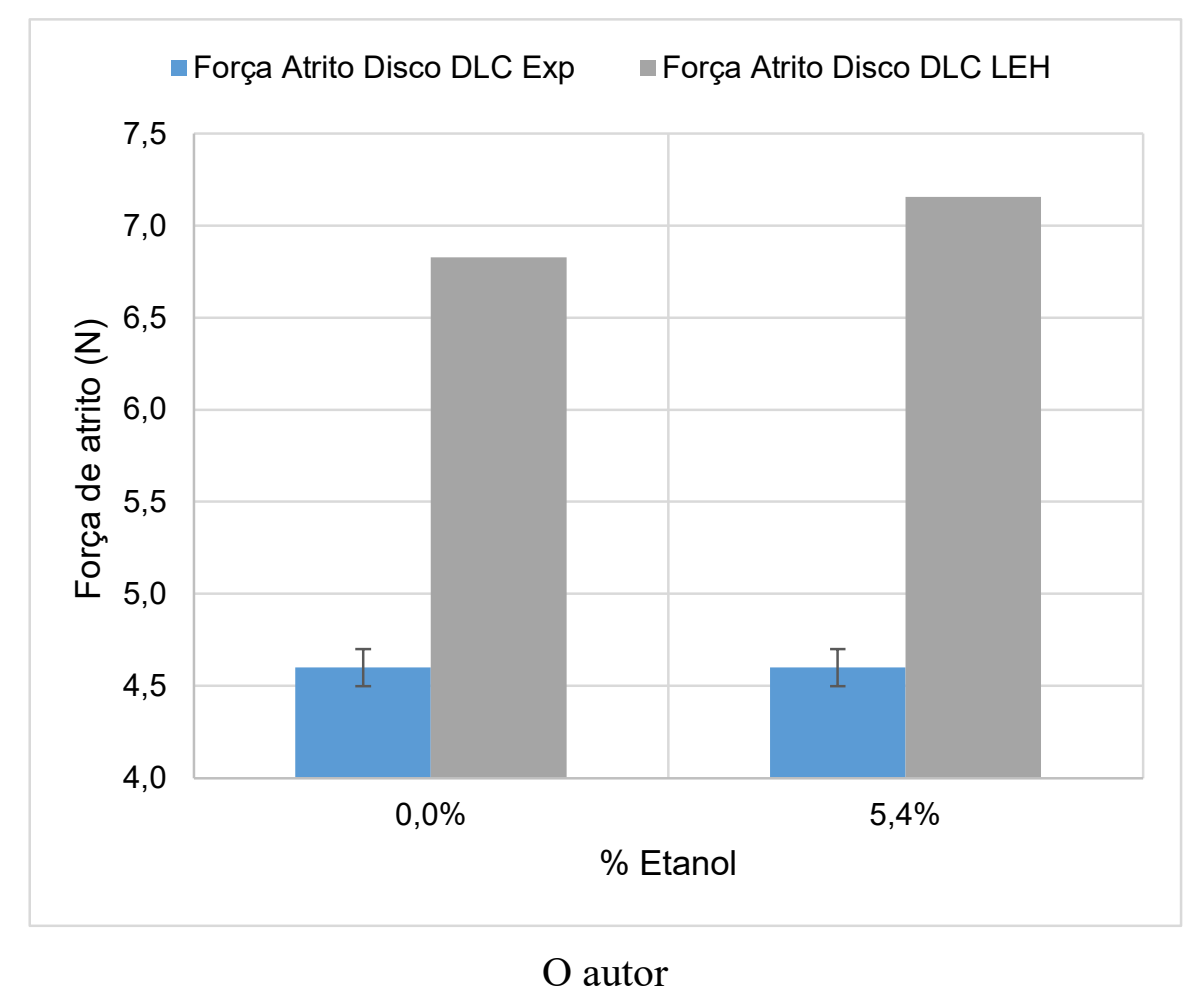

Embora as forças de atrito sejam consideravelmente menores no caso do emprego do disco revestido com H-DLC, em comparação com o emprego do disco usinado, o modelo LEHL não foi sensível às mudanças de dados relativos ao emprego deste filme fino.

\subsection{Modelo LEHL Aplicado aos Dados Experimentais Monocame}

Como já presumido, as espessuras de filme central crescem com o crescimento da viscosidade do lubrificante. Espera-se que a espessura de filme médio tenha o mesmo comportamento. Deste modo, é possível interpolar uma curva de redução da extensão de contato limítrofe, com a adição de teores de Etanol.

O gráfico da Figura 73 exibe tal curva de ajuste. 
Figura 73 - Redução da Extensão de Contato Limítrofe, com Teores de Etanol

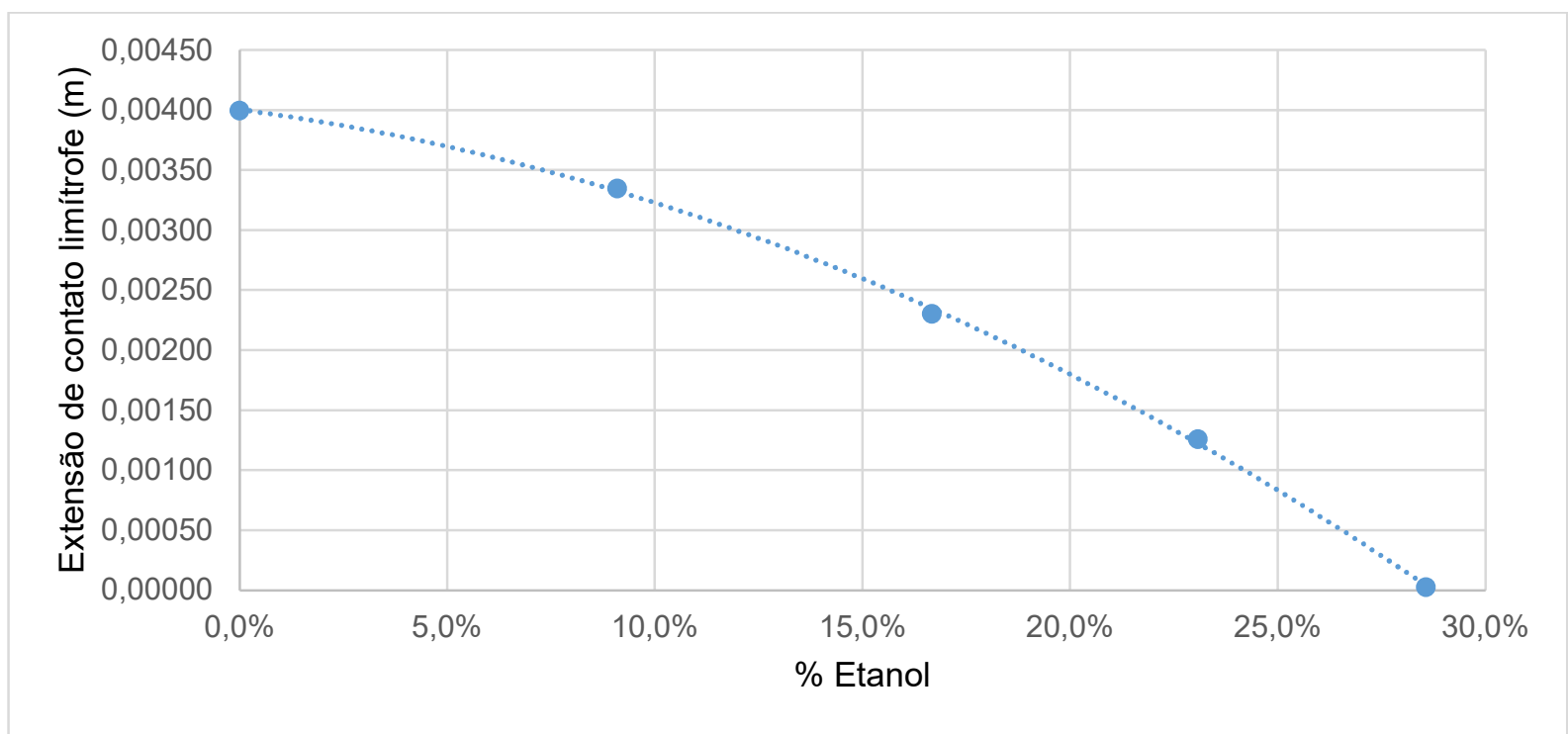

O autor

Introduz-se-se o valor inicial de extensão de contato limítrofe, cerca de $4 \mathrm{~mm}$, à luz da largura de coroa de desgaste observada na Figura 66. As demais extensões de contato limítrofe são calculadas por razão simples (relação espessura de filme médio x espessura de filme central constante) para cada teor de etanol hidratado adicionado.

As espessuras de filme central e médio adquirem as curvas descritas na Figura 74, para diferentes teores de Etanol, considerando-se a Equações 9 e a Equação 21, respectivamente.

Figura 74 - Espessuras de Filme Lubrificante Central e Médio

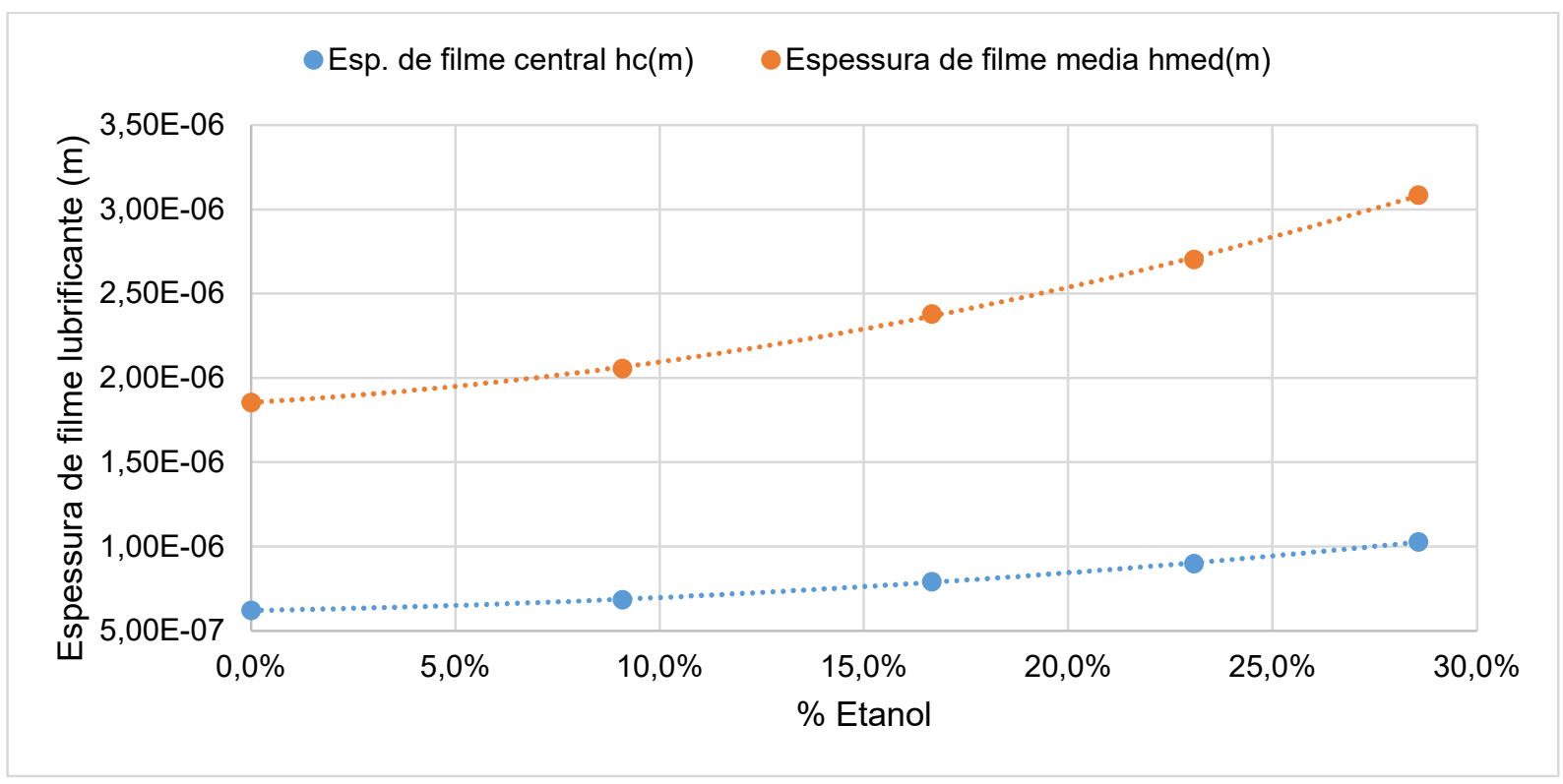

O autor 
O crescimento das espessuras de filme médio acompanha o crescimento das espessuras de filme central, com as adições de etanol.

Desta forma, as forças de atrito totais nariz de came - tucho, calculadas via Equação 23, máximas e mínimas, podem ser verificadas pelo gráfico da Figura 75, para tucho normal.

Figura 75 - Forças LEH Nariz de Came - Tucho Normal

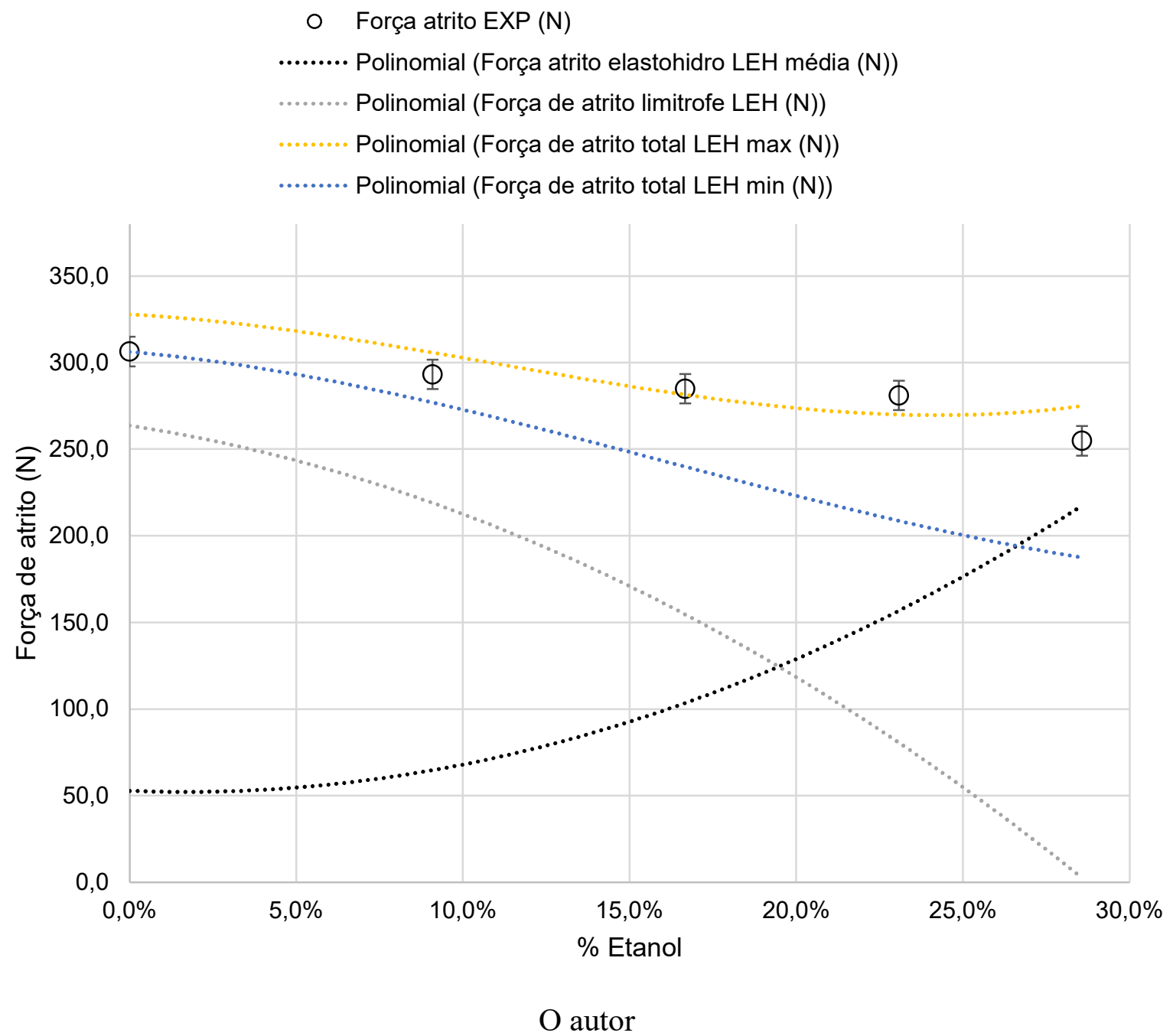

Equivalentemente, para tucho revestido H-DLC, obtém-se o gráfico da Figura 76.

No primeiro caso, Figura 75, atribuiu-se $\mathrm{CA}_{\mathrm{L}}$ de 0,21 (coeficiente de atrito, de contato não lubrificado, atribuído ao tucho normal de produção).

No segundo caso, Figura 76, atribuiu-se $\mathrm{CA}_{\mathrm{L}}$ de 0,16 (coeficiente de atrito, de contato não lubrificado, para tucho revestido com H-DLC).

Desta forma, obtém-se as relações para CA totais, para tucho normal de produção, Figura 77, e para tucho revestido H-DLC, Figura 78. 
O valor de CA $A_{L}$ atribuído ao caso "tucho normal", está dentro da faixa de valores de coeficientes de atrito obtidos por Ashby e Brunton, em ensaios pino-disco de pino de ferro fundido temperado contra dois discos de aço de diferentes rugosidades, não lubrificados, ou seja, entre 0,12 e 0,20, para disco polido e 0,45 a 1,60 para disco bruto [48].

Figura 76 - Forças LEH Nariz de Came - Tucho H-DLC

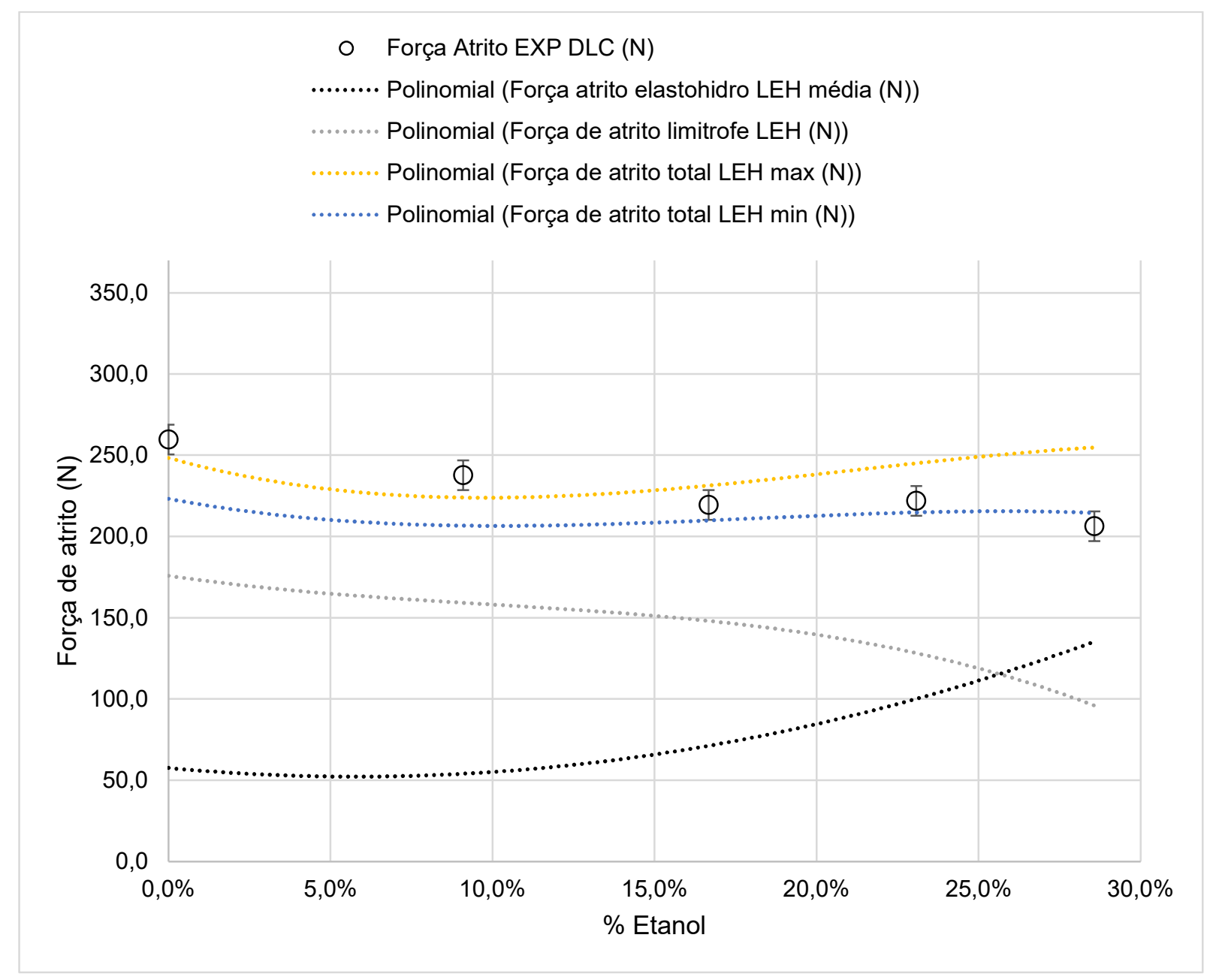

$\mathrm{O}$ autor

O valor de CAL atribuído ao caso "tucho revestido com H-DLC" está dentro da faixa de valores de coeficientes de atrito obtidos por Ronkainen e Holmberg, em ensaios pinodisco de pino de aço contra disco revestido com H-DLC, não lubrificado, ou seja, entre 0,15 e 0,22 [49]. Estes autores reportaram que estes coeficientes de atrito reduzem-se entre 10 e $40 \%$ no caso de ensaio lubrificado. 
Figura 77 - CA total para Tucho Normal de Produção

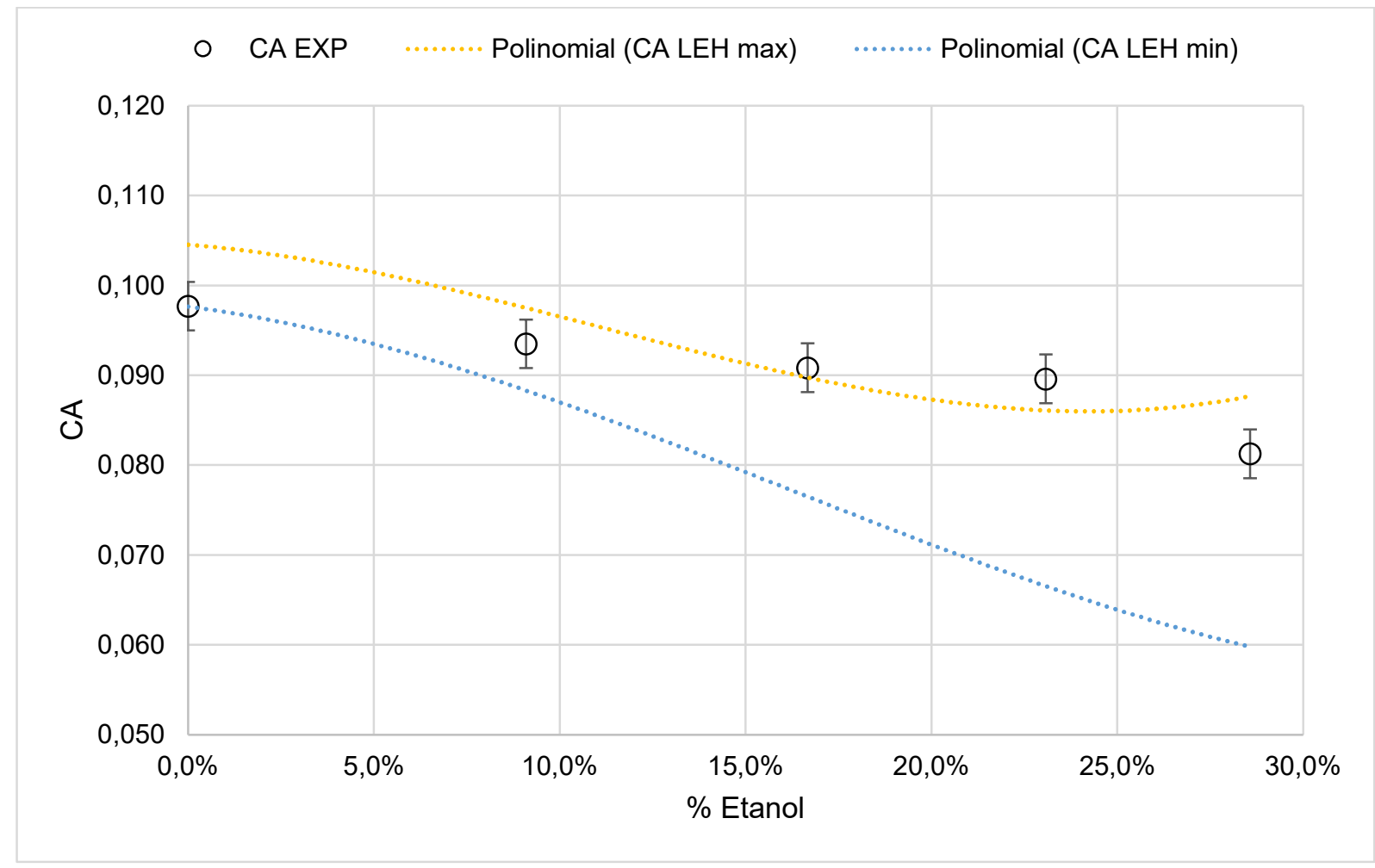

O autor

Figura 78 - CA total para Tucho Revestisdo com H-DLC

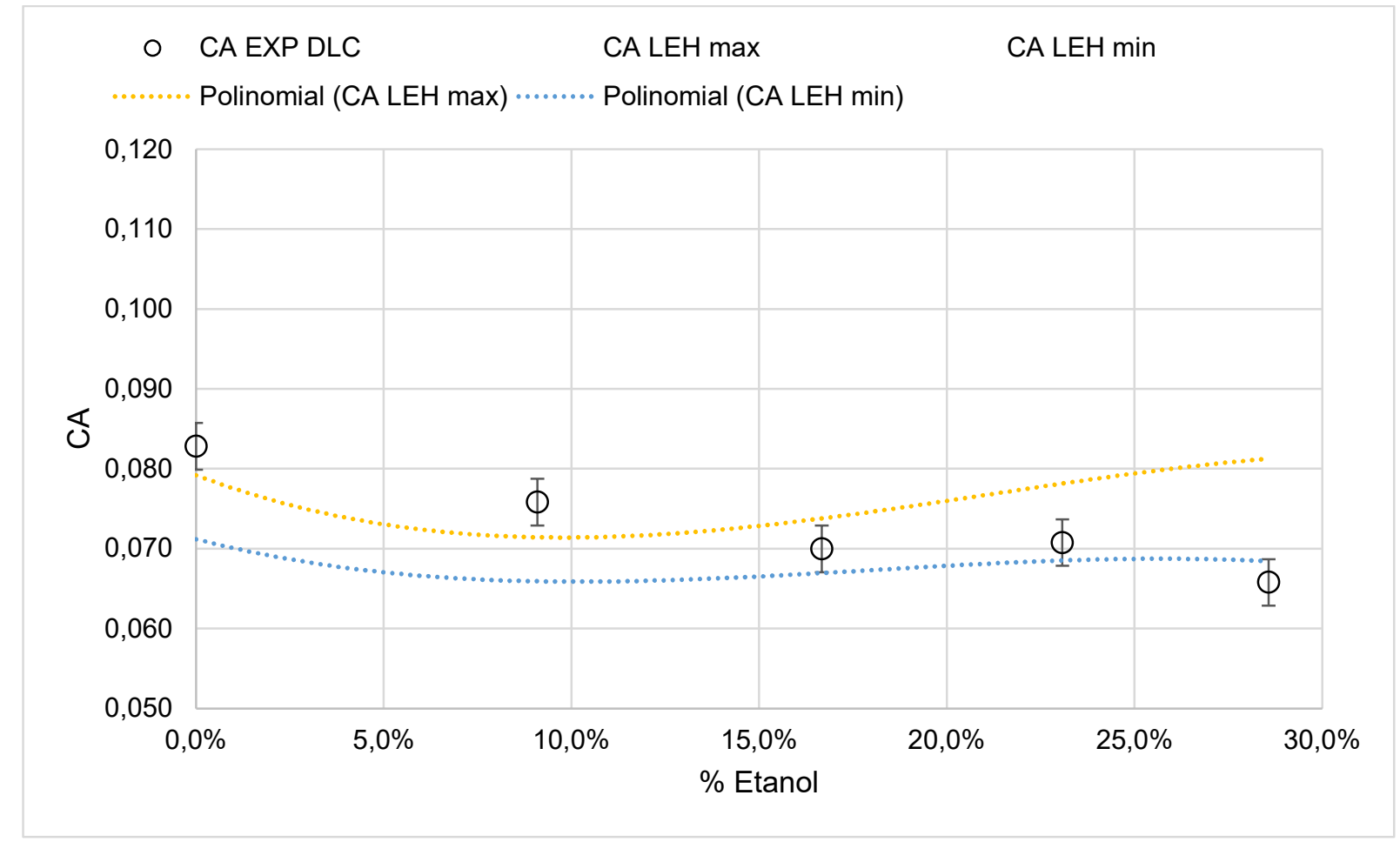

$\mathrm{O}$ autor 
Os resultados descritos pelo modelo semi-empírico LEHL descrevem, de forma satisfatória, os resultados experimentais, plotados em todos os gráficos, obtidos via experimentos monocame, com adições de teores de etanol hidratado.

\subsection{Modelo LEH Aplicado aos Dados Experimentais de Dyson}

Dyson \& Naylor realizaram uma série de experimentos em laboratório, para a determinação dos coeficientes de atrito, com uma variedade de cames e tuchos [13]. Os cames foram fabricados em aço e temperados superficialmente e os tuchos em ferro fundido. Os cames possuíam raios de nariz entre 0,05 a 2 polegadas, ou 1,27 a $50,8 \mathrm{~mm}$, ao passo que os raios de coroa de tucho possuíam raios entre 20 e 100 polegadas, ou 508 a $2540 \mathrm{~mm}$.

É possível observar que o raio de nariz de came e o raio de coroa de tucho das peças utilizadas no experimento monocame estão dentro detes limites. (Tabela 10).

Dyson \& Naylor obtiveram valores de coeficientes de atrito entre 0,08 e 0,12, para 600 RPM de frequência de rotação de came e carregamento máximo (no máximo lift) de 147 lbf, ou 654 N. Os autores observam que estes coeficientes de atrito são valores confiáveis para os contatos na região entre nariz de came e tucho, somente.

Dyson \& Naylor utilizaram como lubrificante, em seus experimentos, óleo base SAE 30 HVI e visavam, principalmente, a determinação dos efeitos de flash temperature. Os autores registraram as temperaturas bulk das peças em contato, apontadas como $127^{\circ} \mathrm{C}$ para $3000 \mathrm{RPM}$.

O gráfico da Figura 79 exibe a variação da viscosidade dinâmica do lubrificante SAE 30 HVI, em função da temperatura.

Pode-se estimar que, para a temperatura bulk dos experimentos Dyson \& Naylor [13], a viscosidade dinâmica será de aproximadamente $1,87.10^{-3}$ Pa.s.

Tomando como base o modelo simplificado LEHL, que foi originalmente carregado com os dados dos ensaios monocame, alterou-se somente os valores dos parâmetros descritos por Dyson \& Naylor. Desta forma, foi possível calcular coeficientes de atrito relativos ao trabalho destes autores (Figura 80). 
Figura 79 - Viscosidades Dinâmicas do Óleo SAE 30 HVI

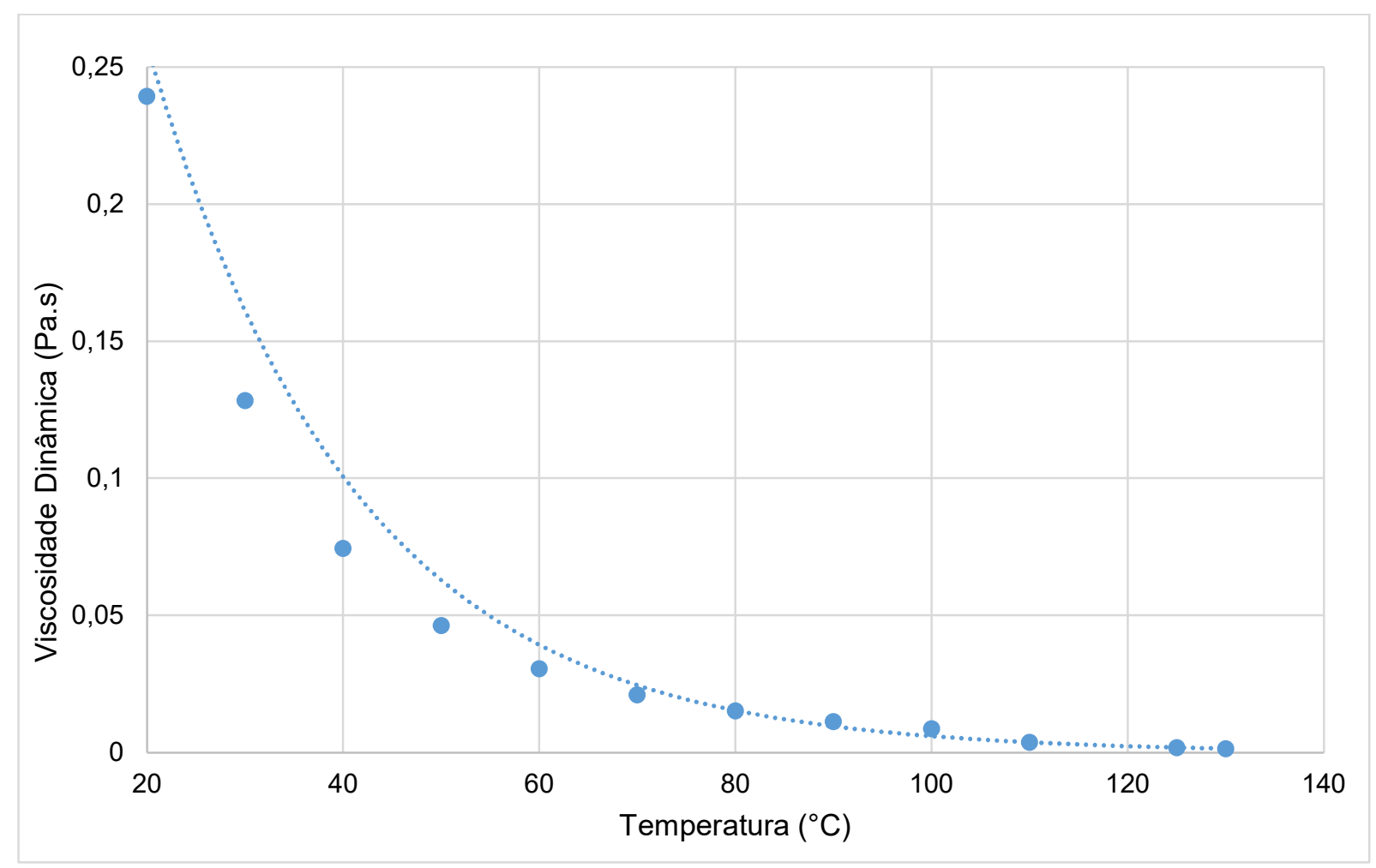

Extraído de [53]

Figura 80 - Valores de CA Dyson \& Naylor x Valores CA Modelo LEH

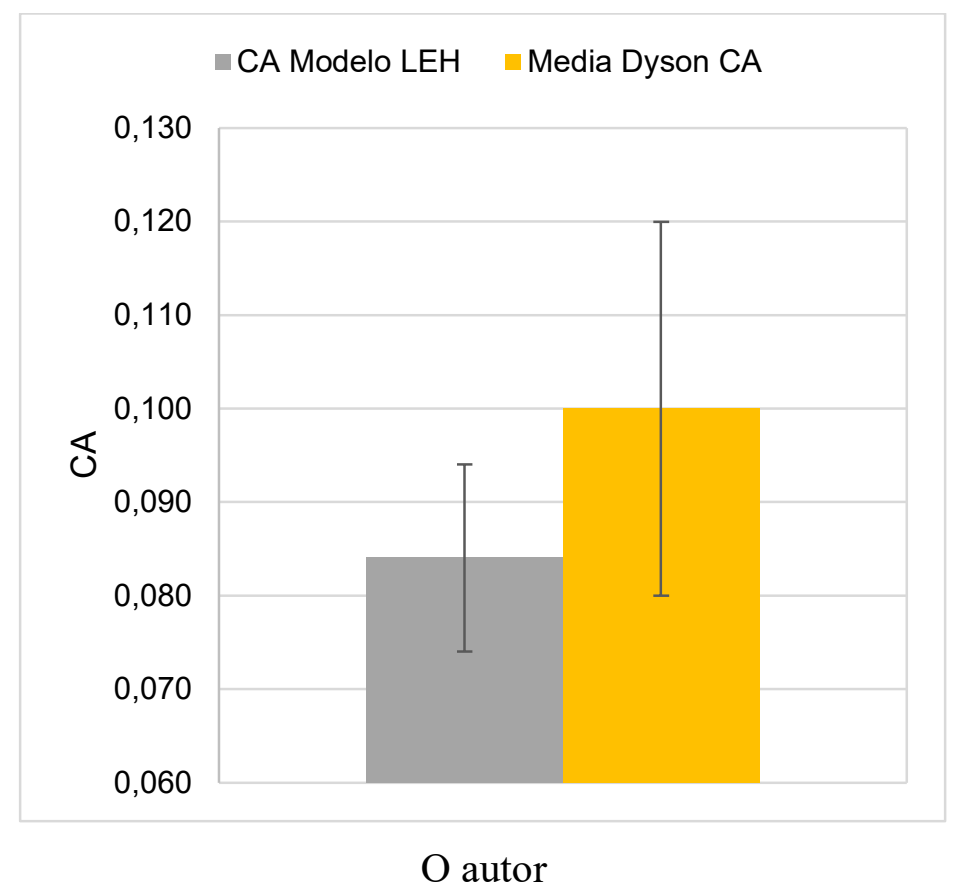


Pode-se observar alguma correlação estatística entre os valores experimentais de CA de Dyson \& Naylor e os valores de CA calculados via modelo LEHL, conforme exibe a Figura 80, porém, os valores absolutos divergem em cerca de $15 \%$.

Cabe observar as limitações, em termos de dados, para uma mais fiel simulação via modelo LEHL. Não são informados, no trabalho de Dyson \& Naylor, valores de rugosidades superficiais de came, de tucho, as viscosidades dinâmicas do lubrificante e a exata temperatura bulk para 600 RPM, dentre outras informações, as quais foram copiadas dos dados do caso monocame. Entretanto, também cabe relembrar que os experimentos de Dyson foram realizados em monocame, de forma semelhante aos experimentos monocame deste trabalho, o que confere credibidade à comparação.

5.9 Resumo de Dados Utilizados na Modelagem LEHL

Alguns dados utilizados nas aplicações do modelo LEHL utilizam-se de valores que visam melhorar a correlação entre os dados provenientes do modelo e correspondentes dados experimentais, conforme exibe a tabela 16 (com sinal *).

Tabela 16 - Sumário de Dados Modelo LEHL x Experimental

\begin{tabular}{|c|c|c|c|}
\hline & \multicolumn{3}{|c|}{ Ensaio } \\
\hline Parâmetro & Pino-Disco & Monocame & Dyson \\
\hline $\mathrm{m}^{*}$ & 4 & 4 & 4 \\
\hline $\mathrm{L}_{\mathrm{L}}$ inicial $(\mathrm{mm})^{*}$ & $\mathrm{n} / \mathrm{a}$ & $4,0 \pm 0,5$ & $4,0 \pm 0,5$ \\
\hline Lubrificante & SAE $5 \mathrm{~W} 30$ & SAE 5W30 & SAE 30 HVI \\
\hline Temp. Lubrificante $\left({ }^{\circ} \mathrm{C}\right)$ & $50 \pm 1$ & $35 \pm 1$ & 125 \\
\hline Velocidade no contato $(\mathrm{m} / \mathrm{s})$ & 1,00 & 2,81 & 1,53 \\
\hline CA limítrofe tucho normal* & $\mathrm{n} / \mathrm{a}$ & 0,21 & 0,21 \\
\hline CA limítrofe tucho H-DLC* & $\mathrm{n} / \mathrm{a}$ & 0,16 & $\mathrm{n} / \mathrm{a}$ \\
\hline
\end{tabular}

O valor de m carrega, em sí, considerações não atendidas pelo modelo EHL e pela Lei de Newton, no que se refere a fenômenos físicos de flash temperature, fenômenos de cisalhamento de filme lubrificante contaminado com etanol hidratado, sob altas pressões, e também procura corrigir a aplicação inadequada da área e pressão de contato de Hertz ao 
contato deslizante came-tucho. As áreas e as pressões de contato de Hertz, a rigor, somente podem ser utlizadas em contatos não deslizantes. $\mathrm{O}$ número $\mathrm{m}=4$ foi adotado no modelo aplicado ao caso monocame (tucho normal e tucho DLC) e no modelo aplicado ao caso pinodisco (disco normal e disco DLC), fornecendo resultados coerentes, exceto no caso pino-disco com disco H-DLC, que, particularmente, poderia ser melhor correlacionado via ajuste de outro valor de $\mathrm{m}$.

O valor de $\mathrm{L}_{\mathrm{L}}$ inicial é medido diretamente, no caso monocame, (Figura 68), mas é atribuído, igualmente, no caso Dyson, por este não fornecer esta informação, dentre outras.

Os valores de CA, normal e DLC, são atribuídos aos contatos predominantemente limítrofes, que supõe-se ocorrer nos casos Monocame e Dyson, à luz de faixas de CA's obtidos experimentalmente por Ashby e Brunton [48] e por Ronkainen e Holmberg [49], para ensaios de contatos limítrofe metal-metal e metal-H-DLC, respectivamente.

\subsection{Discussão Geral Sobre as Condições Tribológicas Came-Tucho}

As condições tribológicas num contato came-tucho de ação direta dependem de uma série de fatores, alguns deles fortemente dependentes do tempo.

O diagrama da Figura 81 representa estas dependências de forma suscinta.

Estes fatores podem ser brevemente explanados:

- Contaminação do Lubrificante: em uso veicular é comum a inserção de materiais estranhos ao lubrificante, como combustíveis (gasolina, etanol), poeira, fuligem, etc, e também o aparecimento de contaminantes provenientes de reações químicas com o próprio lubrificante, como vernizes, "lama", etc;

- Temperatura do Lubrificante: a temperatura do lubrificante depende fortemente da demanda veicular e pode ser drasticamente alterada quando ocorrem danos ao sistema de arrefecimento do motor;

- Aditivos do Lubrificante: a formulação dos aditivos do lubrificante desempenha um papel central nas condições tribológicas, por atuarem nas interações metal-metal e no comportamento viscoso do óleo;

- Formulação Óleo Base: óleos base minerais e sintéticos diferem quanto à capacidade de suportar temperaturas extremas sem grandes alterações de viscosidade. Os óleos sintéticos são mais "resistentes" às condições extremas; 
- Oxidação do Lubrificante: o nível de oxidação de um lubrificante depende fortemente do tempo de uso veicular e das condições de uso. O nível de oxidação altera a viscosidade do lubrificante e favorece a contaminação por etanol, por exemplo;

- Condições superficiais Came-Tucho: As condições superficiais do came e do tucho dependem do processo de fabricação, do "break-in" veicular e das propriedades e estado do lubrificante. Presume-se que o "break-in" veicular promove uma alteração das condições superficiais, implicando em possíveis mudanças de regime tribológico, em associação com as características do lubrificante, conforme pôde-se observar através dos experimentos cametucho e análises de superfícies realizadas neste trabalho. Também se verificou que filmes finos H-DLC aplicados a estas superfícies podem alterar significativamente as condições tribológicas;

Figura 81 - Fatores nas Condições Tribológicas Came-Tucho

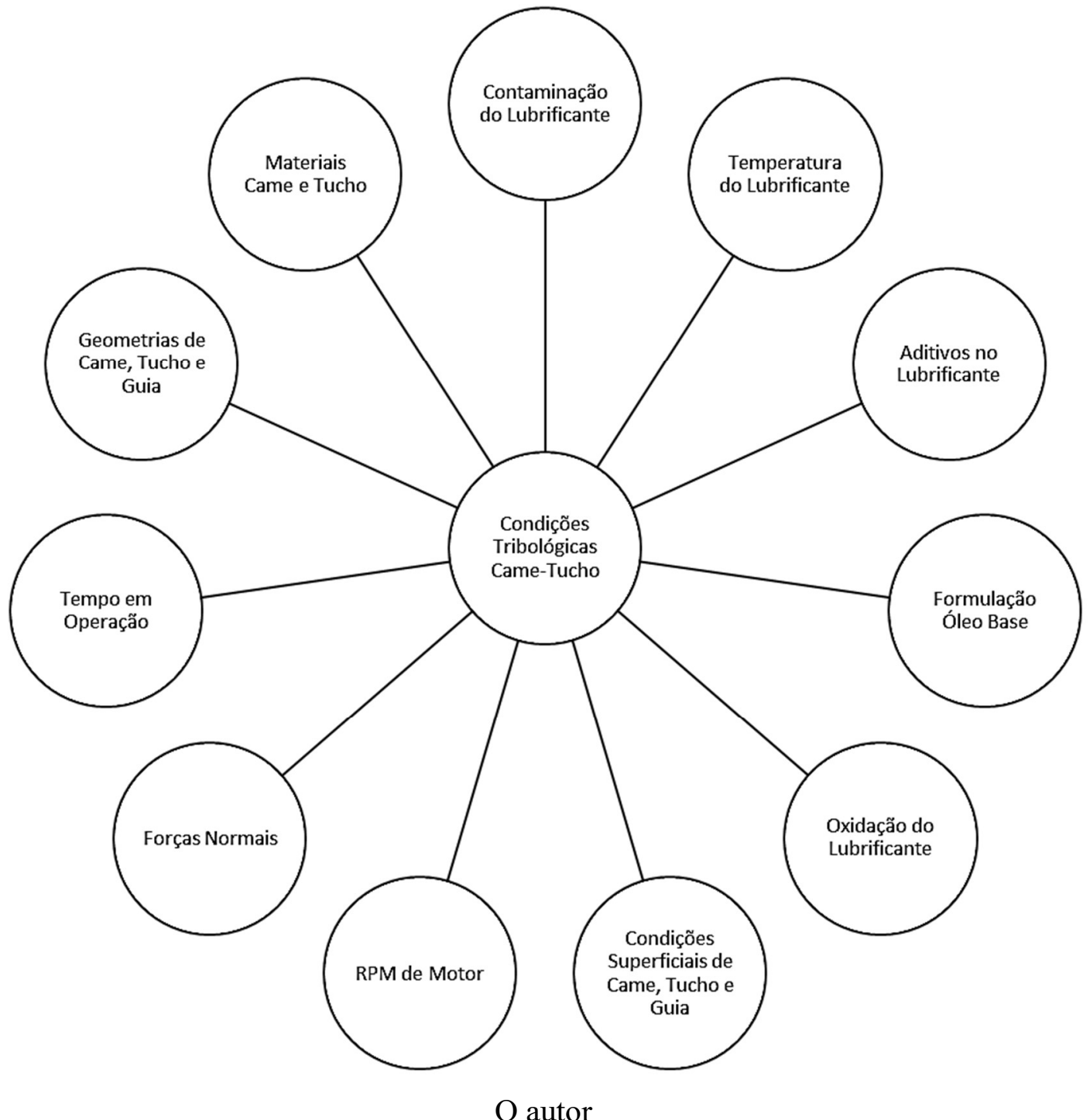

O autor 
- RPM de motor: estudos mostram que o RPM de motor, e consequentemente, o RPM do eixo comando de válvulas, altera as condições tribológicas came-tucho por alterarem a dinâmica do sistema de válvula, por mudarem as tensões cisalhantes no filme lubrificante entre outros aspectos;

- Forças Normais: estas forças dependem fortemente da constante elástica da mola de válvula, em baixas rotações. Para altas rotações, estas forças dependerão também dos efeitos dinâmicos das massas móveis associadas ao tucho. Forças normais de contato alteram as propriedades do filme lubrificante;

- Tempo de Operação: durante um ciclo de operação, o sistema came-tucho frequentemente apresenta alterações no comportamento tribológico, devido a alterações momentâneas das propriedades do óleo lubrificante, por exemplo;

- Geometria de Came: a geometria do came afeta a força normal de contato, pela sua excentricidade e afeta a área de contato com o tucho, também pela sua forma;

- Materiais Came-Tucho: os módulos de elasticidade e coeficientes de Poisson do came e do tucho afetam diretamente as deformações elásticas no contato, alterando as pressões de contato entre estas superfícies; 


\section{Conclusões}

\subsection{Conclusões Sobre os Ensaios Pino-Disco}

Os ensaios pino-disco reproduziram parcialmente efeitos tribológicos, de contato em linha $\mathrm{EH}$, das adições de etanol hidratado aos lubrificantes, em condições controladas de laboratório, sem efeitos típicos das interações came-tucho, tais como spin, tilting, vibrações, etc, além de terem sido realizados com pressões de contato e velocidade de contato diferentes das observadas nas interações came-tucho. Conclui-se que estes fatores são a razão dos valores de CA mais baixos obtidos nos ensaios pino-disco, em relação aos valores obtidos nos ensaios monocame.

Em geral, os resultados obtidos no caso pino-disco, apresentam valores de CA entre 0,04 e 0,07 , variações obtidas pelo uso de disco normal ou disco H-DLC e pelas inserções de etanol hidratado. Tais valores diferem de valores de CA entre nariz de came e tucho, medidos e/ou calculados por outros autores, como Dyson [13], por exemplo, que apontou valores entre 0,08 e 0,12 .

\subsection{Conclusões Sobre os Ensaios Monocame}

A despeito de vários métodos experimentais descritos na literatura, seja para a medição direta ou indireta de forças de contato came-tucho, em motor de combustão interna, seja pela medição destas forças em equipamentos de bancada, projetou-se e construiu-se um equipamento de bancada monocame. Este equipamento foi descrito na seção 4.3, foi dotado de peças reais de motor de combustão interna e dotado de um sistema de aquisição de forças normais e de atrito came-tucho, em tempo real. Tal equipamento mostrou-se útil nos estudos de adições de etanol hidratado, sensível o suficiente e com baixos níveis de ruídos gerados, mesmo sem a aplicação de filtros eletrônicos de sinais elétricos.

Os experimentos preliminares, descritos no item 4.4.1, mostraram que o equipamento reproduz as forças normais e de atrito descritas por Dyson [13], assim como valores típicos de CA amplamente descritos na literatura (Tabela 5).

Em relação aos resultados obtidos com as adições de etanol hidratado, os resultados experimentais, sob as condições experimentais específicas descritas neste trabalho, permitem concluir que: 
- O CA reduz-se com o aumento da quantidade de etanol inserido no meio lubrificante;

- O CA reduz-se cerca de $20 \%$ com o emprego do tucho revestido de H-DLC, em comparação com o emprego do tucho normal de produção, para qualquer teor de etanol hidratado;

Conclui-se, também, que tais reduções sucessivas de CA, com adições de etanol hidratado, são atribuidas aos aumentos de espessura de filme central, apontados pelo modelo $\mathrm{EH}$, ou correspondentemente e efetivamente, aos aumentos de espessura de filme médio, proporcionais aos aumentos de espessura de filme central, cujo efeito é a diminuição das extensões de contato limítrife decorrentes de tilting, como descrito pelo modelo LEHL.

\subsection{Conclusões Gerais}

Conclui-se, sobre a concordância "dados experimentais x resultados do modelo semi-empírico simplificado LEHL":

Pino-disco com disco normal: razoáveis

Pino-disco com disco H-DLC: discrepantes

Monocame com tucho normal: razoáveis

Monocame com disco H-DLC: razoáveis

CA’s de Dyson: razoáveis

O modelo semi-empírico, simplificado, limitro-elastohidrodinâmico (LEHL) foi capaz de descrever, razoavelmente bem, o comportamento dos coeficientes totais de atrito, CA, nas condições experimentais de ensaios monocame, assim como pôde descrever bem os CA obtidos numa analogia com os resultados experimentais de Dyson, o que permite concluir que a divisão do regime tribológico de contato came-tucho, em (a) predominantemente elastohidrodinâmico e (b) predominantemente limítrofe teve sucesso.

Especificamente, este trabalho permite tirar as seguintes conclusões:

1 - Os sistemas came-tucho de ação direta apresentam peculiaridades mecânicas que influenciam diretamente nas respostas em termos de coeficientes de atrito, CA, tais como spin e tilting de tucho;

2 - O efeito das adições de etanol hidratado na viscosidade dinâmica do lubrificante SN5W30, envelhecido em motor até os $10.000 \mathrm{~km}$, é o aumento gradativo de sua viscosidade (mistura); 
3 - Os aumentos gradativos da viscosidade do lubrificante envelhecido SN5W30, com adições de etanol hidratado, implica na redução dos coeficientes de atrito came-tucho, para as condições experimentais mecânicas e reológicas descritos neste trabalho;

4 - O modelo EHL utilizado permite inferir que alterações de viscosidades do lubrificante afetam fortemente as espessuras de filme de lubrificante. Aumentos de viscosidade implicam em aumentos de espessura de filme lubrificante. Entretanto, o modelo LEHL proposto permite afirmar que os aumentos de espessura de filme lubrificante promovem, também, uma redução de contatos limítrofes entre came e tucho, não somente através da diminuição dos contatos de asperezas, mas também pela diminuição das extensões de contatos limítrofes;

5 - Os revestimentos H-DLC preservam a integridade das superfícies metálicas e reduzem atritos, em condições lubrificadas;

6 - Não foi possível descrever satisfatoriamente, via modelo LEHL, os efeitos das adições de etanol hidratado nas interações pino-disco, com disco revestido de H-DLC, o que sugere que existem fenômenos outros, neste caso, não descritos por este modelo. 


\section{Possíveis Próximos Estudos}

Diante deste cenário, alguns possíveis próximos estudos podem ser apontados:

1 - Sobre os efeitos da adição do etanol hidratado na piezo-viscosidade de lubrificantes;

2 - Sobre os diferentes processos de envelhecimento de lubrificantes plenamente formulados e seus efeitos em termos de viscosidades com e sem adição de etanol hidratado;

3 - Sobre a sensibilidade dos valores dos atritos totais came-tucho de ação direta em função de variações de parâmetros geométricos de tucho, came e guia;

4 - Sobre a sensibilidade dos valores dos atritos totais came-tucho de ação direta em função de variações de parâmetros de rugosidades de tucho, came e guia;

5 - Sobre estudos reológicos de diferentes lubrificantes, plenamente formulados ou não, em diferentes temperaturas;

6 - Investigações sobre as interações lubrificante + etanol hidratado $\mathrm{x}$ fime fino deposidado HDLC, ou outros;

7 - Análises, ensaios, modelagens matemáticas, sobre a influência do tilting nas interações came-tucho;

8 - Considerações de comportamentos elásticos de came, tucho e guia, no contexto de modelagem LEHL;

9 - Estudos sobre a dinâmica e vibrações das interações came-tucho para RPMs maiores de eixo came (acima dos 1200 RPM);

10 - Investigações adicionais sobre causas e efeitos de fenômenos flash temperature no contato came-tucho;

11 - Realizar caracterizações de emulsões lubrificante + etanol via distribuição de segunda fase (Raman);

12 - Realizar análises termogravimétricas com as misturas etanol x lubrificante; 


\section{REFERÊNCIAS}

[1] THURSON, R.H. Determination of the Laws and Coefficient of Friction by New Methods and with New Apparatus. Friction and Lubrication, Trübner and Co., Ludgate Hill, London, 1879 .

[2] MARTENS, A. Schmieröluntersuchungen. Mitteilungen aus den Königlichen technischen Versuchsanstalten zu Berlin, Ergänzungsheft III, Verlag von Julius Springer, pp.1-37 Berlin, 1888.

[3] FERRARESE, A. Anéis de Pistão de Baixo Atrito, Mahle Metal Leve, 2015.

[4] ANDERSSON, B.S. Company perspectives in vehicle tribology. Volvo, 17th Leeds-Lyon Symposium on Tribology - Vehicle Tribology, Tribol. Ser. vol. 18 Elsevier, pp. 503-506, Amsterdam, 1991.

[5] WONG, V. W.; TUNG S. C. Overview of automotive engine friction and reduction trends - Effects of surface, material, and lubricant-additive technologies. Friction 4(1), DOI 10.1007/s40544-016-0107-9, 2016.

[6] RATAMERO, L. A.; VENTURA, V. Fuel Economy Sensitivity Analysis for DLC Coatings on Tappets. SAE Technical Paper, 36-0027, 2018.

[7] TOMANIK, E.; LASTRES L. F.; CARVALHO, L. O. Evaluation of an Experimental Lube Oil on Piston Friction, Engine Performance and Vehicle Acceleration. First International Brazilian Conference on Tribology - TriboBr, 2010.

[8] TOMINAGA, T. Effects of Lubricant Composition on Fuel Efficiency in Modern Engines. SAE Technical Paper, 951037, 1995.

[9] MAINWARING, T. R.; MORTIER, R. M. Engine lubricant trends since 1990. Proc. IMechE Vol. 219 Part J: J. Engineering Tribology, J04204 IMechE, 2005.

[10] LUBRIZOL, Ready Reference - Lubricant and Fuels, Version 6, March 2014.

[11] CARVALHO, M. J. S.; SEIDL, P. R.; BELCHIOR, C. R. P.; SODRE, J. R. Lubricant viscosity and viscosity improver additive effects on diesel fuel economy. Tribology International 43 2298-2302, 2010.

[12] JOHNSON, M. D.; JENSEN, R. K., CLAUSING, E. M.; SCHRIEWER, K.; KORSEK, S. Effects of Aging on frictional Properties of Fuel Efficienct Engine Oils. SAE Technical Paper, 952532, 1995.

[13] DYSON, A.; NAYLOR, M. A. Application of the Flash Temperature Concept to Cam and Tappet Wear Problems. Proc Insrn Mech Engrs (AB.), No 8, 1960.

[14] TEODORESCU, M. TARAZA, D. Combined multi-body dynamics and experimental 
investigation for determination of the cam-flat tappet contact condition. Proc. Instn Mech. Engrs Vol. 218 Part K: J. Multi-body Dynamics, 2004.

[15] CHO, M. R.; KIM, H. J.; MOON T.S.; e HAN, D. C. Theoretical and experimental evaluation of tappet rotation for a direct acting valve train system. Int J. Vehicle Design, Vol34, No 1, 2004.

[16] GANGOPADHYAY, Arup.; McWATT D. G.; ZDRODOWSKI, R. J.; SIMKO, S. J.; MATERA, S.; SHEFFER, K.; FURBY, R. S. Valvetrain Friction Reduction through Thin Film Coatings and Polishing. Tribology Transactions, DOI:10.1080/10402004.2011.636169, 2011.

[17] PRIEST, M.; TAYLOR, C.M. Automobile Engine Tribology - approaching the surface. Wear 241 193-203, Elsevier, 2000.

[18] TEODORESCU, M.; KUSHWAHA, M.; RAHNEJAT, H.; ROTHBERG, S. J. Multiphysics analysis of valve train systems: from system level to microscale interactions. Proceedings of the Institution of Mechanical Engineers, Part K: Journal of Multi-body Dynamics, 221 (3), pp. 349-361, 2007.

[19] SCHAMEL, A. R.; GRISCHKE, M.; BETHKE R. Amorphous carbon coatings for low friction and wear and bucket tappet valvetrains. SAE Technical Paper 970004, 1997. [20] TEODORESCU, M.; TARAZA, D.; HENEIN, N. A.; BRYZIK, W. Experimental analysis of dynamics and friction in valve train systems. SAE Technical Paper 2002-01-0484, 2002.

[21] GANGOPADHYAY, A.; SOLTIS, E.; JOHNSON, M. D. Valvetrain friction and wear influence of surface engineering and lubricants. Proc. Instn Mech. Engrs Vol. 218 Part J: J. Engineering Tribology, 2004.

[22] CALABRETTA, M.; CACCIATORE, D.; CARDEN, P. Valvetrain Friction - Modeling, Analysis and Measurement of a High-Performance Engine Valvetrain System. SAE Technical Paper 2010-01-14922010, doi:10.4271/2010-01-1492, 2010.

[23] BOUCHET, D. B.; BOUCHET, M.I., MARTIN J.M. New Trends in Boundary Lubrication of DLC Coatings. In: Donnet C., Erdemir A. (eds) Tribology of Diamond-Like Carbon Films. Springer, Boston, MA., 2008.

[24] KUSHWAHU, M.; RAHNEJAT, H. Transient elastohydrodynamic lubrication of finite line conjunction of cam to follower concentrated contact. Journal of Physics, D: Appl. Phys. $35,2002$. 
[25] OKARMUS, M. M.; KERIBAR, R.; ZDRODOWSKI, R.; GANGOPADHYAY, A. Methodology for Predictive Friction Modeling in Direct-Acting Mechanical Bucket Valvetrain System. SAE International, 2015-01-0677, doi:10.4271/2015-01-0677, 2015.

[26] TEODORESCU, M.; TARAZA, Taraza D.; HEREIN, N. Simplified ElastoHydrodynamic Friction Model of the Cam-Tappet Contact. SAE TECHNICAL PAPER SERIES, 2003-01-0985, ISSN 0148-7191, 2003.

[27] GREENWOOD, J. A.; TRIPP, J. H. The contact of two nominally flat rough surfaces. Proc. Instn Mech. Engrs, 1970-71. 185(48/71), 625-633, 1970.

[28] TOMANIK, E. Modelamento do Desgaste por Deslizamento em Anéis de Pistão de Motores de Combustão Interna. TESE de Doutorado, Escola Politécnica da Universidade de São Paulo, 2000.

[29] PROFITO, F. J. Modelagem Unidimensional do Regime Misto de Lubrificação Aplicada a Superfícies Texturizadas. Dissertação de Mestrado, Escola Politécnica da Universidade de São Paulo, 2010.

[30] ROELANDS, C. J. A. Correlation aspects of viscosity-temperature-pressure relationship of lubricating oils. PhD Thesis, Delft University of Technology, The Netherlands, 1996.

[31] HOGLUND, E. Influence of lubricant properties on elastohydrodynamic lubrication. Wear 232 (1999) 232, 1999.

[32] MASJEDI, M.; KHONSARI M. M. Film Thickness and Asperity Load Formulas for Line Contact Elastohydrodynamic Lubrication with Provision for Surface Roughness. Journal of Tribology, Vol. 134 / 011503-1, JANUARY 2012.

[33] GECIN, B. A. Tribological Study for a Low-Friction Cam/Tappet System Including Tappet Spin. Tribology Transactions, 35:2, 225-234, DOI 10.1080/10402009208982112, 1992. [34] ZHOU, Q.; RICHARDSON S.H. Friction prediction of a cam-tappet interface using an EHL model with consideration of surface texture. Boundary and Mixed Lubrication: Science and Applications, D. Dowson et.al., 2002.

[35] MENG, X.; YU, C.; XIE, Y.; MEI, B. Thermal insulation effect on EHL of coated cam/tappet contact during start up. Industrial Lubrication and Tribology, Vol. 70 Issue: 6, pp.917-926., 2018.

[36] UMAR, M.; MUFTI, R. A.; KHURRAM, M. Effect of flash temperature on engine valve train friction. Tribology International, org/10.1016/j.triboint.2017.09.030, 2018. 
[37] ENGLER, C. M.; NADAI, L.; MARTINS, E. Analysis of Oil Sump Contamination with Ethanol in Flex Fuel Engines after Crank and Warm-up. Society of Automotive Engineers, Inc, 2009.

[38] ABNT NBR 6601:2012. Light road vehicles - Determination of hydrocarbon, carbon monoxide, nitrogen oxide, carbon dioxide and particulate material on exhaust gas. 2012. [39] ZAHID, R.; MASJUKI, H. H.; VARMAN, M.; MUFTI, R. A.; KALAM, A.; GULZAR, M. Effect of Lubricant Formulations on the Tribological Performance of Self-Mated Doped DLC Contacts: a review. Tribol Lett (2015) 58:32 DOI 10.1007/s11249-015-0506-5, 2015.

[40] SHANTA, S. M.; MOLINA, G. J.; SOLOIU, V. Tribological Effects of Mineral-Oil Lubricant Contamination with Biofuels: A Pin-on-Disk Tribometry and Wear Study. Advances in Tribology, Article ID 820795, doi:10.1155/2011/820795, 2011.

[41] GANGOPADHYAY, A. UY, D.; McWATT D.; ZDRODOWSKI, Robert. SIMKO, S. Friction, Wear, and Surface Film Formation Characteristics of Diamondlike Carbon Thin Coating in Valvetrain Application. Ford Research and Advanced Engineering Technical Reports, SRR-2009-01442009, 2009.

[42] BAS, H.; BIYIKLIOGLU, A. CUVALCI, H. A New Test Apparatus for the Tribological Behavior of Cam Mechanisms. Experimental Techniques, Wiley Online Library, 2003.

[43] COSTA, H. L.; SPIKES H. Impact of ethanol on the formation of antiwear tribofilms from engine lubricants. Tribology International, j.triboint.2015.09.021, 2015.

[44] COSTA, H. L.; SPIKES H. Effects of Ethanol Contamination on Friction and Elastohydrodynamic Film Thickness of Engine Oils. Tribology Transactions, 58:1, 158-168, DOI: 10.1080/10402004.2014.957369, 2015.

[45] HANSEN, A. C.; ZHANG, Q.; LYNE, P.W.L. Ethanol - diesel fuel blends - a review, Bioresource Technology 96 (2005) 277-285, 1996.

[46] ROSHAN, R., PRIEST, M.; NEVILlE, A.; MORINA, A.; XIA, X. A Boundary Lubrication Friction Model Sensitive to Detailed Engine Oil Formulation in an Automotive Cam/Follower Interface. Journal of Tribology, Vol. 133 / 042101-1, 2018.

[47] BARTHEM, R. B. Tratamento e Análise de Dados em Física Experimental, Cadernos Didáticos do Instituto de Física (UFRJ), Sub-Reitoria de Ensino de Graduação e Corpo Discente / SR1, 1997.

[48] RONKAINEN, H.; VARJUS, S.; HOLMBERG, K. Friction and wear properties in dry, water- and oil-lubricated DLC against alumina and DLC against steel contacts. Wear 2221998 120-128, 1988. 
[49] LIM, S. C., ASHBY, M. F. BRUNTON J. H. The Effects of Sliding Conditions on the Dry Friction of Metals. Acta metoll. Vol. 37, No. 3, pp. 161-112, 1989. 
APÊNDICE 1

Relatórios de Ensaios da Perfilometria Óptica

Pablo Correia - LFS - Poli USP

\section{Pino Usado}

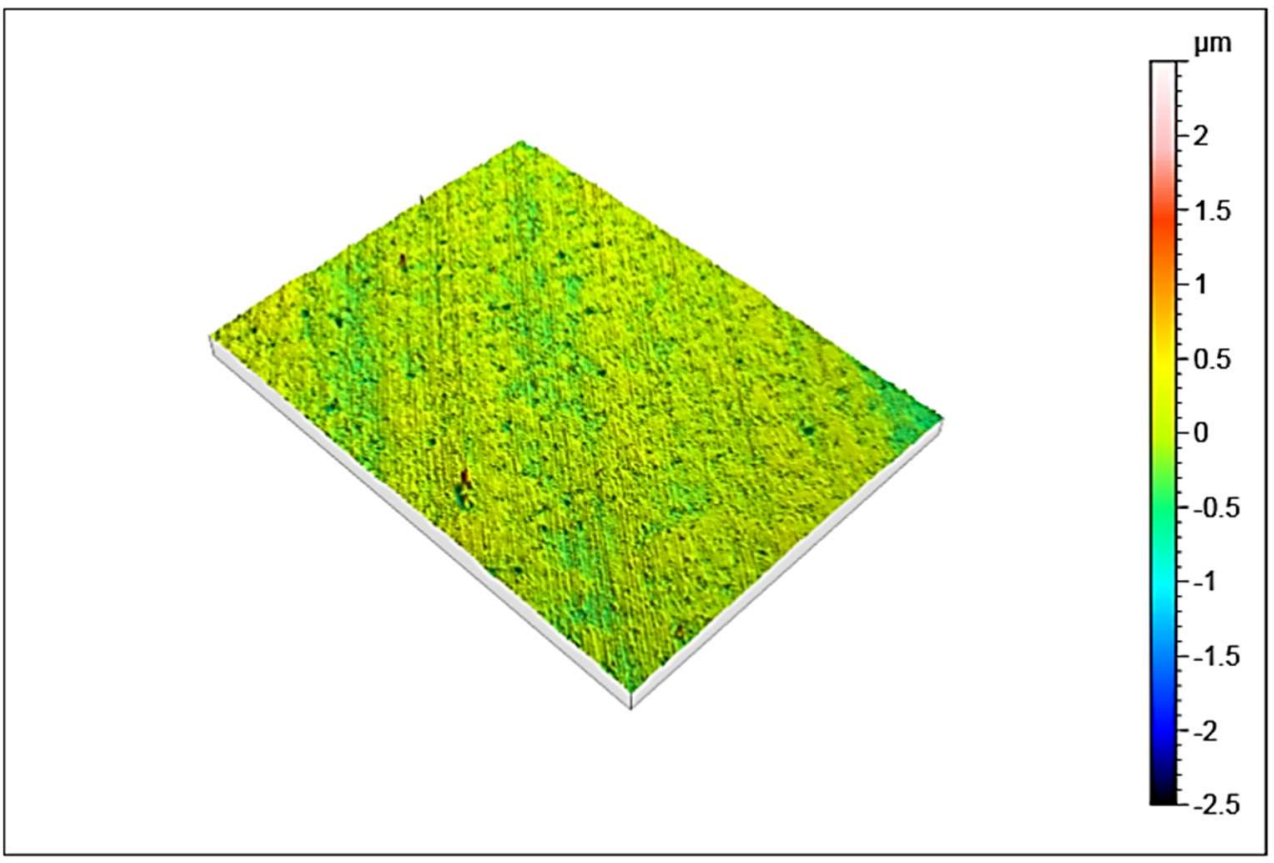

\begin{tabular}{|c|c|c|c|c|}
\hline \multicolumn{5}{|c|}{ ISO 25178} \\
\hline \multicolumn{5}{|c|}{ Height Parameters } \\
\hline Sa & 0.1045 & $\mu \mathrm{m}$ & & Anthmetic mean height \\
\hline $\mathrm{Sq}$ & 0.1423 & $\mu \mathrm{m}$ & & Root mean square height \\
\hline Ssk & -1.123 & & & Skewness \\
\hline Sku & 16.04 & & & Kurtosis \\
\hline Sp & 1.726 & $\mu \mathrm{m}$ & & Maximum peak height \\
\hline Sv & 2.818 & $\mu \mathrm{m}$ & & Maximum pit height \\
\hline Sz & 4.544 & $\mu \mathrm{m}$ & & Maximum height \\
\hline \multicolumn{5}{|c|}{ Functional Parameters (Stratified surfaces) } \\
\hline Sk & 0.3181 & $\mu \mathrm{m}$ & & Core roughness depth \\
\hline Spk & 0.1222 & $\mu \mathrm{m}$ & & Reduced summt height \\
\hline Svk & 0.2213 & $\mu \mathrm{m}$ & & Reduced valley depth \\
\hline \multicolumn{5}{|c|}{ Functional Parameters (Volume) } \\
\hline Vvv & 0.01972 & $\mu \mathrm{m}^{3} / \mu \mathrm{m}^{2}$ & $p=80 \%$ & Pin void volume \\
\hline Vmp & 0.006303 & $\mu \mathrm{m}^{3} / \mu \mathrm{m}^{2}$ & $p=10 \%$ & Peak material volume \\
\hline Vmc & 0.1122 & $\mu \mathrm{m}^{3} / \mu \mathrm{m}^{2}$ & $p=10 \%, q=80 \%$ & Core material volume \\
\hline Vm & 0.006303 & $\mu \mathrm{m}^{3} / \mu \mathrm{m}^{2}$ & $p=10 \%$ & Material volume \\
\hline$V_{V}$ & 0.1674 & $\mu \mathrm{m}^{3} / \mu \mathrm{m}^{2}$ & $p=10 \%$ & Void volume \\
\hline Vvc & 0.1477 & $\mu \mathrm{m}^{3} / \mu \mathrm{m}^{2}$ & $p=10 \%, q=80 \%$ & Core void volume \\
\hline
\end{tabular}




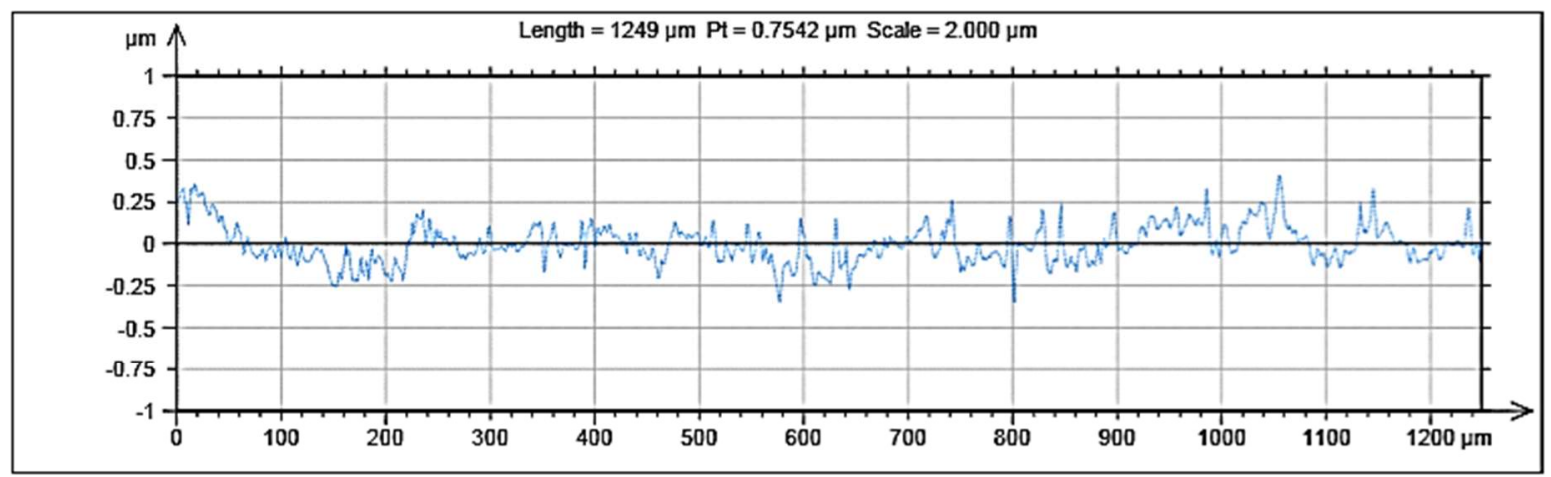

\begin{tabular}{|c|c|c|c|}
\hline \multicolumn{4}{|c|}{ ISO 4287} \\
\hline \multicolumn{4}{|c|}{ Amplitude parameters - Roughness profile } \\
\hline Rp & 0.2530 & $\mu \mathrm{m}$ & Robust Gaussian Fìter, $0.25 \mathrm{~mm}$ \\
\hline Rv & 0.2543 & $\mu \mathrm{m}$ & Robust Gaussian Fïter, $0.25 \mathrm{~mm}$ \\
\hline $\mathbf{R z}$ & 0.6175 & $\mu \mathrm{m}$ & Rabust Gaussian Fiter, $0.8 \mathrm{~mm}$ \\
\hline Rc & 0.2623 & $\mu \mathrm{m}$ & Robust Gaussian Fiiter, $0.8 \mathrm{~mm}$ \\
\hline Rt & 0.6175 & $\mu \mathrm{m}$ & Robust Gaussian Fìter, $0.8 \mathrm{~mm}$ \\
\hline $\mathrm{Ra}$ & 0.07802 & $\mu \mathrm{m}$ & Robust Goussian Fìter, $0.8 \mathrm{~mm}$ \\
\hline $\mathrm{Rq}$ & 0.09755 & $\mu \mathrm{m}$ & Robust Gaussian Fïter, $0.8 \mathrm{~mm}$ \\
\hline Rsk & -0.2869 & & Robust Gaussian Fïter, $0.8 \mathrm{~mm}$ \\
\hline Rku & 3.082 & & Robust Goussian Föter, $0.8 \mathrm{~mm}$ \\
\hline \multicolumn{4}{|c|}{ Spacing parameters - Roughness profile } \\
\hline RSm & 25.74 & $\mu \mathrm{m}$ & Robust Gaussian Fïter, $0.8 \mathrm{~mm}$ \\
\hline \multicolumn{4}{|c|}{ Spacing parameters - Primary profile } \\
\hline PSm & 32.83 & $\mu \mathrm{m}$ & \\
\hline
\end{tabular}

\section{Disco Usado Comum}

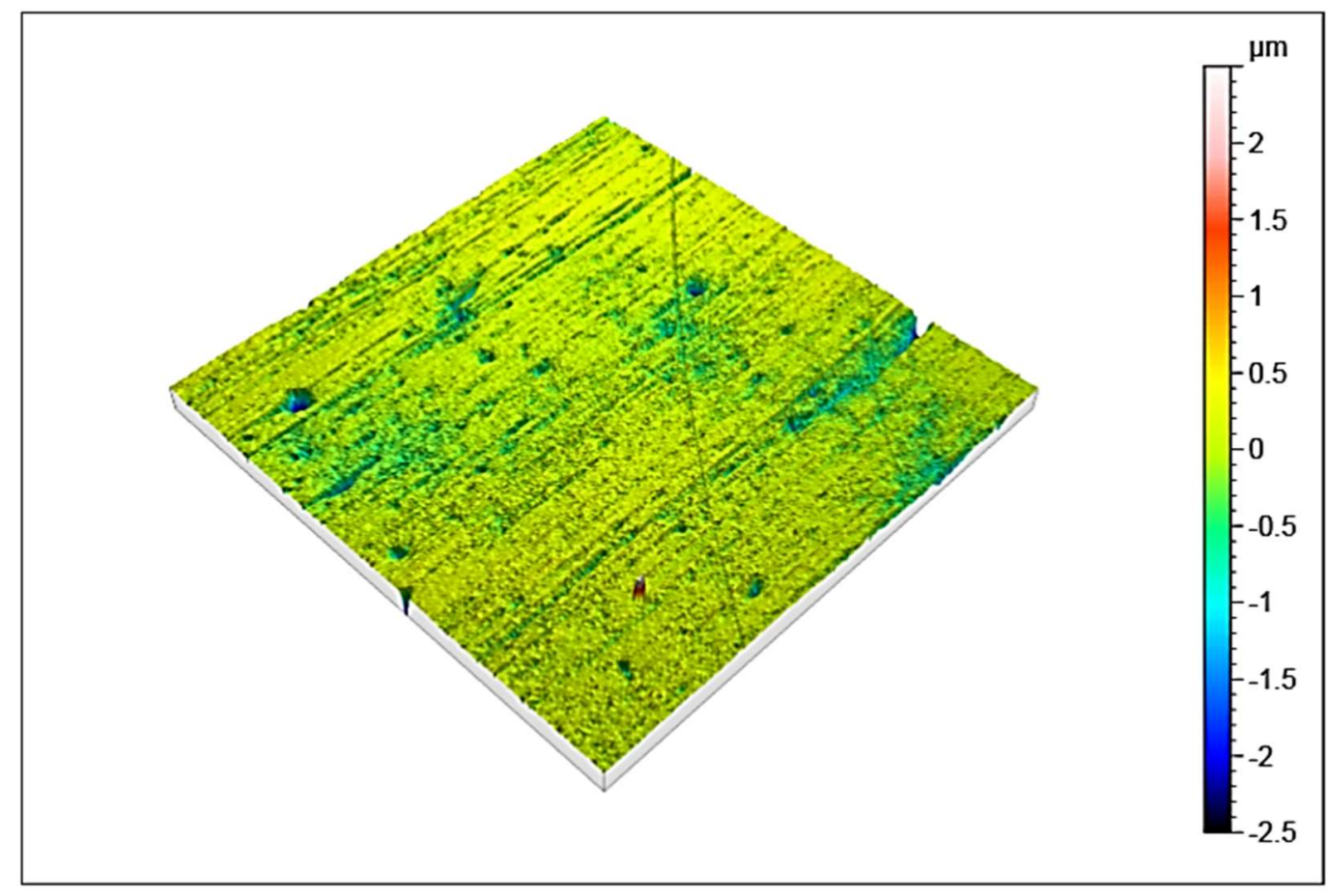




\begin{tabular}{|c|c|c|c|c|}
\hline \multicolumn{5}{|c|}{ ISO 25178} \\
\hline \multicolumn{5}{|c|}{ Height Parameters } \\
\hline Sa & 0.1658 & $\mu \mathrm{m}$ & & Arithmetic mean height \\
\hline Sq & 0.3541 & $\mu \mathrm{m}$ & & Root mean square height \\
\hline Ssk & -13.28 & & & Skewness \\
\hline Sku & 354.6 & & & Kurtosis \\
\hline Sp & 6.196 & $\mu \mathrm{m}$ & & Maximum pesk height \\
\hline Sv & 15.60 & $\mu \mathrm{m}$ & & Maximum pin height \\
\hline Sz & 21.80 & $\mu \mathrm{m}$ & & Maximum height \\
\hline \multicolumn{5}{|c|}{ Functional Parameters (Stratified surfaces) } \\
\hline Sk & 0.3924 & $\mu \mathrm{m}$ & & Core roughness depth \\
\hline Spk & 0.1299 & $\mu \mathrm{m}$ & & Reduced summt height \\
\hline Svk & 0.6697 & $\mu \mathrm{m}$ & & Reduced valley depth \\
\hline \multicolumn{5}{|c|}{ Functional Parameters (Volume) } \\
\hline Vvv & 0.05516 & $\mu \mathrm{m}^{3} / \mathrm{m}^{2}$ & $p=80 \%$ & Pit void volume \\
\hline Vmp & 0.005224 & $\mu \mathrm{m}^{3} / \mu \mathrm{m}^{2}$ & $p=10 \%$ & Peak moterial volume \\
\hline Vmc & 0.1466 & $\mu \mathrm{m}^{3} / \mu \mathrm{m}^{2}$ & $p=10 \%, q=80 \%$ & Core materia/ volume \\
\hline Vm & 0.005224 & $\mu \mathrm{m}^{3} / \mu \mathrm{m}^{2}$ & $p=10 \%$ & Material volume \\
\hline Vv & 0.2302 & $\mu \mathrm{m}^{3} / \mu \mathrm{m}^{2}$ & $p=10 \%$ & Void volume \\
\hline Vvc & 0.1751 & $\mu \mathrm{m}^{3} / \mathrm{m}^{2}$ & $p=10 \%, q=80 \%$ & Core void volume \\
\hline
\end{tabular}

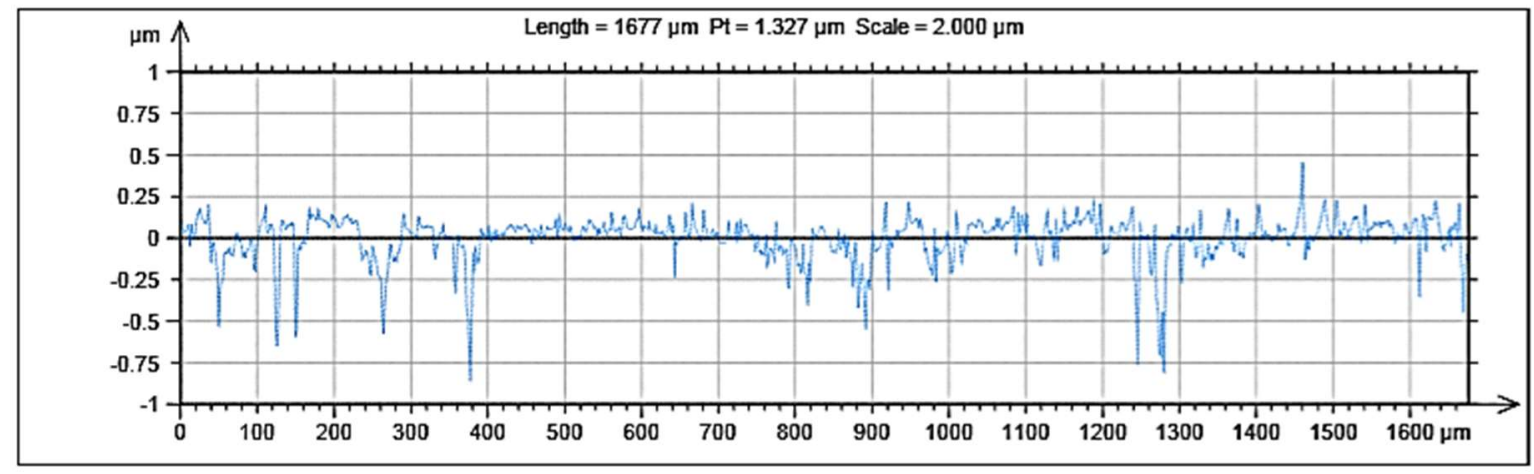

\begin{tabular}{|c|c|c|c|}
\hline \multicolumn{4}{|c|}{ ISO 4287} \\
\hline \multicolumn{4}{|c|}{ Amplitude parameters - Roughness profile } \\
\hline Rp & 0.1851 & $\mu \mathrm{m}$ & Robust Gaussian Fiter, $0.25 \mathrm{~mm}$ \\
\hline Rv & 0.6327 & $\mu \mathrm{m}$ & Robust Gaussian Fiver, $0.25 \mathrm{~mm}$ \\
\hline $\mathbf{R z}$ & 0.7641 & $\mu \mathrm{m}$ & Robust Gaussian Fitter, $0.8 \mathrm{~mm}$ \\
\hline Rc & 0.3454 & $\mu \mathrm{m}$ & Robust Gaussian Fiver, $0.8 \mathrm{~mm}$ \\
\hline Rt & 0.9965 & $\mu \mathrm{m}$ & Robust Gaussian Fiver, $0.8 \mathrm{~mm}$ \\
\hline Ra & 0.07007 & $\mu \mathrm{m}$ & Robust Gaussian Fiver, $0.8 \mathrm{~mm}$ \\
\hline $\mathbf{R q}$ & 0.09649 & $\mu \mathrm{m}$ & Robust Gaussian Fitter, $0.8 \mathrm{~mm}$ \\
\hline Rsk & -1.342 & & Robust Gaussian Fiter, $0.8 \mathrm{~mm}$ \\
\hline Rku & 6.901 & & Robust Gaussian Fitter, $0.8 \mathrm{~mm}$ \\
\hline \multicolumn{4}{|c|}{ Spacing parameters - Roughness profile } \\
\hline $\mathbf{R S m}$ & 26.98 & $\mu \mathrm{m}$ & Robust Gaussian Fìter, $0.8 \mathrm{~mm}$ \\
\hline \multicolumn{4}{|c|}{ Spacing parameters - Primary profile } \\
\hline
\end{tabular}




\section{APÊNDICE 2}

\section{Testes de Misturas Etanol-Óleo}

\section{Tatuí - SP, 31 de Maio de 2015}

São apresentadas quatro experiências com óleo lubrificante motor sintético SN5W30 e Etanol Hidratado, à temperatura ambiente, procurando simular processo de mistura a frio no cárter.

Foram utilizados três tipos de óleo lubrificante: novo, usado até $200 \mathrm{~km}$ em veículo e usado até $15000 \mathrm{~km}$ em veículo de passeio.

Foi observado:

Tempos de separação, se ocorrer;

Mudanças de aspecto no etanol, se ocorrer separação;

Mudanças de aspecto no óleo, se ocorrer separação;

Efeitos da adição de gasolina à mistura;

Experiência \#1 - Óleo Lubrificante - Etanol Hidratado
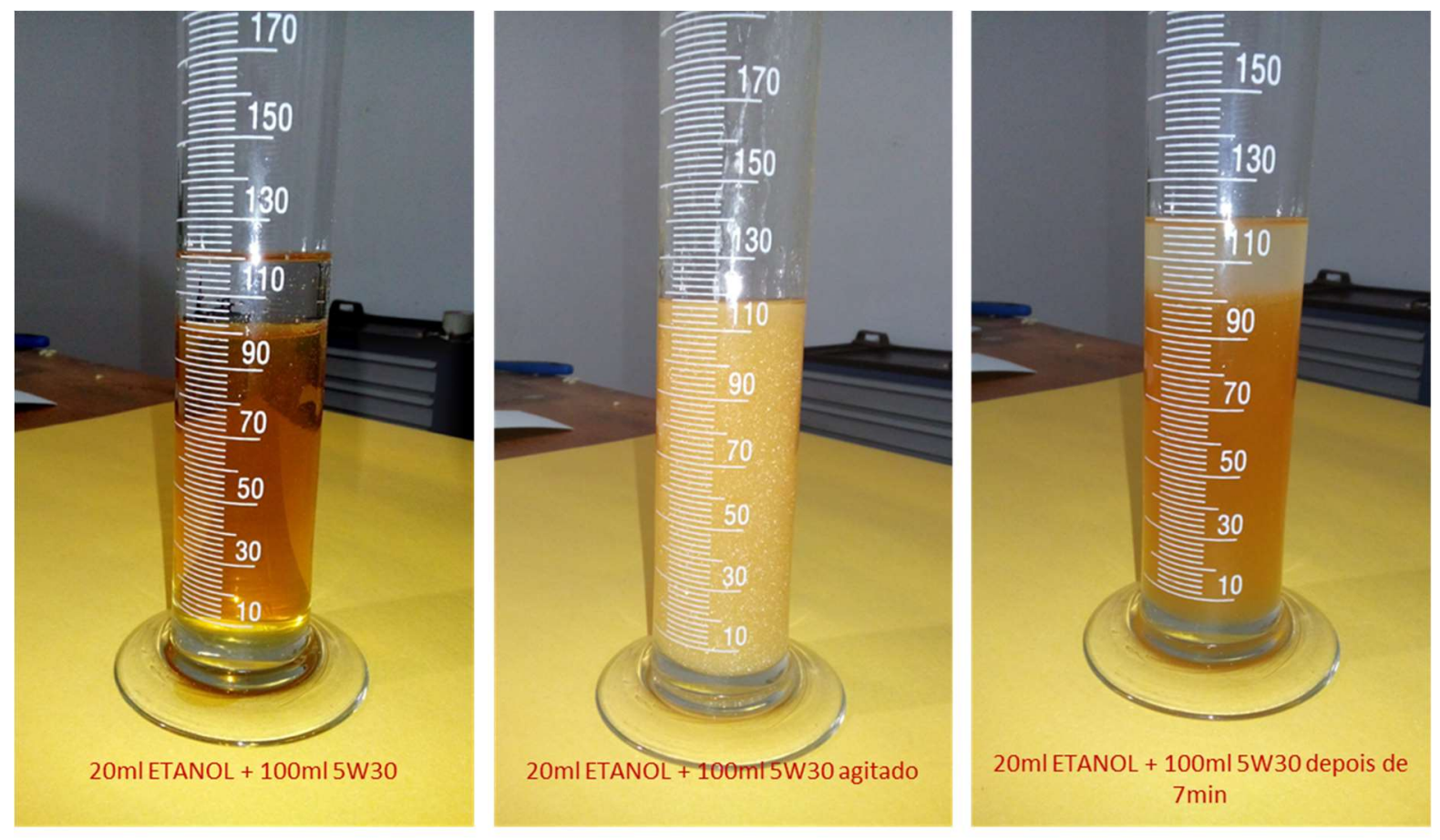

- Tempo de separação: $7 \mathrm{~min}$

- Mudanças de aspecto do etanol: leitoso

- Mudança de aspecto do óleo: leitoso

Experiência \#2 - Óleo Lubrificante - Etanol Hidratado - Gasolina 

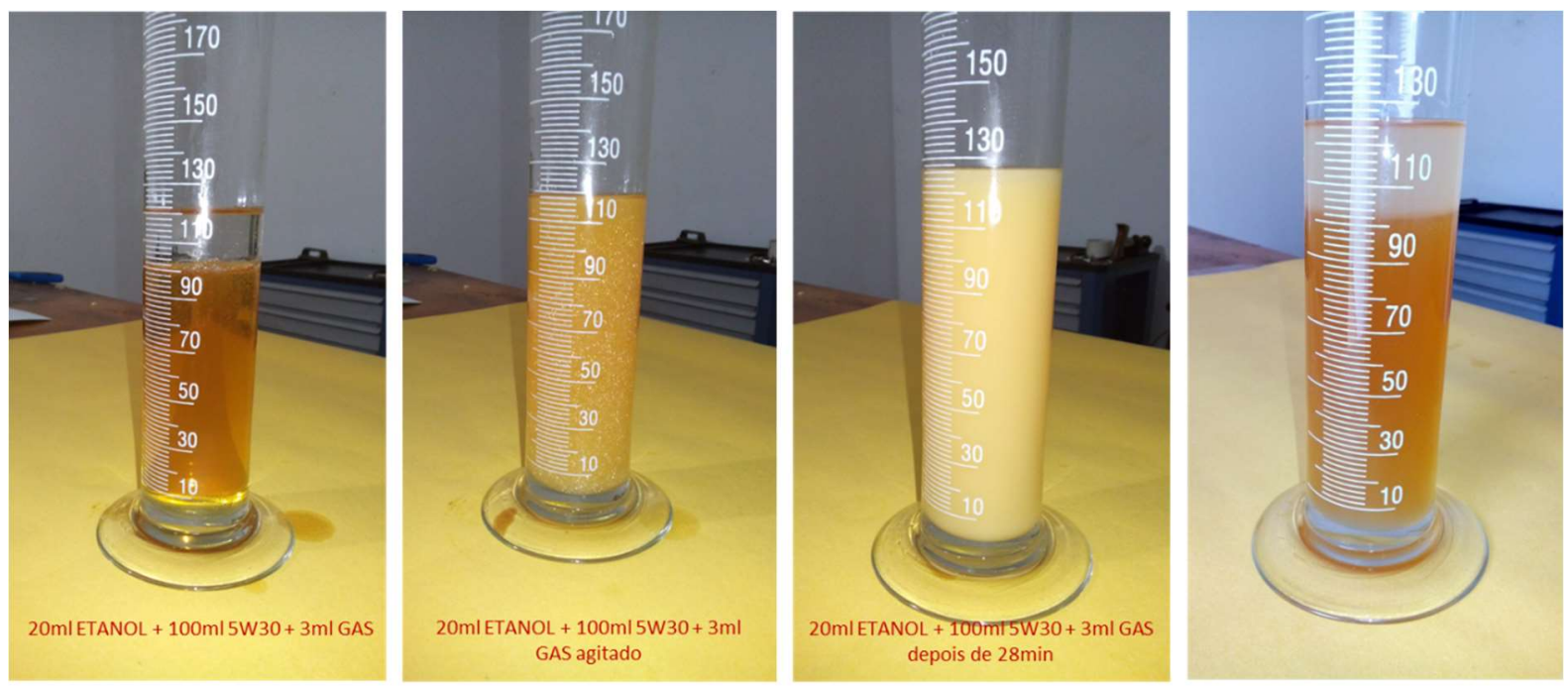

- $\quad$ Tempo de separação: 1 h30min

- Mudanças de aspecto do etanol: leitoso

- $\quad$ Mudança de aspecto do óleo: leitoso

Experiência \#3 - Óleo Lubrificante 2000km - Etanol Hidratado
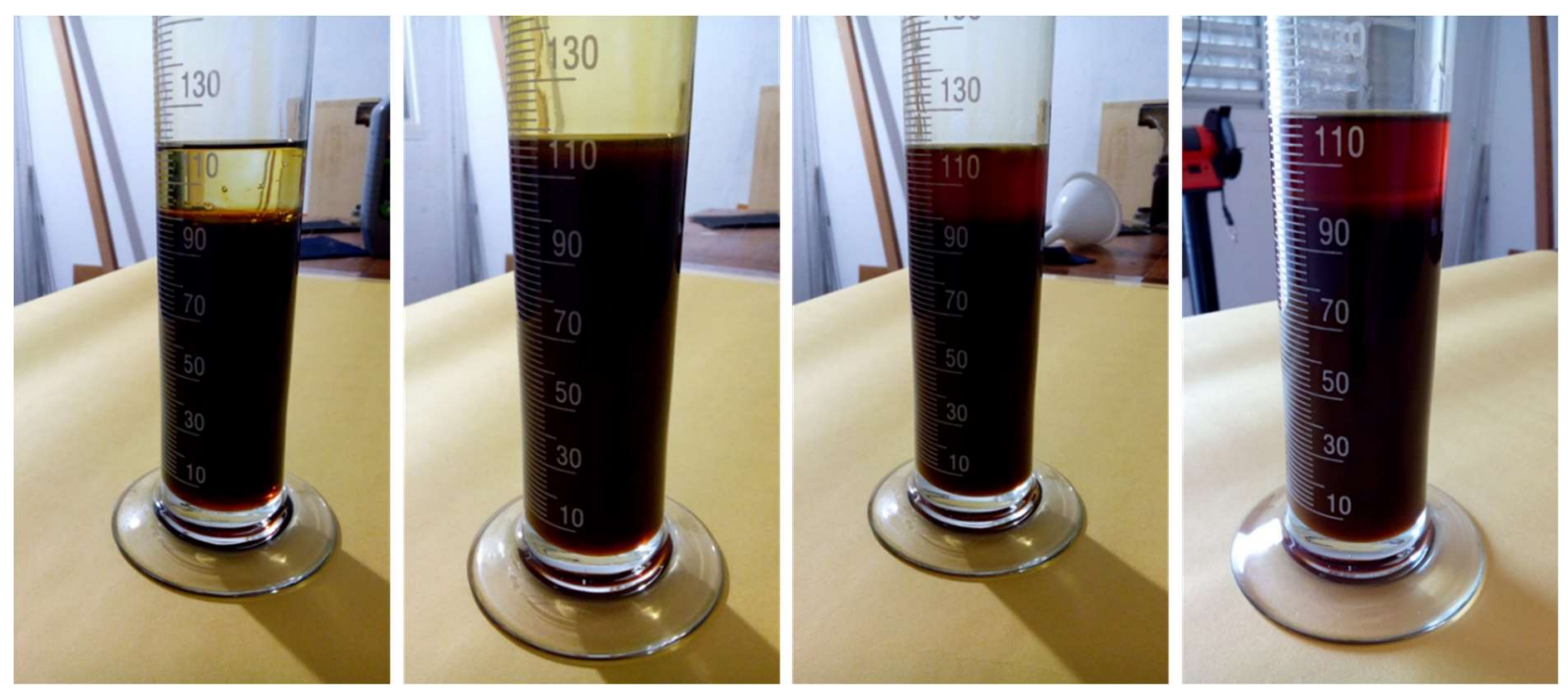

- $\quad$ Tempo de separação: 39min

- Mudanças de aspecto do etanol: caramelizado

- Mudança de aspecto do óleo: sem alteração 
Experiência \#4 - Óleo Lubrificante 15000km - Etanol Hidratado
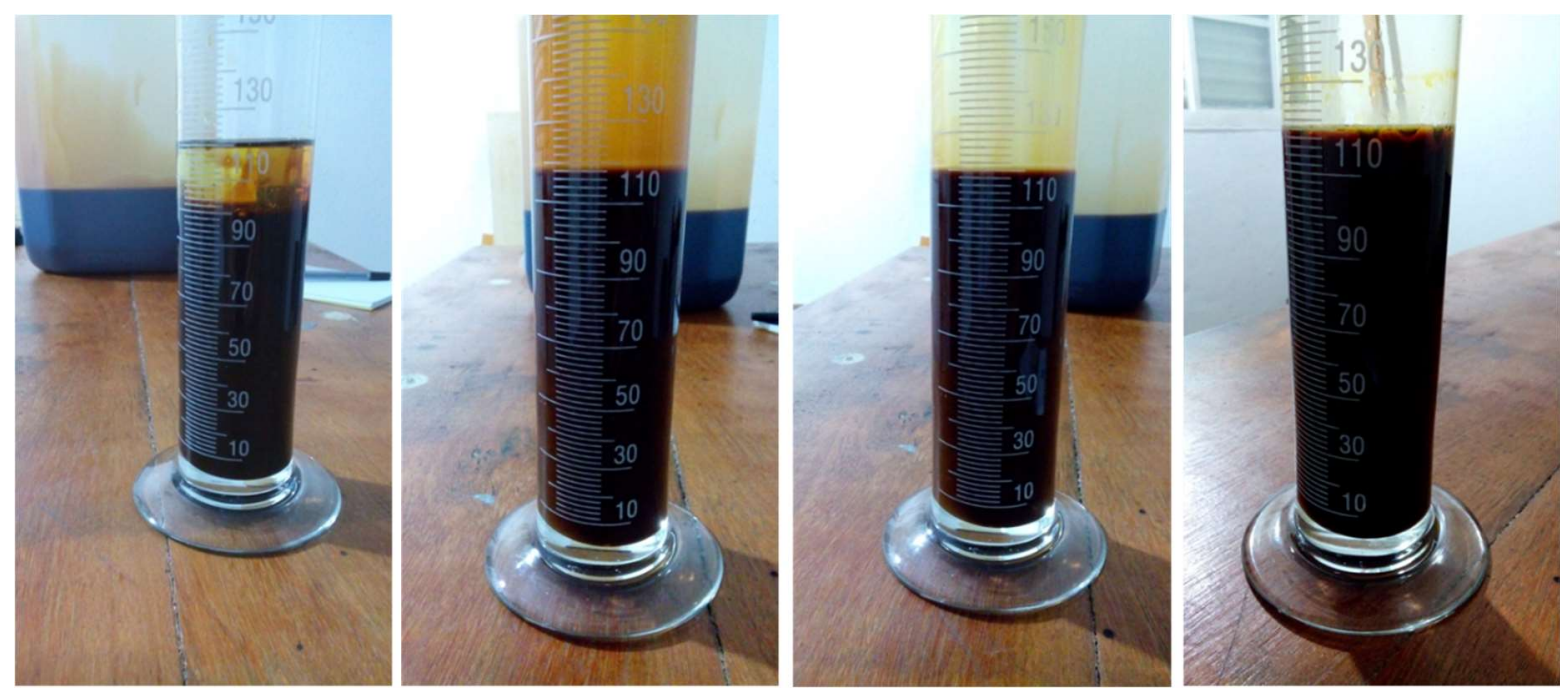

- $\quad$ Tempo de separação: indeterminado

- $\quad$ Mudanças de aspecto do etanol: n/a

- $\quad$ Mudança de aspecto do óleo: n/a 
APÊNDICE 3

Relatórios de Ensaios da Perfilometria Óptica

\section{Rafael Obara - LFS - Poli USP}

\section{Nariz de Came Novo}
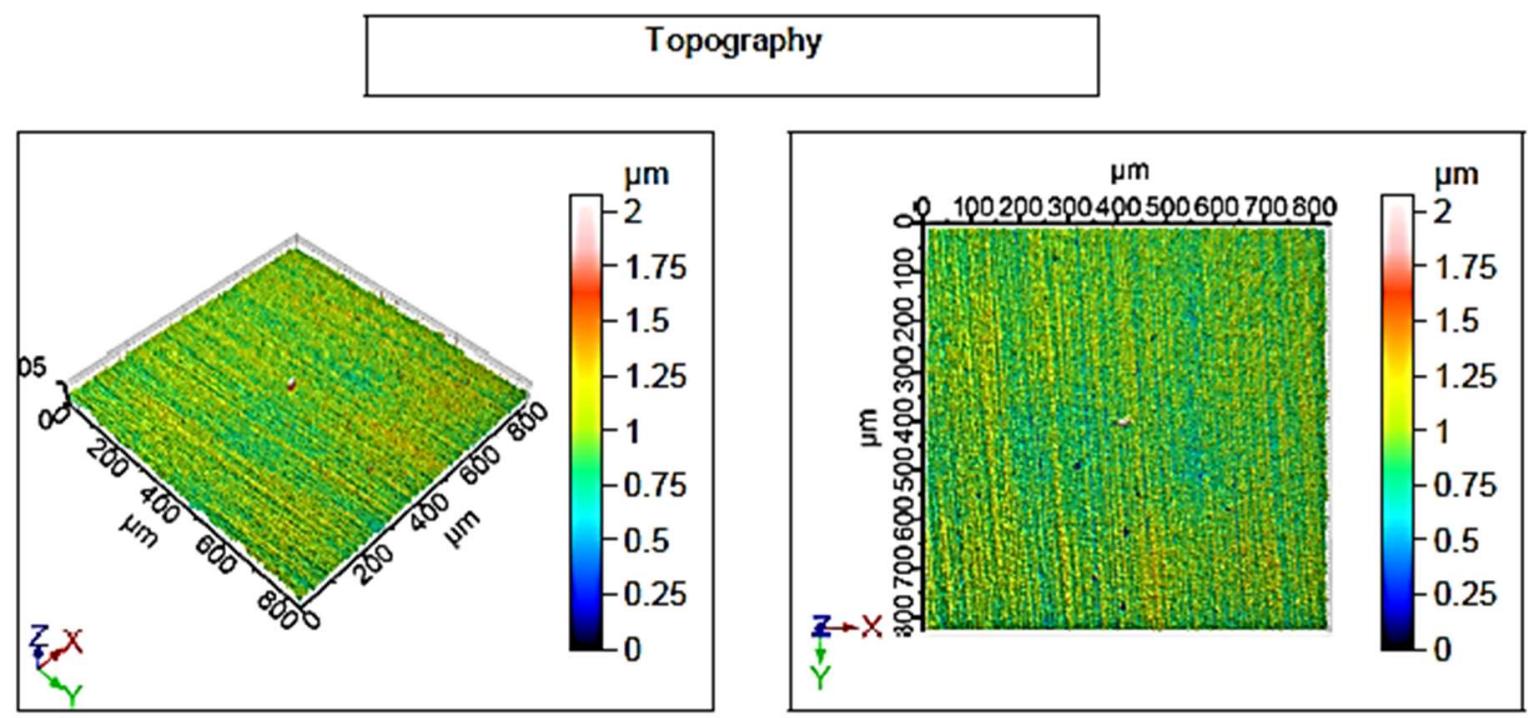

\begin{tabular}{|c|c|c|c|c|}
\hline \multicolumn{5}{|c|}{ ISO 25178} \\
\hline \multicolumn{5}{|c|}{ Height Parameters } \\
\hline $\mathbf{S q}$ & 0.3841 & $\mu \mathrm{m}$ & & Root mean square height \\
\hline Ssk & 28.30 & & & Skewness \\
\hline Sku & 1503 & & & Kurtosis \\
\hline Sp & 23.42 & $\mu \mathrm{m}$ & & Maximum peak height \\
\hline Sv & 7.842 & $\mu \mathrm{m}$ & & Maximum pz height \\
\hline Sz & 31.26 & $\mu \mathrm{m}$ & & Maximum height \\
\hline Sa & 0.1605 & $\mu \mathrm{m}$ & & Arthmetic mean height \\
\hline \multicolumn{5}{|c|}{ Functional Parameters } \\
\hline Smr & 0.00553 & $\%$ & $c=1 \mu \mathrm{m}$ under the highest peak & Areal material ratio \\
\hline Smc & 0.2427 & $\mu \mathrm{m}$ & $p=10 \%$ & Inverse areal material ratio \\
\hline Sxp & 0.4534 & $\mu \mathrm{m}$ & $p=50 \%, q=97.5 \%$ & Extreme peak height \\
\hline \multicolumn{5}{|c|}{ Spatial Parameters } \\
\hline Sal & 5.710 & $\mu \mathrm{m}$ & $s=0.2$ & Auto-correlation length \\
\hline Str & 0.4042 & & $s=0.2$ & Texture-aspect ratio \\
\hline Std & 93.49 & $\circ$ & Reference Angle $=0^{\circ}$ & Texture direction \\
\hline \multicolumn{5}{|c|}{ Hybrid Parameters } \\
\hline Sdq & 0.3398 & & & Root mean square gradient \\
\hline Sdr & 4.875 & $\%$ & & Developed interfacial area ratio \\
\hline \multicolumn{5}{|c|}{ Functional Parameters (Stratified surfaces) } \\
\hline Sk & 0.3751 & $\mu \mathrm{m}$ & not fitered & Core roughness depth \\
\hline Spk & 0.2538 & $\mu \mathrm{m}$ & not fitered & Reouced summit height \\
\hline Svk & 0.3405 & $\mu \mathrm{m}$ & nat fitered & Reouced valley depth \\
\hline Smr1 & 11.94 & $\%$ & not fitered & Upper bearing area \\
\hline Smr2 & 82.39 & $\%$ & not fitered & Lower bearing area \\
\hline \multicolumn{5}{|c|}{ ASME B46.1 } \\
\hline \multicolumn{5}{|c|}{ 3D Parameters } \\
\hline swt & 0.3214 & $\mu \mathrm{m}$ & Gaussian fiter, $0.25 \mathrm{~mm}$ & Area waviness height \\
\hline
\end{tabular}



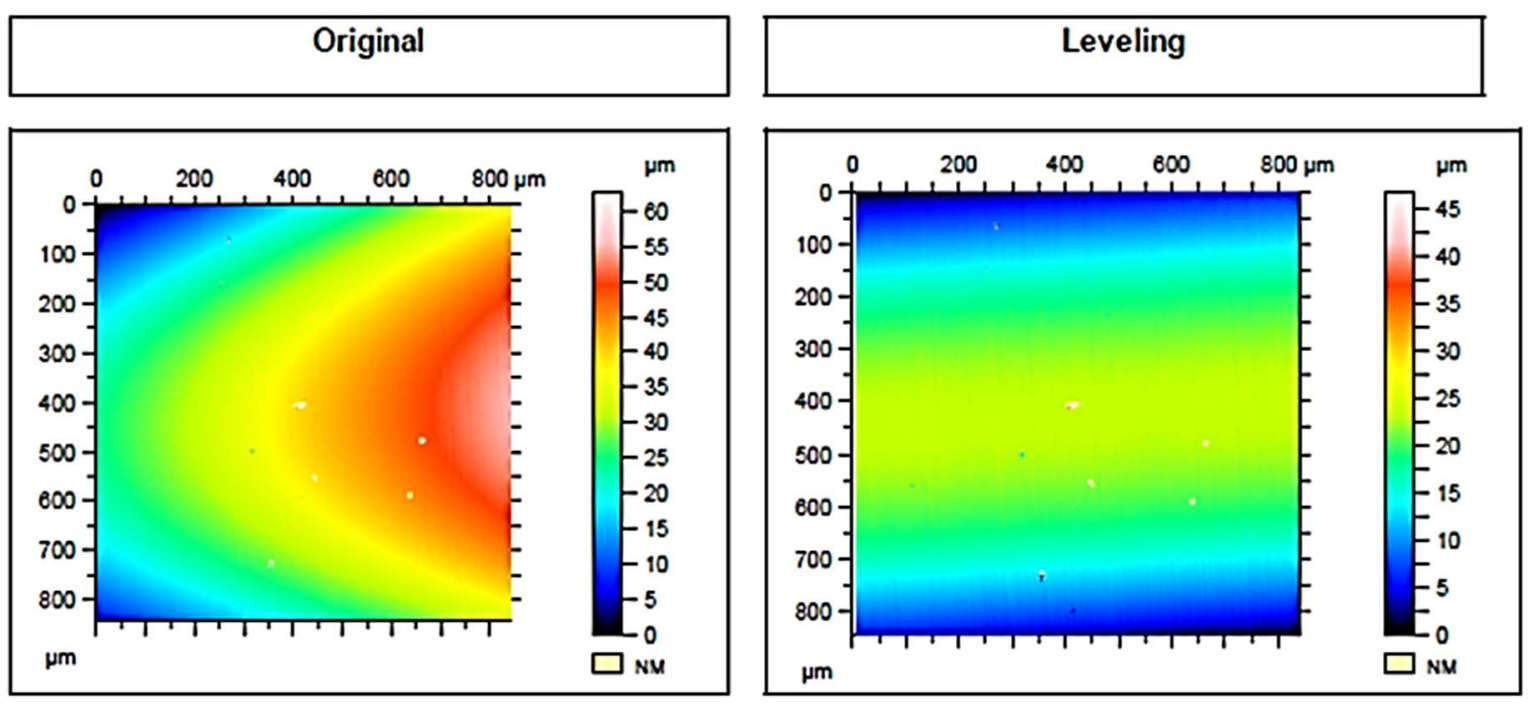

Fill in non-measured points

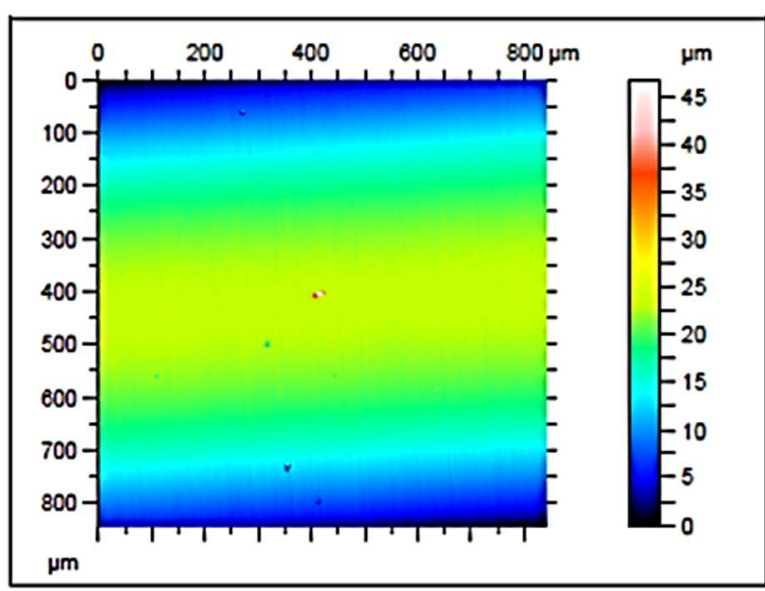

\section{Form Removal}
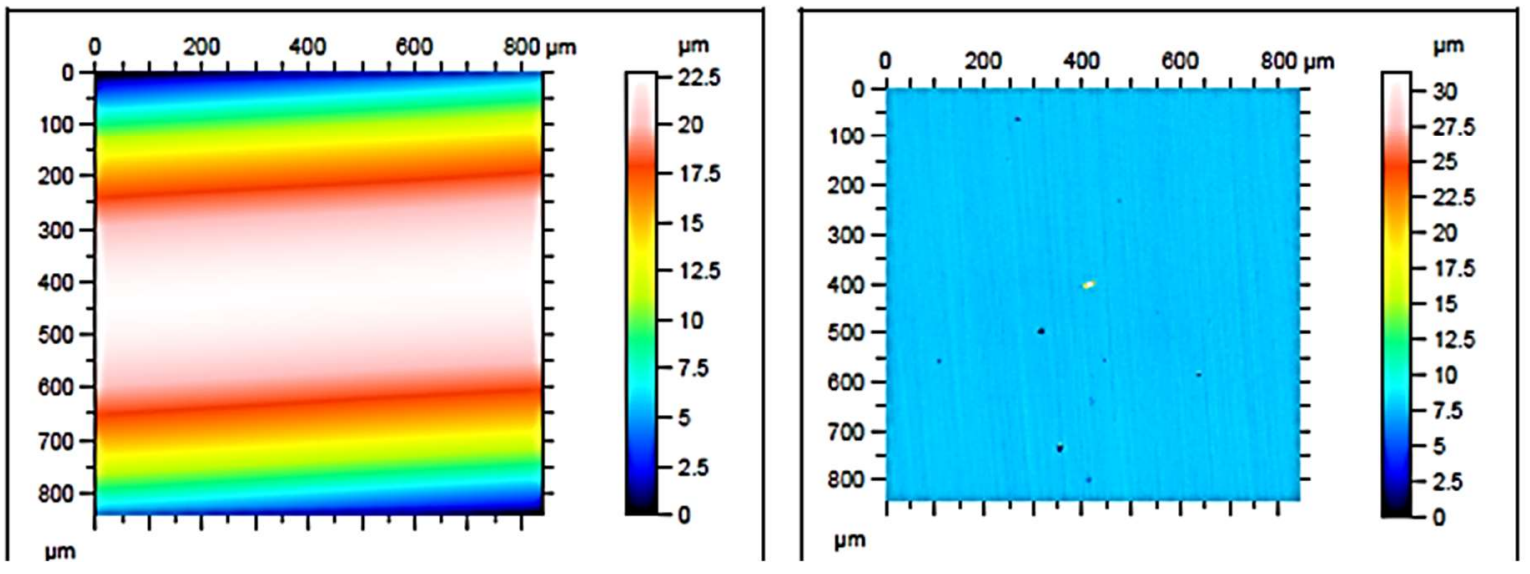


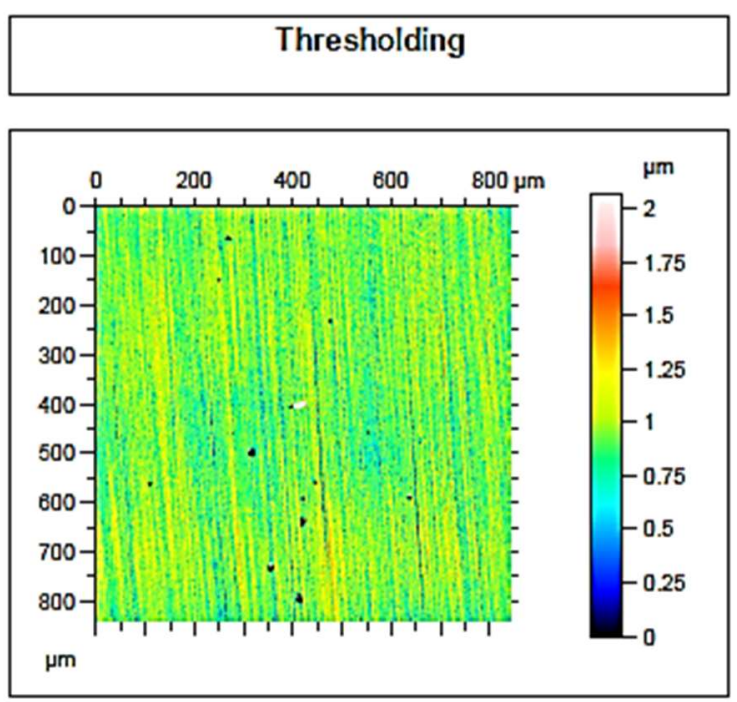


Tucho Normal Novo

\section{Topography}
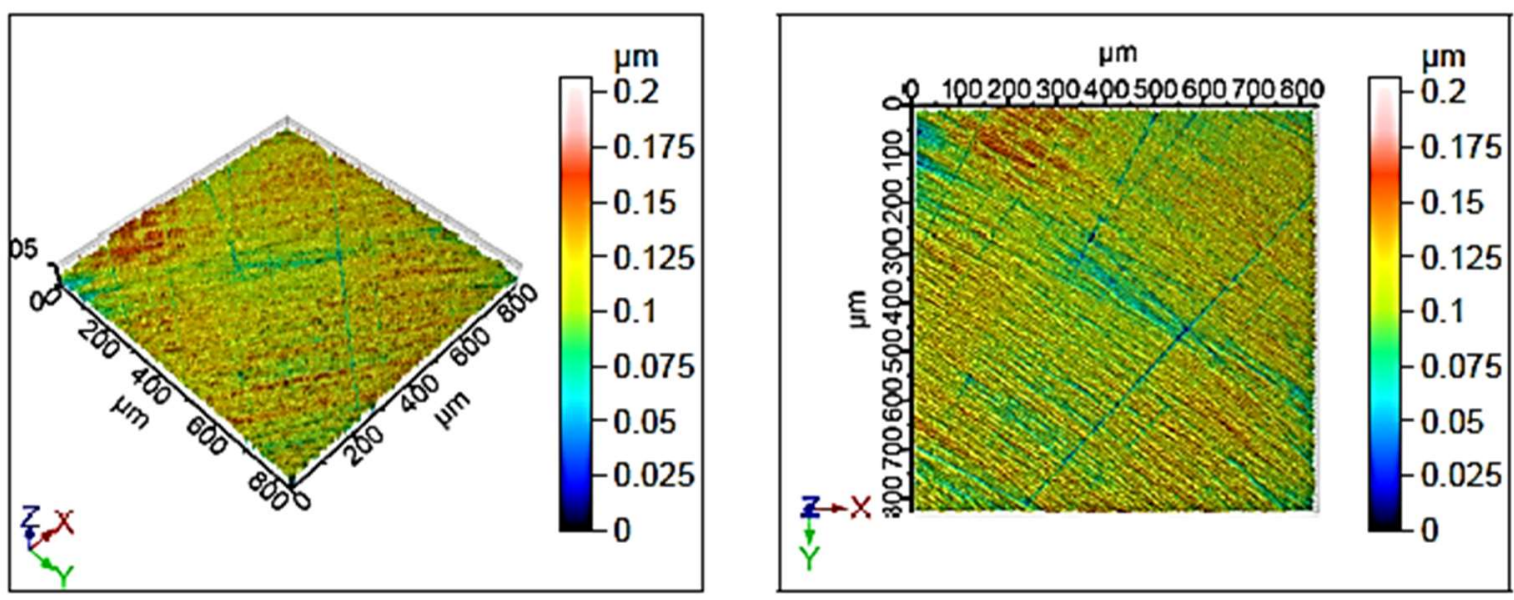

\begin{tabular}{|c|c|c|c|c|}
\hline \multicolumn{5}{|c|}{ ISO 25178} \\
\hline \multicolumn{5}{|c|}{ Height Parameters } \\
\hline Sq & 0.02577 & $\mu \mathrm{m}$ & & Root mean square height \\
\hline Ssk & -0.4789 & & & Skewness \\
\hline Sku & 12.80 & & & Kurtosis \\
\hline Sp & 1.145 & $\mu \mathrm{m}$ & & Maximum peak height \\
\hline Sv & 0.8228 & $\mu \mathrm{m}$ & & Maximum ps height \\
\hline Sz & 1.968 & $\mu \mathrm{m}$ & & Maximum height \\
\hline Sa & 0.01954 & $\mu \mathrm{m}$ & & Arthmetic mean height \\
\hline \multicolumn{5}{|c|}{ Functional Parameters } \\
\hline Smr & 0.01129 & $\%$ & $c=1 \mu \mathrm{m}$ under the highest peak & Areal material ratio \\
\hline Smc & 0.03052 & $\mu \mathrm{m}$ & $p=10 \%$ & Inverse areal material ratio \\
\hline Sxp & 0.0589 & $\mu \mathrm{m}$ & $p=50 \%, q=97.5 \%$ & Extreme peak height \\
\hline \multicolumn{5}{|c|}{ Spatial Parameters } \\
\hline Sal & 1.601 & $\mu \mathrm{m}$ & $s=0.2$ & Auto-correlation length \\
\hline Str & 0.0439 & & $s=0.2$ & Texture-aspect ratio \\
\hline Std & 151.5 & 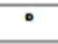 & Reference Angle $=0^{\circ}$ & Texture direction \\
\hline \multicolumn{5}{|c|}{ Hybrid Parameters } \\
\hline Sdq & 0.03167 & & & Root mean square gradient \\
\hline Sdr & 0.05007 & $\%$ & & Developed interfacial area ratio \\
\hline \multicolumn{5}{|c|}{ Functional Parameters (Stratified surfaces) } \\
\hline Sk & 0.05905 & $\mu \mathrm{m}$ & not filtered & Core roughness depth \\
\hline Spk & 0.02229 & $\mu \mathrm{m}$ & not filered & Reduced summit height \\
\hline Svk & 0.04583 & $\mu \mathrm{m}$ & not fitered & Reduced valey depth \\
\hline Smr1 & 7.953 & $\%$ & not filered & Upper bearing area \\
\hline Smr2 & 86.85 & $\%$ & not filtered & Lower bearing area \\
\hline \multicolumn{5}{|c|}{ ASME B46.1 } \\
\hline \multicolumn{5}{|c|}{ 3D Parameters } \\
\hline SWt & 0.03079 & $\mu \mathrm{m}$ & Gaussian fiter, $0.25 \mathrm{~mm}$ & Area waviness height \\
\hline
\end{tabular}



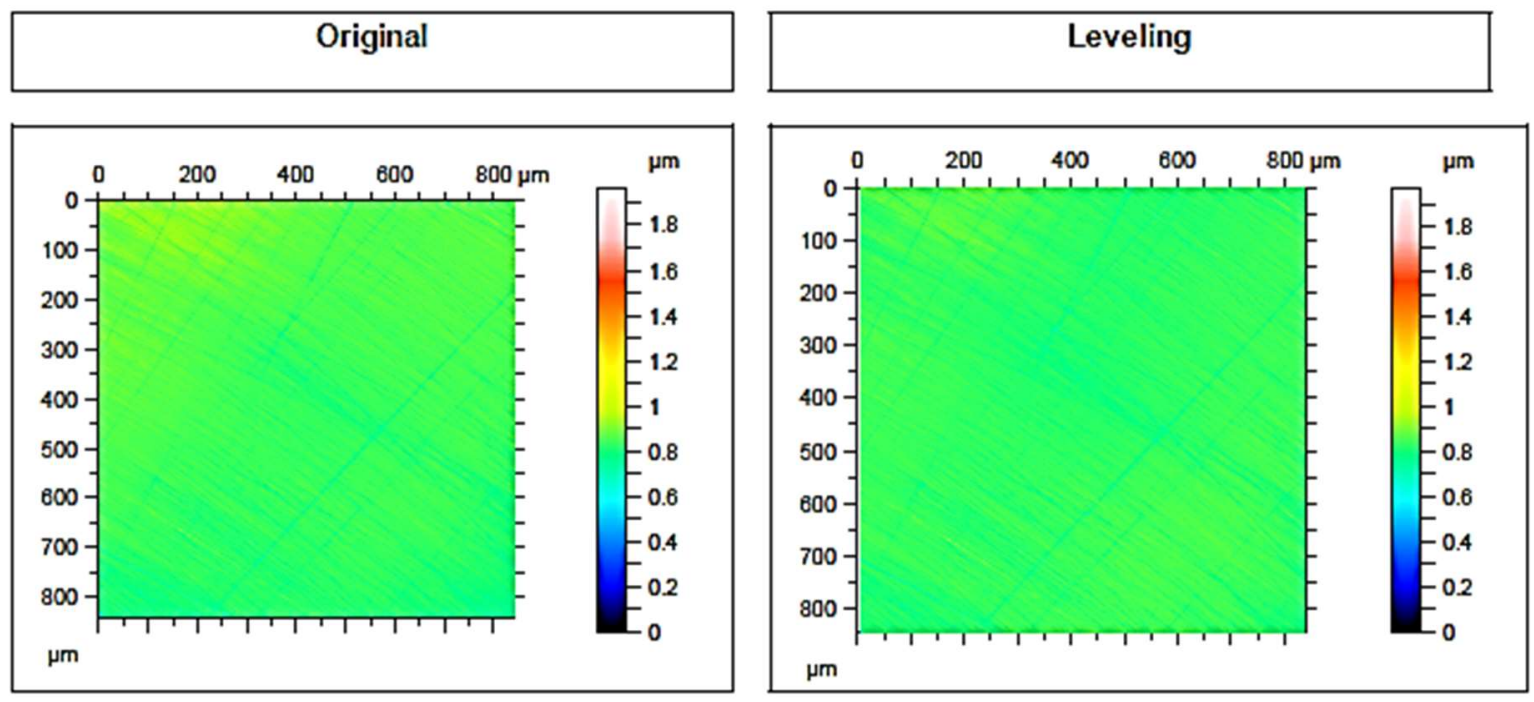

Fill in non-measured points

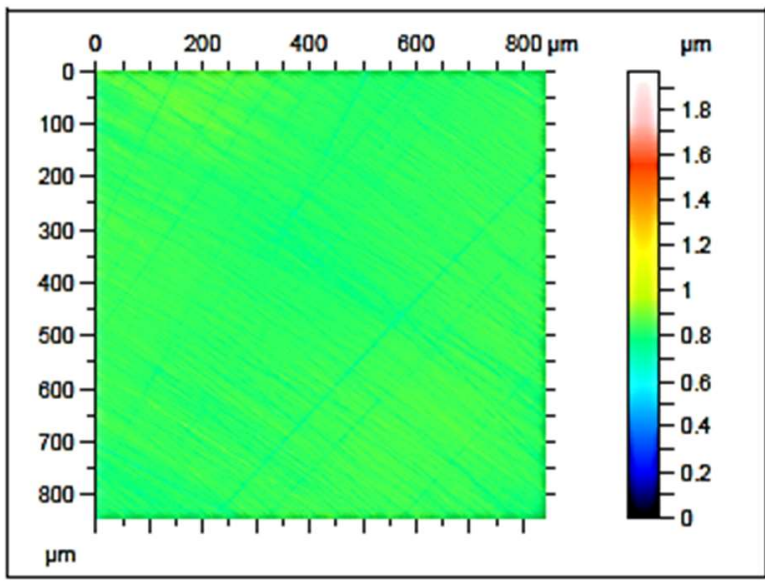

\section{Form Removal}
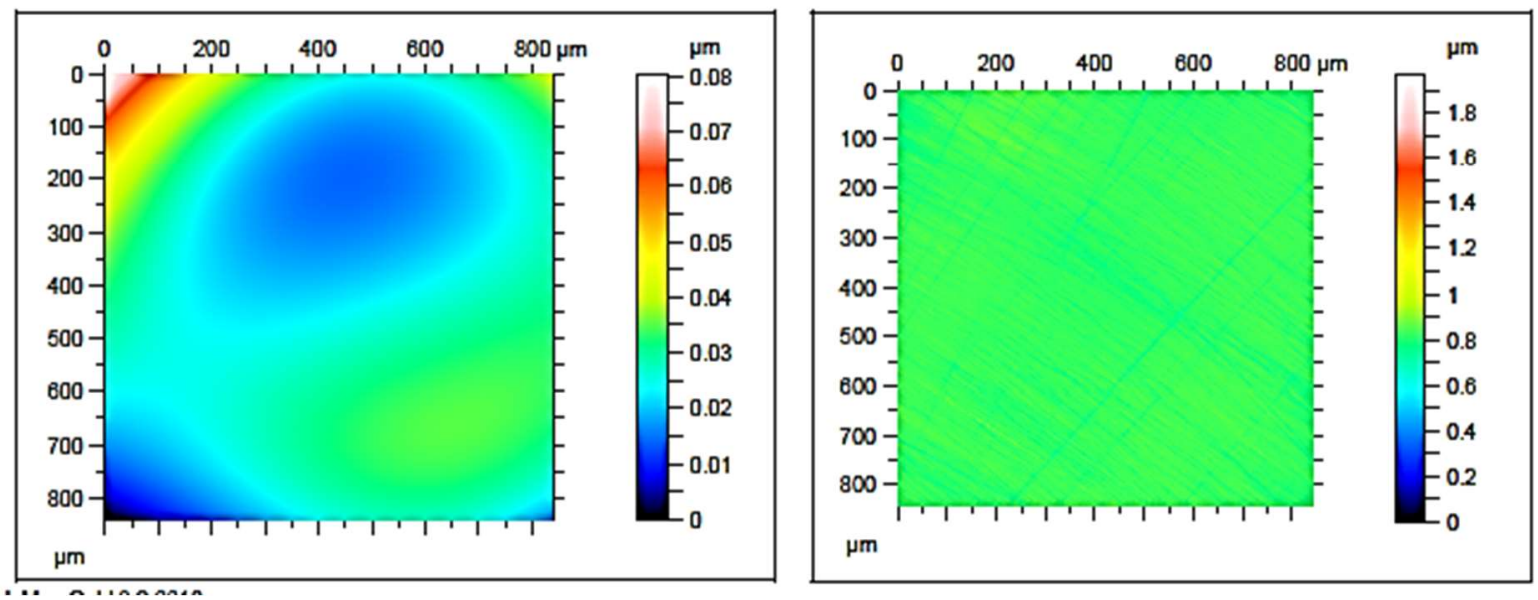
Thresholding

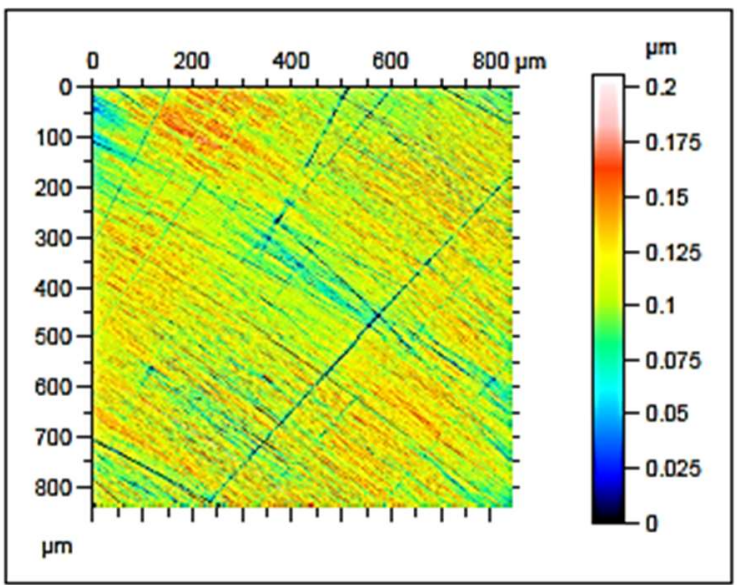




\section{Tucho H-DLC Novo}

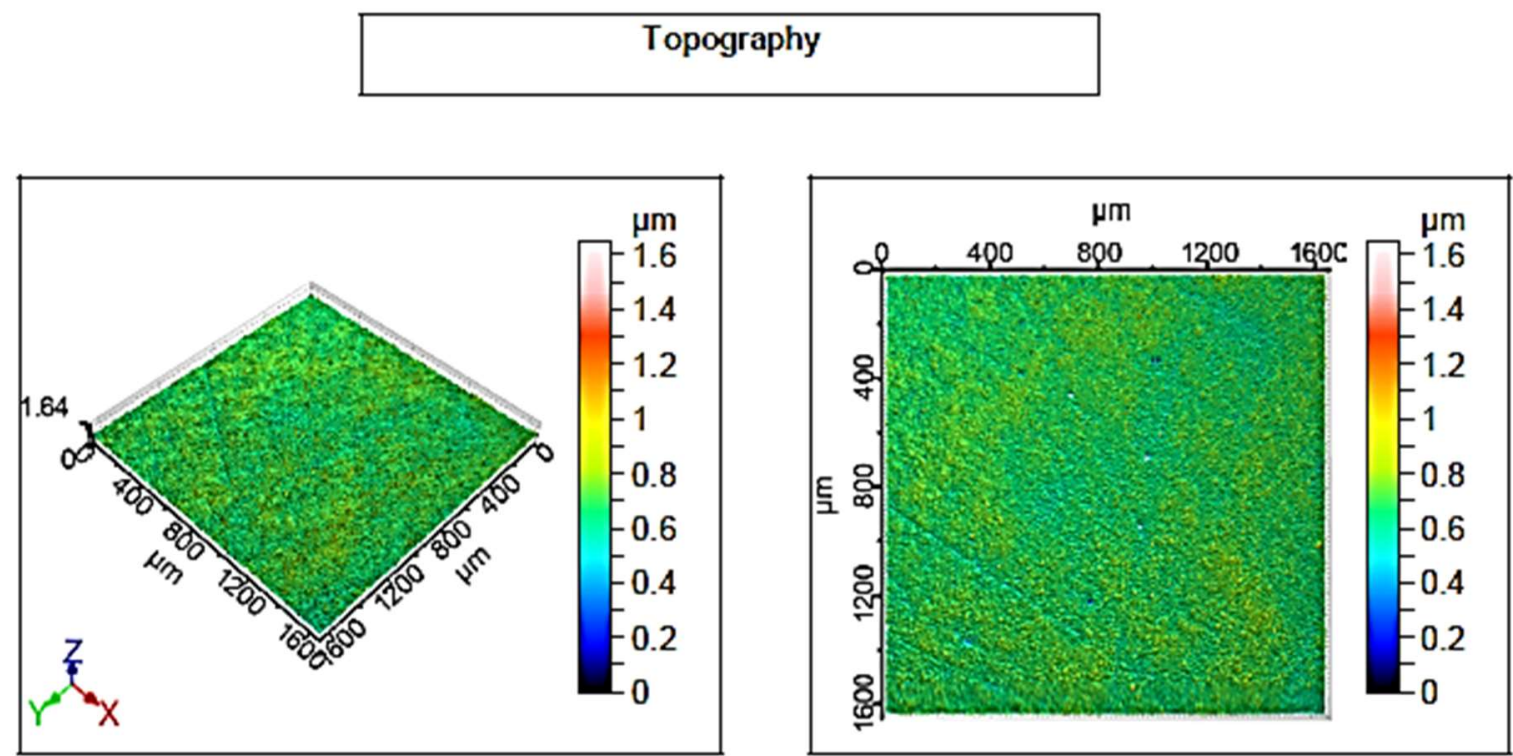

\begin{tabular}{|c|c|c|c|c|}
\hline \multicolumn{5}{|c|}{ ISO 25178} \\
\hline \multicolumn{5}{|c|}{ Height Parameters } \\
\hline Sq & 0.1365 & $\mu \mathrm{m}$ & & Root mean square height \\
\hline Ssk & -2.981 & & & Skewness \\
\hline Sku & 130.8 & & & Kurtosis \\
\hline Sp & 3.201 & $\mu \mathrm{m}$ & & Maximum peak height \\
\hline Sv & 5.242 & $\mu \mathrm{m}$ & & Maximum pit height \\
\hline Sz & 8.443 & $\mu \mathrm{m}$ & & Maximum height \\
\hline $\mathbf{S a}$ & 0.0762 & $\mu \mathrm{m}$ & & Anthmetic mean height \\
\hline \multicolumn{5}{|c|}{ Functional Parameters } \\
\hline Smr & 0.00124 & $\%$ & $c=1 \mu \mathrm{m}$ under the highest peak & Areal material ratio \\
\hline Smc & 0.1048 & $\mu \mathrm{m}$ & $p=10 \%$ & Inverse areal material ratio \\
\hline Sxp & 0.2508 & $\mu \mathrm{m}$ & $p=50 \%, q=97.5 \%$ & Extreme peak height \\
\hline \multicolumn{5}{|c|}{ Spatial Parameters } \\
\hline Sal & 3.171 & $\mu \mathrm{m}$ & $s=0.2$ & Auto-correlation length \\
\hline Str & 0.6800 & & $s=0.2$ & Texture-aspect ratio \\
\hline Std & 117.8 & $\cdot$ & Reference Angle $=\infty^{\circ}$ & Texture direction \\
\hline \multicolumn{5}{|c|}{ Hybrid Parameters } \\
\hline Sdq & 0.1099 & & & Root mean square gradient \\
\hline Sdr & 0.5837 & $\%$ & & Developed interfacial area ratio \\
\hline \multicolumn{5}{|c|}{ Functional Parameters (Stratified surfaces) } \\
\hline Sk & 0.1435 & $\mu \mathrm{m}$ & not fitered & Core roughness depth \\
\hline Spk & 0.2135 & $\mu \mathrm{m}$ & not fitered & Reduced summè height \\
\hline Svk & 0.2315 & $\mu \mathrm{m}$ & not fitered & Reduced valley depth \\
\hline Smr1 & 14.92 & $\%$ & not fitered & Upper beaning area \\
\hline Smr2 & 82.77 & $\%$ & not fitered & Lower bearing area \\
\hline \multicolumn{5}{|c|}{ ASME B46.1 } \\
\hline \multicolumn{5}{|c|}{ 3D Parameters } \\
\hline swt & 0.04519 & $\mu \mathrm{m}$ & Gaussian fiter, $0.8 \mathrm{~mm}$ & Area waviness height \\
\hline
\end{tabular}



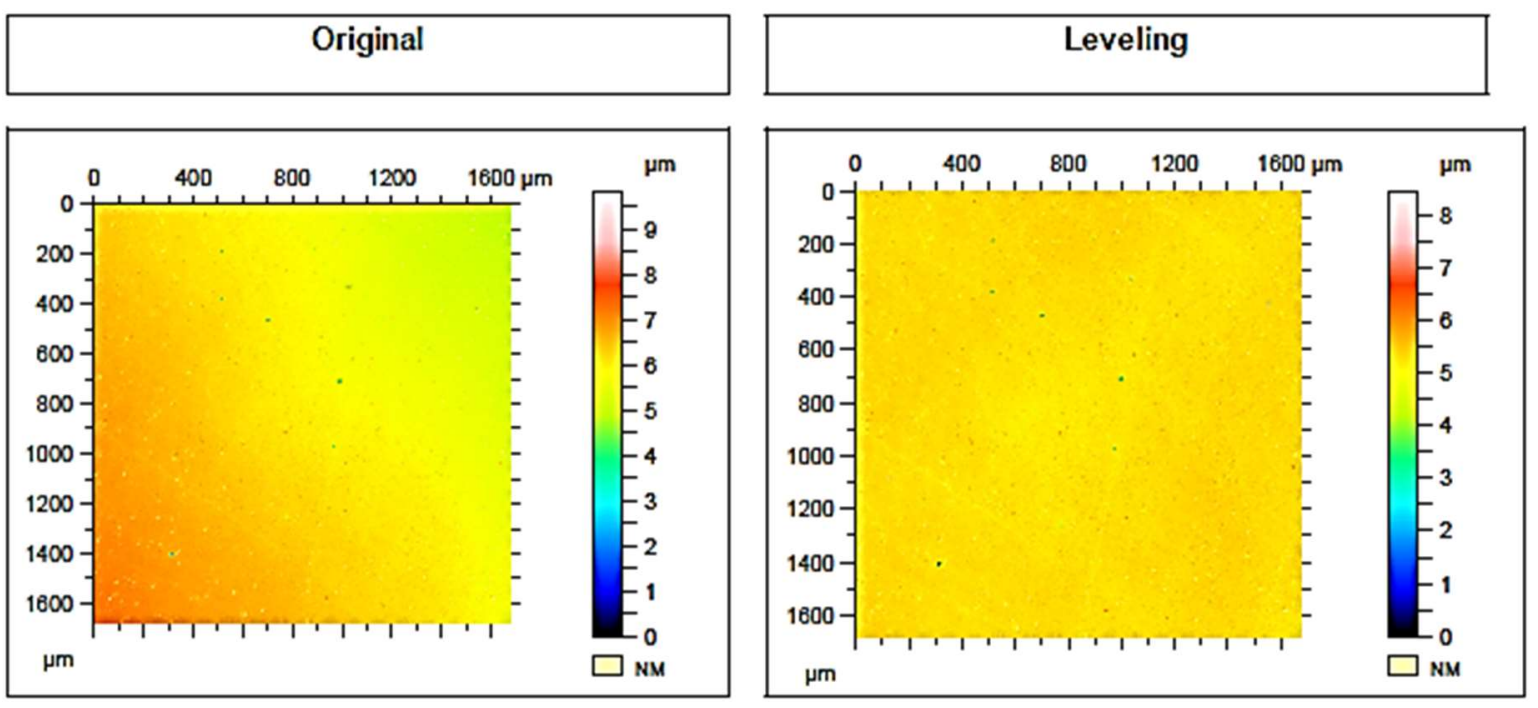

Fill in non-measured points

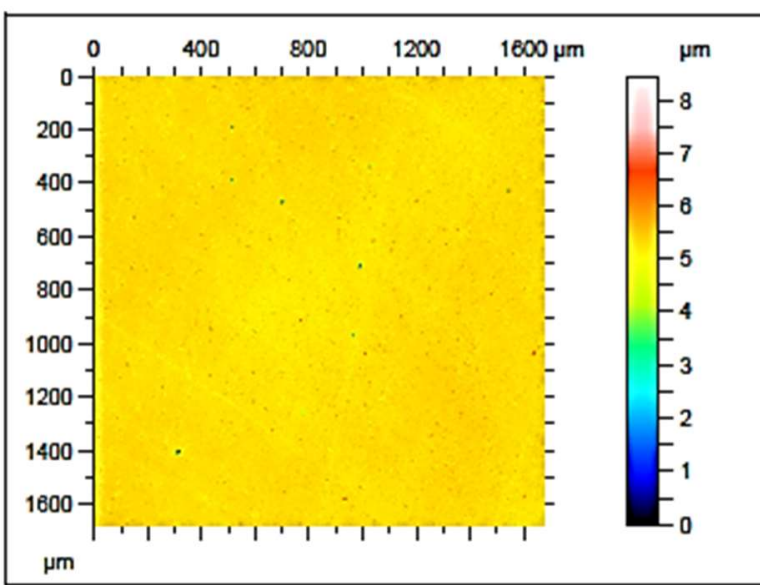

FormRemoval
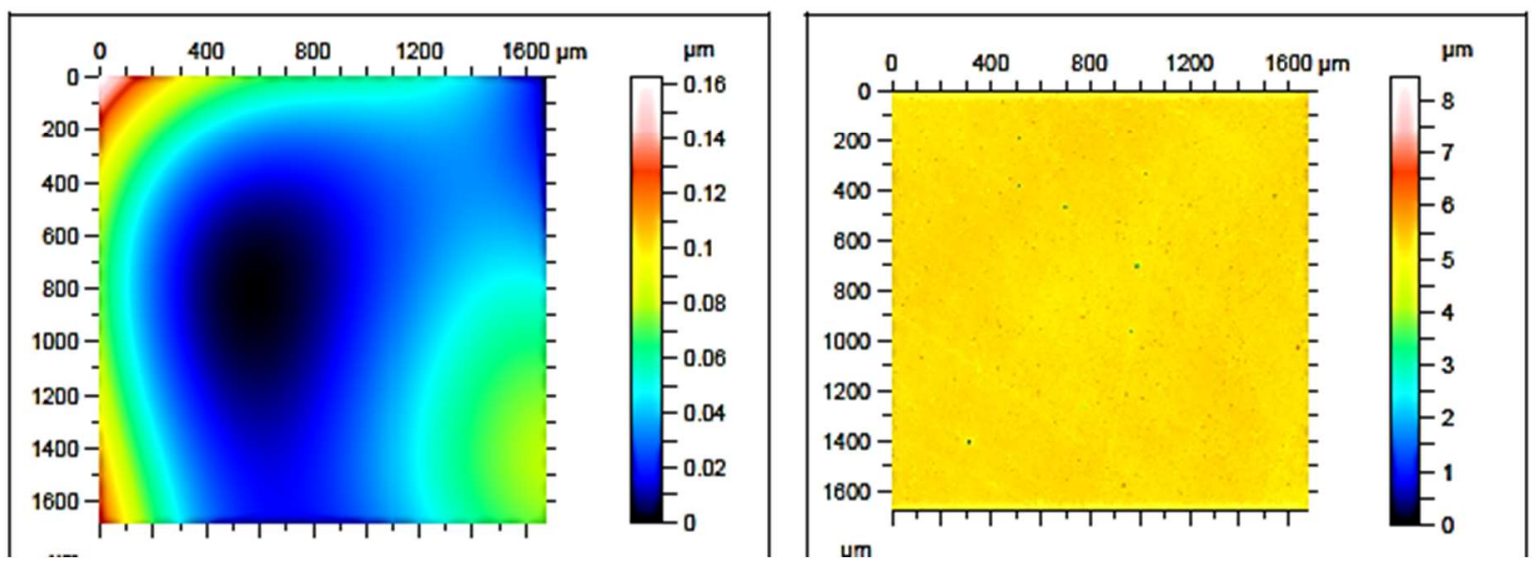

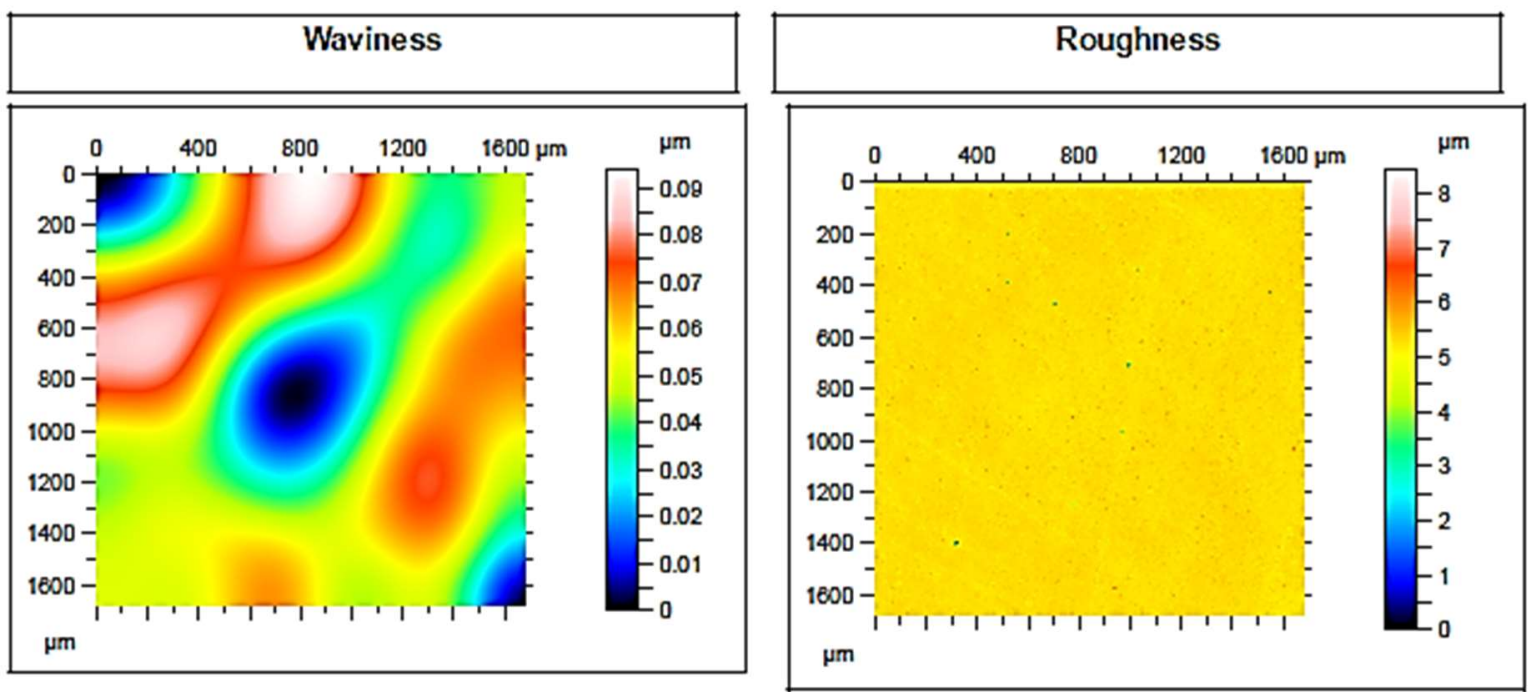

Thresholding

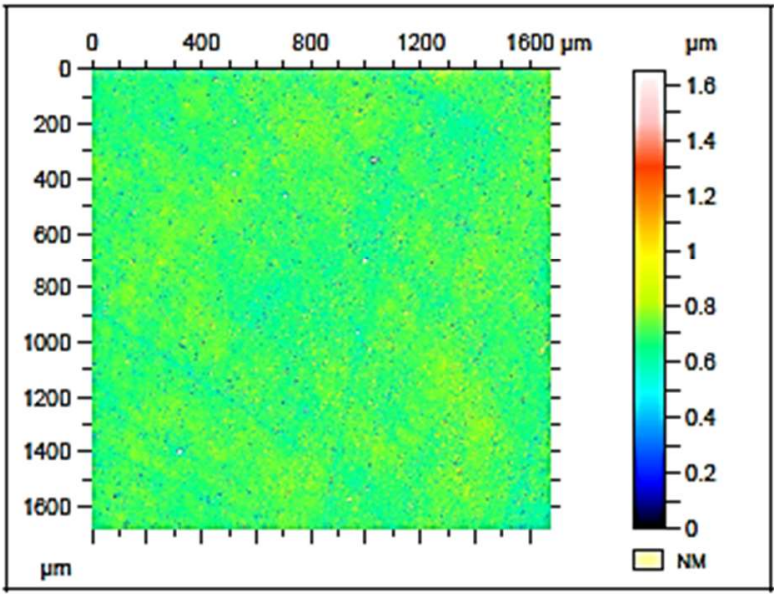




\section{APÊNDICE 4}

\section{Ensaios de Perfilometria Óptica}

\section{Pablo Correa, LFS - Poli USP}

\section{Nariz de Came Após Ensaios Monocame}

\begin{tabular}{|cccc|}
\hline \multicolumn{3}{c}{ PREPROCE } \\
\hline \hline \multicolumn{3}{|c|}{ AS MEASURED } \\
\hline \hline & & \\
\hline
\end{tabular}
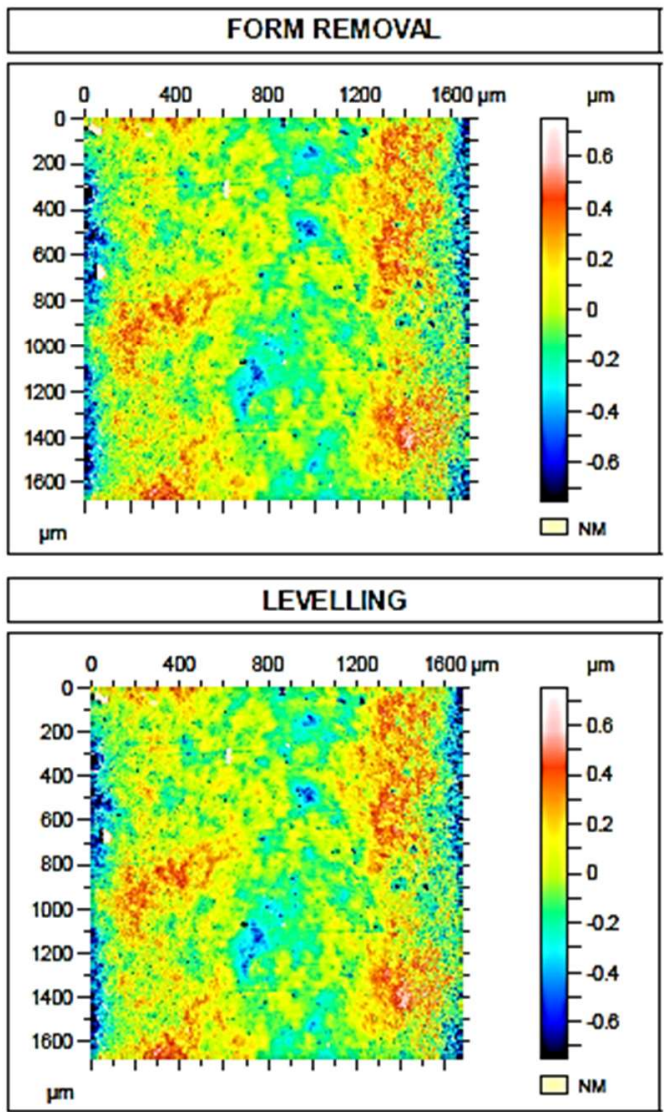

\begin{tabular}{|c|c|}
\hline \multicolumn{2}{|r|}{ IDENTITY CARD } \\
\hline & Identity card \\
\hline $\begin{array}{l}\text { Name: } \\
\text { Measured by: } \\
\text { Flename: } \\
\text { iRBuUT (L. F } \\
\text { Created on: }\end{array}$ & 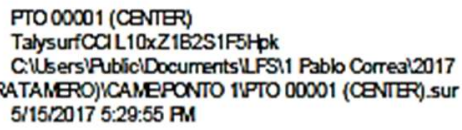 \\
\hline $\begin{array}{l}\text { Axis: } \mathbf{X} \\
\text { Length: } \\
\text { Siz: } \\
\text { Spacing: } \\
\text { Offset }\end{array}$ & $\begin{array}{l}1875 \mu \mathrm{m} \\
512 \text { points } \\
3.278 \mu \mathrm{m} \\
58072 \mu \mathrm{m}\end{array}$ \\
\hline $\begin{array}{l}\text { Axis: } \mathbf{Y} \\
\text { Length: } \\
\text { Siz: } \\
\text { Spacing: } \\
\text { Offset }\end{array}$ & $\begin{array}{l}1875 \mu \mathrm{m} \\
512 \text { lines } \\
3.279 \mu \mathrm{m} \\
23298 \mu \mathrm{m}\end{array}$ \\
\hline $\begin{array}{l}\text { Axis: } Z \\
\text { Length: } \\
\text { Zmin: } \\
Z \text { max } \\
\text { Size: } \\
\text { Spacing: } \\
\text { NMP ratio: }\end{array}$ & $\begin{array}{l}61.51 \mu \mathrm{m} \\
48038 \mu \mathrm{m} \\
48098 \mu \mathrm{m} \\
6151159 \text { digits } \\
1 \mathrm{e}-005 \mu \mathrm{m} \\
0.4181 \% \text { (1096 Pts) }\end{array}$ \\
\hline
\end{tabular}

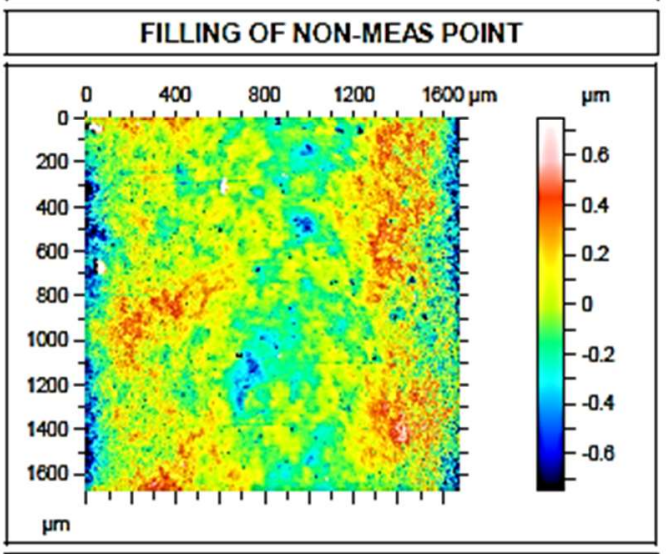

FINALLY: TRESHOLDING (TO THE NEXT PAGE)

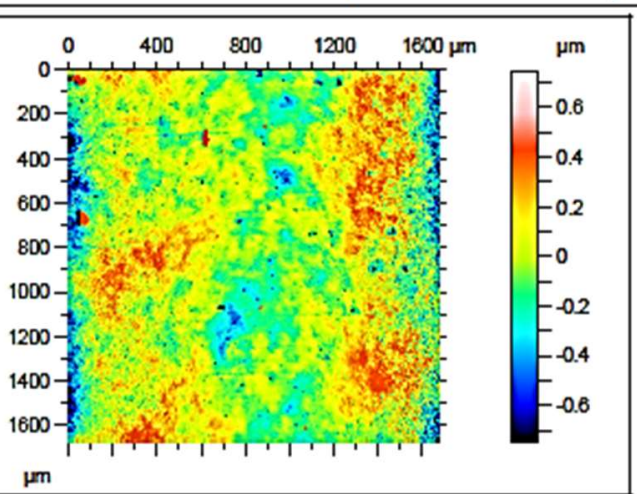


PREPROCESSED TOPOGRAPHY

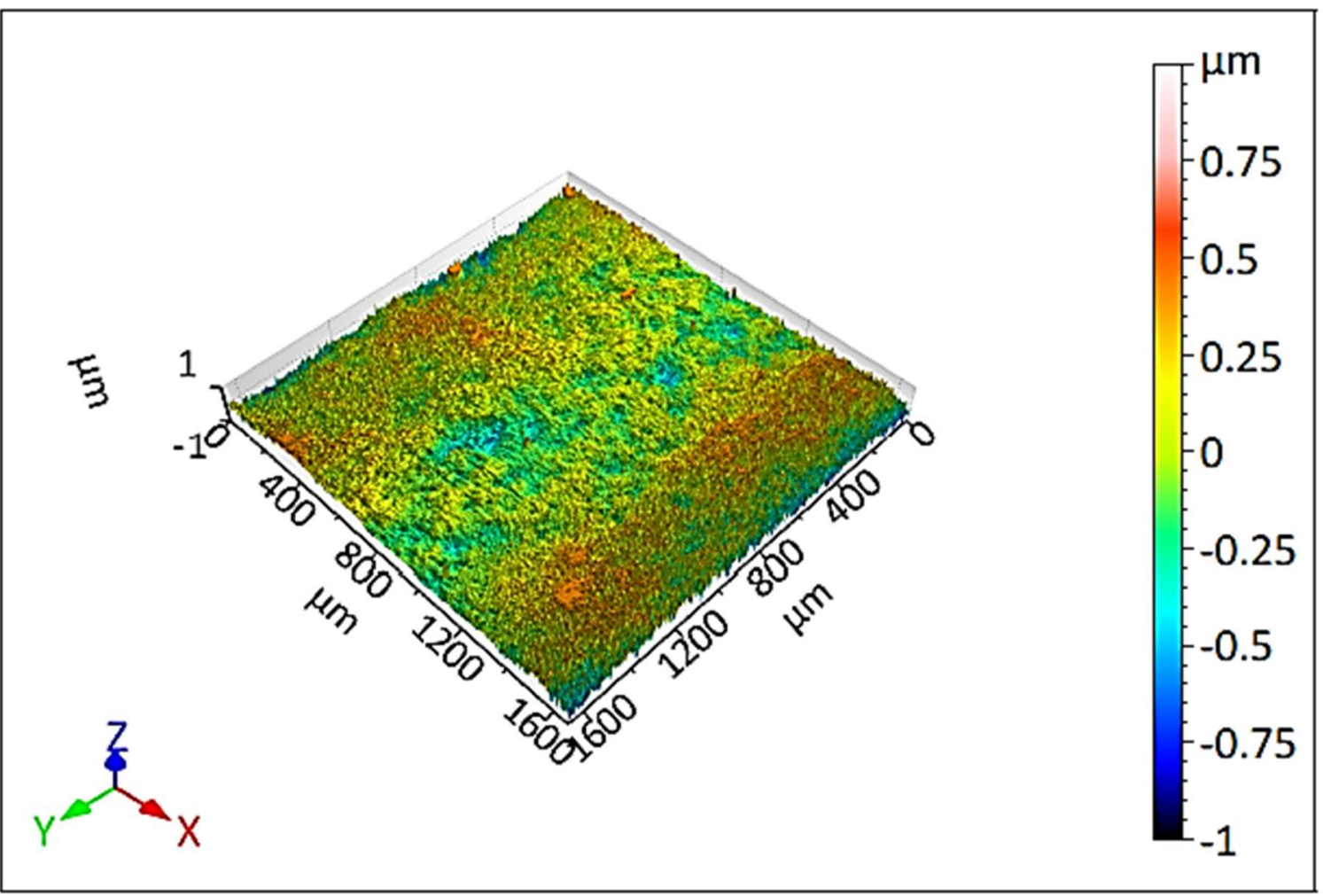




\begin{tabular}{|c|c|c|c|c|}
\hline \multicolumn{5}{|c|}{ ISO 25178} \\
\hline \multicolumn{5}{|c|}{ Height Parameters } \\
\hline Sq & 0.2036 & $\mu \mathrm{m}$ & & Root mean square neight \\
\hline Ssk & -0.609 & & & Skewness \\
\hline Sku & 5.412 & & & Kuntosis \\
\hline Sp & 0.4100 & $\mu \mathrm{m}$ & & Maxlmum peak neight \\
\hline Sv & 2.456 & $\mu \mathrm{m}$ & & Maximum pr height \\
\hline Sz & 2.886 & $\mu \mathrm{m}$ & & Maximum helght \\
\hline Sa & 0.1548 & $\mu \mathrm{m}$ & & Arthmettc mean neight \\
\hline \multicolumn{5}{|c|}{ Functional Parameters } \\
\hline Smr & 92.09 & $\%$ & $c=1$ m under the highest peak & Areal matertal ratio \\
\hline Smc & 0.2568 & $\mu \mathrm{m}$ & $p=10 \%$ & inverse area/material ratso \\
\hline Sxp & 0.4498 & $\mu \mathrm{m}$ & $p=50 \%, q=97.5 \%$ & Extreme peak neght \\
\hline \multicolumn{5}{|c|}{ Spatial Parameters } \\
\hline Sal & 116.2 & $\mu \mathrm{m}$ & $s=0.2$ & Auto-correlation length \\
\hline Str & 0.1372 & & $s=0.2$ & Texture-aspect ratio \\
\hline Std & 2.013 & $\cdot$ & Reference Angle $=0^{\circ}$ & Texture drection \\
\hline \multicolumn{5}{|c|}{ Hybrid Parameters } \\
\hline Sdq & 0.04792 & & & Root mean square gradlent \\
\hline Sdr & 0.1144 & $\%$ & & Developed inferficial area rato \\
\hline \multicolumn{5}{|c|}{ Functional Parameters (Volume) } \\
\hline Vm & 0.008507 & $\mu \mathrm{m}^{2} / \mu \mathrm{m}^{2}$ & $p=10 \%$ & Matertal vaume \\
\hline Vv & 0.2654 & $\mu \mathrm{m}^{2} / \mu \mathrm{m}^{2}$ & $p=10 \%$ & Vord volume \\
\hline Vmp & 0.008507 & $\mu \mathrm{m}^{2} / \mu \mathrm{m}^{2}$ & $p=10 \%$ & Peak matertar volume \\
\hline Vmc & 0.1638 & $\mu \mathrm{m}^{2} / \mu \mathrm{m}^{x}$ & $p=10 \%, q=80 \%$ & Core matertar valume \\
\hline Vrc & 0.2367 & $\mu \mathrm{m}^{2} / \mu \mathrm{m}^{2}$ & $p=10 \%, q=80 \%$ & core vold voume \\
\hline Vvv & 0.02864 & $\mu \mathrm{m}^{2} / \mu \mathrm{m}^{2}$ & $p=80 \%$ & Pr valu volume \\
\hline \multicolumn{5}{|c|}{ Feature Parameters } \\
\hline Spd & 0.0008271 & $1 / \mu \mathrm{m}^{2}$ & pruning $=5 \%$ & Density of peaks \\
\hline Spc & 0.04028 & $1 / \mu \mathrm{m}$ & pruning $=5 \%$ & Arthmettc mean peak curvature \\
\hline $510 z$ & 2.290 & $\mu \mathrm{m}$ & pruning $=5 \%$ & Ten point neight \\
\hline S5p & 0.5670 & $\mu \mathrm{m}$ & pruning $=5 \%$ & Five point peak helght \\
\hline S5v & 1.723 & $\mu \mathrm{m}$ & pruning $=5 \%$ & Five point ar height \\
\hline Sda & 773.4 & $\mu \mathrm{m}^{2}$ & pruning $=5 \%$ & Mean dale area \\
\hline Sha & 1058 & $\mu \mathrm{m}^{2}$ & pruning $=5 \%$ & Mean hor area \\
\hline Sdv & 11.64 & $\mu \mathrm{m}^{2}$ & pruning $=5 \%$ & Mean dale voume \\
\hline Shv & 19.18 & $\mu \mathrm{m}^{2}$ & pruning $=5 \%$ & Mean ha valume \\
\hline \multicolumn{5}{|c|}{ Functional Parameters (Stratified surfaces) } \\
\hline Sk & 0.2911 & $\mu \mathrm{m}$ & Gaussian nker, $0.8 \mathrm{~mm}$ & Core roughness depth \\
\hline Spk & 0.09439 & $\mu \mathrm{m}$ & Gaussian nter, $0.8 \mathrm{~mm}$ & Reduced summt height \\
\hline Svk & 0.1982 & $\mu \mathrm{m}$ & Gaussian nter, $0.8 \mathrm{~mm}$ & Reduced valley depth \\
\hline Smr1 & 7.322 & $\%$ & Gaussian nter, $0.8 \mathrm{~mm}$ & Upper Dearng area \\
\hline Smr2 & 88.42 & $\%$ & Gausslan nter, $0.8 \mathrm{~mm}$ & Lower Dearng area \\
\hline Spq & 0.1145 & & Gaussian nter, $0.8 \mathrm{~mm}$ & Plateau root mean square roughness \\
\hline Svq & 0.7058 & & Gausslan nter, $0.8 \mathrm{~mm}$ & Valley root mean square roughness \\
\hline Smq & 99.30 & & Gaussian nter, $0.8 \mathrm{~mm}$ & Matertal rath at plateau-to-valey transtion \\
\hline
\end{tabular}




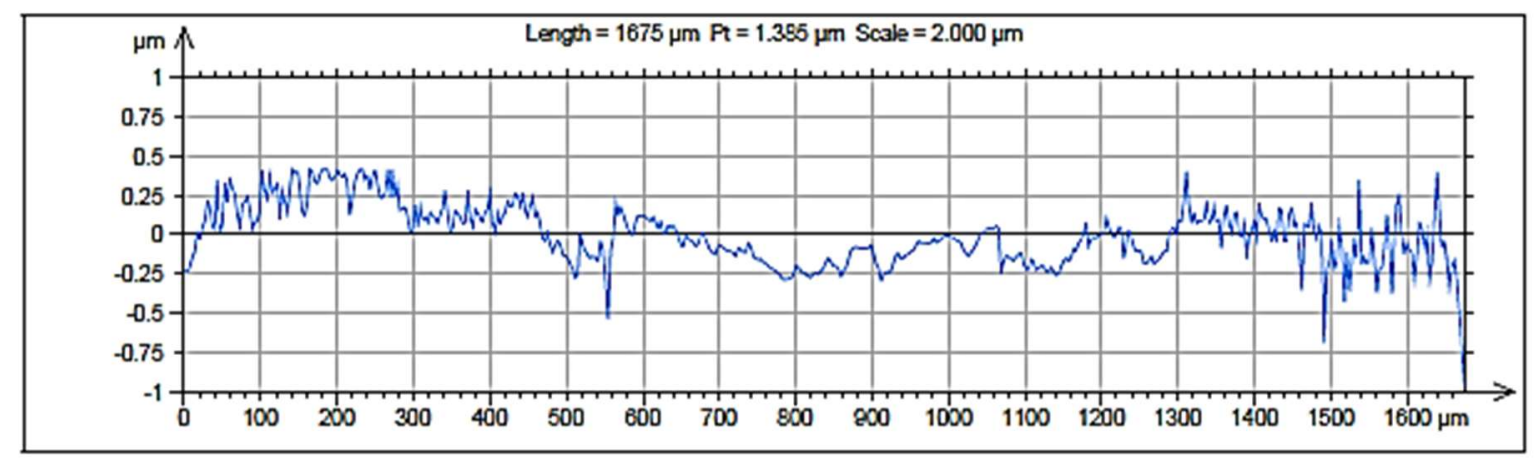

\begin{tabular}{|c|c|c|c|}
\hline ISO 4 & & & \\
\hline Amplitu & arameters & oughnes: & rofile \\
\hline Ra & 0.03926 & $\mu \mathrm{m}$ & Gaussian nter, $0.025 \mathrm{~mm}$ \\
\hline $\mathbf{R q}$ & 0.04939 & $\mu \mathrm{m}$ & Gausslan nter, $0.025 \mathrm{~mm}$ \\
\hline Rsk & 0.08423 & & Gayssian nter, $0.025 \mathrm{~mm}$ \\
\hline Rku & 2.698 & & Gausstan nter, $0.025 \mathrm{~mm}$ \\
\hline ISO 1 & & & \\
\hline ISO 13 & & & \\
\hline Rk & 0.07343 & $\mu \mathrm{m}$ & Gaussian nter, $0.025 \mathrm{~mm}$ \\
\hline Rpk & 0.1021 & $\mu \mathrm{m}$ & Gaussian nter, $0.025 \mathrm{~mm}$ \\
\hline Rvk & 0.0288 & $\mu \mathrm{m}$ & Gaussian nter, $0.025 \mathrm{~mm}$ \\
\hline$M r 1$ & 17.18 & $\%$ & Gaussian nter, $0.025 \mathrm{~mm}$ \\
\hline Mr2 & 82.68 & $\%$ & Gaysstan iter, $0.025 \mathrm{~mm}$ \\
\hline A1 & 0.008772 & $\mu \mathrm{m}^{2} / \mu \mathrm{m}$ & Gaussian nter, $0.025 \mathrm{~mm}$ \\
\hline A2 & 0.008567 & $\mu \mathrm{m}^{2} / \mu \mathrm{m}$ & Gausstan nter, $0.025 \mathrm{~mm}$ \\
\hline $\mathbf{R p k}^{\mathbf{*}}$ & 0.3136 & $\mu \mathrm{m}$ & Gausslan nter, $0.025 \mathrm{~mm}$ \\
\hline $\mathrm{Rvk}^{*}$ & 0.3779 & $\mu \mathrm{m}$ & Gausstan nter, $0.025 \mathrm{~mm}$ \\
\hline ASME & 16.1 & & \\
\hline 2D Par: & ters & & \\
\hline $\mathbf{R z}$ & 0.7431 & $\mu \mathrm{m}$ & Gausslan nter, $0.8 \mathrm{~mm}$ \\
\hline
\end{tabular}


Tucho Normal após Experimento Monocame

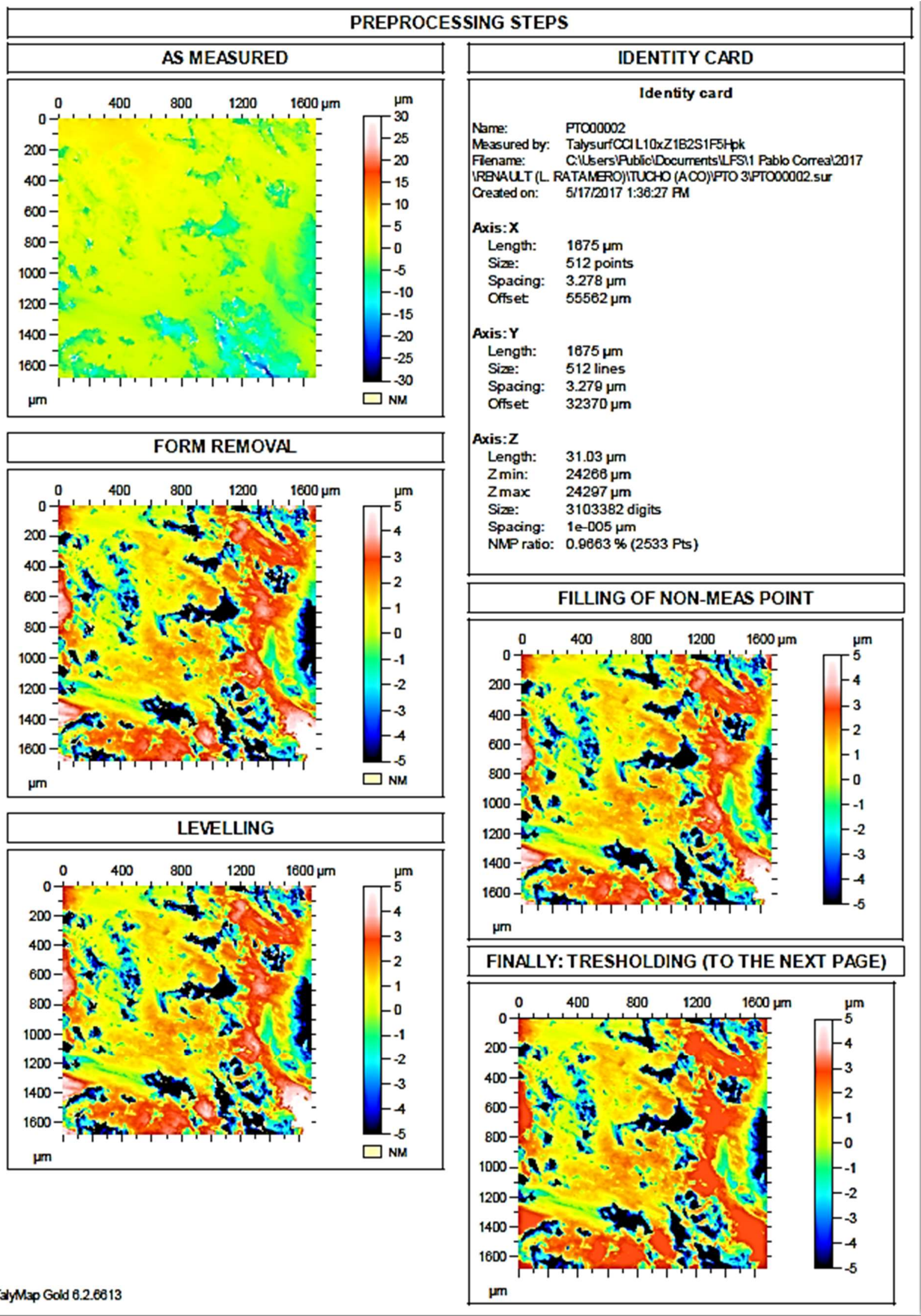




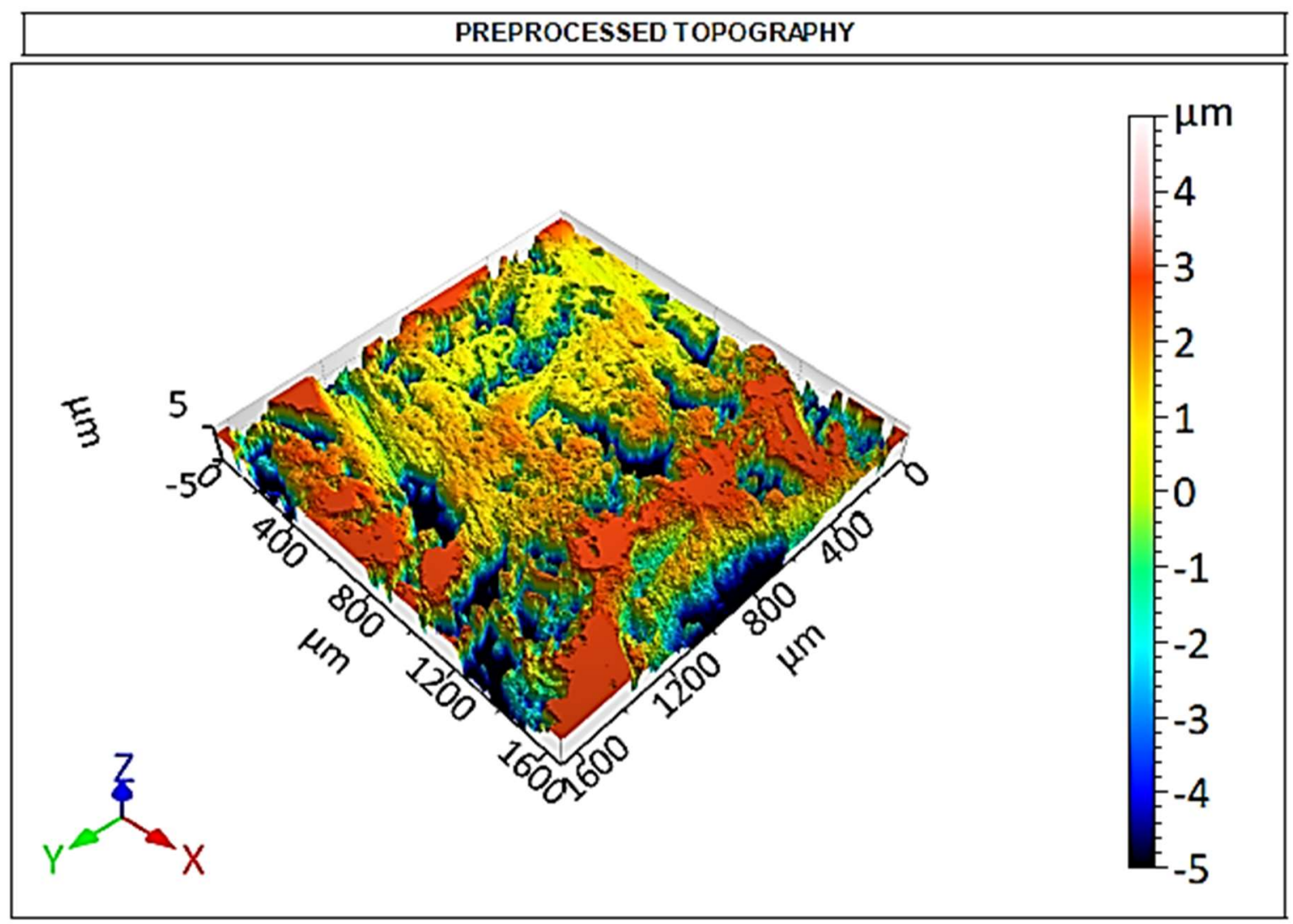




\begin{tabular}{|c|c|c|c|c|}
\hline \multicolumn{5}{|c|}{ ISO 25178} \\
\hline \multicolumn{5}{|c|}{ Height Parameters } \\
\hline Sq & 2.716 & $\mu \mathrm{m}$ & & Root mean square heght \\
\hline Ssk & -1.426 & & & Skewness \\
\hline Sku & 4.872 & & & Kuntosis \\
\hline Sp & 2.245 & $\mu \mathrm{m}$ & & Maxmum peak neight \\
\hline Sv & 15.74 & $\mu \mathrm{m}$ & & Maxmum prs helght \\
\hline Sz & 18.68 & $\mu \mathrm{m}$ & & Maxmum helght \\
\hline Sa & 2.078 & $\mu \mathrm{m}$ & & Arthmestc mean heght \\
\hline \multicolumn{5}{|c|}{ Functional Parameters } \\
\hline Smr & 22.48 & $\%$ & $c=1 \mathrm{pm}$ under the highest peak & Areal material rato \\
\hline Smc & 2.845 & $\mu \mathrm{m}$ & $p=10 \%$ & inverse areal material rath \\
\hline Sxp & 8.046 & $\mu \mathrm{m}$ & $p=50 \%, q=97.5 \%$ & Extreme peak neght \\
\hline \multicolumn{5}{|c|}{ Spatial Parameters } \\
\hline Sal & 78.17 & $\mu \mathrm{m}$ & $s=0.2$ & Auto-corretaton length \\
\hline Str & 0.6671 & & $s=0.2$ & Texture-aspect ratio \\
\hline Std & 176.3 & $\bullet$ & Reference Angle $=0^{\circ}$ & Texture drection \\
\hline \multicolumn{5}{|c|}{ Hybrid Parameters } \\
\hline Sdq & 0.2270 & & & Root mean square gradent \\
\hline Sdr & 2.395 & $\%$ & & Developed interfactal area rato \\
\hline \multicolumn{5}{|c|}{ Functional Parameters (Volume) } \\
\hline$V_{m}$ & 0.002073 & $\mu \mathrm{m}^{2} / \mu \mathrm{m}^{2}$ & $p=10 \%$ & Matera/ voume \\
\hline Vv & 2.855 & $\mu \mathrm{m}^{2} / \mu \mathrm{m}^{2}$ & $p=10 \%$ & Vold vaume \\
\hline Vmp & 0.002073 & $\mu \mathrm{m}^{2} / \mu \mathrm{m}^{2}$ & $p=10 \%$ & Peak material vaume \\
\hline Vmc & 2.433 & $\mu \mathrm{m}^{2} / \mu \mathrm{m}^{2}$ & $p=10 \%, q=80 \%$ & Core matertal valume \\
\hline Vrc & 2.325 & $\mu \mathrm{m}^{2} / \mu \mathrm{m}^{2}$ & $p=10 \%, q=80 \%$ & Care vold voume \\
\hline Vvv & 0.5296 & $\mu \mathrm{m}^{2} / \mu \mathrm{m}^{2}$ & $p=80 \%$ & Pr valu voume \\
\hline \multicolumn{5}{|c|}{ Feature Parameters } \\
\hline Spd & $4.312 \mathrm{e}-005$ & $1 / \mu \mathrm{m}^{x}$ & pruning $=5 \%$ & Density of peaks \\
\hline Spc & 0.1926 & $1 / \mathrm{pm}$ & pruning $=5 \%$ & Arthmetc mean peak curvature \\
\hline S10z & 12.82 & $\mu \mathrm{m}$ & prunhy $=5 \%$ & Ten point neight \\
\hline S5p & 4.716 & $\mu \mathrm{m}$ & pruning $=5 \%$ & FNe pont peak helght \\
\hline S5v & 8.106 & $\mu \mathrm{m}$ & pruning $=5 \%$ & Fve pont pr neight \\
\hline Sda & 5135 & $\mu \mathrm{m}^{2}$ & prunng $=5 \%$ & Mean vale area \\
\hline Sha & 10451 & $\mu \mathrm{m}^{2}$ & pruning $=5 \%$ & Mean nu area \\
\hline Sdv & 715.2 & $\mu \mathrm{m}^{2}$ & pruning $=5 \%$ & Mean dale volume \\
\hline Shv & 975.3 & $\mu \mathrm{m}^{2}$ & pruning $=5 \%$ & Mean nu voume \\
\hline \multicolumn{5}{|c|}{ Functional Parameters (Stratified surfaces) } \\
\hline Sk & 2.110 & $\mu \mathrm{m}$ & Gaussian AYer, $0.8 \mathrm{~mm}$ & Core roughness deptn \\
\hline Spk & 0.6633 & $\mu \mathrm{m}$ & Gaussian Arer, $0.8 \mathrm{~mm}$ & Reduced summit height \\
\hline Syk & 5.580 & $\mu \mathrm{m}$ & Gaussian Arer, $0.8 \mathrm{~mm}$ & Reduced valey oepth \\
\hline Smr1 & 11.25 & $\%$ & Gaussian AYer, $0.8 \mathrm{~mm}$ & Upper Dearng area \\
\hline Smr2 & 74.10 & $\%$ & Gaussian arer, $0.8 \mathrm{~mm}$ & Lower Dearng area \\
\hline Spq & w... & & Gaussian Arer, $0.8 \mathrm{~mm}$ & Plateau root mean square roughness \\
\hline Svq & "w.." & & Gaussian AYer, $0.8 \mathrm{~mm}$ & Valley root mean square roughness \\
\hline Smq & "w!" & & Gaussian Arer, $0.8 \mathrm{~mm}$ & Matertal ratb at plateau-to-valey transition \\
\hline
\end{tabular}




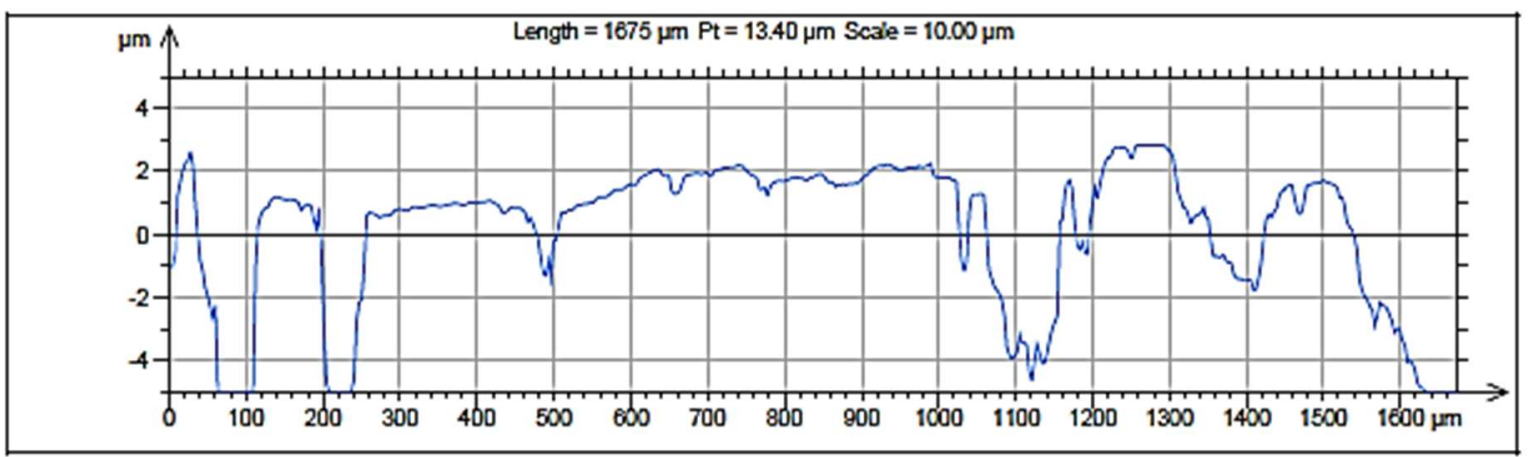

\begin{tabular}{|c|c|c|c|}
\hline ISO 4 & & & \\
\hline Amplitt & sarameter & Roughne: & profile \\
\hline Ra & 0.1127 & $\mu \mathrm{m}$ & Gaussian fier, $0.025 \mathrm{~mm}$ \\
\hline $\mathbf{R q}$ & 0.1516 & $\mu m$ & Gaussian frer, $0.025 \mathrm{~mm}$ \\
\hline Rsk & 0.1022 & & Gaussian frer, $0.025 \mathrm{~mm}$ \\
\hline Rku & 3.029 & & Gaussian frer, $0.025 \mathrm{~mm}$ \\
\hline ISO 1 & & & \\
\hline ISO 13 & & & \\
\hline $\mathbf{R k}$ & 0.1144 & $\mu \mathrm{m}$ & Gaussian fier, $0.025 \mathrm{~mm}$ \\
\hline Rpk & 0.3582 & $\mu \mathrm{m}$ & Gausstan nter, $0.025 \mathrm{~mm}$ \\
\hline Rvk & 0.3895 & $\mu \mathrm{m}$ & Gaussian fiter, $0.025 \mathrm{~mm}$ \\
\hline MrI & 19.58 & $\%$ & Gaussian Ner, $0.025 \mathrm{~mm}$ \\
\hline Mr2 & 78.81 & $\%$ & Gaussian frer, $0.025 \mathrm{~mm}$ \\
\hline A1 & 0.03509 & $\mu \mathrm{m}^{2} / \mu \mathrm{m}$ & Gaussian frer, $0.025 \mathrm{~mm}$ \\
\hline A2 & 0.04128 & $\mu \mathrm{m}^{2} / \mu \mathrm{m}$ & Gaussian frer, $0.025 \mathrm{~mm}$ \\
\hline $\mathbf{R p k}^{*}$ & 1.785 & $\mu \mathrm{m}$ & Gausstan nter, $0.025 \mathrm{~mm}$ \\
\hline $\mathbf{R v k}^{ \pm}$ & 2.188 & $\mu \mathrm{m}$ & Gaussian nier, $0.025 \mathrm{~mm}$ \\
\hline ASME & 16.1 & & \\
\hline 2D Par & ters & & \\
\hline $\mathbf{R z}$ & 6.417 & $\mu \mathrm{m}$ & Gaussian fter, $0.8 \mathrm{~mm}$ \\
\hline
\end{tabular}


Tucho H-DLC após Experimento Monocame

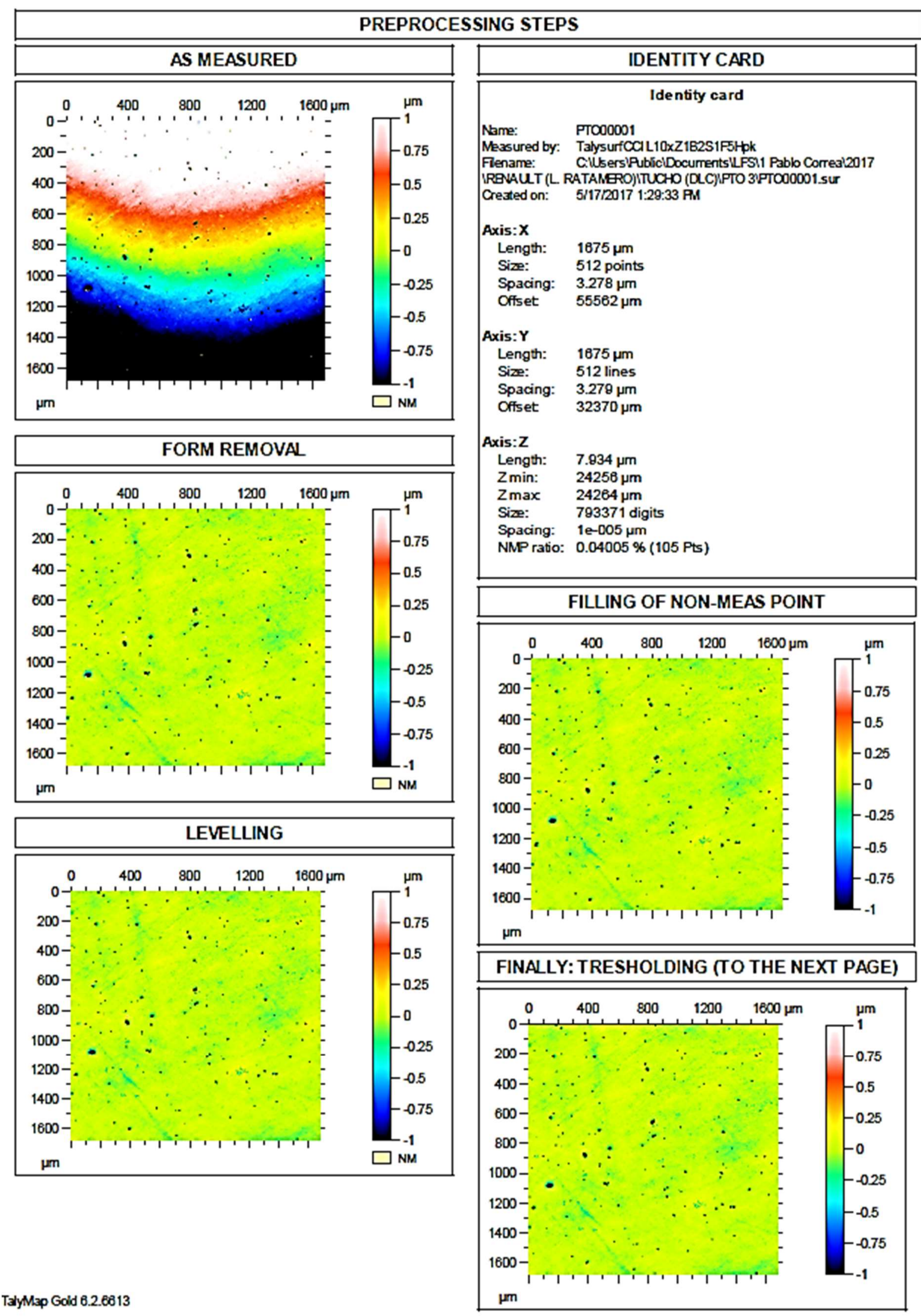




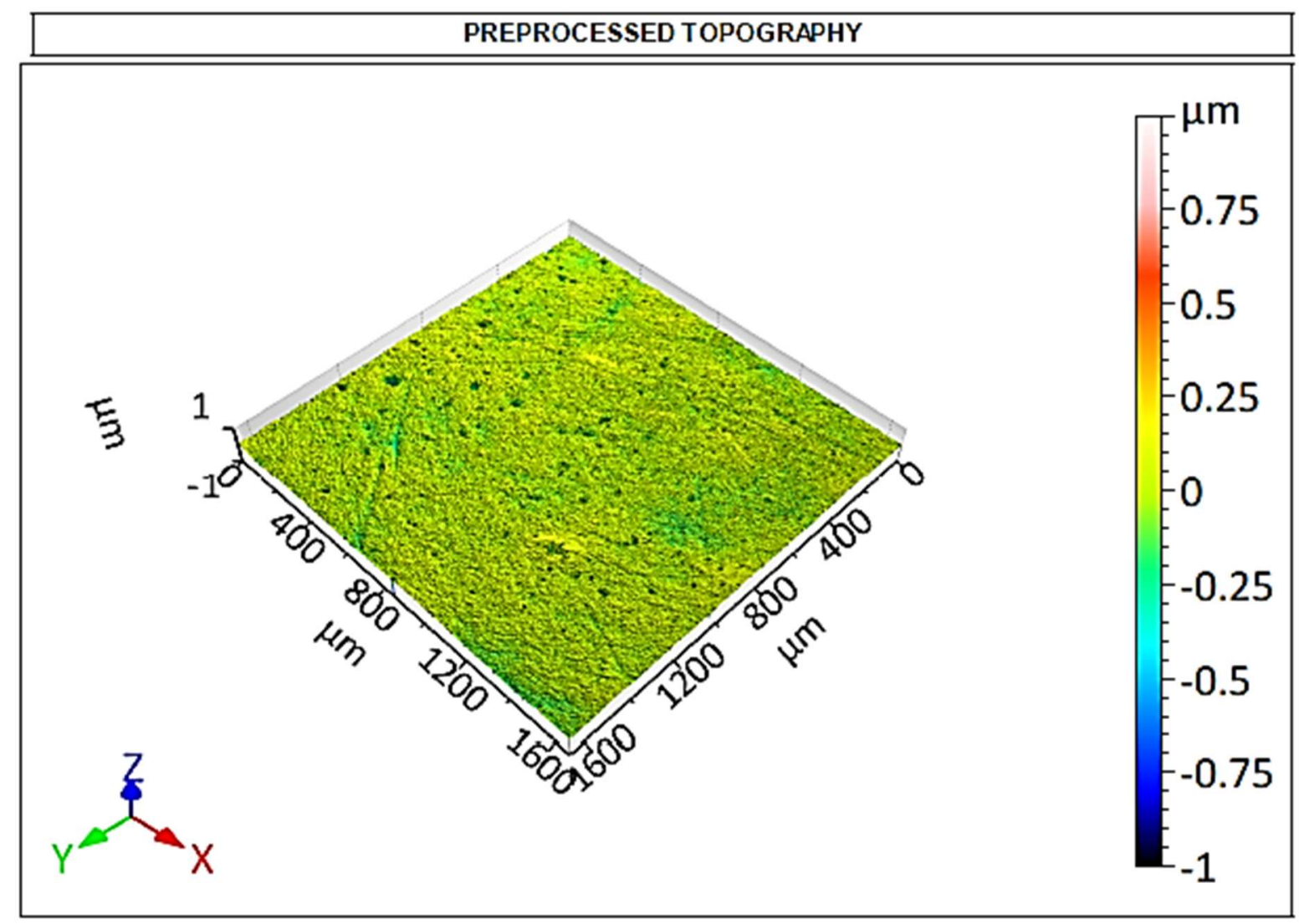




\begin{tabular}{|c|c|c|c|c|}
\hline \multicolumn{5}{|c|}{ ISO 25178} \\
\hline \multicolumn{5}{|c|}{ Height Parameters } \\
\hline Sq & 0.1476 & $\mu \mathrm{m}$ & & Root mean square height \\
\hline Ssk & -14.73 & & & Skewness \\
\hline Sku & 264.4 & & & Kurtosis \\
\hline Sp & 0.1021 & $\mu \mathrm{m}$ & & Maxmum peak helght \\
\hline Sv & 3.317 & $\mu \mathrm{m}$ & & Maxmum pt height \\
\hline Sz & 3.419 & $\mu \mathrm{m}$ & & Maximum helght \\
\hline Sa & 0.0478 & $\mu \mathrm{m}$ & & Arthmetic mean helght \\
\hline \multicolumn{5}{|c|}{ Functional Parameters } \\
\hline Smr & 89.62 & $\%$ & $c=1 \mu \mathrm{m}$ under the nighest peak & Areal material rato \\
\hline Smc & 0.06834 & $\mu \mathrm{m}$ & $p=10 \%$ & Inverse areal matenal rato \\
\hline Sxp & 0.1192 & $\mu \mathrm{m}$ & $p=50 \%, q=97.5 \%$ & Extreme peak height \\
\hline \multicolumn{5}{|c|}{ Spatial Parameters } \\
\hline Sal & 12.25 & $\mu \mathrm{m}$ & $s=0.2$ & Auto-correlation length \\
\hline Str & 0.7515 & & $s=0.2$ & Texture-aspect rato \\
\hline Std & 39.50 & $\cdot$ & Reference Angle $=0^{\circ}$ & Texture drection \\
\hline \multicolumn{5}{|c|}{ Hybrid Parameters } \\
\hline Sdq & 0.04223 & & & Root mean square gradlent \\
\hline Sdr & 0.08663 & $\%$ & & Developed intertaclar area rato \\
\hline \multicolumn{5}{|c|}{ Functional Parameters (Volume) } \\
\hline Vm & 0.0016 & $\mu \mathrm{m}^{2} / \mu \mathrm{m}^{2}$ & $p=10 \%$ & Material volume \\
\hline Vv & 0.07095 & $\mu \mathrm{m}^{2} / \mu \mathrm{m}^{x}$ & $p=10 \%$ & Valor volume \\
\hline Vmp & 0.0016 & $\mu \mathrm{m}^{2} / \mu \mathrm{m}^{2}$ & $p=10 \%$ & Peak material voiume \\
\hline Vmc & 0.04063 & $\mu \mathrm{m}^{2} / \mu \mathrm{m}^{x}$ & $p=10 \%, q=80 \%$ & Core material voiume \\
\hline Vrc & 0.05466 & $\mu \mathrm{m}^{2} / \mu \mathrm{m}^{2}$ & $p=10 \%, q=80 \%$ & core voll volume \\
\hline Vrv & 0.01628 & $\mu \mathrm{m}^{2} / \mu \mathrm{m}^{x}$ & $p=80 \%$ & Prt vald voume \\
\hline \multicolumn{5}{|c|}{ Feature Parameters } \\
\hline Spd & 0.000 & $1 / \mu \mathrm{m}^{x}$ & prunng $=5 \%$ & Densty of peaks \\
\hline Spc & 'm! & $1 / \mu \mathrm{m}$ & prunng $=5 \%$ & Arthmecic mean peak curvature \\
\hline $\mathbf{S 1 0 z}$ & 'm! & $\mu \mathrm{m}$ & prunng $=5 \%$ & Ten point height \\
\hline S5p & $m \cdot$ & $\mu \mathrm{m}$ & pruning $=5 \%$ & Flve point peak helght \\
\hline S5v & 3.229 & $\mu \mathrm{m}$ & pruning $=5 \%$ & Flie pont pt helght \\
\hline Sda & 5811 & $\mu \mathrm{m}^{2}$ & prunng $=5 \%$ & Mean dale area \\
\hline Sha & mit & $\mu \mathrm{m}^{2}$ & prunng $=5 \%$ & Mean nu area \\
\hline Sdv & 84.79 & $\mu \mathrm{m}^{2}$ & prunng $=5 \%$ & Mean dale valume \\
\hline Shv & $m$ & $\mu \mathrm{m}^{2}$ & prunng $=5 \%$ & Mean nu volume \\
\hline \multicolumn{5}{|c|}{ Functional Parameters (Stratified surfaces) } \\
\hline Sk & 0.1028 & $\mu \mathrm{m}$ & Gaussian nter, $0.8 \mathrm{~mm}$ & Core rougmess depth \\
\hline Spk & 0.03289 & $\mu \mathrm{m}$ & Gaussian nter, $0.8 \mathrm{~mm}$ & Reduced summit helght \\
\hline Svk & 0.2583 & $\mu \mathrm{m}$ & Gaussian nter, $0.8 \mathrm{~mm}$ & Reduced valey depth \\
\hline Smr1 & 9.739 & $\%$ & Gaussian nter, $0.8 \mathrm{~mm}$ & Upper bearing area \\
\hline Smr2 & 88.64 & $\%$ & Gaussian nter, $0.8 \mathrm{~mm}$ & Lower bearing area \\
\hline Spq & m... & & Gaussian nter, $0.8 \mathrm{~mm}$ & Piateau root mean square roughness \\
\hline Svq & m.1 & & Gausslan nter, $0.8 \mathrm{~mm}$ & Valley root mean square roughness \\
\hline Smq & $m$ & & Gausslan nter, $0.8 \mathrm{~mm}$ & Materal rato at pateau-to-valey transition \\
\hline
\end{tabular}




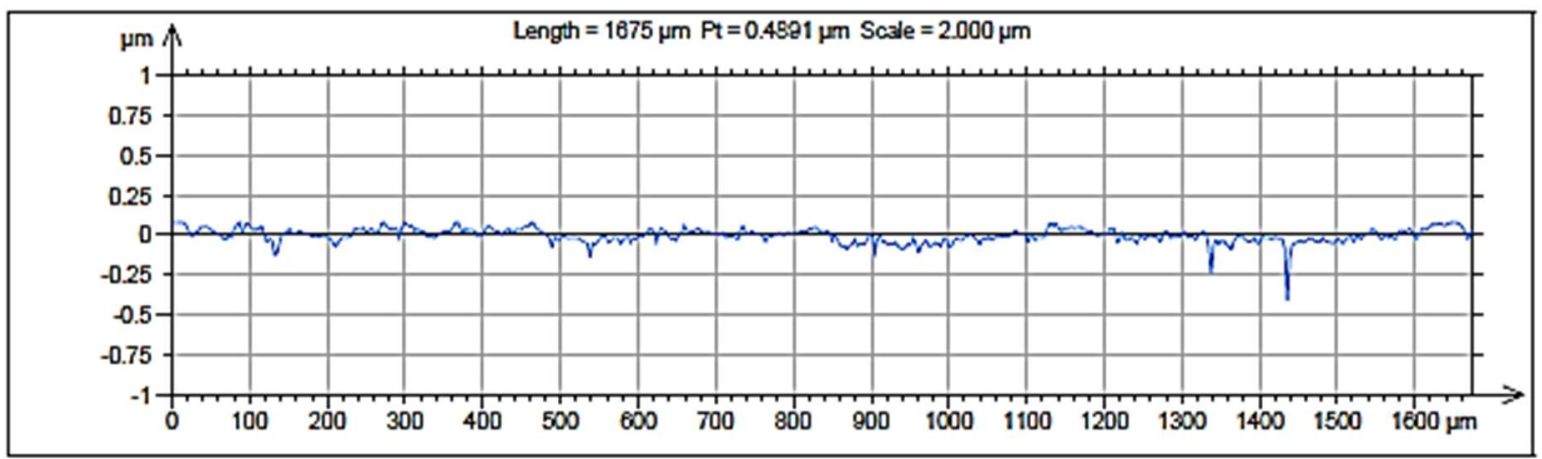

\begin{tabular}{|c|c|c|c|}
\hline \multicolumn{4}{|c|}{ ISO 4287} \\
\hline \multicolumn{4}{|c|}{ Amplitude parameters - Roughness profile } \\
\hline Ra & 0.01146 & $\mu \mathrm{m}$ & Gausstan flter, $0.025 \mathrm{~mm}$ \\
\hline $\mathbf{R q}$ & 0.01465 & $\mu \mathrm{m}$ & Gausstan fiter, $0.025 \mathrm{~mm}$ \\
\hline Rsk & -0.227 & & Gausslan flter, $0.025 \mathrm{~mm}$ \\
\hline Rku & 2.731 & & Gausstan flter, $0.025 \mathrm{~mm}$ \\
\hline \multicolumn{4}{|c|}{ ISO 13565} \\
\hline \multicolumn{4}{|c|}{ ISO 13585-2 } \\
\hline Rk & 0.02944 & $\mu \mathrm{m}$ & Gausstan flter, $0.025 \mathrm{~mm}$ \\
\hline Rpk & 0.01701 & $\mu \mathrm{m}$ & Gausstan flter, $0.025 \mathrm{~mm}$ \\
\hline Rvk & 0.02941 & $\mu \mathrm{m}$ & Gausstan nter, $0.025 \mathrm{~mm}$ \\
\hline $\mathrm{Mr}-1$ & 11.43 & $\%$ & Gausslan fler, $0.025 \mathrm{~mm}$ \\
\hline Mr2 & 85.89 & $\%$ & Gausslan fter, $0.025 \mathrm{~mm}$ \\
\hline A1 & 0.0009723 & $\mu \mathrm{m}^{2} / \mu \mathrm{m}$ & Gausstan flter, $0.025 \mathrm{~mm}$ \\
\hline A2 2 & 0.002075 & $\mu \mathrm{m}^{2} / \mu \mathrm{m}$ & Gausslan fiter, $0.025 \mathrm{~mm}$ \\
\hline Rpk $^{*}$ & 0.04474 & $\mu \mathrm{m}$ & Gausstan nter, $0.025 \mathrm{~mm}$ \\
\hline $\mathrm{Rvk}^{*}$ & 0.2145 & $\mu \mathrm{m}$ & Gausstan flter, $0.025 \mathrm{~mm}$ \\
\hline \multicolumn{4}{|c|}{ ASME B46.1 } \\
\hline \multicolumn{4}{|c|}{ 2D Parameters } \\
\hline $\mathbf{R z}$ & 0.2374 & $\mu \mathrm{m}$ & Gausstan flter, $0.8 \mathrm{~mm}$ \\
\hline
\end{tabular}

